University of Tennessee Health Science Center UTHSC Digital Commons

\title{
PIP2 Modulation of Afterhyperpolarizations in Magnocellular Supraoptic Neurons
}

\author{
Matthew Karl Kirchner \\ University of Tennessee Health Science Center
}

Follow this and additional works at: https://dc.uthsc.edu/dissertations

Part of the Medical Biophysics Commons, and the Neurosciences Commons

\section{Recommended Citation}

Kirchner, Matthew Karl (http://orcid.org/0000-0001-6960-7685), "PIP2 Modulation of Afterhyperpolarizations in Magnocellular Supraoptic Neurons" (2018). Theses and Dissertations (ETD). Paper 479. http://dx.doi.org/10.21007/etd.cghs.2018.0460. 


\title{
PIP2 Modulation of Afterhyperpolarizations in Magnocellular Supraoptic Neurons
}

\begin{abstract}
Magnocellular neurosecretory cells (MNCs) are large oxytocin (OT)- and vasopressin (VP)-releasing neurons that secrete these hormones into the circulatory system in response to physiological stimuli. These cells exhibit unique phasic and burst firing patterns to release these peptides into the circulatory system where they primarily control milk ejection and parturition (OT) as well as salt-water balance and vasoconstriction (VP). This firing is underlain by intrinsic ionic mechanisms that shape the duration and frequency of these bursts. One of these mechanisms is the Ca2+-dependent afterhyperpolarization (AHP), which activates during bursts and causes spike frequency adaptation. This afterhyperpolarization has three distinct conductances: a fast component (fAHP) underlain by BK channels, a medium component (mAHP) underlain by apamin-sensitive SK channels, and a slow component (sAHP) which is an apamin-insensitive $\mathrm{K}+$ conductance. The mechanisms that control the SAHP are poorly understood in MNCs. The work embodied here explores the mechanisms involved in generation of AHPs, specifically how the phospholipid, PIP2 can activate and modulate the mAHP and sAHP. The major discovery is that the mechanisms that generate mAHP and SAHP are different between OT and VP neurons. PIP2 depletion via wortmannin in the cells abolishes the MAHP and sAHP of OT but not VP neurons. This demonstrates OT neurons require PIP2 to activate an AHP while VP neurons do not. Interestingly, increasing PIP2 within the cells has little effect on OT neurons while drastically enhancing the sAHP in VP neurons, thus PIP2 plays a different role in both cell types. In OT neurons, PIP2 exerts its effect by facilitating $\mathrm{Ca} 2+$ entry through voltage-gated $\mathrm{Ca} 2+$ channels, demonstrated by inhibited $\mathrm{Ca} 2+$ currents in the presence of wortmannin.
\end{abstract}

The mechanistic differences extend to which $\mathrm{Ca} 2+$ channels contribute $\mathrm{Ca} 2+$ to the MAHP and sAHP. In OT neurons, $\mathrm{N}$-type $\mathrm{Ca} 2+$ channels couple primarily to both components. In VP neurons, N-type channels couple to the mAHP while the SAHP receives a contribution from R-type channels. The precise way PIP2 modulates $\mathrm{Ca} 2+$ channels in OT neurons is explored further in dissociated neurons genetically labeled for OT or VP. PIP2 depletion inhibited the amplitude, shifted the steady-state activation curve leftward, and modestly accelerated the inactivation of both the whole-cell and isolated $\mathrm{N}$-type current in OT neurons only. This suggests that PIP2 is not required, but is a co-factor, for channel activation. The PIP2 mechanisms of AHP modulation in VP neurons appear complex, as the enhancement observed during increased PIP2 didn't occur when EGTA was replaced with fura-2 in the pipette. In order to understand what happens to [Ca2+]i during this enhancement, we changed the $\mathrm{Ca} 2+$ indicator to fluo- 4 and was able to observe enhancement under specific conditions. This suggests that VP modulation is critically dependent on the time course and buffering of available $\mathrm{Ca} 2+$.

Finally, I also performed a cursory evaluation of possible morphological implications in AHP generation. I used regression analysis to assess the relationships between AHP amplitude, [Ca2+]i, and dendritic size. There is a moderate relationship between AHP amplitude and dendritic length in both OT and VP neurons, suggesting that a considerable portion of the AHP conductance could occur in the dendritic tree of these neurons. These studies highlight the unique AHP mechanisms between OT and VP neurons of supraoptic nucleus.

\section{Document Type}

Dissertation

Degree Name

Doctor of Philosophy (PhD) 


\section{Program}

Biomedical Sciences

Research Advisor

William E. Armstrong, Ph.D.

\section{Keywords}

afterhyperpolarization, calcium, oxytocin, PIP2, vasopressin

\section{Subject Categories}

Medical Biophysics | Medical Sciences | Medicine and Health Sciences | Neurosciences 


\title{
PIP2 Modulation of Afterhyperpolarizations in Magnocellular Supraoptic Neurons
}

\author{
A Dissertation \\ Presented for \\ The Graduate Studies Council \\ The University of Tennessee \\ Health Science Center \\ In Partial Fulfillment \\ Of the Requirements for the Degree \\ Doctor of Philosophy \\ From The University of Tennessee
}

By

Matthew Karl Kirchner

August 2018 
Portions of Chapter 3 C 2017 by John Wiley and Sons. All other material (c) 2018 by Matthew Karl Kirchner. All rights reserved. 


\section{DEDICATION}

I dedicate this dissertation to my parents Drs. Joyce E. Johnson and Fredrick K. Kirchner. Their inspiring love for medicine and science, combined with their support and wisdom, made this dissertation possible.

I also dedicate this dissertation to Katherine Schiller, the love of my life. 


\section{ACKNOWLEDGEMENTS}

I would like to first and foremost thank my mentor Dr. William Armstrong and primary committee member Dr. Robert Foehring for their endless support, expertise, and trust in me as a growing scientist. They provided a supportive lab environment to accomplish the work embodied in this dissertation. I am grateful to my committee members, Drs. Detlef Heck, Joseph Callaway, and Fu-ming Zhou and their commitment to my progress in the $\mathrm{PhD}$ program.

I want to also thank members of the Armstrong and Foehring lab for their help and advice. I especially want to thank Dr. Lie Wang for providing a wealth of training in electrophysiology and immunochemistry. I want to thank Dr. Dongxu Guan for his training in preparation and recording of acutely dissociated neurons. I thank other lab members Drs. Giri Chandaka and Dhruba Pathak, as well as Li Li for their support.

A special thanks to my friends and comrades in graduate school, with whom much learning and many laughs were shared: Stu McAfee, Kevin Hope, and Zach Goldsmith. 


\begin{abstract}
Magnocellular neurosecretory cells (MNCs) are large oxytocin (OT)- and vasopressin (VP)-releasing neurons that secrete these hormones into the circulatory system in response to physiological stimuli. These cells exhibit unique phasic and burst firing patterns to release these peptides into the circulatory system where they primarily control milk ejection and parturition (OT) as well as salt-water balance and vasoconstriction (VP). This firing is underlain by intrinsic ionic mechanisms that shape the duration and frequency of these bursts. One of these mechanisms is the $\mathrm{Ca}^{2+}-$ dependent afterhyperpolarization (AHP), which activates during bursts and causes spike frequency adaptation. This afterhyperpolarization has three distinct conductances: a fast component (fAHP) underlain by BK channels, a medium component (mAHP) underlain by apamin-sensitive SK channels, and a slow component (sAHP) which is an apamininsensitive $\mathrm{K}^{+}$conductance. The mechanisms that control the sAHP are poorly understood in MNCs. The work embodied here explores the mechanisms involved in generation of AHPs, specifically how the phospholipid, $\mathrm{PIP}_{2}$ can activate and modulate the mAHP and sAHP. The major discovery is that the mechanisms that generate mAHP and sAHP are different between OT and VP neurons. PIP $_{2}$ depletion via wortmannin in the cells abolishes the mAHP and sAHP of OT but not VP neurons. This demonstrates OT neurons require $\mathrm{PIP}_{2}$ to activate an AHP while VP neurons do not. Interestingly, increasing $\mathrm{PIP}_{2}$ within the cells has little effect on OT neurons while drastically enhancing the sAHP in VP neurons, thus $\mathrm{PIP}_{2}$ plays a different role in both cell types. In OT neurons, $\mathrm{PIP}_{2}$ exerts its effect by facilitating $\mathrm{Ca}^{2+}$ entry through voltage-gated $\mathrm{Ca}^{2+}$ channels, demonstrated by inhibited $\mathrm{Ca}^{2+}$ currents in the presence of wortmannin.
\end{abstract}

The mechanistic differences extend to which $\mathrm{Ca}^{2+}$ channels contribute $\mathrm{Ca}^{2+}$ to the mAHP and sAHP. In OT neurons, $\mathrm{N}$-type $\mathrm{Ca}^{2+}$ channels couple primarily to both components. In VP neurons, N-type channels couple to the mAHP while the sAHP receives a contribution from R-type channels. The precise way PIP 2 modulates $\mathrm{Ca}^{2+}$ channels in OT neurons is explored further in dissociated neurons genetically labeled for OT or VP. PIP 2 depletion inhibited the amplitude, shifted the steady-state activation curve leftward, and modestly accelerated the inactivation of both the whole-cell and isolated N-type current in OT neurons only. This suggests that $\mathrm{PIP}_{2}$ is not required, but is a co-factor, for channel activation. The $\mathrm{PIP}_{2}$ mechanisms of AHP modulation in VP neurons appear complex, as the enhancement observed during increased PIP $_{2}$ didn't occur when EGTA was replaced with fura-2 in the pipette. In order to understand what happens to $\left[\mathrm{Ca}^{2+}\right]_{\mathrm{i}}$ during this enhancement, we changed the $\mathrm{Ca}^{2+}$ indicator to fluo-4 and was able to observe enhancement under specific conditions. This suggests that VP modulation is critically dependent on the time course and buffering of available $\mathrm{Ca}^{2+}$.

Finally, I also performed a cursory evaluation of possible morphological implications in AHP generation. I used regression analysis to assess the relationships between AHP amplitude, $\left[\mathrm{Ca}^{2+}\right]$, and dendritic size. There is a moderate relationship between AHP amplitude and dendritic length in both OT and VP neurons, suggesting that a considerable portion of the AHP conductance could occur in the dendritic tree of these 
neurons. These studies highlight the unique AHP mechanisms between OT and VP neurons of supraoptic nucleus. 


\section{TABLE OF CONTENTS}

CHAPTER 1. LITERATURE REVIEW AND SPECIFIC AIMS ...........................1

Magnocellular Neurosecretory Cells: Anatomy and Relevant Physiology ................... 1 Anatomy of the Central Magnocellular Neurosecretory System ...............................1

Animal and Cellular Physiology of OT and VP Neurons ...........................................

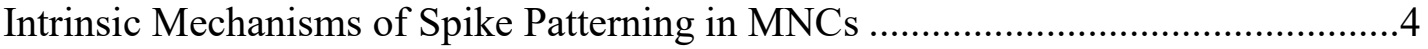

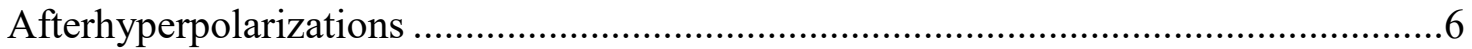

Initial Discovery and Characterization ..........................................................

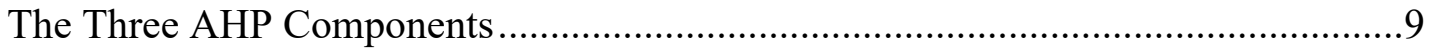

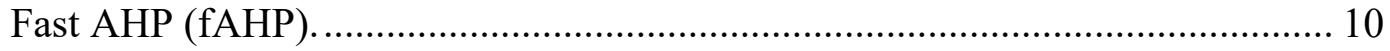

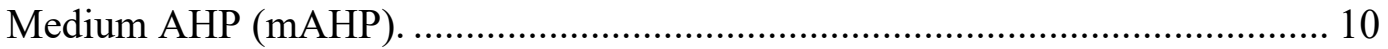

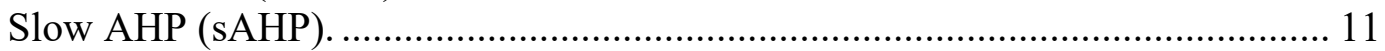

AHP Plasticity during Pregnancy and Lactation in SON .....................................13

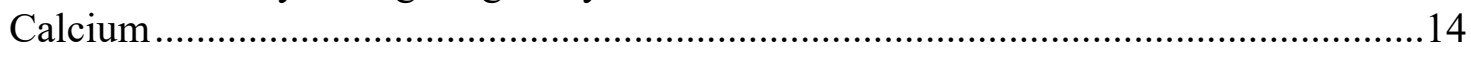

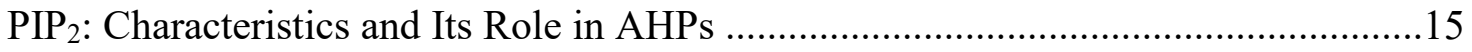

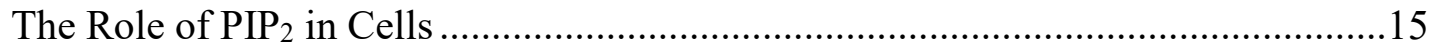

$\mathrm{PIP}_{2}$ Modulation of Ion Channels: Implications for AHPs .....................................15

Rationale and Specific Aims.......................................................................... 16

CHAPTER 2. METHODOLOGY .........................................................................19

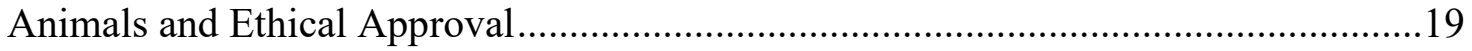

Cell and Tissue Preparation for Electrophysiological Recordings .............................19

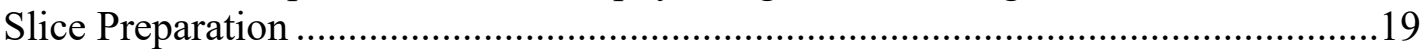

Acutely Dissociated Neuron Preparation ...............................................................19

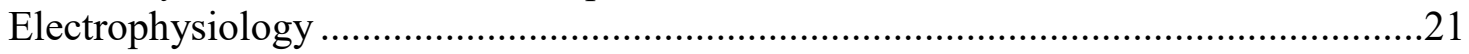

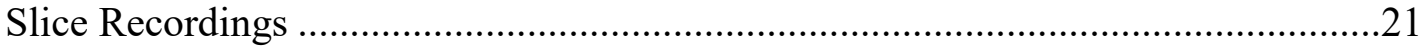

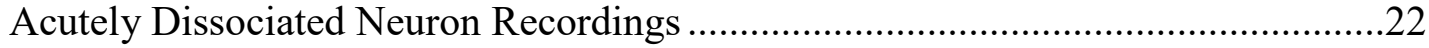

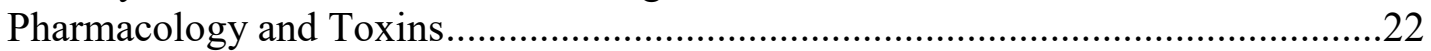

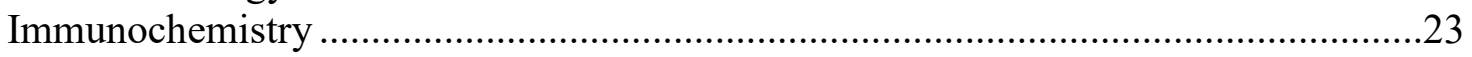

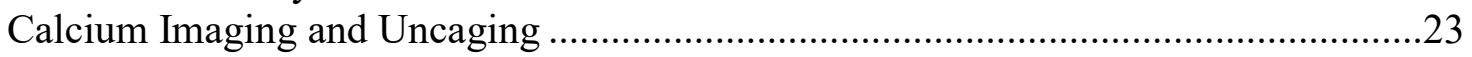

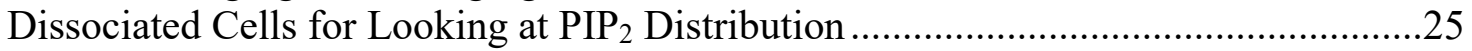

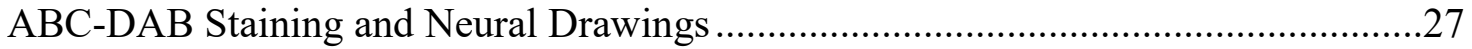

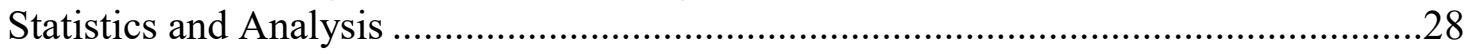

\section{CHAPTER 3. DIFFERENTIAL PIP2 MODULATION OF AHPS IN}

OXYTOCIN AND VASOPRESSIN NEURONS ......................................................30

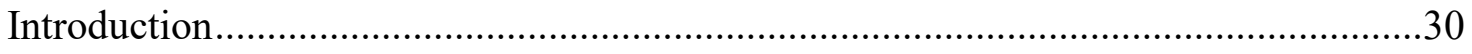

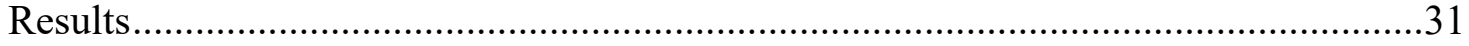

Depleting $\mathrm{PIP}_{2}$ from Cells Inhibits the $I_{\mathrm{AHP}}$ of OT but Not VP Neurons.................... 31

Wortmannin Inhibits the $I_{\mathrm{SAHP}}$ in the Presence of Apamin in OT Neurons ................34

Wortmannin Reduced PIP 2 Immunoreactivity in OT Neurons...................................34

$\mathrm{diC}_{8}-\mathrm{PIP}_{2}$ Slows Rundown of the $I_{\mathrm{mAHP}}$ in OT; Enhances the $I_{\mathrm{sAHP}}$ in VP .................37

$\mathrm{diC}_{8}-\mathrm{PIP}_{2}$ in the Pipette Prevents $I_{\mathrm{mAHP}}$ and $I_{\mathrm{sAHP}}$ Inhibition by Wortmannin ............37 
Supplying the $\mathrm{PIP}_{2}$ Precursor, Myo-Inositol, also Prevents Inhibition by

Wortmannin

Changes in $I_{\mathrm{mAHP}}$ and $I_{\mathrm{sAHP}}$ via PIP 2 Are Unlikely to Be the Result of

Phospholipase C-Dependent Phenomena

Differences between OT and VP Neurons in the $I_{\mathrm{mAHP}}$ and $I_{\mathrm{sAHP}}$ May Be Due to

Changes in $\mathrm{Ca}^{2+}$ Influx after Wortmannin .

$\mathrm{PIP}_{2}$ Depletion Has No Effect on AHPs Generated by Uncaging $\mathrm{Ca}^{2+}$

$\mathrm{PIP}_{2}$ Depletion Inhibits Whole Cell $\mathrm{Ca}^{2+}$ Currents in OT Neurons .

KCNQ Channels Don't Appear to Contribute the AHP in Either Cell Type ............47

Discussion

Wortmannin-induced Inhibition of $\mathrm{I}_{\mathrm{AHPs}}$ Results from a Restriction of $\mathrm{PIP}_{2}$

Availability

$\mathrm{PIP}_{2}$ Depletion Alters $\mathrm{Ca}^{2+}$ Entry through Voltage-gated $\mathrm{Ca}^{2+}$ Channels in OT

Neurons

CHAPTER 4. CALCIUM CHANNELS COUPLED TO THE AHP IN SON . .54

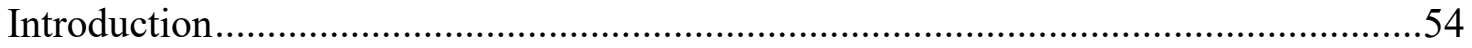

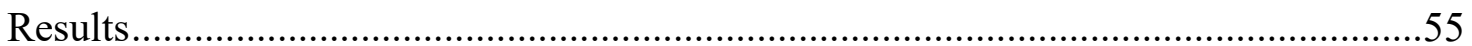

$\mathrm{Cd}^{2+}$ Block of HVA Ca ${ }^{2+}$ Channels Inhibits Most of the AHP .................................55

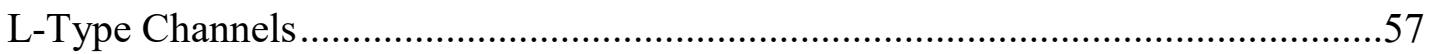

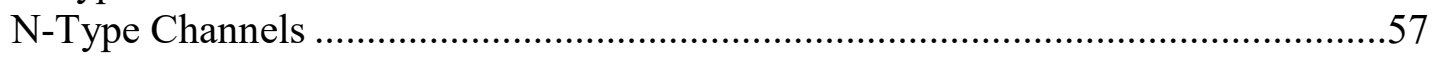

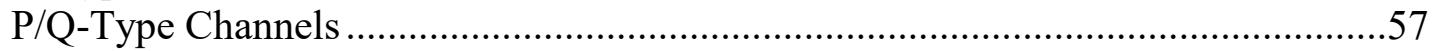

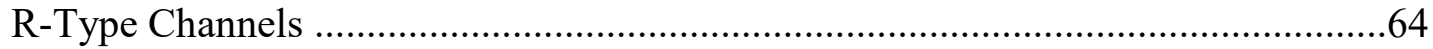

N-Type Block with Subsequent P/Q Block ........................................................66

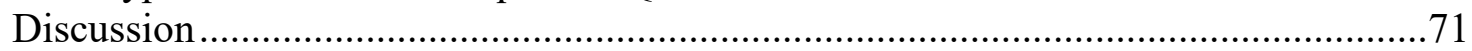

The Major Contribution of N-type Channels to the AHP .................................... 71

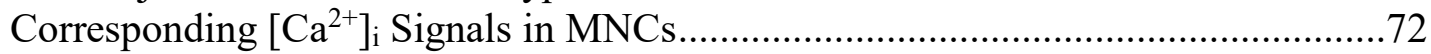

Strict Coupling of mAHPs to $\mathrm{Ca}^{2+}$ Microdomains .................................................... 72

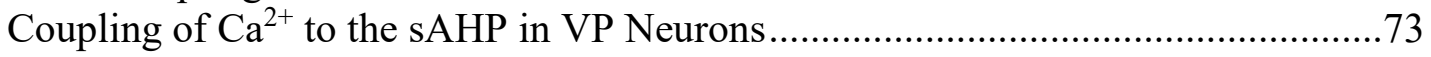

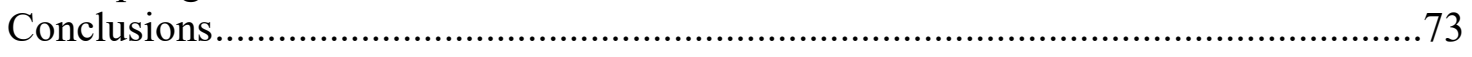

\section{CHAPTER 5. PIP2 MODULATION OF CALCIUM CHANNEL CURRENTS}

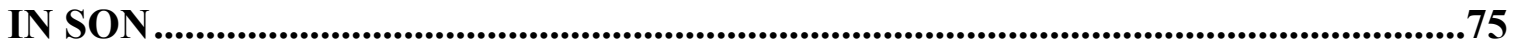

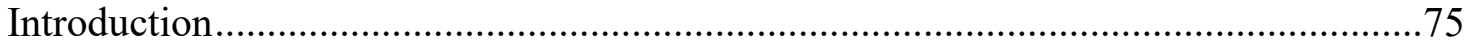

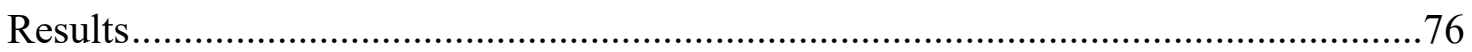

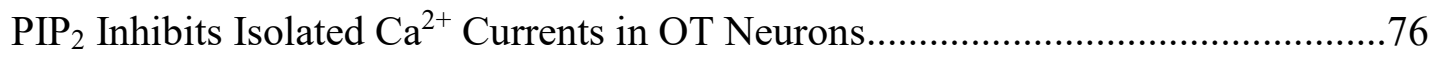

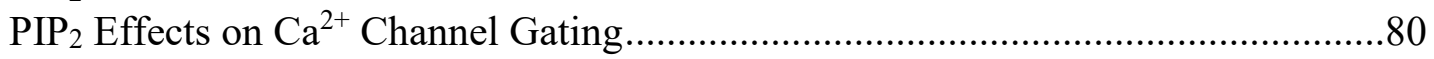

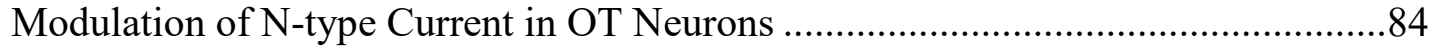

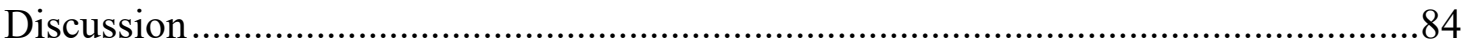

CHAPTER 6. DENDRITIC ARCHITECTURE AND AHPS ....................................89

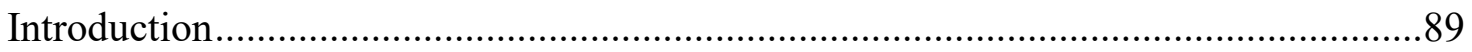

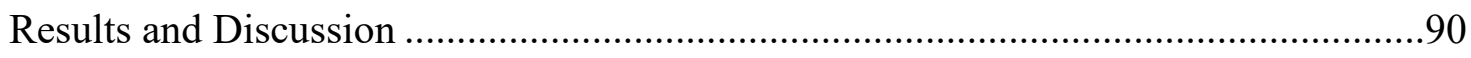

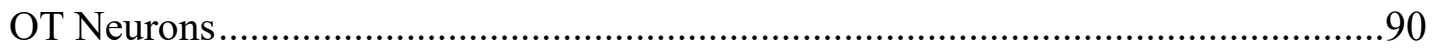

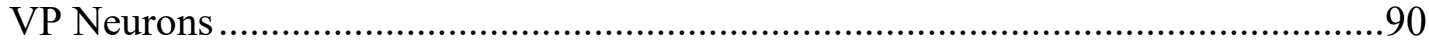

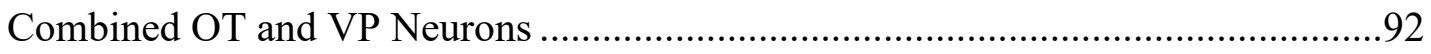


CHAPTER 7. ELUSIVE PIP2 ENHANCEMENT OF VP NEURONS, AND

CONCLUSIONS .....................................................................................................93

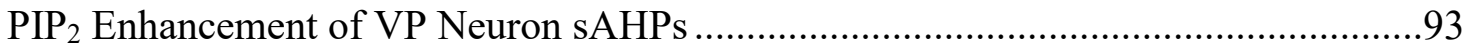

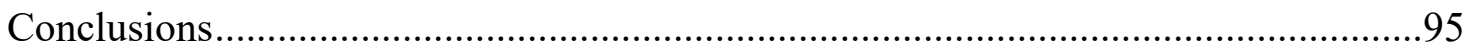

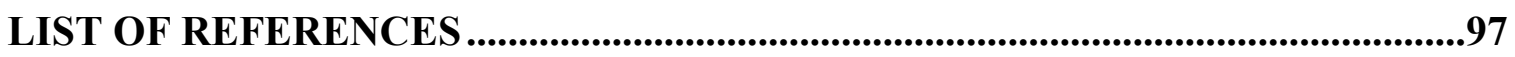

VITA 


\section{LIST OF FIGURES}

Figure 1-1. Anatomy of the Magnocellular Neurosecretory System.................................2

Figure 1-2. Example of phasic bursting and subsequent afterpotentials in a vasopressin neuron.

Figure 1-3. DAP and AHP afterpotentials that shape phasic burst patterns in OT and VP neurons.

Figure 1-4. AHPs in SON are underlain by three distinct components.............................8

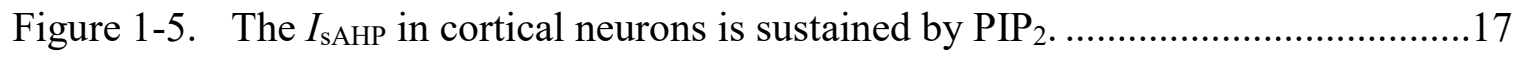

Figure 2-1. Explants of supraoptic nucleus were removed from rat brain. ....................20

Figure 2-2. Example of a positively identified OT cell using immunolabeling..............24

Figure 2-3. $\mathrm{Ca}^{2+}$ imaging in an SON neuron with corresponding AHP and $\left[\mathrm{Ca}^{2+}\right]_{\mathrm{i}}$

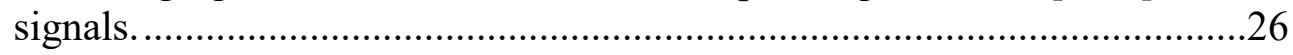

Figure 3-1. Diagram of the relevant $\mathrm{PIP}_{2}$ pathways...................................................32

Figure 3-2. Wortmannin $(10 \mu \mathrm{M})$, a $\mathrm{PIP}_{2}$ and $\mathrm{PIP}_{3}$ synthesis inhibitor, blocks the $I_{\mathrm{mAHP}}$ and $I_{\mathrm{sAHP}}$ of OT neurons but not VP neurons. ....................................33

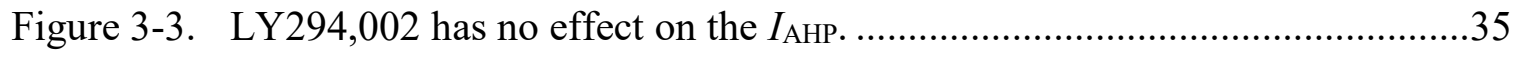

Figure 3-4. Wortmannin had no significant effect on single spike parameters................35

Figure 3-5. Wortmannin inhibits the apamin-treated $I_{\mathrm{AHP}}$ in OT neurons while having no effect in VP neurons................................................................36

Figure 3-6. Effect of wortmannin on $\mathrm{PIP}_{2}$ expression in OT neurons..............................38

Figure 3-7. Inclusion of water-soluble $\mathrm{PIP}_{2}$ analog $\operatorname{diC}_{8}-\mathrm{PIP}_{2}(30 \mu \mathrm{M})$ in the recording pipette slows $I_{\mathrm{AHP}}$ rundown in OT .............................................38

Figure 3-8. Dialyzing OT neurons with $\mathrm{diC}_{8}-\mathrm{PIP}_{2}$ prevents inhibition of the $I_{\mathrm{AHP}}$ by wortmannin.

Figure 3-9. Wortmannin fails to inhibit OT neurons in aCSF containing myoinositol.

Figure 3-10. The PLC inhibitor U73122 $(10 \mu \mathrm{M})$ failed to inhibit the $I_{\mathrm{mAHP}}$ or $I_{\mathrm{sAHP}}$ in OT neurons. 
Figure 3-11. Wortmannin $(1 \mu \mathrm{M})$ inhibits the $I_{\mathrm{mAHP}}, I_{\mathrm{sAHP}}$ and somatic $\mathrm{Ca}^{2+}$ while having no effect on these measures in VP neurons.

Figure 3-12. Wortmannin has no effect on AHPs or somatic $\mathrm{Ca}^{2+}$ when AHPs are generated via uncaging $\mathrm{Ca}^{2+}$ in OT neurons.

Figure 3-13. Wortmannin inhibits whole cell $\mathrm{Ca}^{2+}$ currents in OT neurons while having no effect in VP neurons.

Figure 3-14. XE-991 has no effect on the AHP.....

Figure 4-1. $400 \mu \mathrm{M} \mathrm{Cd}^{2+}$ application to MNCs inhibited nearly all of the AHP in current clamp. AHPs were evoked using a pulse train of 20 spikes and measured at peak (mAHP + sAHP) and $1 \mathrm{~s}$ (sAHP) following the pulse. ....56

Figure 4-2. Effect of L-type blocker $5 \mu \mathrm{M}$ Nif on AHPs and corresponding $\mathrm{Ca}^{2+}$ transients in OT (A-D) and VP (E-H) neurons.

Figure 4-3. Effect of N-type blocker $1 \mu \mathrm{M}$ CnTx GVIA on AHPs and corresponding $\mathrm{Ca}^{2+}$ transients in OT (A-D) and VP (E-H) neurons.

Figure 4-4. Effect of P/Q-type blocker 0.5 $\mu \mathrm{M}$ AgTx IVA on AHPs and corresponding $\mathrm{Ca}^{2+}$ transients in OT (A-D) and VP (E-H) neurons.

Figure 4-5. SNX-482 blocks transient outward rectification and broadens spikes.

Figure 4-6. Effect of R-type blocker SNX-482 $(0.3 \mu \mathrm{M})$ on AHPs and their corresponding $\mathrm{Ca}^{2+}$ transients in OT (A-D) and VP (E-H) neurons.

Figure 4-7. N-type blocker $1 \mu \mathrm{M}$ CnTx GVIA and subsequent block with $1 \mu \mathrm{M}$ CnTx MVIIC on AHPs and corresponding $\mathrm{Ca}^{2+}$ transients in OT (A-D) and VP (E-H) neurons.

Figure 5-1. Comparison of $\mathrm{Ca}^{2+}$ current $\mathrm{I}-\mathrm{V}$ relationship in ramps versus steps.

Figure 5-2. Wortmannin inhibits whole cell $\mathrm{Ca}^{2+}$ currents in OT neurons but not VP neurons.

Figure 5-3. Wortmannin does not significantly affect activation and deactivation time constants in both OT and VP neurons.

Figure 5-4. Inactivation properties of OT and VP neurons before and after wortmannin.

Figure 5-5. $\mathrm{PIP}_{2}$ significantly reduces pharmacologically isolated $\mathrm{N}$-type $\mathrm{Ca}^{2+}$ currents in OT neurons. 
Figure 5-6. Wortmannin significantly accelerates inactivation of N-Type currents in

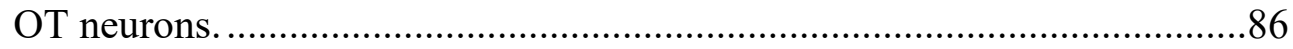

Figure 6-1. Drawings of MNCs in which dendritic size was measured. ..........................91

Figure 6-2. Regression plots for OT (top) VP (bottom) and OT+VP (right) for AHP amplitude vs. dendritic length. .....................................................................91

Figure 7-1. $\mathrm{diC}_{8}-\mathrm{PIP}_{2}$ dialyzed through the pipette enhances $\mathrm{Ca} 2+$ in the presence of

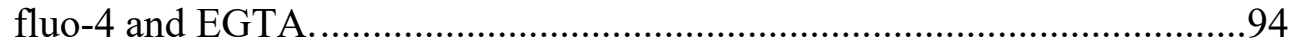




\section{LIST OF ABBREVIATIONS}

\begin{tabular}{|c|c|}
\hline 4-AP & 4-Aminopyridine \\
\hline AP5 & 2R)-amino-5-phosphonovaleric acid \\
\hline $\mathrm{aCSF}$ & Artificial Cerebrospinal Fluid \\
\hline AHP & Afterhyperpolarization \\
\hline BAPTA & 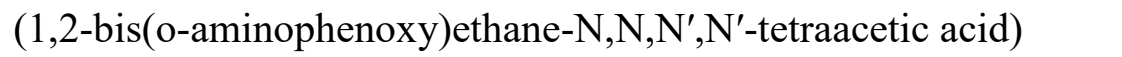 \\
\hline$\left[\mathrm{Ca}^{2+}\right]_{\mathrm{i}}$ & Intracellular Calcium Entry + Extrusion/Buffering \\
\hline $\mathrm{Ca}^{2+}$ & Calcium \\
\hline $\mathrm{Cav}$ & voltage-gated calcium channel \\
\hline $\mathrm{CC}$ & Current Clamp \\
\hline ChTx & charybdotoxin \\
\hline $\mathrm{Cs}^{+}$ & Cesium \\
\hline $\mathrm{diC}_{8}-\mathrm{PIP}_{2}$ & synthetic, water-soluble 8-chain $\mathrm{PIP}_{2}$ \\
\hline DNQX & 6,7-dinitroquinoxaline-2,3-dione \\
\hline EGTA & Ethylene glycol-bis(2-aminoethylether)-N, $\mathrm{N} \mathrm{N}^{\prime}, \mathrm{N}^{\prime}$-tetraacetic acid \\
\hline$E_{\mathrm{K}}$ & Potassium Reversal Potential \\
\hline EPSP & Excitatory Post-Synaptic Potential \\
\hline fAHP & Fast Afterhyperpolarization \\
\hline GPCR & G-Protein Coupled Receptor \\
\hline GVIA & $\omega-$ conotoxin GVIA \\
\hline HBSS & Hanks Buffered Saline Solution \\
\hline$I_{\mathrm{A}}$ & A-Current \\
\hline IbTx & Iberiotoxin \\
\hline
\end{tabular}




\begin{tabular}{|c|c|}
\hline$I_{\mathrm{fAHP}}$ & Fast Afterhyperpolarization Current \\
\hline$I_{\mathrm{mAHP}}$ & Medium Afterhyperpolarization Current \\
\hline $\mathrm{IP}_{3}$ & Inositol Trisphosphate \\
\hline$I_{\mathrm{SAHP}}$ & Slow Afterhyperpolarization Current \\
\hline IVA & Agatoxin IVA \\
\hline $\mathrm{K}^{+}$ & Potassium \\
\hline $\mathrm{K}_{\text {ATP }}$ & ATP-gated potassium channel \\
\hline $\mathrm{K}_{\mathrm{D}}$ & Dissociation Constant \\
\hline Kir & Inwardly rectified potassium channel \\
\hline $\mathrm{K}_{\mathrm{ON}}$ & Forward Rate Constant \\
\hline mAHP & Medium Afterhyperpolarization \\
\hline $\mathrm{MNC}$ & Mangocellular Neurosecretory Cell \\
\hline MVIIC & $\omega-$ conotoxin MVIIC \\
\hline $\mathrm{Na}^{+}$ & Sodium \\
\hline Nif & Nifedipine \\
\hline OT & Oxytocin \\
\hline PBS & Phosphate Buffered Saline \\
\hline $\mathrm{PIP}_{2}$ & Phosphotidylinositol 4,5-bisphosphate \\
\hline PLC & Phospholipase C \\
\hline PVN & Paraventricular Nucleus \\
\hline Px & Picrotoxin \\
\hline sAHP & Slow Afterhyperpolarization \\
\hline SON & Supraoptic Nucleus \\
\hline
\end{tabular}


$\tau$

TTX

VC

VP tau; time constant

tetrodotoxin

Voltage Clamp

Vasopressin 


\section{CHAPTER 1. LITERATURE REVIEW AND SPECIFIC AIMS}

Magnocellular neurosecretory cells (MNCs) projecting to the pituitary gland serve highly critical roles in animal physiology by releasing the hormones oxytocin (OT) and vasopressin (VP) into neurohypophysial capillaries (Hatton 1988). The neurohormones then enter systemic circulation where they act on distal targets. The frequency, pattern, and volume of release is highly correlated with the firing patterns of Magnocellular Neurosecretory Cells (MNCs) in response to physiological stimuli (Poulain and Wakerley 1982). While the distinguished array of firing patterns are well characterized (Armstrong 1995), mechanisms underlying the frequency and duration of repetitive firing remain unclear. This dissertation seeks to reveal $\mathrm{PIP}_{2}$-mediated mechanisms of afterhyperpolarization generation, a $\mathrm{K}^{+}$current that shapes firing patterns in MNCs (and other neurons).

\section{Magnocellular Neurosecretory Cells: Anatomy and Relevant Physiology}

MNCs represent the final common pathway of hormone release in response to physiological stimuli. The relevant anatomy, animal physiology, and cellular physiology are explored in the following section.

\section{Anatomy of the Central Magnocellular Neurosecretory System}

MNCs primarily reside in two nuclei: the paraventricular nucleus (PVN) and the supraoptic nucleus (SON). These nuclei are the two main sources of OT- and VPsecreting neurons, bilaterally hugging the walls of the $3^{\text {rd }}$ ventricle $(\mathrm{PVN})$ and the lateral edges of the optic tract/chiasm (SON) (Armstrong 2015b). Besides these two nuclei, many accessory nuclei scattered throughout the hypothalamus contain small numbers of MNCs. These include the nucleus circularis, anterior and posterior fornical nuclei, and anterior commissural nucleus (Tweedle and Hatton 1976; Armstrong et al. 1980;

Sofroniew and Glasmann 1981; Ju et al. 1986). The axons of MNCs from primary nuclei project down the neural stalk and terminate in the posterior lobe of the pituitary (Watson and Paxinos 2014; Armstrong 2015a) (Figure 1-1). The SON is relatively uniform, comprising mostly MNCs, but the PVN cell population is diverse. It contains parvocellular neurosecretory cells (PNCs) in addition to MNCs (Swanson and Kuypers 1980; Swanson et al. 1986; Armstrong 2015a). These PNCs are immunoreactive to a myriad of hormone peptides and project to the median eminence where they influence release of hormones from the anterior lobe of the pituitary. For a comprehensive description of the PVN and PNCs, refer to The Rat Nervous System, $4^{\text {th }}$ Edition Chapter 14 (Armstrong 2015a). The rest of this work focuses on MNCs in SON.

MNCs produce either OT or VP for secretion with a small (2-3\%) number of MNCs producing both (Mezey and Kiss 1991; Armstrong et al. 1994). These neurons have large cell bodies, averaging $\sim 25 \mu \mathrm{m}$ in size with a capacitance of $15.2 \mathrm{pF}$ 


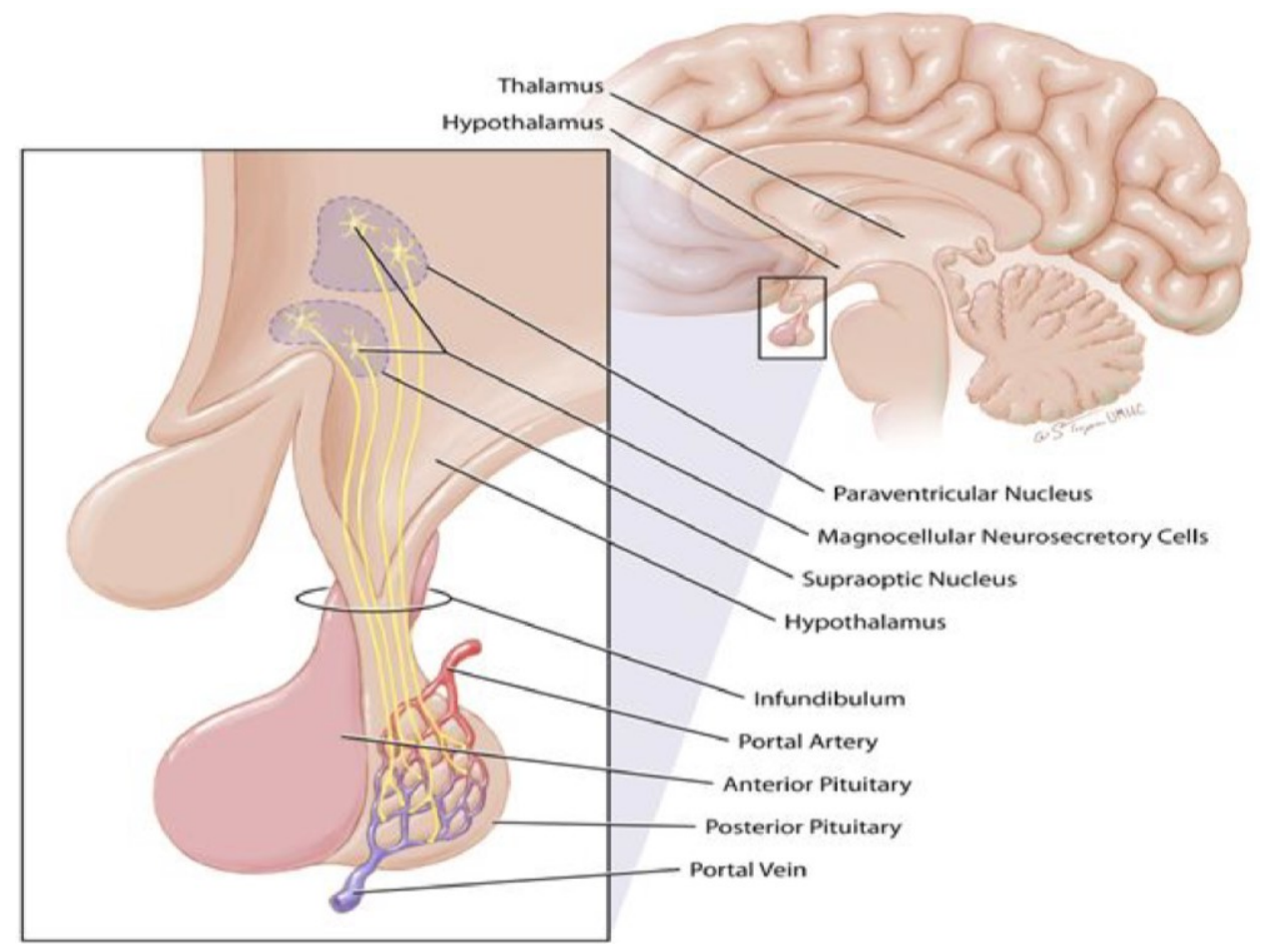

Figure 1-1. Anatomy of the Magnocellular Neurosecretory System. MNCs primarily originate in two main nuclei of the hypothalamus: the paraventricular nucleus (PVN) and the supraoptic nucleus (SON). Axons from these two neurons bundle ventrally and project down the infundibular stalk to terminate on blood vessels outside of their respective nuclei. These blood vessels are in the posterior pituitary. Synaptic input to these neurons can generate action potentials which propagate down the axons and into the terminals where dense core vesicles are stored. Action potentials trigger vesicle fusion with the terminal membrane to secrete OT and VP into the circulatory system, where they can act at distal targets. Reprinted with open access permission. Cassels J. The Posterior Pituitary Pathway | GLOWM [Online]. 2012. http://www.glowm.com/section_view/item/283/recordset/18975/value/283 [23 Jul. 2018]. 
(Sofroniew 1985; Oliet and Bourque 1992). Each MNC contains a singular axon projecting to the posterior pituitary, and 2-3 long dendrites. While the originating dendrites are lengthy, the $2^{\text {nd }}$ and $3^{\text {rd }}$ order arobors are limited (Perlmutter et al. 1984; Randle et al. 1986; Smith and Armstrong 1990). The electrotonic properties of these dendrites is varies highly between individual neurons (Armstrong and Smith 1990), and the dendrites release peptides from neurosecretory vesicles (Ludwig 1998). Thus, these neurons demonstrate relatively simple dendritic morphology compared to other neuronal cell types, yet present highly complex functional roles (Preston et al. 1980; Foehring et al. 1991; Clark et al. 2005).

\section{Animal and Cellular Physiology of OT and VP Neurons}

OT is most notably involved in the milk ejection reflex in which oxytocin neurons will fire in response to suckling behavior (Lincoln and Paisley 1982). The bolus release of OT into the blood stream from the posterior pituitary triggers a milk ejection in the mammary gland (Wakerly and Lincoln 1971). This milk ejection is pulsatile, and reflects synchronous bursting of OT neurons in PVN and SON (Cobo et al. 1967; Wakerley and Lincoln 1971; Lincoln and Wakerley 1974; Lincoln and Paisley 1982; Belin et al. 1984; Belin and Moos 1986). This synchrony is achieved, in part, via local release of OT (Freund-Mercier and Richard 1981; Freund-Mercier M J and Richard P 1984). OT also plays a role in uterine contractions during parturition (Ott and Scott 1909; Higuchi et al. 1986). OT neurons are also activated during hyperosmolality OT, serving a natriuretic function at the kidney (Stricker et al. 1987).

VP plays a critical homeostatic role in regulating salt-water balance changes, signaling water retention in the kidneys in response to hyperosmolality during dehydration or salt loading, and constricting blood vessels in response to low hypotension/hypovolemia (Wakerley et al. 1978; Bourque et al. 1998). In contrast to OT neurons, VP neurons demonstrate asynchronous and prolonged phasic activity, resulting in a constant release of VP into circulation during hyperosmotic or hypovolemic stimulation (Poulain and Wakerley 1982). VP release is enhanced in response to dehydration (Wakerley et al. 1978).

Both OT and VP neurons are consequently sensitive to osmotic challenge (Brimble and Dyball 1977; Bourque and Renaud 1984; Maícas Royo et al. 2016). OT and VP neurons undergo morphological, genetic, and electrophysiological plasticity in response to changes in hyperosmolality (Somponpun and Sladek 2003; Ghorbel et al. 2006; Trudel and Bourque 2010; Shah et al. 2014; Greenwood et al. 2015). OT and VP secretion also occurs centrally, releasing from MNC terminals projecting in distal CNS targets as well as from dendrites (Pow and Morris 1989; Morris et al. 2000). Dendritic, paracrine release of peptide has been studied extensively and is a cardinal feature of these neurons (Morris et al. 2000; Morris and Ludwig 2004; Ludwig and Leng 2006).

Spatiotemporal differences in peptide release patterns in axons versus dendrites indicate that release mechanisms are relatively distinct and independent (Ludwig 1998). Additionally, OT and VP neurons express receptors for their peptide on cell bodies, 
indicating these peptides play an autoregulatory role (Freund-Mercier et al. 1994; FreundMercier and Stoeckel 1995; Dayanithi et al. 2000).

Though MNCs secrete dense core vesicles of peptide, they are categorically neurons as they receive synaptic input, fire action potentials, and display $\mathrm{Ca}^{2+}$-triggered vesicle release from nerve terminals (Morris 1976a, 1976b; Poulain and Wakerley 1982; Tasker and Dudek 1993; Armstrong et al. 1994; De Crescenzo et al. 2004; Leng et al. 2005). Much of the activity in MNCs is marked by strong periodicity, wherein OT neurons fire in bursts (2-4 sec.; 30-50 Hz) with long interburst intervals (minutes), and VP neurons display longer bursts marked by tens of seconds of spiking and equally long periods of quiescence (Poulain and Wakerley 1982; Belin and Moos 1986) (Figure 1-2). This firing activity is initially high frequency, but attenuates within a single burst in both cell types. This phenomenon is called spike frequency adaptation. OT neurons demonstrate synchronous firing, resulting in salvos of hormone release into the bloodstream; VP neurons demonstrate phasic and asynchronous firing, resulting in a steady release of VP into the bloodstream (Bourque et al. 1998). The functional significance of this burst and phasic activity is that it produces maximal hormone release at lower stimulation frequencies compared to continuous activity (Dutton and Dyball 1979).

\section{Intrinsic Mechanisms of Spike Patterning in MNCs}

in vivo, both OT and VP neurons display action potential discharge with either slow irregular or continuous patterns. This firing encompasses the typical activity of MNCs until they are stimulated by lactation and parturition (OT), or by hyperosmotic, hypovolemic, and hypotensive challenges (OT and VP). Responses to the latter challenges vary between the cell types. For example: Dehydration, a hyperosmotic and hypovolemic challenge, shifts VP firing from a slow $(2 \mathrm{~Hz})$ irregular pattern to an accelerated $(6-7 \mathrm{~Hz})$ phasic firing pattern while it shifts OT firing from a similar resting pattern to a slightly faster $(4 \mathrm{~Hz}$ ) continuous discharge (Wakerley et al. 1978; Bourque and Renaud 1984). As mentioned earlier, OT neurons demonstrate unique patterns of bursting that are synchronous between neurons within and across the SON and PVN in response to suckling or parturition (Belin et al. 1984; Belin and Moos 1986).

While synaptic activity largely dictates action potential discharge in vivo, the activation of intrinsic mechanisms shapes the periodic spike activity of these neurons in an in vitro slice preparation. Synaptic input does appear to play a more significant role in shaping bursts when these inputs remain intact in an in vivo preparation. The most important evidence for this idea is that blocking synaptic activity abolishes phasic bursting in vivo (Nissen et al. 1995; Brown et al. 2004) yet has little effect on this in vitro (Hatton 1982; Li et al. 2007). Intrinsic mechanisms still factor in vivo, but probably have heightened influence in vitro where synaptic activity has been depressed (Sabatier et al. 2004). The following work will focus on the intrinsic mechanisms that shape phasic bursting. 

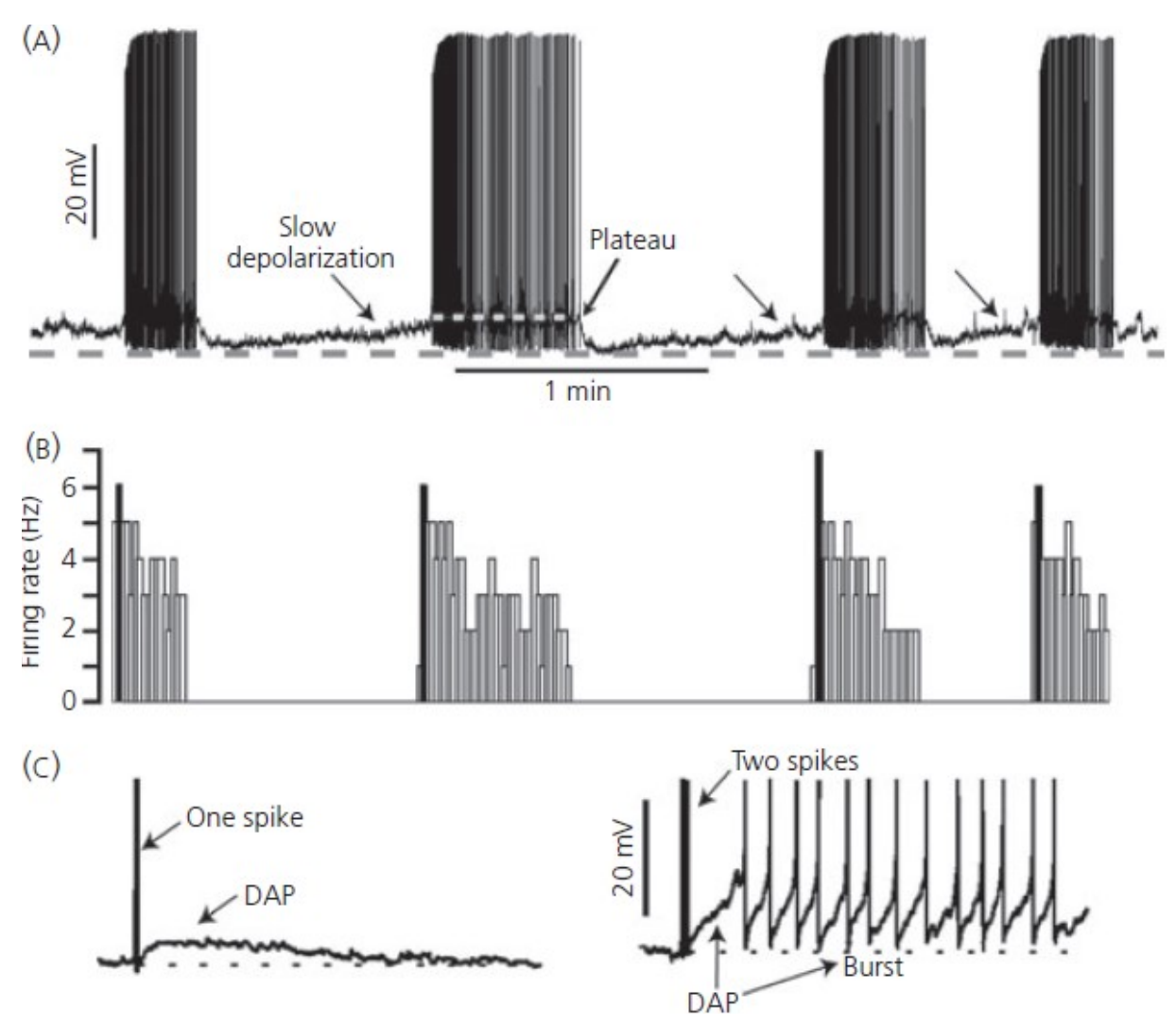

Figure 1-2. Example of phasic bursting and subsequent afterpotentials in a vasopressin neuron.

(A) Voltage record of phasic bursting VP neuron recorded with the whole cell patch technique in the supraoptic nucleus (SON) of a hypothalamic slice made from an adult female rat. Bursts are underlain by a plateau potential (white dashed line), and separated by silent periods consisting of a slow depolarization. The grey dashed line indicates the peak of the post-burst hyperpolarization. (B) Ratemeter histogram of the spike activity shown in (A). Note the highest firing rate occurs in the first $2 \mathrm{~s}$ of the burst (blackened line) followed by a slowing of frequency, indicating adaptation. (C). Depolarizing Afterpotentials (DAPs) activate by one spike (left) summates after two spikes, instigating a burst. Modified with permission. Armstrong WE, Wang L., Li C, Teruyama R.

Performance, Properties and Plasticity of Identified Oxytocin and Vasopressin Neurones In Vitro. J Neuroendocrinol 22: 330-342, 2010. 
The activation and termination of phasic bursting in MNCs reflects an interplay between two intrinsic afterpotentials: The depolarizing afterpotential (DAP) and the afterhyperpolarization (AHP), respectively. The DAP reflects a plateau potential activation to initiate phasic bursting while the AHP activates during spikes to terminate the bursts (Andrew and Dudek 1983, 1984; Bourque 1986; Armstrong et al. 2010). One can observe these potentials experimentally by examining the membrane potential immediately after a train of spikes. The afterpotentials are revealed with the AHP followed by a DAP. The full time course of one afterpotential is revealed by block of the other (Figure 1-3).

The DAP is a voltage- and $\mathrm{Ca}^{2+}$-dependent conductance that iss insensitive to TTX (Bourque 1986). The ionic identity of the current is unresolved, but evidence exists for two possibilities. Some demonstrate a reversal potential near $E_{\mathrm{K}}$ (Li and Hatton 1997), while other reports show the DAP is dependent on the presence of multiple cations (Smith and Armstrong 1993; Ghamari-Langroudi and Bourque 2002). DAP incidence is much lower in OT neurons $(17 \%)$ compared to VP neurons $(82 \%)$ (Teruyama and Armstrong 2002). Consequently, much of the work addressing the DAP's role in phasic burst initiation was done in VP neurons (Harris et al. 1975; Bicknell and Leng 1981; Andrew and Dudek 1983; Li et al. 1995, 1999; Ghamari-Langroudi and Bourque 2002). DAP incidence in OT, but not VP neurons increases significantly during pregnancy (61\%). The slow component of the DAP is blocked by $\mathrm{Cs}^{+}$(Ghamari-Langroudi and Bourque 1998). The excitatory neurotransmitter histamine enhances the DAP, highlighting one mechanism by which excitatory neurotransmitters may stimulate phasic MNC activity (Smith and Armstrong 1993). This mechanism ties nicely to observations that the AHP is attenuated by application of histamine in other cell types (Haas and Konnerth 1983). This highlights that neurotransmission isn't purely the gating of ionotropic receptors, but also the modulation of intrinsic membrane properties. The mechanisms of the DAP's overlapping intrinsic membrane property, the AHP, is described below.

\section{Afterhyperpolarizations}

MNCs and other neurons demonstrate AHPs that fall below resting potential after one or many spikes that decays over seconds. The AHP is underlain by AHP multuple $\mathrm{K}^{+}$ currents $\left(I_{\mathrm{AHPs}}\right)$ that determine the size, shape, and duration. AHPs activate during trains of spikes, and are observed by depolarizing the neuron with a step or pulse train of injected of current (current clamp, CC) or clamping the voltage to positive potentials (voltage clamp, VC) and then immediately clamping the cell to rest (Figure 1-4).

\section{Initial Discovery and Characterization}

Some of the earliest descriptions of AHPs were from embryonic chick heart tissue cultures, where they showed AHP amplitude changed when extracellular potassium 

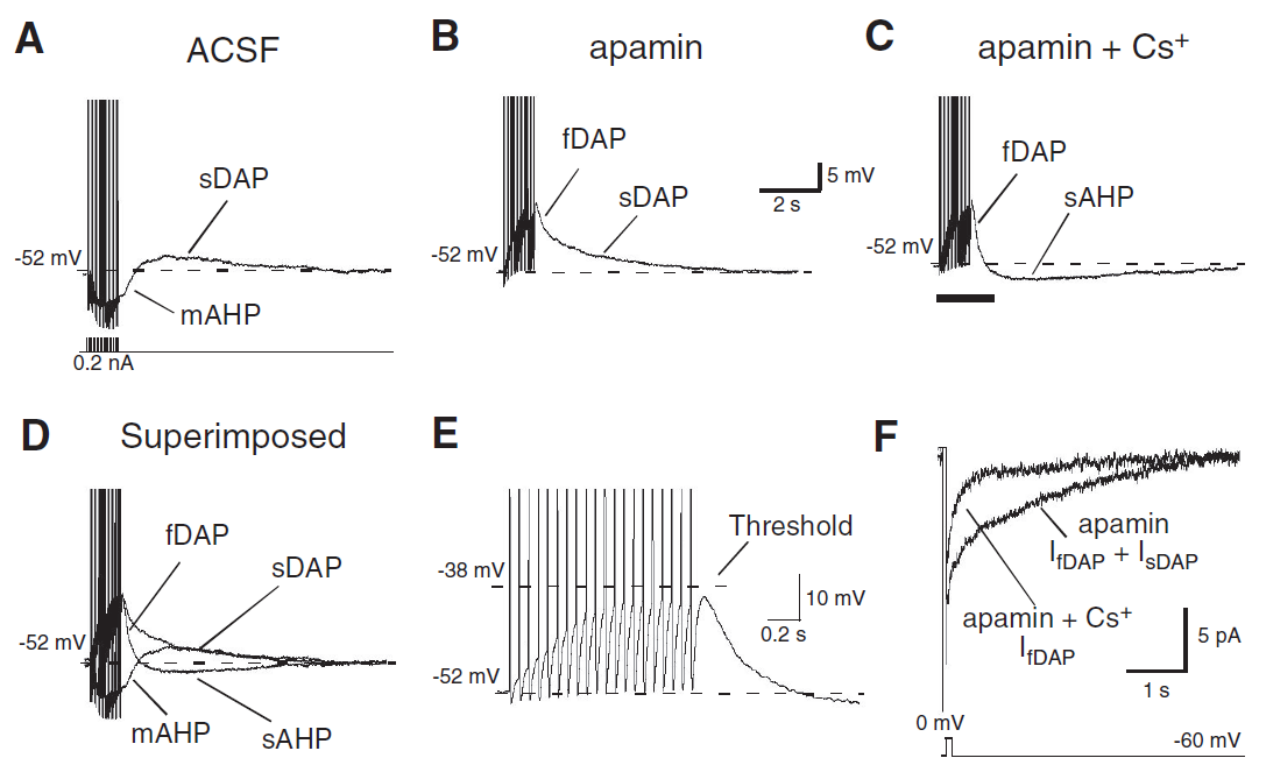

Figure 1-3. DAP and AHP afterpotentials that shape phasic burst patterns in OT and VP neurons.

Afterpotentials in a MNC were generated by a train of action potentials evoked by intracellular current injections (20-spike, $5 \mathrm{~ms}$ width depolarizing pulses, $100-250 \mathrm{pA}$, $20 \mathrm{~Hz}$ ). (A) In artificial cerebrospinal fluid (ACSF), the train of action potentials is followed by a distinct medium afterhyperpolarization (mAHP) that is subsequently followed by the slow DAP (sDAP). (B) Bath application of apamin $(100 \mathrm{nM})$ completely blocks the mAHP and unmasks the presence of the fast DAP (fDAP), which is followed by the sDAP. (C) Additional application of $\mathrm{Cs}^{+}(5 \mathrm{mM})$ blocks the sDAP, revealing the sAHP. (D) Superimposed traces of A-C illustrate the temporally overlapping, multiple afterpotentials. (E) Expanded portion of the trace in C (indicated by underline) reveals that the onset of the fDAP occurs after the 1st action potential and its amplitude increases with each subsequent action potential until a plateau is reached after 12 spikes. (F) Inward tail current thought to be underlying the DAPs ( $\left.I_{\mathrm{DAPs}}\right)$ was generated by $50 \mathrm{~ms}$ steps to $0 \mathrm{mV}$ from a holding potential of $-60 \mathrm{mV}$. Tail currents with similar time courses as the fast and slow DAPs were obtained and the application of $5 \mathrm{mM} \mathrm{Cs}^{+}$blocked only

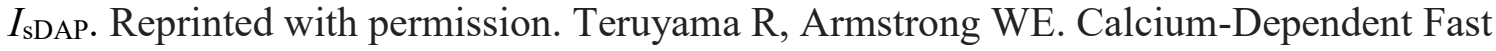
Depolarizing Afterpotentials in Vasopressin Neurons in the Rat Supraoptic Nucleus. J Neurophysiol 98: 2612-2621, 2007. 
A
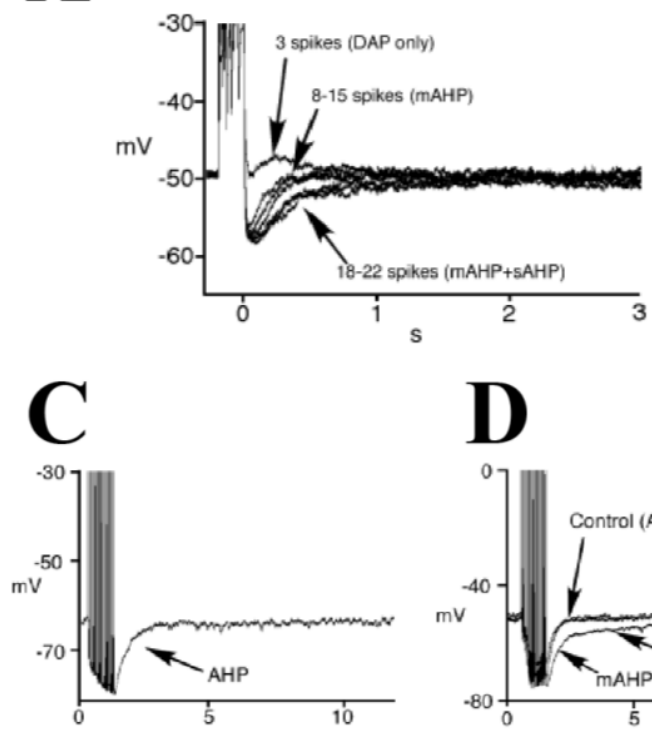

B

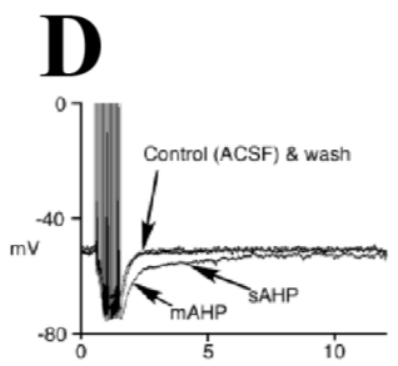

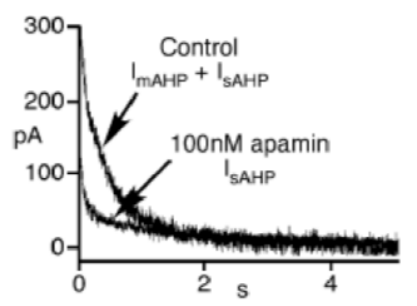

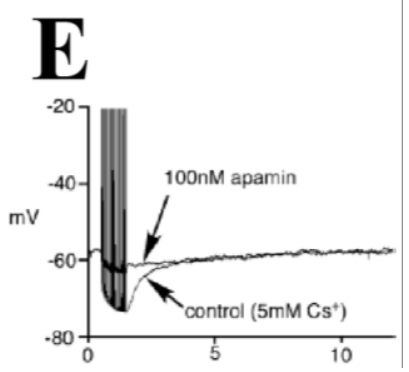

Figure 1-4. AHPs in SON are underlain by three distinct components.

(A) AHP obtained from an OT neuron of a virgin Sprague-Dawley rat demonstrating how AHP amplitude and duration increases with number of evoked spikes in a train. Three spikes during a $200 \mathrm{~ms}$ current injection evokes an fAHP-obscuring DAP, indicating AHPs are still not fully activated. When increasing the depolarizing current, the mAHP (apamin sensitive) reaches its peak after 8-15 spikes. The appearance of a second, slower AHP is observed after 18-22 spikes, indicating sAHP activation. (B) Recording of an AHP tail current $\left(I_{\mathrm{AHP}}\right)$ in voltage clamp. Currents display as a positive, outward $\mathrm{K}^{+}$ current following a $200 \mathrm{~ms}$ square pulse. The curves are well fit by a double exponential, indicating the presence of a $I_{\mathrm{mAHP}}$ and $I_{\mathrm{sAHP}}$. (C) Example of an AHP recorded under control conditions following a 20-spike protocol at $20 \mathrm{~Hz}$. (D) The mAHP and sAHP are fully revealed after $5 \mathrm{mM} \mathrm{Cs}+$ application. Cs + results in abrupt deceleration of the decay of the AHPs, and therefore reveals the presence of the mAHP and sAHP more clearly. (E) Application of $100 \mathrm{nM}$ apamin blocks the $\mathrm{mAHP}$, leaving the apamin-insensitive sAHP intact. Modified with permission. Foehring RC, Armstrong WE. Pharmacological dissection of high-voltage-activated $\mathrm{Ca} 2+$ current types in acutely dissociated rat supraoptic magnocellular neurons. J Neurophysiol 76: 977-983, 1996. 
concentration was changed (DeHaan and Gottlieb 1968). Early descriptions of AHPs in neurons appeared in the 1970s when Gustafsson and colleagues published a series of papers highlighting their characterization of the AHP as a $\mathrm{K}^{+}$conductance and its role in spike frequency adaptation in cat motoneurons (Baldissera and Gustafsson 1971, 1974a, 1974b).

Starting in the late 1970s and early 1980s, numerous reports of AHPs emerged from a myriad of neuronal cell types. These AHPs were exceptionally long-lasting, compared to those reported in cardiac muscle and invertebrates (Meech 1978). Much early work was done in CA1 and CA3 pyramidal cells, where groups first characterized core features of the AHP including (1) its amplitude as a function of spike train duration, (2) critical dependence on intracellular $\mathrm{Ca}^{2+}$, (3) lack of voltage dependence, (4) attenuation by neurotransmitters, and (5) role in spike frequency adaptation (Alger and Nicoll 1980; Hotson and Prince 1980; Madison and Nicoll 1982; Brown and Griffith 1983; Haas and Konnerth 1983). These AHP characteristics were corroborated by studies in neurons of the locus coeruleus (Andrade and Aghajanian 1984; Williams et al. 1984), the nucleus of solitary tract (Dekin and Getting 1984), and myenteric neurons (Morita et al. 1982). The consensus was that this outward $\mathrm{K}^{+}$conductance activated during trains of spike activity, slowing firing rate, and resulting in spike frequency adaptation.

AHPs in MNCs were first described in 1984 (Andrew and Dudek 1984). As in previous descriptions, the MNC AHP follows brief evoked spike trains and increases in size and duration with increasing frequency and duration of the evoked spike trains. Chelation of $\mathrm{Ca}^{2+}$ via high molar EGTA dialysis through the patch pipette eliminated the AHP, demonstrating intracellular $\mathrm{Ca}^{2+}$ dependence (Andrew and Dudek 1984). It was proposed that AHPs caused the spike frequency adaptation of phasic bursts as well as the ensuing post-burst periods of silence observed in MNCs (Brimble and Dyball 1977; Dutton and Dyball 1979; Poulain and Wakerley 1982; Andrew and Dudek 1984).

\section{The Three AHP Components}

As dissection of the AHP continued, it was discovered that cells generating an AHP often contained multiple components. It was obvious that the AHP was $\mathrm{Ca}^{2+}$ dependent, and so $\mathrm{Ca}^{2+}$-activated $\mathrm{K}^{+}\left(\mathrm{K}_{\mathrm{Ca}}\right)$ channels became target candidates for channel identity of the AHP. It became apparent that block of certain $\mathrm{K}_{\mathrm{Ca}}$ channels such as the small-conductance $\mathrm{K}_{\mathrm{Ca}}(\mathrm{SK})$ channel didn't block the entire AHP. Additionally, the AHP was often described as being fit by more than one exponential curve. This suggested the phenomenon was the coalescence of multiple $\mathrm{K}^{+}$channel types. (Pennefather et al. 1985; Bourque and Brown 1987; Storm 1987; Schwindt et al. 1988b; Storm 1989, 1990). The three components now identified are a fast AHP (fAHP), medium AHP (mAHP), and slow AHP (sAHP). An example of these three distinct AHP components in SON neurons is provided (Figure 1-4). 
Fast AHP (fAHP). The fAHP is a short-duration ( $<5-15 \mathrm{~ms})$ hyperpolarization that follows single spikes. The BK channel's underlying $\mathrm{K}^{+}$conductance contributes to spike repolarization, but is not the only $\mathrm{K}^{+}$channel to do so (Schwindt et al. 1988b; Pathak et al. 2016). The fAHP is consequential of a $\mathrm{K}^{+}$conductance through big conductance calcium-activated $\mathrm{K}^{+}(\mathrm{BK})$ channels (Lancaster and Nicoll 1987; Storm 1987). Early studies of the fAHP in cat sensorimotor cortex showed TEA and $\mathrm{Ca}^{2+}$-free external decreased the fAHP additively, and that apamin and $\mathrm{Cd}^{2+}$ didn't affect the fAHP (Schwindt et al. 1988b). This suggested that BK channels have a degree of Ca2+ dependence, and that spike repolarization and fAHP have distinct mechanisms, and that the fAHP is categorically different from the mAHP. The mechanisms of fAHP activation are complicated and dynamic. While BK are activated by $\mathrm{Ca}^{2+}$, they are also activated by $\mathrm{Mg}^{2+}$ (Marty and Neher 1985; Behrens et al. 1988; Yang et al. 2015).

Some of the first descriptions of BK in SON came from experiments in guinea pigs. BK currents were described as a minimally inactivating outward $\mathrm{K}^{+}$current (Hlubek and Cobbett 1997). Similar to studies in sensorimotor cortex of cat, these currents were inhibited by TEA, charybdotoxin (ChTx), iberiotoxin (IbTx), and blockage of $\mathrm{Ca}^{2+}$ entry with $\mathrm{Cd}^{2+}$ (Hlubek and Cobbett 1997; Greffrath et al. 1998; Dopico et al. 1999). Though, it should be noted that ChTx also blocks spike-repolarizing $\mathrm{K}_{\mathrm{V}} 1$ channels. Block of these channels also resulted in widening of spike repolarization (Hlubek and Cobbett 2000). Interestingly, BK currents were inhibited by both ChTx and IbTx, but only ChTx resulted in spike widening (Dopico et al. 1999; Hlubek and Cobbett 2000). This suggested that regionally segregated populations of BK channels exist in SON neurons with distinct pharmacological and biophysical properties that contribute to spike repolarization and AHPs differently (Dopico et al. 1999). This was reinforced later in which certain BK splice variants were found to be restricted to somas (Salzmann et al. 2010). Much work has been done on ethanol's effect of BK channel modulation in these neurons, where ethanol upregulates BK channel activity in terminals but not soma (Widmer et al. 1998; Dopico et al. 1999, 2014). While SON neurons clearly express BK channels that generate a fAHP, this dissertation does not investigate them, but instead focuses on the mAHP and sAHP. This thesis attempts to understand the mechanisms of the later, slower currents as opposed to the repolarization and hyperpolarization of single spikes.

Medium AHP (mAHP). The mAHP is a $\mathrm{Ca}^{2+}$-activated, voltage-independent phenomenon underlain by the $I_{\mathrm{mAHP}}$ (Vogalis et al. 2003b; Adelman et al. 2012). Much of the early work on mAHPs described them as a separate current from BK channels because they displayed low sensitivity to TEA and strong $\mathrm{Ca}^{2+}$ dependence (Meech and Standen 1975; Meech 1978; Romey and Lazdunski 1984). The critical discovery of the high-affinity $\left(\mathrm{IC}_{50}<0.1 \mathrm{nM}\right)$ toxin apamin has advanced our understanding of the mAHP; it is derived from bee venom (Burgess et al. 1981). Apamin blocks small conductance $\mathrm{Ca}^{2+}$-activated $\mathrm{K}^{+}(\mathrm{SK})$ channels and was shown to inhibit a mediumduration, voltage-independent AHP generated by short trains of action potentials in a variety of neurons (Pennefather et al. 1985; Blatz and Magleby 1986; Schwindt et al. 1988b, 1988a; Lorenzon and Foehring 1992; Pineda et al. 1992). d-tubocurarine is another channel toxin that blocks SK channels at the same binding site as apamin. 
Though the affinity is lower $\left(\mathrm{IC}_{50}=2.4 \mu \mathrm{M}\right)$, d-tubocurarine is easily reversible (Köhler et al. 1996). There are three members of the SK channel family: SK1, SK2, and SK3. These channels have varying degrees of sensitivity to apamin, but are all blocked robustly by $100 \mathrm{nM}$ apamin; SK1 channels having the lowest sensitivity (Shah and Haylett 2000; Grunnet et al. 2001). In the SON, SK3 appears to be the only SK channel expressed (Stocker and Pedarzani 2000). In pyramidal neurons, block of the mAHP with apamin leads to increased firing frequency with no effect on spike frequency adaptation (Lorenzon and Foehring 1992).

While the localization of SK channels was determined in SON before any electrophysiological studies (Mourre et al. 1986), the effect that apamin has on the mAHP was characterized shortly after (Bourque and Brown 1987). The mAHP in SON follows brief trains of action potentials, is blocked by apamin, is reversibly blocked by removal of extracellular $\mathrm{Ca}^{2+}$, is voltage-independent, and has a reversal potential near $E_{\mathrm{K}}$ (Armstrong et al. 1994; Kirkpatrick and Bourque 1996; Greffrath et al. 1998, 2004). In continuously firing MNCs, apamin increases firing frequency and in phasically firing MNCs, apamin increases the frequency while also decreasing phasic burst duration by $\sim 50 \%$ (Kirkpatrick and Bourque 1996). Application of apamin often unmasked a DAP which encouraged the neurons to fire in a burst pattern.

Recent work has highlighted the modulation of SK channels in MNCs. The SK channel forms a complex with constitutive calmodulin (CaM), casein kinase 2 (CK2), and protein phosphatase 2A (PP2A). CK2 and PP2A modulate the $\mathrm{Ca}^{2+}$ sensitivity of the channel by respectively dampening or amplifying the effect of bound $\mathrm{Ca}^{2+}$. It does so by either phosphorylating (CK2) or dephosphorylating (PP2A) SK-associated CaM (Adelman et al. 2012). Recent work has demonstrated this complex is present in SON neurons and that enhancements in mAHP observed during pregnancy reflect in part a downregulation of CK2 (Wang et al. 2018).

Slow AHP (sAHP). The sAHP is a slow (5-10s of seconds), $\mathrm{Ca}^{2+}$ dependent component of the AHP. It is characterized by insensitivity to apamin, which when applied blocks the mAHP, and reveals a lower amplitude longer lasting AHP. The sAHP shares many features with the mAHP, including its $\mathrm{Ca}^{2+}$ dependence, voltageindependence, and reversal near $E_{\mathrm{K}}$ (Alger and Nicoll 1980; Hotson and Prince 1980; Schwindt et al. 1988a; Ghamari-Langroudi and Bourque 2004). One feature that separates the sAHP from the fAHP and mAHP (aside from kinetics) is its susceptibility to neurotransmitter modulation. Early work demonstrated attenuation following application of norepinephrine or histamine (Madison and Nicoll 1982; Haas and Konnerth 1983; Schwindt et al. 1988a). Subsequent studies revealed that many additional neurotransmitters could modulate sAHPs, including muscarine (Scroggs et al. 2001; Ghamari-Langroudi and Bourque 2004), serotonin (Lorenzon and Foehring 1992), and dopamine (Pedarzani and Storm 1995). Like the mAHP, the sAHP also underlies spike frequency adaptation, the slowing of firing frequency during a prolonged train. Attenuation of the sAHP via neurotransmitters abolishes this spike frequency adaptation (Lorenzon and Foehring 1992). 
The sAHP's kinetics and attenuation by neurotransmitters spurred extensive studies of the pathways triggered by those transmitters. The mechanism of action for neurotransmitter attenuation of AHPs is cell-type specific. The transmitter pathways that modulate these pathways typically fall into one of two categories: (1) the activation of $\mathrm{G \alpha}_{\mathrm{s}}$-coupled receptors, leading to elevated cAMP and subsequent PKA activation, and (2) the activation of $\mathrm{G} \alpha_{q}$-coupled receptors, leading to activation of phospholipase-C (PLC), which cleaves $\mathrm{PIP}_{2}$ into DAG and $\mathrm{IP}_{3}$. These products activate $\mathrm{PKC}$ and bind $\mathrm{IP}_{3}$ receptors to trigger $\mathrm{Ca}^{2+}$ release from endoplasmic $\mathrm{Ca}^{2+}$ stores. The PKA modulation pathway is well studied, where hippocampal neurons are known to be modulated by this pathway (Madison and Nicoll 1982; Pedarzani and Storm 1993; Lancaster et al. 2006). This pathway has been comprehensively mapped in enteric neurons (Vogalis et al. 2003a). The second pathway, mediated by PLC-cleavage of PIP 2 into DAG and $\mathrm{IP}_{3}$, is influential of sAHPs in cortex, hippocampus, and SON (Krause et al. 2002; GhamariLangroudi and Bourque 2004; Villalobos et al. 2011). AHPs in these neurons are attenuated by muscarine or acetylcholine.

While neurotransmitters and their signaling pathways are known to modulate the sAHP, how does the influx of $\mathrm{Ca}^{2+}$ lead to the activation of a sAHP? The activation and decay of the current are too slow to simply reflect the binding of $\mathrm{Ca}^{2+}$ to a proximal channel. This suggests that there are intermediary steps involved. The sAHP activates after longer trains of spikes, in which the amplitude of the sAHP is non-linearly correlated with spike count. It is clear that the sAHP is activated by elevated cytoplasmic $\mathrm{Ca}^{2+}$ (Hotson and Prince 1980; Abel et al. 2004). How do the sAHP channels sense this change in $\left[\mathrm{Ca}^{2+}\right]_{\mathrm{i}}$ ? $\mathrm{Ca}^{2+}$ sensor (NCS) proteins may provide an explanation for this detection. Most notable is the dependency of sAHPs on the NCS hippocalcin in CA1. When hippocalcin expression is drastically knocked down, $I_{\mathrm{SAHPS}}$ are nearly abolished in CA1 neurons (Tzingounis et al. 2007). This same study also showed that when CA1 neurons were given extremely strong pulses (long duration; high frequency), they could elicit a tiny sAHP in the hippocalcin knockouts. This current was insensitive to noradrenergic modulation. Other $\mathrm{Ca}^{2+}$ sensors have been implicated in a similar manner in other cell types such as calcineurin in myenteric neurons (Vogalis et al. 2004) and neurocalcin $\delta$ in cortex (Villalobos and Andrade 2010). A more detailed explanation on how the cellular $\mathrm{Ca}^{2+}$ environment affects AHPs is provided in the next section.

A captivating aspect of the sAHP is that the channel(s) has eluded identification. Many candidates have been proposed. One proposal was that of intermediateconductance $\mathrm{Ca}^{2+}$-dependent $\mathrm{K}^{+}$channels (IK), formerly known as the SK4 channel (King et al. 2015). This has been widely contested by the field due to failure of IK block to produce abolishment of AHPs (Wang et al. 2016a). Additionally, IK channel presence in the brain is sparse at best, expressing mostly in non-nervous tissues and some peripheral neurons (Jensen et al. 2001; Neylon et al. 2004). The best evidence for a single channel is $\mathrm{KCNQ}\left(\mathrm{K}_{\mathrm{v}} 7\right)$ channels. $\mathrm{KCNQ}$, in concert with hippocalcin, contributes a portion of the $I_{\mathrm{SAHP}}$ in CA1 (Tzingounis and Nicoll 2008; Tzingounis et al. 2010). $\mathrm{KCNQ} 2,3$, and 5 knockout animals generate shunted sAHPs, indicating that KCNQ channels contribute to a portion of the sAHP, but not all of it. In the same study, they 
evaluated superior cervical ganglion neurons, cells with KCNQ channels but no hippocalcin or sAHP. When they introduced a hippocalcin-expressing virus, the cells could generate a sAHP. This demonstration makes a powerful statement about sAHP gating: that SAHP activation reflects the detection of elevated $\mathrm{Ca}^{2+}$ and downstream coupling to $\mathrm{K}^{+}$channels, as opposed to the opening of a single ion channel species. Though it may not be the same in all cell types, as KCNQ blockers in neocortical pyramidal neurons failed to affect the sAHP (Guan et al. 2011; Andrade et al. 2012).

Others have observed another slow component in some neurons that appears to be carried by $\mathrm{Na}^{+}$-dependent $\mathrm{K}^{+}$channels or the exchange of ions through the $\mathrm{Na}^{+} / \mathrm{K}^{+}$ATPase (Schwindt et al. 1988a; Foehring et al. 1989; Gulledge et al. 2013). This type of AHP is beyond the scope of this review.

With regards to the sAHP in MNCs, they can be categorically called sAHPs due to possessing the same cardinal features of sAHPs found in other neuronal cell types (Greffrath et al. 1998, 2004; Ghamari-Langroudi and Bourque 2004). The major characterization of sAHPs in SON was accomplished by attenuating the sAHP with muscarine and evaluating the effects on the phasic bursting. Due diligence was taken to ensure that muscarine wasn't affecting other $\mathrm{Ca}^{2+}$ dependent parameters such as singlespike shape or the DAP. sAHP inhibition via muscarine produces increased phasic bursting duration, spike count, and firing frequency, resulting in an enhanced plateau potential (Ghamari-Langroudi and Bourque 2004). This provides direct evidence for how muscarinic attenuation of the sAHP can facilitate phasic firing in MNCs via attenuation of a hyperpolarizing current. This study further highlights the interplay between DAP and sAHP to intrinsically produce and terminate phasic bursting.

\section{AHP Plasticity during Pregnancy and Lactation in SON}

AHPs demonstrate marked plasticity during the reproductive cycle in MNCs. At labor and during subsequent lactation OT neurons produce robust, synchronous firing to trigger massive release of OT for parturition and milk ejection (Poulain and Wakerley 1982; Belin et al. 1984). The plastic changes in AHP and DAP may shape the phasic pattern changes observed in OT neurons during these periods. Specifically, the AHP enhances in amplitude and decay during pregnancy and lactation of OT but not VP neurons (Stern and Armstrong 1996; Teruyama and Armstrong 2002, 2005). This translates to stronger spike frequency adaptation during phasic activity in OT, but not VP neurons. OT and VP neurons were shown to undergo some plastic changes in single spike parameters through the reproductive cycle. The only change in DAP observed was an increase in DAP incidence of OT neurons, which is significantly lower in virgin OT neurons compared to VP neurons. Neither cell type showed changes in passive membrane properties. Closer analysis revealed that both mAHP and sAHP components were enhanced during lactation in OT but not VP neurons. Interestingly, corresponding $\left[\mathrm{Ca}^{2+}\right]_{\mathrm{i}}$ measurements revealed a significantly faster decay tau but no change in peak for both OT and VP neurons. Peak $\mathrm{Ca}^{2+}$ currents also increased, but so did membrane capacitance during lactation, suggesting the increased currents was a result of increased cell body 
size, as when adjusted for current density there was no difference (Teruyama and Armstrong 2005). Finally, blockade of oxytocin receptors during gestation produces smaller sAHPs (Teruyama et al. 2008). This suggests that central OT modulation of sAHPs contributes to the synchronization of OT neurons during parturition and lactation.

\section{Calcium}

Intracellular $\mathrm{Ca}^{2+}$ concentration is so vital for AHP generation that it warrants special consideration in terms of its role, sources, buffering, and signaling mechanisms. This is especially true for the sAHP, where activation isn't simply the binding of $\mathrm{Ca}^{2+}$ ions to $\mathrm{K}^{+}$channels but rather a complex activation of intermediary pathways.

$\mathrm{Ca}^{2+}$ sources for the AHP include high-voltage-gated $\mathrm{Ca}^{2+}$ channels as inorganic channel blockers inhibit the AHP (Andrade and Aghajanian 1984; Schwindt et al. 1988a; Ghamari-Langroudi and Bourque 2004). Specific types of voltage-gated $\mathrm{Ca}^{2+}$ channels often couple to AHPs, depending on the cell type. A detailed list of these couplings can be found in the Introduction to Chapter 4 of this document as well as in Andrade et al. (2012). Specific types of $\mathrm{Ca}^{2+}$ channels that couple to the mAHP and sAHP in MNCs are explored in Chapter 4 as well. In addition to entry through plasma membrane channels, $\mathrm{Ca}^{2+}$ from intracellular stores, such as ryanodine-sensitive stores, contribute to the AHP in certain neurons. Block of $\mathrm{Ca}^{2+}$ induced $\mathrm{Ca}^{2+}$ release from these stores inhibits the AHPs in mature repetitively firing enteric neurons, and hippocampal pyramidal neurons (Torres et al. 1996; Vogalis et al. 2001).

The fAHP and mAHP are thought to be activated by nanodomains and microdomains of $\mathrm{Ca}^{2+}$, the nano- and micro reflecting the order of magnitude of distance these pools of $\mathrm{Ca}^{2+}$ are from AHP channels. Nanodomains ( $\sim 10 \mathrm{nM}$ from the channel) of $\mathrm{Ca}^{2+}$ are formed during transient activation of $\mathrm{Ca}^{2+}$ channels which can activate $\mathrm{BK}$ channels (Fakler and Adelman 2008). This $\mathrm{Ca}^{2+}$ will combine with $\mathrm{Ca}^{2+}$ from other $\mathrm{Ca}^{2+}$ channels to form a microdomain, a pocket of elevated $\mathrm{Ca}^{2+}$ near the plasma membrane (Fakler and Adelman 2008). $\mathrm{Ca}^{2+}$ reuptake and buffering mechanisms are fast $(<1 \mathrm{~ms})$, and occur through mechanisms such as the absorption into intracellular stores or extruded from the cell via a pump (Guerini 1998; Yang et al. 2018). The ability of $\mathrm{Ca}^{2+}$ to bind BK and SK channels through respective nanodomains and microdomains reflects these channels' affinity for binding $\mathrm{Ca}^{2+}$ (as well as the activity of the $\mathrm{Ca}^{2+}$ channels). SK channels have a higher affinity for $\mathrm{Ca}^{2+}$ (submicromolar) compared to $\mathrm{BK}$ channels (micromolar); this affinity is inversely proportional to their distance from the $\mathrm{Ca}^{2+}$ source (Fakler and Adelman 2008).

These microdomains have important implications for how AHPs are triggered by $\mathrm{Ca}^{2+}$ influx. In cortex and dopamine neurons, there was only a very rough, non-sigmoidal relationship between bulk $\left[\mathrm{Ca}^{2+}\right]_{i}$ and the mAHP, while the entire AHP displayed a cooperative, sigmoidal dose response relationship with bulk $\left[\mathrm{Ca}^{2+}\right]_{\mathrm{i}}$ (Wilson and Callaway 2000; Abel et al. 2004). This suggests that SK channels are activated by localized microdomains of $\mathrm{Ca}^{2+}$ while the kinetically slower sAHP responds to bulk 
increases in $\left[\mathrm{Ca}^{2+}\right]_{i}$. This is because bulk $\left[\mathrm{Ca}^{2+}\right]_{\mathrm{i}}$ is being measured and $\mathrm{Ca}^{2+}$ at the membrane decreases. This sAHP response constitutes a mechanism by which sAHP channels sense bulk rises in $\left[\mathrm{Ca}^{2+}\right]$, such as hippocalcin in CA1 (Tzingounis et al. 2007).

\section{PIP2: Characteristics and Its Role in AHPs}

\section{The Role of PIP2 in Cells}

Phosphotidylinositol 4,5-bisphosphate, $\operatorname{PtdIns}(4,5) \mathrm{P}_{2}$, or simply $\mathrm{PIP}_{2}$, is a long chain phospholipid found on the inner leaflet of cell membranes. $\mathrm{PIP}_{2}$ levels are constitutive. In other words, molecules of $\mathrm{PIP}_{2}$ are constantly synthesized and broken down, resulting in maintenance of basal $\mathrm{PIP}_{2}$ molecules (Xu et al. 2003; Dickson et al. 2013). In addition to the $\mathrm{IP}_{3} / \mathrm{DAG}$ pathway, $\mathrm{PIP}_{2}$ controls a varied range of cellular functions including organization of filamentous actin, cellular differentiation, exocytosis, and ion channel maintenance (Eberhard et al. 1990; Sun et al. 1999; Hilgemann et al. 2001; Hille et al. 2015). PIP 2 's modulation of ion channels is well known. KCNQ (KV7) channels are certainly the best documented example (Suh and Hille 2002, 2007; Li et al. 2005; Zaydman and Cui 2014; Hille et al. 2015), but much evidence exists for modulation of Voltage-gated $\mathrm{Ca}^{2+}$ channels (Cav) channels, inwardly rectified $\mathrm{K}^{+}(\mathrm{Kir})$ channels, and ATP-gated $\mathrm{K}^{+}\left(\mathrm{K}_{\mathrm{ATP}}\right)$ channels (Suh et al. 2010; Xie et al. 2014; Borschel et al. 2017). Often, the depletion of $\mathrm{PIP}_{2}$ from the membrane results in decreased channel activity in these cases.

\section{PIP2 Modulation of Ion Channels: Implications for AHPs}

Some of the leading sAHP channel candidates are channels that also bind $\mathrm{PIP}_{2}$ such as KCNQ, KATP, and TREK1 channels (Tzingounis and Nicoll 2008; Andrade et al. 2012; Ford et al. 2013; Cabanos et al. 2017). This is most apparent in the KCNQ channel, a candidate for a channel underlying the sAHP. PIP 2 stabilizes the opening of KCNQ channels and in many cases, shifts the voltage activation of the channel into ranges at which the sAHP generates (Kim et al. 2016b). It has also been proposed that KCNQ channels are not strictly voltage dependent, and that the presence of $\mathrm{PIP}_{2}$ is required to couple the pore domain to the voltage-sensing domain of the channel (Zaydman et al. 2013; Kim et al. 2017). High $\mathrm{PIP}_{2}$ levels also alters the muscarinic sensitivity of the channel independent of the classic muscarinic modulation of M-Current via G-proteins (Hernandez et al. 2009; Zhou et al. 2013). The involvement of PIP $2, K C N Q$ channels, and sAHPs is highlighted in (Kim et al. 2016b), where $\mathrm{PIP}_{2}$ concentration played a critical role in dictating which KCNQ channels contributed to the sAHP. KCNQ3 knockout animals still displayed a prominent sAHP, but was shown to be dependent on the presence of hippocalcin, suggesting that perhaps $\mathrm{Ca}^{2+}$ sensors are the primary gating components of sAHPs in CA1 neurons. 
With regards to the SK-mediated mAHP, recent single channel studies of SK channels in transfected HEK cells revealed that these channels became inert when $\mathrm{PIP}_{2}$ was depleted from them, suggesting a constitutive role of $\mathrm{PIP}_{2}$ in the SK-channel complex as $\mathrm{PIP}_{2}$ binds to the SK-CaM interface (Zhang et al. 2014).

There are other ion channels besides AHP channels that $\mathrm{PIP}_{2}$ could bind to influence the AHP. For example bound $\mathrm{PIP}_{2}$ to $\mathrm{Ca}^{2+}$ channels (Suh et al. 2010), and the consequent modulation of $\mathrm{Ca}^{2+}$ entry could influence $\left[\mathrm{Ca}^{2+}\right]_{i}$ and activation of the sAHP.

Recent evidence in neocortical pyramidal neurons demonstrates that $\mathrm{PIP}_{2}$ is a strong candidate as an intermediary between $\mathrm{Ca}^{2+}$ sensing and AHP activation. Rundown of the sAHP over long recording periods is rescued when $\mathrm{PIP}_{2}$ production is increased via overexpression of PIP5K (the PIP to $\mathrm{PIP}_{2}$ generating enzyme); rundown is accelerated when $\mathrm{PIP}_{2}$ is depleted via wortmannin (Villalobos et al. 2011) (Figure 1-5). An important finding was that $\mathrm{PIP}_{2}$ facilitation appeared to increase the sAHP amplitude by facilitating the ability of $\mathrm{Ca}^{2+}$ to activate an SAHP, suggesting that PIP2 presence is an important co-factor alongside $\mathrm{Ca}^{2+}$ to activate the $I_{\mathrm{SAHP}}$. There is a rising body of literature highlighting $\mathrm{PIP}_{2}$ 's modulation of ion channels and its role in the AHP. The following thesis explores the potential role of $\mathrm{PIP}_{2}$ in modulation and gating of AHPs in MNCs of SON.

\section{Rationale and Specific Aims}

OT and VP neurons in SON display $\mathrm{Ca}^{2+}$-dependent AHPs. While the mechanisms for the mAHP are relatively well documented, much remains unknown of the mechanisms underlying the sAHP including the specific channels involved. Recent work in cortical pyramidal neurons demonstrated that sAHPs were affected by the presence of $\mathrm{PIP}_{2}$. Excess $\mathrm{PIP}_{2}$ appeared to increase the sAHP sensitivity to $\mathrm{Ca}^{2+}$ and curb rundown while depletion of $\mathrm{PIP}_{2}$ enhanced rundown of the sAHP. This highlights an intracellular mechanism for sAHP gating consistent with the conductance's slow kinetics (Villalobos et al. 2011). The CaM-SK channel complex conducting the mAHP is critically dependent on $\mathrm{PIP}_{2}$ in transfected cells (Zhang et al. 2014). The SON AHP shares many of the features of AHPs in other neuron types. SON AHPs are inhibited by muscarine, a transmitter that activates PLC cleavage of $\mathrm{PIP}_{2}$. Therefore, I explored the possibility of $\mathrm{PIP}_{2}$ involvement in AHPs of OT and VP neurons. Herein I primarily incorporated the use of whole-cell patch clamp electrophysiology with simultaneous $\mathrm{Ca}^{2+}$ imaging to determine $\mathrm{PIP}_{2}$ 's role in the generation of AHPs.

- Aim 1: Determine whether of PIP $_{2}$ to generate an AHP in both OT and VP neurons in the SON as well as characterize how it affects $\mathrm{Ca}^{2+}$-activation of the AHP (Chapter 3).

- Aim 2: Determine which high-voltage-activated $\mathrm{Ca}^{2+}$ channels contributed $\mathrm{Ca}^{2+}$ to mAHP and sAHP generation in both the OT and VP neurons of the SON (Chapter 4). 

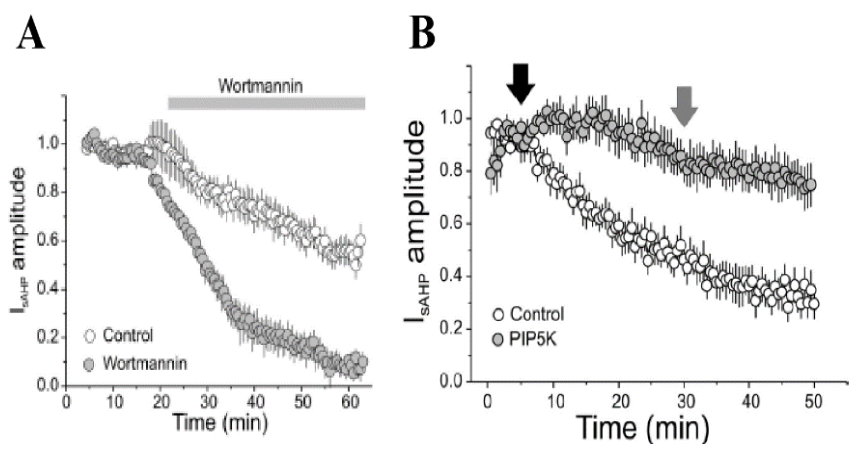

C

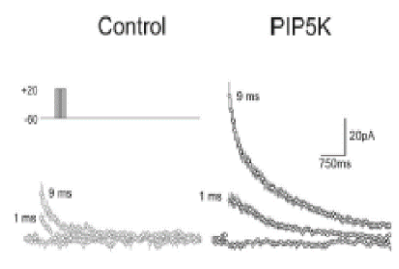

Figure 1-5. The $I_{\text {sAHP }}$ in cortical neurons is sustained by PIP2.

During long recording periods, the $I_{\mathrm{SAHP}}$ current displays drastic rundown in its amplitude. This rundown is thought be in part due to cutoff of $\mathrm{PIP}_{2}$ supply to the neuron since its substrate, myo-inositol, is normally recruited from the animal's diet. (A) Control rundown time course is plotted (white points) against rundown time courses for neurons in which $\mathrm{PIP}_{2}$ is depleted by wortmannin (gray points). Wortmannin accelerates the rundown of the $I_{\mathrm{SAHP}}$ (B) Similar rundown time course as plotted in (A), but with Control (white points) plotted against rundown time courses for neurons in which $\mathrm{PIP}_{2}$ is maintained by overexpression of PIP5K (gray points). PIP5K overexpression prevents the rundown of the $I_{\mathrm{sAHP}}$. (C) The ability of PIP5K to facilitate the calcium gating of $I_{\mathrm{sAHP}}$ is most evident when using very short depolarizing steps (1-10 ms). Under control conditions, such short steps fail to significantly activate $I_{\mathrm{SAHP}}$, while after transfection with PIP5K they produce robust, graded activations of this current. Modified with permission. Villalobos C, Foehring RC, Lee JC, Andrade R. Essential Role for Phosphatidylinositol 4,5-Bisphosphate in the Expression, Regulation, and Gating of the Slow Afterhyperpolarization Current in the Cerebral Cortex. J Neurosci 31: 18303$18312,2011$. 
- Aim 3: Determine the precise mechanism by which $\mathrm{PIP}_{2}$ modulates $\mathrm{Ca}^{2+}$ channels in OT neurons (Chapter 5).

- Aim 4: Explore the possibility of dendritic localization of AHP currents in both OT and VP neurons of SON (Chapter 6). 


\section{CHAPTER 2. METHODOLOGY}

\section{Animals and Ethical Approval}

These studies were performed on either virgin adult Sprague-Dawley female rats (Harlan Laboratories, Indianapolis) or transgenic Wistar-Kyoto rats containing the AVPeGFP fusion and/or the OXT-mRFP1 fusion transgenes (Ueta et al. 2005; Katoh et al. 2011). These rats weighed between 140-230 g. The UTHSC IACUC review board approved all experiments and the experiments conform to the principles of UK regulations as described in (Drummond 2009). Animals were on an ad libitum diet. For use in experiments, rats were deeply anesthetized with either sodium pentobarbital (100 $\left.\mathrm{mg} \mathrm{kg}^{-1}\right)$ or ketamine/xylasine ( $10 \%$ xylasine; $\left.100 \mathrm{mg} \mathrm{kg}^{-1}\right)$ and perfused through the heart with artificial cerebrospinal fluid (aCSF) with $\mathrm{NaCl}$ replaced by $210 \mathrm{mM}$ sucrose. The rats were decapitated via guillotine. The brains were then removed and subsequently sliced for use in whole cell patch clamp electrophysiology. AHPs in OT neurons undergo significant plastic changes during the female reproductive cycle (Teruyama and Armstrong 2002, 2005). Because of this, most of our studies are in females because these changes offer insights into the MNC-specific mechanisms of AHP generation.

\section{Cell and Tissue Preparation for Electrophysiological Recordings}

\section{Slice Preparation}

$250 \mu \mathrm{m}$ coronal brain slices were cut using a Leica VT1000S vibratome in icecold aCSF with $210 \mathrm{mM}$ sucrose replacing $\mathrm{NaCl}$. After cutting, the brain slices were transferred to an aCSF-filled holding chamber and warmed for $15-20$ min at $32 \pm 1{ }^{\circ} \mathrm{C}$. aCSF was continuously bubbled with $95 \% \mathrm{O}_{2}-5 \% \mathrm{CO}_{2}$, and_contained (in $\mathrm{mM}$ ) $20 \mathrm{D}$ glucose, 0.45 ascorbic acid, $2.5 \mathrm{KCl}, 1 \mathrm{MgSO}_{4}, 1.25 \mathrm{NaH}_{2} \mathrm{PO}_{4} \cdot \mathrm{H}_{2} \mathrm{O}, 26 \mathrm{NaHCO}_{3}, 125$ $\mathrm{NaCl}, 2 \mathrm{CaCl}_{2}$. Slices were then transferred to aCSF at room temperature, where they remained for at least 40 minutes prior to recording.

\section{Acutely Dissociated Neuron Preparation}

After removal, the brain was placed under a dissecting microscope for the dissection of supraoptic tissue. The brain was placed with the ventral surface up. Using iris scissors, a horizontal strip of tissue was excised from the ventral surface of the brain containing the supraoptic nucleus attached to the optic chiasm/tract. This strip of tissue was divided into four even strips of optic tract with hypothalamus attached (Figure 2-1). These explants were then submerged in aCSF bubbled with $95 \% \mathrm{O}_{2}-5 \% \mathrm{CO}_{2}$. After resting a minimum of 30 minutes, tissue was transferred to a glass chamber warmed by a water bath at $34{ }^{\circ} \mathrm{C}$. The chamber containing the tissue was aCSF $+1 \mathrm{mg} / \mathrm{ml}$ of Streptomyces griseus (Type XIV) enzyme bubbled with $95 \% \mathrm{O}_{2}-5 \% \mathrm{CO}_{2}$ for $24-30$ 


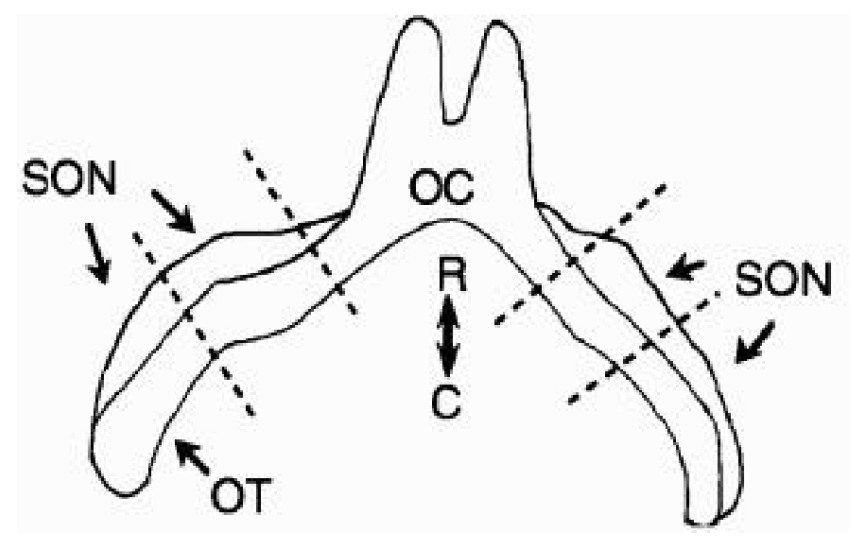

Figure 2-1. Explants of supraoptic nucleus were removed from rat brain.

Schematic of the horizontal sections used to isolate the SON. The location of the SON and the dissection are shown. Dotted lines: cuts made after the initial incubation, before enzyme treatment. The midline tissue rostral to the medial cuts was discarded and the SON-optic tract sectioned into four pieces. OT, optic tract; OT, optic chiasm; R, rostral; C, caudal. Modified with permission. Foehring RC, Armstrong WE. Pharmacological dissection of high-voltage-activated $\mathrm{Ca} 2+$ current types in acutely dissociated rat supraoptic magnocellular neurons. J Neurophysiol 76: 977-983, 1996. 
minutes. After enzymatic treatment, tissue was transferred to a glass test tube containing a solution (in $\mathrm{mM}$ ): $140 \mathrm{Na}^{+}$Isethionate, $2 \mathrm{KCl}, 0.1 \mathrm{CaCl}_{2}, 4 \mathrm{MgCl}_{2}, 20$ Glucose, 10 HEPES, $\mathrm{pH}$ balanced to 7.2 with $\mathrm{NaOH}$. The tissue was then titrated through flamepolished glass pipettes three times in three successfully smaller diameter pipettes. The supernatant was removed and plated onto a culture dish, which was placed into the chamber of an inverted microscope (Nikon Diaphot 300). The cells were allowed 7 minutes to settle on the dish. A background flow of Hanks buffered saline solution (HBSS) was adminstered and cells were visualized.

\section{Electrophysiology}

\section{Slice Recordings}

Slices were placed in the well of a plexiglass chamber attached to a modified stage on an Olympus BX51WI upright microscope and perfused with aCSF containing 5 $\mathrm{mM} \mathrm{CsCl}$ to block the slow depolarizing after-potential (sDAP) (Ghamari-Langroudi and Bourque 1998; Teruyama and Armstrong 2005, 2007). The aCSF was bubbled constantly with $95 \% \mathrm{O}_{2}-5 \% \mathrm{CO}_{2}$, warmed to $32{ }^{\circ} \mathrm{C} \pm 1{ }^{\circ} \mathrm{C}$, and flowed at $\sim 2 \mathrm{ml} / \mathrm{min}$. Whole cell voltage clamp recordings were obtained using an Axon Multiclamp 700B amplifier (Molecular Devices, Sunnyvale, CA, USA). Traces were digitized using an Axon 1440A Digitizer at $10 \mathrm{kHz}$ and filtered at $2 \mathrm{kHz}$ on a Dell desktop computer running Clampex 9 software (Molecular Devices).

Recording pipettes (4-8 M $\Omega$ ) were pulled from borosilicate glass with an outer diameter of $1.5 \mathrm{~mm}$ using a P-1000 flaming/brown horizontal micropipette puller (Sutter Instruments, Sovato, CA, USA). The pipette internal solution for analyzing AHP tail currents consisted of (in mM): $135 \mathrm{KMeSO}_{4}, 8 \mathrm{NaCl}, 10$ HEPES, $2 \mathrm{Mg}$-ATP, $0.3 \mathrm{Na}-$ GTP, 0.1 leupeptin, 6 phosphocreatine, 0.2 EGTA with pH 7.2-7.4 and 285-295 mOsmol $\left(\mathrm{kg} \mathrm{H}_{2} \mathrm{O}\right)^{-1} .0 .1 \%$ biocytin (Sigma-Aldrich, USA) was added to an aliquot on the day of the experiment for visualization during immunochemical identification of cell type. The liquid junction potential for the $\mathrm{KMeSO}_{4}$ internal was $\sim-10 \mathrm{mV}$, and was not corrected.

$I_{\mathrm{AHP}}$ tail currents were evoked using a voltage clamp protocol of an unclamped 17 spike, $5 \mathrm{~ms}$ pulse train at $20 \mathrm{~Hz}$ from a holding potential of $-60 \mathrm{mV}$ to $+20 \mathrm{mV}$; the $I_{\mathrm{AHP}}$ was clamped at $-60 \mathrm{mV}$ immediately following the train. This was done to mimic a train of action potentials, and at $20 \mathrm{~Hz}, 17$ spikes produced an $I_{\mathrm{AHP}}$ amplitude near maximum in pilot experiments (data not shown). In MNCS $I_{\mathrm{AHP}}$ amplitude correlates with spike count (Ghamari-Langroudi and Bourque 2004). All $I_{\mathrm{AHP}}$ recordings were taken in the presence of synaptic blockers $10 \mu \mathrm{M}$ 6,7-dinitroquinoxaline-2,3-dione (DNQX), $40 \mu \mathrm{M}$ $2 R$ )-amino-5-phosphonovaleric acid (AP5), and $100 \mu \mathrm{M}$ picrotoxin to block fast synaptic currents. Cells whose series resistance exceeded $20 \mathrm{M} \Omega$ and/or changed by more than $20 \%$ during the recording were discarded. $I_{\mathrm{AHPs}}$ were averaged over 2 or more runs.

For measuring whole cell $\mathrm{Ca}^{2+}$ currents, the external bath solution contained (in $\mathrm{mM}$ ): $110 \mathrm{NaCl}, 50 \mathrm{TEA}-\mathrm{Cl}, 5 \mathrm{CsCl}, 1 \mathrm{MgCl}_{2}, 10 \mathrm{HEPES}, 10$ Glucose, 0.0005 
tetrodotoxin (TTX), 0.1 picrotoxin, $4 \mathrm{CaCl}_{2}$. The pipette internal solution contained: 180 $\mathrm{N}$-methyl-D-glucamine, $4 \mathrm{MgCl}_{2}$, 40 HEPES, 10 EGTA, 12 phosphocreatine, 2 ATP-Mg, 0.4 GTP-Na. The liquid junction potential for this internal is $\sim 5 \mathrm{mV}$ and was not corrected. Cells were held at $-70 \mathrm{mV}$. For I-V curves, cells were hyperpolarized to -90 $\mathrm{mV}$ for $200 \mathrm{~ms}$ followed by $10 \mathrm{mV} 1000 \mathrm{~ms}$ steps up to $+10 \mathrm{mV}$. $400 \mu \mathrm{M} \mathrm{Cd}^{2+}$ was bathapplied at the end of each trial to confirm the $\mathrm{Ca}^{2+}$ current. I-V curves were derived from the steady-state measurement of these steps. Currents were leak subtracted by scaling the current in response to a $+10 \mathrm{mV}$ step from baseline.

\section{Acutely Dissociated Neuron Recordings}

Recording pipettes (2.5-5 M $\Omega$ ) were pulled from borosilicate glass with an outer diameter of $1.5 \mathrm{~mm}$ using a P-1000 flaming/brown horizontal micropipette puller (Sutter Instruments, Sovato, CA, USA). The pipette tips were coated in candle wax to minimize capacitive artifacts during recordings. The pipette internal solution consisted of (in $\mathrm{mM}$ ): $180 \mathrm{~N}$-methyl-D-glucamine, $4 \mathrm{MgCl}_{2}$, 40 HEPES, 2 Na-ATP, $0.4 \mathrm{Mg}-\mathrm{GTP}, 12$ phosphocreatine, 0.1 leupeptin, 10 EGTA; pH: 7.2 adjusted with TEA-OH; 270-280 mOsmol $\left(\mathrm{kg} \mathrm{H}_{2} \mathrm{O}\right)^{-1}$. Cells were perfused with a background solution of HBSS. After achieving a whole-cell patch, a $\mathrm{Ca}^{2+}$ current- isolating solution was delivered to the cells via a gravity-driven multibarrel array of glass capillary tubing (150 $\mu \mathrm{m}$ OD) mounted on a planted manipulator opposite to the recording pipette. $\mathrm{Ca}^{2+}$ currents were isolated with a solution in which $\mathrm{Ba}^{2+}$ replaced $\mathrm{Ca}^{2+}$ as the charge carrier. This was done because $\mathrm{Ba}^{2+}$ produces larger currents compared to $\mathrm{Ca}^{2+}$, it blocks $\mathrm{K}^{+}$channels, and it minimizes the activation of intracellular $\mathrm{Ca}^{2+}$-dependent mechanisms. This solution contained (in $\mathrm{mM}$ ): 10 Glucose, 10 HEPES, $5 \mathrm{BaCl}_{2}$, 150 TEA-Cl, $\mathrm{pH}=7.2$ balanced with TEA-OH. Drugs were administered using this same multibarrel array. Recordings were filtered at $2 \mathrm{kHz}$. Series resistance was corrected online by $60-85 \%$.

All recordings in acutely dissociated neurons were obtained in $\mathrm{VC}$. We used a ramp protocol at $0.33 \mathrm{mV} / \mathrm{ms}$ to evoke isolated $\mathrm{Ca}^{2+}$ currents stimulated from $-60 \mathrm{mv}$ to $+50 \mathrm{mV}$. We also used a step protocol to evaluate time constants of activation, inactivation, and tail currents (500 ms step duration from $-60 \mathrm{mV}$ to $+50 \mathrm{mV}$ in $10 \mathrm{mV}$ increments). All neurons received $400 \mu \mathrm{M} \mathrm{Cd}^{2+}$ to confirm measurement of $\mathrm{Ca}^{2+}$ channels at the end of the recording. During analysis, all traces were leak subtracted and $\mathrm{Cd}^{2+}$ subtracted. Every measurement from an individual cell is an average of 2 or more sweeps.

\section{Pharmacology and Toxins}

Experimental reagents included: 0.001-10 $\mu \mathrm{M}$ wortmannin (Sigma-Aldrich, USA), $100 \mathrm{nM}$ apamin (Sigma-Aldrich, USA), $10 \mu \mathrm{M}$ 2-(4-morpholinyl)-8-phenyl-4H-1benzopyran-4-one (LY294,002) (Sigma-Aldrich, USA) to block PI3K, $10 \mu \mathrm{M}$ 1-[6[[(17ß)-3-Methoxyestra-1,3,5(10)-trien-17-yl]amino]hexyl]-1 $H$-pyrrole-2,5-dione (U73122) (Sigma-Aldrich, USA) to block PLC, and $300 \mu \mathrm{M}$ (cells were incubated before 
the experiment in $1 \mathrm{mM}$ ) myo-inositol (Sigma-Aldrich, USA) (Villalobos et al. 2011) to supplement the substrate for $\mathrm{PIP}_{2}$ production. For certain experiments, $30 \mu \mathrm{M}$ diC $_{8}-\mathrm{PIP}_{2}$ (Echelon Biosciences, Salt Lake City, UT, USA) reconstituted in $\mathrm{H}_{2} \mathrm{O}$ was added to the internal solution.

Experiments evaluating $\mathrm{Ca}^{2+}$ channel contribution to AHPs used the following reagents: $5 \mu \mathrm{M}$ nifedipine (Nif; Sigma-Aldrich, USA) to block L-type channels, $1 \mu \mathrm{M}$ $\omega$-conotoxin GVIA (GVIA; Peptides International, USA or Alomone Labs, Israel) to block N-type channels, 0.5 $\mu \mathrm{M}$ Agatoxin-IVA (AgTx IVA; Alomone Labs, Israel) to block P/Q-type channels, and 0.3 $\mu \mathrm{M}$ SNX-482 (Alomone Labs, Israel) to block R-type channels. Since SNX-482 also blocks A-type $\mathrm{K}^{+}$currents (Liu and Bean, 2014), $4 \mathrm{mM} 4-$ aminopyridine (4-AP; Sigma-Aldrich, USA) was used to block A-Current $\left(I_{\mathrm{A}}\right)$ and other voltage-gated $\mathrm{K}^{+}$channels contributing to spike width prior to administering SNX-482.

\section{Immunochemistry}

Slices were fixed in $4 \%$ paraformaldehyde and $0.2 \%$ picric acid in phosphate buffered saline (PBS) and stored at $4^{\circ} \mathrm{C}$ post-experimentally. Biocytin-labeled neurons were processed for double labeling with either anti-OT- or VP- neurophysins. The antiVP-neurophysin is a rabbit polyclonal antibody provided by Alan Robinson (UCLA, Emeritus), and was used at 1:20,000. The anti-OT-neurophysin antibody (PS36) is a mouse monoclonal antibody provided by Harold Gainer (National Institutes of Health, Emeritus) and was used at 1:500. All antibodies and labeling reagents were dissolved in PBS $+0.5 \%$ Triton X-100 (PBST). After $36-72 \mathrm{~h}$ of incubation at $4{ }^{\circ} \mathrm{C}$, the slices were washed with PBST and incubated in a cocktail of secondary antibodies including Alexa Fluor 488 goat anti-rabbit immunoglobulin G (IgG) and Alexa Fluor 594 goat anti-mouse IgG (1:200) along with Avidin-AMCA (1:200) for reaction with the biocytin. The specimens were mounted on a slide with $50 \%$ water $/ 50-\%$ glycerol solution. Double staining of biocytin and one antibody complemented with the negative staining of the other identified neurons as OT or VP (Figure 2-2).

\section{Calcium Imaging and Uncaging}

Electrophysiology and $\mathrm{Ca}^{2+}$ imaging were performed simultaneously on a single computer using a custom windows-based program (CCD32; written by Dr. J. Callaway, UTHSC, Memphis, TN, based on software developed by (Lasser-Ross et al. 1991). Voltage clamp recordings were acquired using an Axopatch 700A (Molecular Devices, Sunnyvale, CA). Electrodes were pulled using borosilicate electrodes (4-8 M $\Omega$ ) as previously described. The pipette internal solution for analyzing AHP tail currents was as previously described, except with $0.2 \mathrm{mM}$ EGTA replaced with $0.1 \mathrm{mM}$ fura-2. Images were obtained with a CCD Imago Sensicam camera, using a Polychrome V monochromater (TILL Photonics, Planegg, Germany) to control excitation wavelength and intensity. Calcium fluorescence was obtained by exciting fura- 2 at $380 \mathrm{~nm}$ using a 

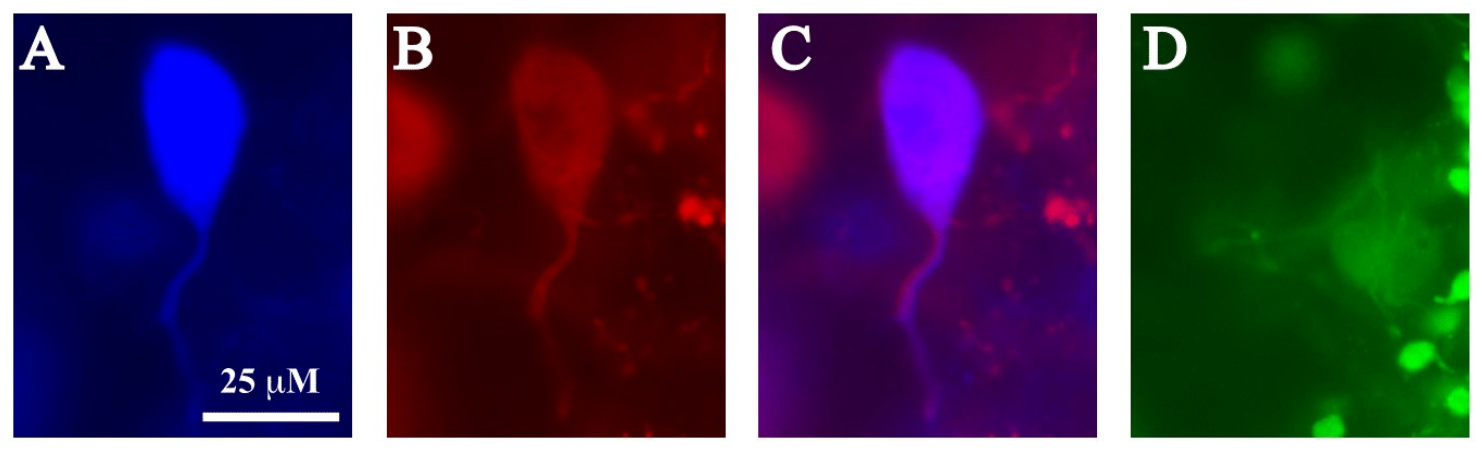

Figure 2-2. Example of a positively identified OT cell using immunolabeling.

(A) A single cell loaded with biocytin during recording, and subsequently labeled with Avid-AMCA. The tissue was then labeled for OT- and VP-neurophysins (NP) by double immunofluorescence using Alexa Fluor 594- and Alexa Fluor 488- conjugated antibodies, respectively. This biocytin-labeled cell was immunoreactive to the OT-NP (B, C) but not to VP-NP (D). 
USHIO UXL-150MO $150 \mathrm{~W}$ Xenon arc lamp. We measured fluorescence changes at an emission wavelength of $520 \pm 40 \mathrm{~nm}$. Photobleaching was corrected by subtracting a $\mathrm{Ca}^{2+}$ signal from a control sweep at equal length, in which the cell was not stimulated and held at a hyperpolarized holding potential $(-70 \mathrm{mV})$ to minimize $\mathrm{Ca}^{2+}$ entry. We subtracted background autofluorescence by using a reference area near the cell. Measurements were made from the soma, excluding the nucleus (Figure 2-3).

A Zeiss two-photon was used for some imaging experiments while the Polychrome V system described was under repair. When using the two-photon system, $\mathrm{Ca}^{2+}$ transients were acquired with windows-based software, Zeiss Zen 2010. Cells were imaged on an Zeiss LSM 7MP 2 photon system equipped with a Coherent Chameleon Vision-S laser (Titanium-Sapphire). We excited fura-2 at $800 \mathrm{~nm}$. Cells were imaged using a raster scan at $30-40 \mathrm{~Hz}$ depending on the region of interest size. This equipment was used to supplement that from the Polychrome V when the latter was under repair.

To uncage $\mathrm{Ca}^{2+}$, we used $2 \mathrm{mM}$ DM-Nitrophen as the $\mathrm{Ca}^{2+}$ caging compound loaded into the internal solution with $40 \%$ calcium occupancy $\left(0.8 \mathrm{mM} \mathrm{CaCl}_{2}\right)$. In the internal solution, $0.2 \mathrm{mM}$ EGTA was replaced with $0.05 \mathrm{mM}$ fluo-4 for $\mathrm{Ca}^{2+}$ imaging. Fluo-4 was excited at $488 \mathrm{nM}$ and measured at $520 \pm 40 \mathrm{~nm}$. Additionally, Mg-ATP was replaced by Na-ATP to avoid loading the caging compound with $\mathrm{Mg}^{2+}$. We used a xenon flashlamp (Rapp Optoelectronic, JML-C2) for photolysis and discharged $72.6 \mathrm{~J}$ in $\sim 1 \mathrm{~ms}$ with UV light. Upon photolysis, the $\mathrm{K}_{\mathrm{d}}$ of DM-Nitrophen for $\mathrm{Ca}^{2+}$ increases from $5 \mathrm{nM}$ to $3 \mathrm{mM}$, rapidly releasing $\mathrm{Ca}^{2+}$ into the cell (Sah and Clements 1999).

All $\mathrm{Ca}^{2+}$ imaging data are reported as $\% \Delta \mathrm{F} / \mathrm{F}$. These data were analyzed either with the custom acquisition program described above, or with Igor Pro 7.0 (Wavemetrics Inc., Portland, OR).

\section{Dissociated Cells for Looking at PIP 2 Distribution}

Adult female rats (150-220 g) $(n=5)$ were anaesthetized with ketamine/xylazine (dose) and perfused through the heart with cold sucrose solution as described above for slices. We adapted the Shah et. al. (2014) protocol for assessing PIP 2 labeling in dissociated SON neurons. Tissue blocks from the SON area were excised from $200 \mu \mathrm{m}$ sections taken with a vibratome, and incubated in oxygenated PIPES (in mM: $110 \mathrm{NaCl}$, $5 \mathrm{KCl}, 1 \mathrm{MgCl} 2,1 \mathrm{CaCl} 2,20$ PIPES and 25 glucose, $\mathrm{pH} 7.1$, containing trypsin $(0.6$ $\mathrm{mg} / \mathrm{ml}$, Sigma Aldrich) for 90 minutes at $34^{\circ} \mathrm{C}$. The tissue was transferred to oxygenated PIPES without trypsin for 30 minutes at room temperature, then gently triturated with 3different sizes of fire-polished pasture pipettes. The cells were plated into two wells from a 6-well plate (Cat. P06-1.5H-N, In Vitro Scientific, Sunnyvale, CA) and allowed to settle at room temperature for 30 minutes. One well was then treated with $100 \mathrm{nM}$ wortmannin in PIPES for 30 minutes at room temperature, while the second well was untreated. The media in each well was then replaced with fixative- $4 \%$ paraformaldehyde with $0.2 \%$ picric acid in $0.01 \mathrm{M}$ phosphate-buffered saline (PBS), and incubated overnight at $4{ }^{\circ} \mathrm{C}$. The fixative was rinsed $3 \mathrm{x}$ with PBS and the cells then treated with $10 \%$ non-fat 

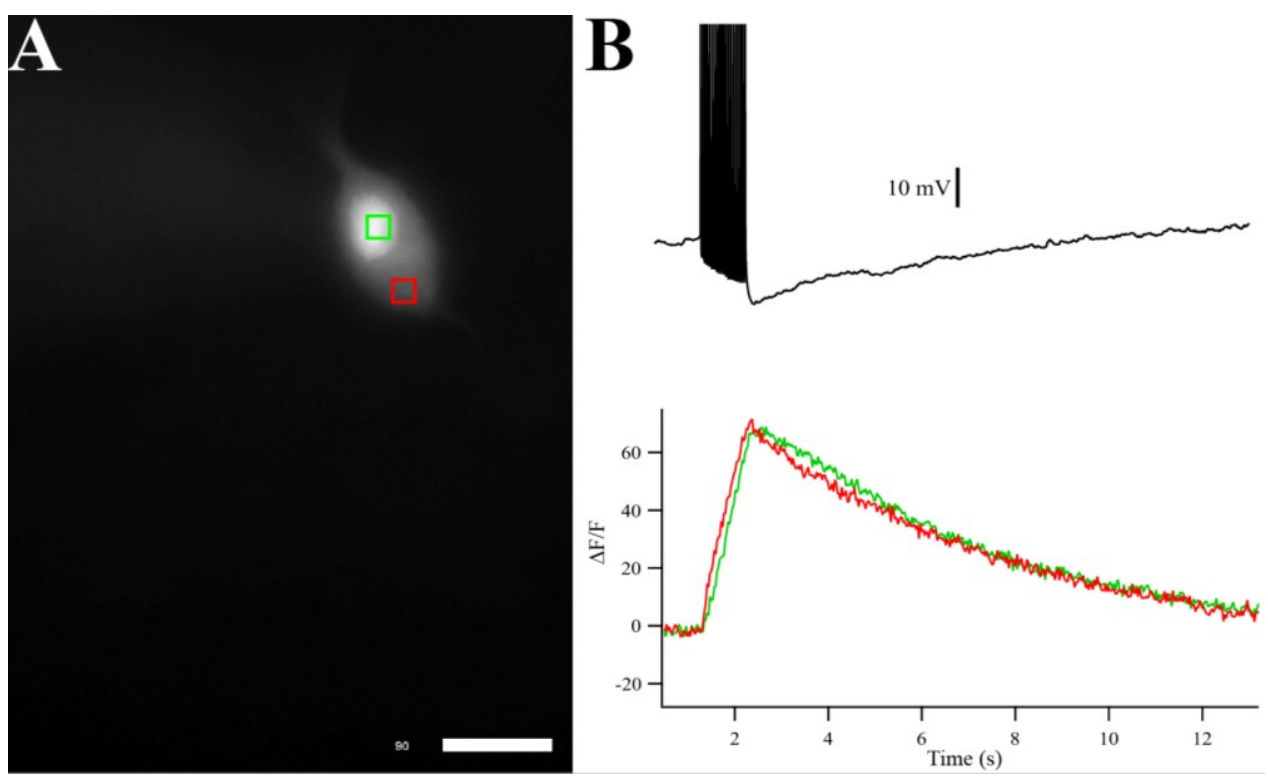

Figure 2-3. $\mathrm{Ca}^{2+}$ imaging in an $\mathrm{SON}$ neuron with corresponding $\mathrm{AHP}$ and $\left[\mathrm{Ca}^{2+}\right]_{\mathrm{i}}$ signals.

(A) Image of an SON neuron filled with the $\mathrm{Ca}^{2+}$ indicator dye, fura-2 $(100 \mu \mathrm{M})$ through the patch pipette. The red and green boxes indicate the region of interest in which fluorescence is measured for soma and nucleus, respectively. (B) Example of a 20-spike AHP (top) and its corresponding $\mathrm{Ca}^{2+}$ signal (bottom) taken from the same cell as imaged in (A). $\left[\mathrm{Ca}^{2+}\right]_{\mathrm{i}}$ was measured as the change in fluorescence divided by the total measured fluorescence $(\Delta \mathrm{F} / \mathrm{F})$. Note the rise and decay time of the nucleus signal (green) is delayed compared to the somatic signal (red), while the amplitude of the signals are equal. 
dry milk in PBS for $1 \mathrm{hr}$ at room temperature to block non-specific antibody interactions. The cells were incubated overnight at $4{ }^{\circ} \mathrm{C}$ for double labeling with an antibody raised in rabbit against OT-NP (Oxytocin-Neurophysin, 1:5000) + mouse anti-PIP 2 antibody (1:1000, Cat. ADI-915-062-100, Enzo Life Sciences), rinsed 3x in PBS then incubated in a cocktail of secondary antibodies for 1 hour at room temperature. The secondary antibodies used were goat-anti-rabbit (Alexa Fluor 568 nm, Invitrogen, Carlsbad, USA) and goat-anti-mouse (Alexa Flour 488 nm, Invitrogen, Carlsbad, USA) conjugated IgGs at 1:200 dilutions with PBS. Cells were rinsed 3x in PBS then stained with DAPI (300 nM, Cat. D9542, Sigma Aldrich) in PBS for 5 mins. Cells were rinsed 3x in PBS and left immersed in PBS for microscopic analysis.

Images were acquired with a Zeiss 710 confocal inverted microscope (Carl Zeiss Microscopy, Thornwood, NY) using a 63x oil-immersion objective (n.a. 1.4). OTpositive neurons were located and $1 \mu \mathrm{m}$ optical sections were collected from the top to the bottom of each cell sampled. The laser power (18\%) and the pin-hole (2.5 AU) were constant for all the images taken and well below saturation. Only cells that were positive for both OT-NP and $\mathrm{PIP}_{2}$ antibodies as well as exhibiting clear DAPI nuclear staining were considered for the study. For each group, from each animal, at least 31 images were taken. Thus a total of more than 150 cells per group (control and wortmannin treated) were analyzed for this study. Data were analyzed blind to treatment type. One investigator made the dissociated cell preparation, drug treatment and antibody staining. A second investigator acquired the images blind to the two groups, then coded the digital images for measurements by the first investigator. Thereafter the second investigator decoded the cells, and the first investigator made the appropriate statistical analysis.

Images were analyzed with Image J (NIH, Bethesda, MD). Each Z-stack had between 15 and 25 optical sections, thus a PIP $_{2}$ image for analysis was selected from each cell based on the maximum size of the nucleus through the stack. For measuring the average membrane (or near membrane) intensity of $\mathrm{PIP}_{2}$ staining for each cell, the line tool with freehand line option was used to draw a line (5 pixels) around the edge of the cell and the mean pixel intensity value was recorded. To measure the average intensity of the cytoplasm, an area excluding the nucleus and the perimeter of the cell was selected using the polygon tool (1 pixel), and the mean intensity was recorded. Such mean intensities recorded were then subtracted from the mean background intensity for each cell. To measure mean background intensity from each cell, a uniform dark spot was selected using the polygon tool (1 pixel), and the mean intensity was recorded. The data are presented as cytoplasm: membrane ratios. These ratios were then averaged for each group in each animal, and analyzed with a Wilcoxon Ranked-Sum non-parametric test, using JMP Pro 12.

\section{ABC-DAB Staining and Neural Drawings}

Biocytin-labeled neurons in paraformaldehyde-fixed slices were processed for avidin-biotin complex (ABC) and 3, 3'-diaminobenzidine peroxidase (DAB) using a VECTASTAIN ABC-HRP Kit (SK-4100; Vector Laboratories). We used this stain to 
visualize, draw, and measure MNC dendrites from neurons. Slices with cells first identified as OT and VP types were rinsed of their glycerol mounting solution and placed in $\mathrm{H}_{2} \mathrm{O}_{2}$ (2 drops/ $\left.5 \mathrm{ml}\right)$ for 30 minutes. $1 \% \mathrm{ABC}$ mixture in PBS $+0.5 \%$ Triton was made and applied to the samples at 1:5 for 4 hours. Slices were then rinsed 3 times with PBS $+0.5 \%$ Triton. Slices were then incubated in DAB solution containing: 2 drops of buffer, 4 drops of DAB, 2 drops of Nickel, 2 drops of $\mathrm{H}_{2} \mathrm{O}_{2}$ per $5 \mathrm{ml} \mathrm{H}_{2} \mathrm{O}$ for 5 minutes or until slices changed to light orange/brown. Slices were then rinsed with BS without Triton. 3 times, then incubated in $1 \mathrm{ml} \mathrm{0.05 \%} \mathrm{Osmium} \mathrm{Tetroxide} \mathrm{for} 20$ minutes or until slices turned dark brown to stabilize the DAB reaction product. Osmium was then rinsed thoroughly with PBS without Triton. Slices were then mounted to slides using a standard polyvinyl alcohol medium. Cells were drawn by hand using the tracing software Neurolucida v10.0 (MBF Bioscience). Dendritic length, area, and volume were measured using the same software at 40x magnification.

\section{Statistics and Analysis}

In MNC VC experiments, the $I_{\mathrm{fAHP}}$ is a fast, transient event lasting $<15 \mathrm{~ms}$ (Dopico et al. 1999), and was not evaluated herein. The $I_{\mathrm{mAHP}}$ decay tau is $500 \mathrm{~ms}$ in MNCs (Teruyama and Armstrong 2005), whereas the $I_{\text {sAHP }}$ has a decay tau of 1-2 s in MNCs (Ghamari-Langroudi and Bourque 2004). With this consideration, we operationally defined the $I_{\mathrm{mAHP}}$ and $I_{\mathrm{sAHP}}$ as the amplitude of the AHP tail current $\left(I_{\mathrm{AHP}}\right)$ at $100 \mathrm{~ms}$ and $1000 \mathrm{~ms}$ after the stimulus, respectively. While measurement of the $I_{\mathrm{mAHP}}$ at $100 \mathrm{~ms}$ likely contains a small contribution from the $I_{\mathrm{SAHP}}$, it is dominated by the $I_{\mathrm{mAHP}}$ due to the slower onset kinetics of the $I_{\mathrm{SAHP}}$ (Teruyama and Armstrong 2005).

Furthermore, we demonstrate in the Results that the SK channel blocker apamin (100 $\mathrm{nM}$ ) inhibits the $I_{\mathrm{mAHP}}$ by $70.5 \pm 5.5 \%$ (data not shown). In some experiments, the $I_{\mathrm{sAHP}}$ was selectively evaluated after isolation in the presence of $100 \mathrm{nM}$ apamin.

For current clamp experiments, we evaluated AHPs from 20- and 5-spike protocols. 20-spike AHPs were evaluated at peak (mAHP+sAHP), as well as 1 second (sAHP) after the pulse. 5-spike AHPs were evaluated at peak only (mAHP).

All electrophysiological traces were analyzed in ClampFit 10.2 (Molecular Devices) or Igor Pro. Because the $I_{\mathrm{mAHP}}$ and $I_{\mathrm{sAHP}}$ are relatively small currents, special considerations were taken when measuring them in voltage clamp. During analysis, the currents were further filtered using a Gaussian lowpass filter at $1 \mathrm{kHz}$. Measurements of amplitude were averaged over a $30 \mathrm{~ms}$ segment of current (30 points). This was done to marginalize the contribution of electrical noise to individual points. All statistics were performed in SPSS. Unless stated otherwise, data was compared using a two-way ANOVA. For the experiment comparing controls to apamin and apamin + wortmannin, we ran a repeated measures ANOVA with a Bonferroni post-hoc test for pairwise comparisons. All reported values are represented as Mean \pm SEM. We used a repeated measures ANOVA with a Bonferroni post-hoc analysis to evaluate AP half width, as well as a One-way ANOVA to evaluate differences in spike broadening during trains. In the cases of 4-AP followed by SNX-482 block (Fig. 6), we used a Friedman's test as some of 
this data was not normally distributed. If the Friedman's test was significant, we used a Bonferroni-Dunn post hoc analysis to make between-groups comparisons. We used regression $\left(\mathrm{r}^{2}\right)$ plots to evaluate dendritic size with AHP and $\left[\mathrm{Ca}^{2+}\right]_{i}$ amplitudes. Spikes in figures are truncated. Data in figures is marked as statistically significant depending on the number of asterisks associated with a difference between groups: ${ }^{*} p<0.05,{ }^{*} p<0.01$, $* * * p<0.001$, and $* * * * p<0.0001$. 


\section{CHAPTER 3. DIFFERENTIAL PIP2 MODULATION OF AHPS IN OXYTOCIN AND VASOPRESSIN NEURONS*}

\section{Introduction}

Oxytocin- (OT) and vasopressin- (VP) secreting magnocellular neurosecretory cells (MNCs) play a crucial role in many physiological functions including lactation, parturition (OT cells) and cardiovascular regulation (VP cells) (Armstrong et al., 2010). The release of both hormones is optimized by a burst-firing pattern of action potentials, albeit of different form in the two cell types (Dutton \& Dyball, 1979; Bicknell \& Leng, 1981; Cazalis et al., 1985). Sustained stimulation of these cells (most notably VP) results in significant reduction of hormone release over time, whereas periods of quiescence reverse this secretory fatigue (Bicknell, 1988). Furthermore, the burst-firing is synchronized among all OT neurons in the supraoptic nucleus (SON) and paraventricular nucleus (PVN) (Belin et al., 1984) during lactation, whereas VP neurons burst asynchronously (Sabatier \& Leng, 2007). Many cell types, including MNCs, express calcium-activated potassium currents that (i) produce afterhyperpolarizations (AHPs) following a single action potential or train of action potentials and (ii) shape firing patterns. In MNCS, the AHP typically comprises three components with varying time courses mediated by different channels: The fast (fAHP), medium (mAHP), and slow (sAHP). The fast AHP current $\left(I_{\mathrm{fAHP}}\right)$ is contributed by $\mathrm{K}_{\mathrm{Ca}} 1.1(\mathrm{BK})$ channels as well as voltage-gated $\mathrm{K}^{+}$channels, and lasts $<15 \mathrm{~ms}$ (Dopico et al., 1999; Hlubek \& Cobbett, 2000; Roper et al., 2003). The $\mathrm{Ca}^{2+}$-depenmdent medium AHP current ( $\left.I_{\mathrm{mAHP}}\right)$ lasts $\sim 500$ $\mathrm{ms}$, is underlain by $\mathrm{K}_{\mathrm{Ca}} 2.3$ (SK3) channels (Stocker \& Pedarzani, 2000; Tacconi et al., 2001), and is blocked by apamin (Bourque \& Brown, 1987). The channel underlying the slow AHP current $\left(I_{\mathrm{SAHP}}\right)$ in MNCS (and most neuron types) is unknown, but is $\mathrm{Ca}^{2+}$ dependent and lasts on the order of seconds (Ghamari-Langroudi \& Bourque, 2004; Andrade et al., 2012). Pinpointing an exact mechanism underlying the sAHP has been difficult because the $I_{\mathrm{sAHP}}$ characteristics differ among neuronal cell types (Andrade $e t$ al., 2012). However, there are some common features, including activation by rises in $\left[\mathrm{Ca}^{2+}\right] \mathrm{i}$, modulation by neurotransmitters, and voltage-independence. This gap in our understanding is important because the $I_{\mathrm{sAHP}}$ controls spike frequency adaptation and is affected by major intracellular signals in many cell types of several brain regions. With regards to MNCs, the $I_{\mathrm{mAHP}}$ and $I_{\mathrm{SAHP}}$ are of particular interest due to their significant influence on burst firing patterns. Further, the AHPs in OT neurons get larger during late pregnancy and lactation (Stern \& Armstrong, 1996; Teruyama \& Armstrong, 2002), coinciding with an increase in pulsatile OT release from the neurohypophysis during labor and lactation (Wakerly \& Lincoln, 1971; Higuchi et al., 1986) and the adoption of synchronized bursting firing patterns (Poulain \& Wakerley, 1982).

\footnotetext{
* Portions of chapter from previously published article modified with permission of John Wiley and Sons. Kirchner MK, Foehring RC, Wang L, Chandaka GK, Callaway JC, Armstrong WE. Phosphatidylinositol 4,5-bisphosphate (PIP2) modulates afterhyperpolarizations in oxytocin neurons of the supraoptic nucleus. J Physiol 595: 4927-4946, 2017.
} 
While we do not know how $\mathrm{Ca}^{2+}$ activates the unknown AHP channels, a study in neocortical pyramidal cells demonstrated that phosphatidylinositol 4,5-bispohsphate $\left(\mathrm{PIP}_{2}\right)$ facilitates the $I_{\mathrm{sAHP}}$ but not the SK-mediated $I_{\mathrm{mAHP}}$ (Villalobos et al., 2011). This is intriguing because $\mathrm{PIP}_{2}$ is known to influence the properties of a host of channel types and is activated by $\mathrm{G}_{\mathrm{q}}$-coupled receptors (Hille, 1994; Suh \& Hille, 2002, 2008; Suh et al., 2010; Kruse \& Hille, 2013), including receptors that are activated by neurotransmitters known to attenuate the $I_{\mathrm{SAHP}}$, (e.g., acetylcholine via muscarinic receptors). These features, combined with the slow current kinetics and strong $\mathrm{Ca}^{2+}$ dependence, support the hypothesis that a biochemical signaling cascade contributes to modulation of the $I_{\mathrm{SAHP}}$, which may influence more than one channel type (Andrade et al., 2012).

\section{Results}

\section{Depleting PIP 2 from Cells Inhibits the $I_{\mathrm{AHP}}$ of OT but Not VP Neurons}

Previous work demonstrated that $\mathrm{PIP}_{2}$ levels are critical for generation of $I_{\mathrm{sAHP}}$, but not $I_{\mathrm{mAHP}}$, in cortical pyramidal neurons (Villalobos et al. 2011). To test this in SON neurons, we bath-applied wortmannin and measured the macroscopic AHP tail current (I $\left.I_{\mathrm{AHP}}\right)$ at two time points (see Methods: Data and Analysis section). Wortmannin is a pharmacological agent known to inhibit $\mathrm{PIP}_{2}$ levels by blocking the rate-limiting enzyme of $\mathrm{PIP}_{2}$ production, PI4K $\alpha$ (Nakanishi et al. 1995) (Figure 3-1). Application of wortmannin $(10 \mu \mathrm{M})$ caused a significant decrease in both $I_{\mathrm{mAHP}}$ and $I_{\mathrm{sAHP}}$ of OT supraoptic neurons $(\mathrm{n}=10, p<0.001 ; 100 \mathrm{~ms}$ : control $22.12 \pm 1.9 \mathrm{pA}$ vs. Wortmannin $2.67 \pm 0.3 \mathrm{pA} ; 1000 \mathrm{~ms}$ : control $6.48 \pm 0.9 \mathrm{pA}$ vs. wortmannin $1.01 \pm 0.4 \mathrm{pA}$ ) (Figure 3-2). In contrast to OT cells, VP cells demonstrated no significant change in $I_{\mathrm{mAHP}}$ and $I_{\mathrm{sAHP}}$ in response to wortmannin $(\mathrm{n}=9, p>0.05 ; 100 \mathrm{~ms}$ : control $19.67 \pm 4.2 \mathrm{pA} v s$. wortmannin $23.72 \pm 5.1 \mathrm{pA} ; 1000 \mathrm{~ms}$ : control $5.44 \pm 1 \mathrm{pA} v s$. wortmannin $6.12 \pm 1.1 \mathrm{pA}$ )

(Figure 3-2). To characterize wortmannin's effect on AHPs further, we generated a dose response curve measuring percentage of $I_{\mathrm{mAHP}}$ inhibition as a function of wortmannin concentration. We used the $I_{\text {mAHP }}$ time point because current amplitudes were much larger, allowing clear measurements at all doses. Wortmannin's effects on OT neurons were dose-dependent, characterized by a sigmoidal dose response relationship with an $\mathrm{IC}_{50}=58 \mathrm{nM}$ and a Hill coefficient of 1.6 (Figure 3-2). This indicates that wortmannin exhibits specific effects at nanomolar concentrations, with positive cooperative binding. While the effect of wortmannin was similarly dose-dependent on the $I_{\mathrm{SAHP}}$, with stronger inhibition at increased wortmannin concentrations, dose response plots could not be reliably fitted with a Hill equation due to the small amplitude of the $I_{S A H P}(\leq 20 \mathrm{pA}$; data not shown).

Although wortmannin is an inhibitor of $\mathrm{PIP}_{2}$ synthesis, it also depletes $\mathrm{PIP}_{3}$ by inhibiting phosphoinositide 3-kinase (PI3K) (Meyers and Cantley 1997; Vanhaesebroeck, et al. 2001). Furthermore, PI3K is the higher affinity target in comparison to PI4Ka (Meyers and Cantley 1997; Vanhaesebroeck, et al. 2001). We thus bath-applied 


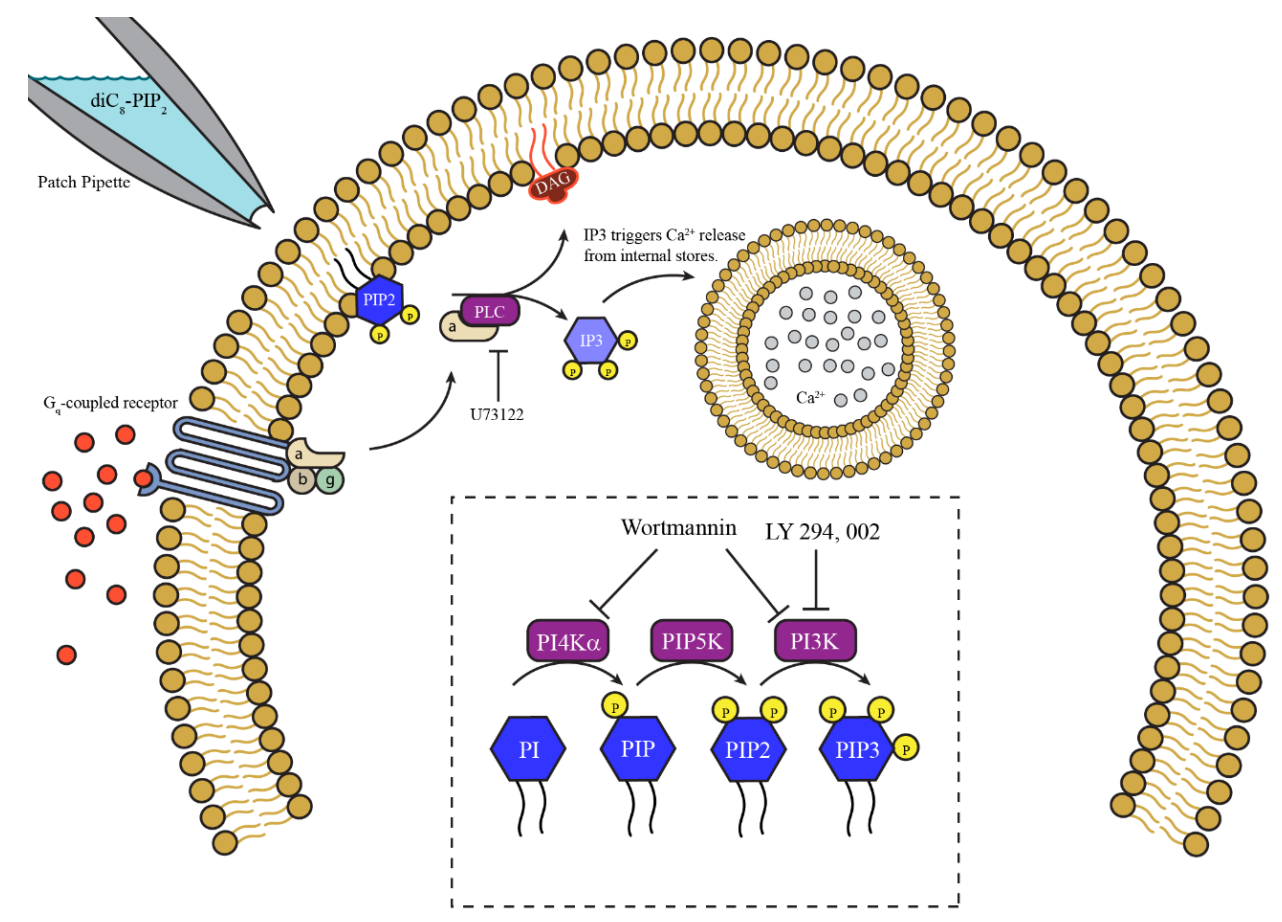

Figure 3-1. Diagram of the relevant $\mathrm{PIP}_{2}$ pathways.

Upon stimulation of $\mathrm{G}_{\mathrm{q}}$-coupled receptors, the $\alpha$ component of the $\mathrm{G}$-protein activates phospholipase-C (PLC), which cleaves membrane-bound $\mathrm{PIP}_{2}$ into diacylglycerol (DAG) and inositol trisphosphate $\left(\mathrm{IP}_{3}\right)$. DAG activates protein kinase $\mathrm{C}$ while $\mathrm{IP}_{3}$ triggers release of $\mathrm{Ca}^{2+}$ ions from internal $\mathrm{Ca}^{2+}$ stores. U73122 blocks the activity of PLC. PIP 2 has been demonstrated to modulate several ion channels in previous studies, such as Kv7 channels (Suh \& Hille, 2007) and SK channels (Zhang et al., 2014). Inset-Dashed Box This box displays the pathway for production of different PIP molecules (blue hexagons), and the enzymes that phosphorylate each of them (purple boxes). Wortmannin blocks synthesis of $\mathrm{PIP}_{2}$ and $\mathrm{PIP}_{3}$ production while LY294,002 only blocks $\mathrm{PIP}_{3}$ production. Both work by blocking the synthetic enzymes. 
A
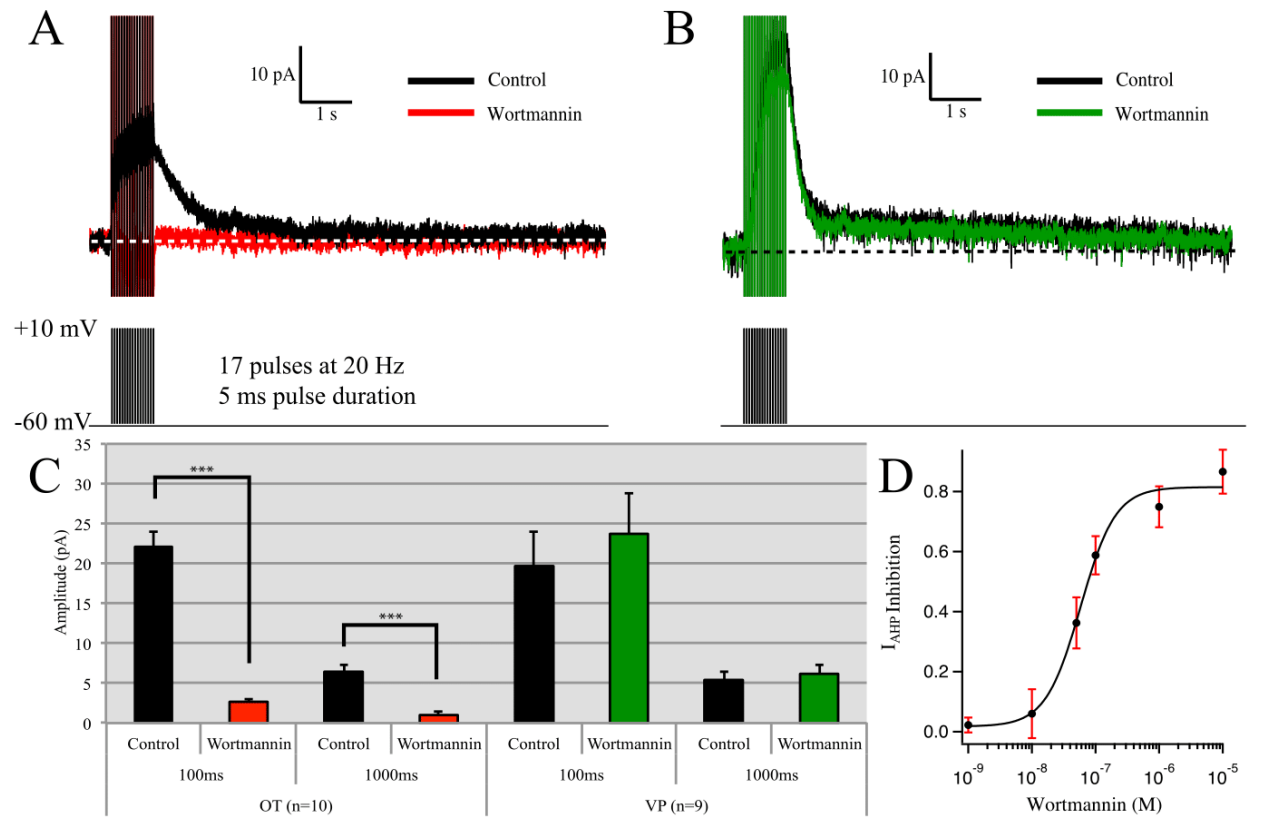

Figure 3-2. Wortmannin $(10 \mu \mathrm{M})$, a PIP 2 and $\mathrm{PIP}_{3}$ synthesis inhibitor, blocks the $I_{\mathrm{mAHP}}$ and $I_{\text {sAHP }}$ of $\mathrm{OT}$ neurons but not VP neurons.

(A, B) Voltage clamp recording of a supraoptic magnocellular OT (A) and VP (B) cell before and after wortmannin application. Wortmannin application inhibits both the $I_{\mathrm{mAHP}}$ and $I_{\mathrm{SAHP}}$ in OT cells while having no effect in VP cells. (C) Summary data of the wortmannin effect on OT and VP cells: $I_{\mathrm{AHP}}$ amplitude was measured at $100 \mathrm{~ms}\left(I_{\mathrm{mAHP}}\right)$ and $1000 \mathrm{~ms}\left(I_{\mathrm{sAHP}}\right)$ after the end of the pulse. OT cells demonstrate statistically significant inhibition of both the $I_{\mathrm{mAHP}}$ and $I_{\mathrm{SAHP}}(\mathrm{n}=10, * * * p<.001)$. In contrast, VP cells demonstrate no significant change in $I_{\mathrm{mAHP}}$ or $I_{\mathrm{sAHP}}$ amplitude $(\mathrm{n}=9, p>0.05)$. (D) Dose-response curve for wortmannin in OT neurons. We plotted peak $I_{\mathrm{mAHP}}$ inhibition as a function of wortmannin concentration. Wortmannin exerted robust inhibition at nanomolar concentrations $\left(\mathrm{IC}_{50}=58 \mathrm{nM}\right.$ ). The Hill Coefficient of $1.6 \pm 0.02$ indicates positive cooperative binding. A minimum of 5 cells was collected for each concentration of wortmannin. 
the specific PI3K inhibitor LY294,002 (10 $\mu$ M: (Vlahos et al. 1994; Lee et al. 2007; Wang et al. 2016b) to both OT and VP neurons to test for $\mathrm{PIP}_{3}$ involvement. This control has been used previously in studies of PIP $_{2}$-affected AHPs in cortex (Villalobos et al. 2011). As in pyramidal neurons, LY294,002 had no significant effect on the $I_{\mathrm{mAHP}}$ or $I_{\text {sAHP }}$ of either cell type (OT: $\mathrm{n}=7, p>0.05$; control $46.1 \pm 6.4 \mathrm{pA}$ vs. wortmannin 44.18 \pm 7.4 pA; VP: $n=4 p>0.05$; control $36.48 \pm 10.4$ pA vs. wortmannin $38.58 \pm 10.5 \mathrm{pA}$ )

(Figure 3-3), consistent with wortmannin reducing the AHPs by its action on PI4K $\alpha$.

To ensure that wortmannin's effects reflected a response specific to AHPs and not a change in general cell health, $10 \mathrm{MNCs}$ (5 OT and $5 \mathrm{VP}$ ) were assessed in current clamp recordings, where we found no significant differences in spike amplitude (OT $p>$ $0.05 ; 61.5 \pm 2.8 \mathrm{mV}$ control vs. $59.2 \pm 3.2 \mathrm{mV}$ wortmannin; VP $p>0.05 ; 65.6 \pm 4.0 \mathrm{mV}$ control vs. $65.0 \pm 3.8 \mathrm{mV}$ wortmannin), spike half-width (OT $p>0.05 ; 2.3 \pm 0.1 \mathrm{~ms}$ control vs. $2.5 \pm 0.1 \mathrm{~ms}$ wortmannin; VP $p>0.05 ; 2.5 \pm 0.1 \mathrm{~ms}$ control vs. $2.4 \pm 0.1 \mathrm{~ms}$ wortmannin), resting membrane potential (OT $p>0.05 ;-60.0 \pm 0.6 \mathrm{mV}$ control vs. -60.2 $\pm 0.7 \mathrm{mV}$ wortmannin; VP $p>0.05 ;-58.9 \pm 2.6 \mathrm{mV}$ control vs. $-60.6 \pm 2.2 \mathrm{mV}$ wortmannin), or input resistance (OT $p>0.05 ; 467.37 \pm 57.5 \mathrm{M} \Omega$ control vs. $444.49 \pm$ $55.3 \mathrm{M} \Omega$ wortmannin; VP $p>0.05 ; 545.75 \pm 110.8 \mathrm{M} \Omega$ control vs. $528 \pm 107.3 \mathrm{M} \Omega$ wortmannin) in cells before and after wortmannin application (Figure 3-4).

\section{Wortmannin Inhibits the IsAHP in the Presence of Apamin in OT Neurons}

To isolate wortmannin's effects on the sAHP, we tested its effects in the presence of apamin, which blocks SK channels and thus the $I_{\mathrm{mAHP}}$ in MNCs (Bourque and Brown 1987; Erickson et al. 1993; Armstrong et al. 1994; Kirkpatrick and Bourque 1996; Teruyama and Armstrong 2005). Since we bath applied apamin (100 nM) first, followed by the addition of wortmannin $(1 \mu \mathrm{M})$, we first ran a repeated measures ANOVA that revealed a significant main effect $(p<0.001)$. Post hoc analysis found that in OT neurons, apamin resulted in robust $(\sim 70 \%)$ inhibition of the $I_{\mathrm{mAHP}}$ (measured at $100 \mathrm{~ms}$ : $\mathrm{n}=7, p<0.001$; control $18.76 \pm 2.5 \mathrm{pA}$ vs. apamin $6.14 \pm 1.8 \mathrm{pA}$; Fig. 5) while having no effect on the $I_{\mathrm{sAHP}}$ (measured at $1 \mathrm{~s}: \mathrm{n}=7, p>0.05$; control $6.70 \pm 1.5 \mathrm{pA}$ vs. apamin $6.10 \pm 1.4 \mathrm{pA}$; Fig. 5). Application of wortmannin inhibited the $I_{\mathrm{sAHP}}$ in the presence of apamin (measured at $1 \mathrm{~s}: \mathrm{n}=7, p<0.05$; apamin $6.10 \pm 1.4 \mathrm{pA}$ vs. wortmannin + apamin $2.81 \pm 0.8 \mathrm{pA}$; Fig. 5). We also observed further inhibition of the $I_{\mathrm{AHP}}$ at $100 \mathrm{~ms}(\mathrm{n}=7, p$ $<0.05$; apamin $6.14 \pm 1.8$ pA vs. wortmannin + apamin $1.2 \pm 0.4$ pA) (Figure 3-5). For comparison, wortmannin had no effect on apamin-treated VP neurons (measured at $1 \mathrm{~s}$ : $\mathrm{n}=6, p>0.05$; apamin $6.79 \pm 1.6 \mathrm{pA}$ vs. wortmannin + apamin $6.23 \pm 1.9 \mathrm{pA})$ (Figure 3-5). This data confirms that wortmannin acts on the isolated $I_{\mathrm{sAHP}}$ in addition to $I_{\mathrm{mAHP}}$ in OT cells.

\section{Wortmannin Reduced PIP 2 Immunoreactivity in OT Neurons}

To determine whether the application of wortmannin at a similar dose to our

electrophysiological experiments was associated with changes in the cellular distribution 

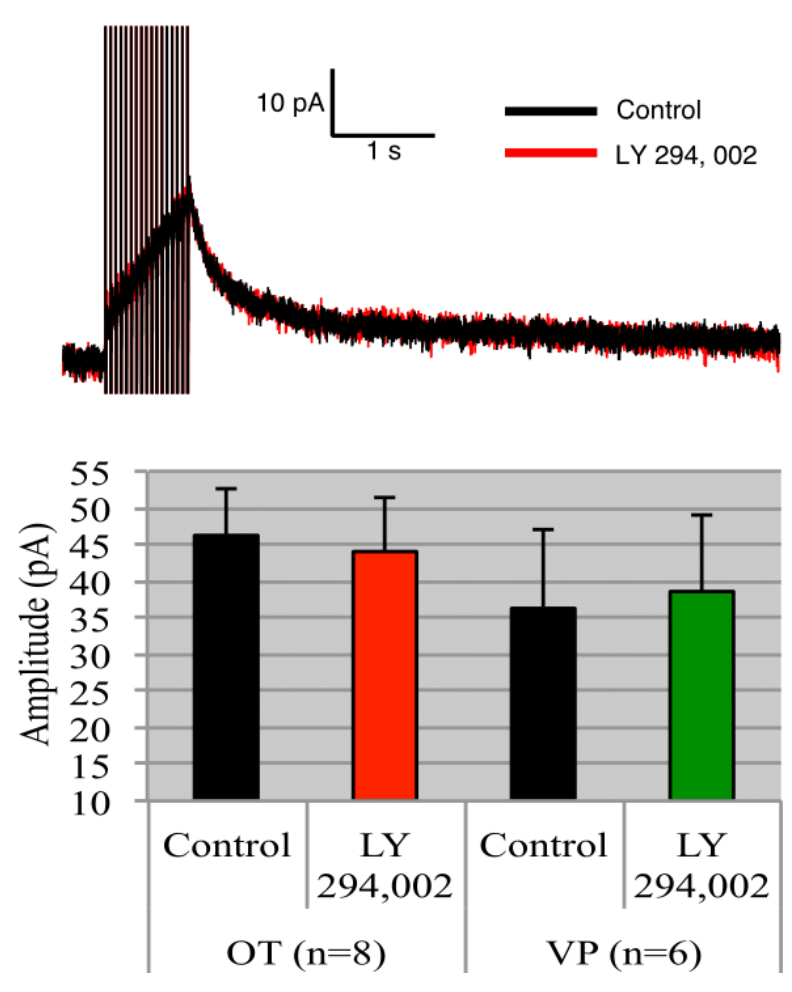

Figure 3-3. LY294,002 has no effect on the $I_{\mathrm{AHP}}$.

Because wortmannin also blocks PIP 3 , we tested the selective $\mathrm{PIP}_{3}$ blocker LY294,002 on the $I_{\text {AHP. }}$ (Top Trace) An example of LY294,002's effect on an OT neuron. (Bottom Trace) Summary data of $I_{\mathrm{mAHP}}$ amplitude in OT neurons. There was no significant difference (OT: $\mathrm{n}=8$, VP: $\mathrm{n}=6 ; p>0.05)$.

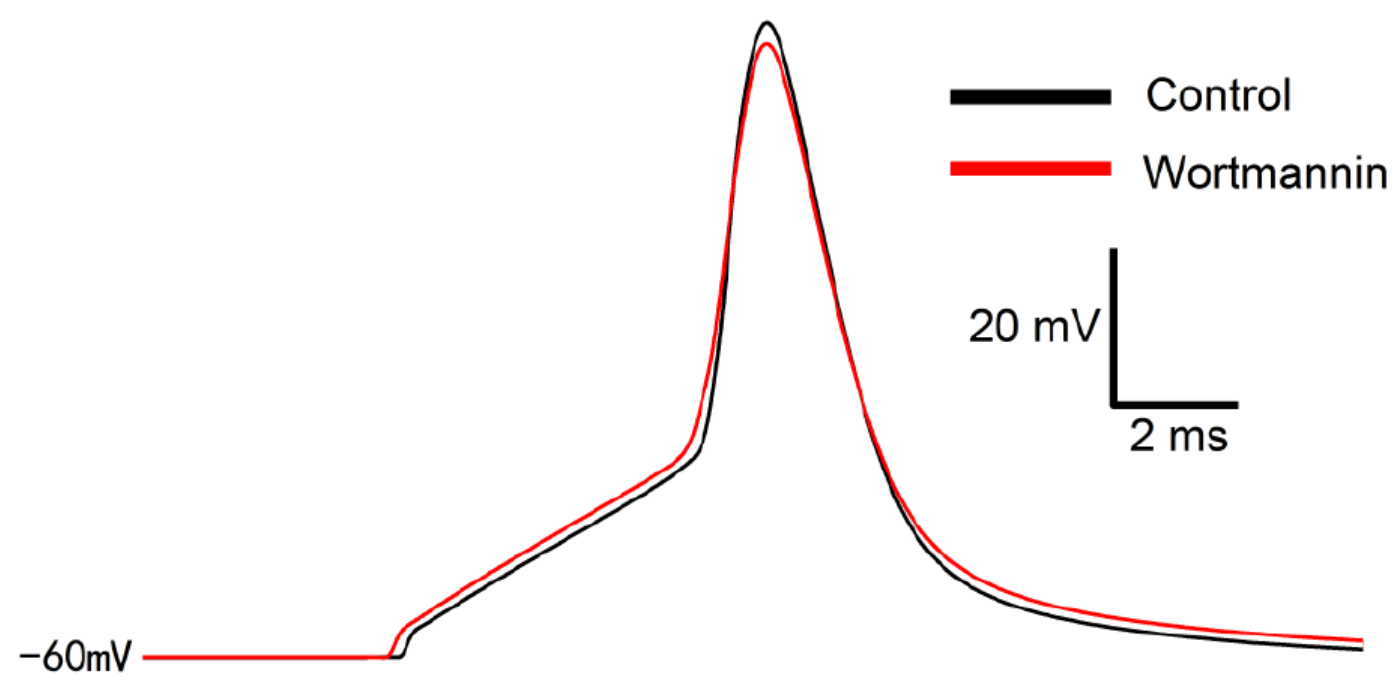

Figure 3-4. Wortmannin had no significant effect on single spike parameters. 
A
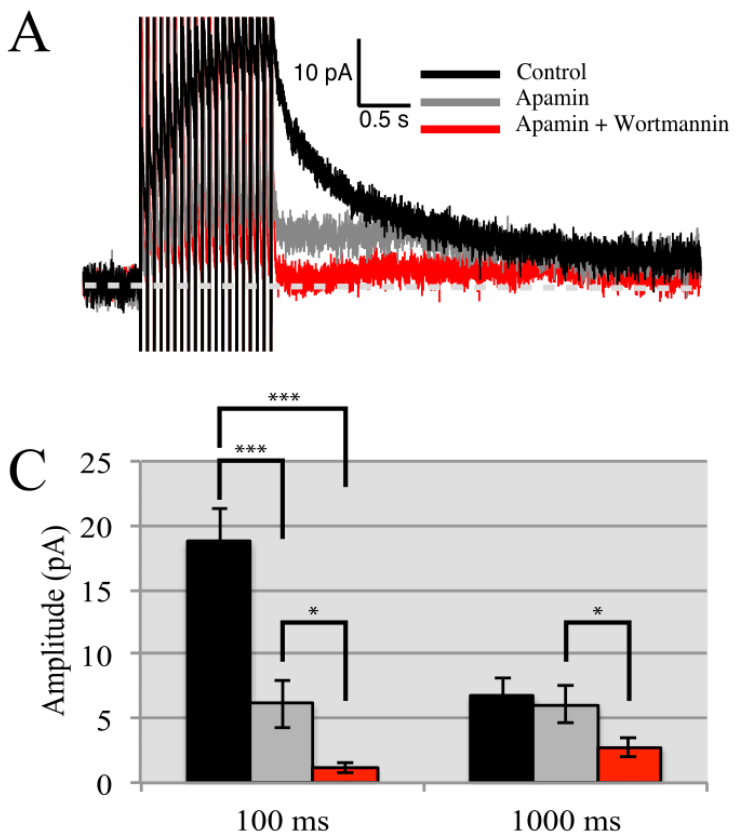

$\mathrm{B}$
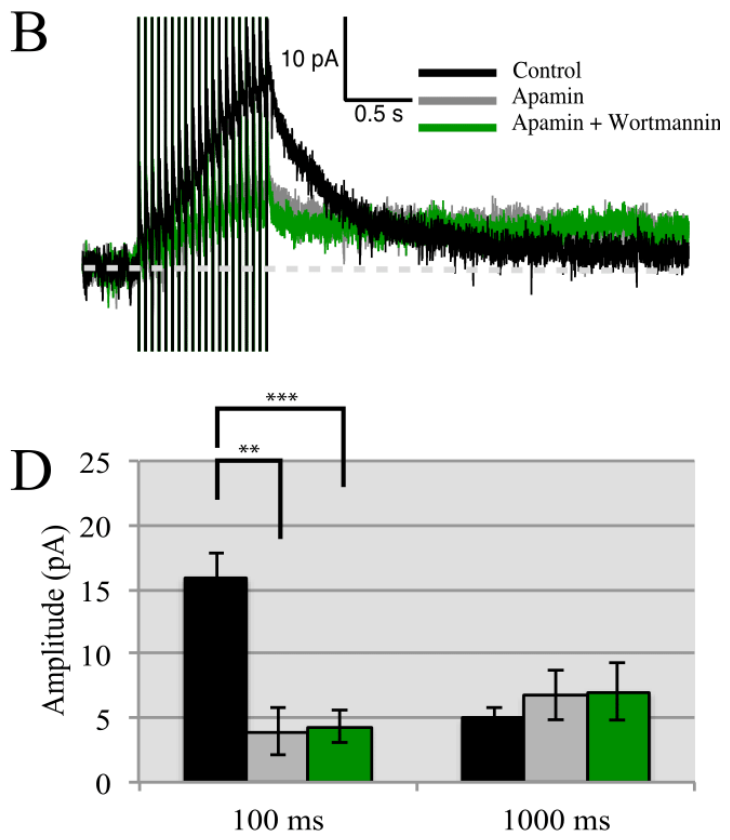

Figure 3-5. Wortmannin inhibits the apamin-treated $I_{\mathrm{AHP}}$ in OT neurons while having no effect in VP neurons.

Apamin $(100 \mathrm{nM})$ was applied to MNCs to block the $I_{\mathrm{mAHP}}$ in both cell types, followed by wortmannin $(1 \mu \mathrm{M})$ to observe effects on the isolated $I_{\mathrm{SAHP}}$. (A) Voltage clamp trace of $I_{\mathrm{AHP}}$ from an OT neuron. This contains a baseline recording (black trace), apamin treated trace to block the $I_{\mathrm{mAHP}}$ (grey), and a trace with apamin \& wortmannin (red). Wortmannin inhibited the apamin-isolated $I_{\mathrm{SAHP}}$. (B) Voltage clamp trace of $I_{\mathrm{AHP}}$ from an VP neuron. This contains a baseline recording (black trace), apamin treated trace to block the $I_{\mathrm{mAHP}}$ (grey), and a trace with apamin \& wortmannin (green). Wortmannin failed to inhibit the apamin-isolated $I_{\mathrm{SAHP}}$. (C) Summary data of OT $(\mathrm{n}=6)$ neurons. There was a significant main effect (repeated measures ANOVA, $F(2,12)=45.97, * * * p<0.001$ ). Apamin inhibits the $I_{m \mathrm{AHP}}$ at $100 \mathrm{~ms}(* * * p<0.001)$. Measurements of the $I_{\mathrm{sAHP}}(1000$ $\mathrm{ms}$ ) indicate that apamin has little effect at this time, while subsequent wortmannin application significantly reduces the isolated $I_{\mathrm{SAHP}}(* p<0.05)$. (D) Summary data of VP $(\mathrm{n}=6)$ neurons. Apamin inhibits the $I_{\mathrm{mAHP}}$ in VP neurons $(* * * p<0.01)$. There was no significant effect of additional wortmannin $(p>0.05)$. 
of $\mathrm{PIP}_{2}$ in OT neurons, we calculated the ratio of the staining intensity of $\mathrm{PIP}_{2}$ immunoreactivity of the cytoplasm vs. membrane in dissociated cell preparations and compared control neurons with those exposed to $100 \mathrm{nM}$ wortmannin $(\mathrm{n}=5$ animals in each group). As shown in (Figure 3-6), this ratio was significantly increased by wortmannin, suggesting depletion of membrane $\mathrm{PIP}_{2}$. This type of redistribution is similar to that reported for $\mathrm{PIP}_{2}$ in response to muscarinic modulation in sympathetic neurons (Suh and Hille 2002; Delmas and Brown 2005).

\section{diC8-PIP2 Slows Rundown of the $I_{\text {mAHP in }}$ OT; Enhances the $I_{\text {sAHP }}$ in VP}

We have shown that application of wortmannin blocks both the medium and slow $I_{\mathrm{AHPs}}$ in OT neurons. We interpret this as wortmannin blocking $\mathrm{PIP}_{2}$ synthesis and thus reducing total $\mathrm{PIP}_{2}$ levels. In contrast, wortmannin has no significant effect on these $I_{\mathrm{AHPs}}$ in VP neurons. We next tested whether directly increasing the amount of available $\mathrm{PIP}_{2}$ inside the cell could affect the AHP. We evaluated this in the context of rundown. Rundown is a term used to describe the gradual decay of $I_{\text {AHPs }}$ amplitude over long recording sessions (Figure 3-7). Since a previous study in neocortical pyramidal neurons showed that enhancement or inhibition of $\mathrm{PIP}_{2}$ slows or hastens the rundown of the sAHP, respectively (Villalobos et al. 2011), we supplied the cells with water-soluble $\mathrm{diC}_{8}-\mathrm{PIP}_{2}(30 \mu \mathrm{M})$, and then evaluated rundown of the peak $I_{\mathrm{AHP}}$ in cells with or without $\mathrm{diC}_{8}-\mathrm{PIP}_{2}$. OT cells dialyzed with $\mathrm{diC}_{8}-\mathrm{PIP}_{2}$ display slower rundown compared to controls over 30 minutes (Figure 3-7).

In contrast, VP cell $I_{\mathrm{AHPs}}$ demonstrated a gradual increase in both the amplitude and inactivation tau starting 10-17 mins after break-in under normal recording conditions This change is substantial, but eventually stabilizes . Because of this phenomenon, cells that demonstrated a changing $I_{\mathrm{AHP}}$ were monitored until the measurement of the tail current was stable for at least 2 minutes (Fig. 7B, grey trace).

\section{$\mathrm{diC}_{8}-\mathrm{PIP}_{2}$ in the Pipette Prevents $I_{\mathrm{mAHP}}$ and $I_{\mathrm{sAHP}}$ Inhibition by Wortmannin}

We next tested whether directly increasing the amount of available $\mathrm{PIP}_{2}$ inside the cell could prevent the wortmannin's inhibition. We supplied the water-soluble $\mathrm{PIP}_{2}$ analog $\mathrm{diC}_{8}-\mathrm{PIP}_{2}(30 \mu \mathrm{M})$ into neurons through the patch pipette to provide a constant source of $\mathrm{PIP}_{2}$. Wortmannin had no significant effect on $I_{\mathrm{mAHP}}$ and $I_{\mathrm{sAHP}}$ in OT neurons when diC $_{8}$-PIP 2 was dialyzed into the cell. (100 ms: $\mathrm{n}=8, p>0.05 ; \mathrm{diC}_{8}-\mathrm{PIP}_{2} 17.62 \pm 1.9$ pA vs. diC $_{8}-\mathrm{PIP}_{2}+$ wortmannin $15.18 \pm 2.4 \mathrm{pA} ; 1000 \mathrm{~ms}: \mathrm{n}=8 p>0.05 ; \mathrm{diC}_{8}-\mathrm{PIP}_{2} 4.13 \pm$ $0.8 \mathrm{pA}$ vs. $\mathrm{diC}_{8}-\mathrm{PIP}_{2}+$ wortmannin $3.82 \pm 1 \mathrm{pA}$ ) (Figure 3-8). These results indicate that supplying the neurons with $\mathrm{diC}_{8}-\mathrm{PIP}_{2}$ through the pipette can prevent the inhibition of AHPs by wortmannin-induced $\mathrm{PIP}_{2}$ depletion. 

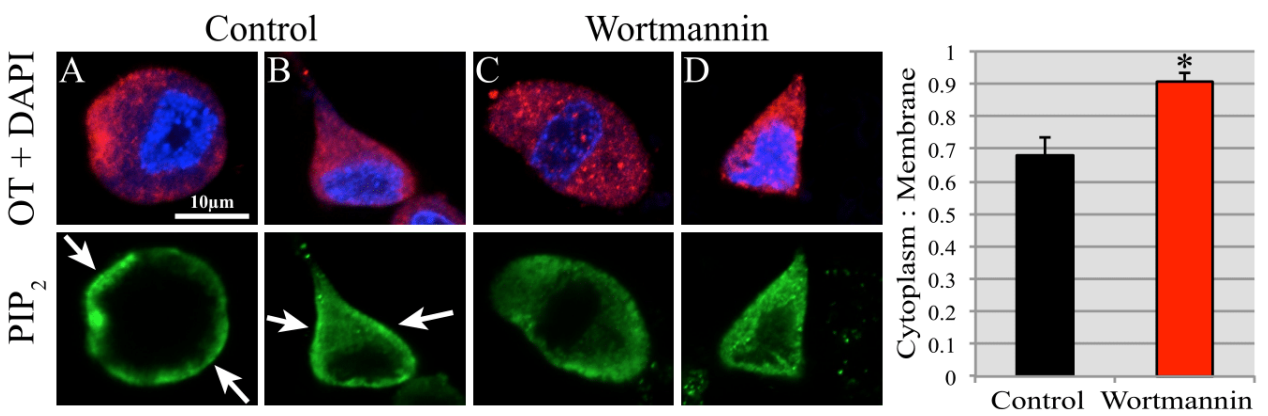

Figure 3-6. Effect of wortmannin on PIP 2 expression in OT neurons.

Double immunofluorescence confocal microscopy revealed that $\mathrm{PIP}_{2}$ (green) in OT neurons is expressed more densely in the cell membrane in the control group (A \& B; lower panels). Upon wortmannin $(100 \mathrm{nM})$ treatment for $30 \mathrm{mins}$, OT neurons show a decreased $\mathrm{PIP}_{2}$ expression in the cell membranes $(\mathbf{C} \boldsymbol{\&} \mathbf{D}$; lower panels) relative to the cytosol. The upper panels show the expression of oxytocin-neurophysin (OT-NP) (red) expression and DAPI (blue) staining for nucleus. The histogram on the right side shows the mean cytoplasm: membrane ratios between the two groups, and indicates a significant difference $(*$ Control $v s$. Wortmannin; $* p \leq 0.016) . \mathrm{n}=5$ animals per group.

A

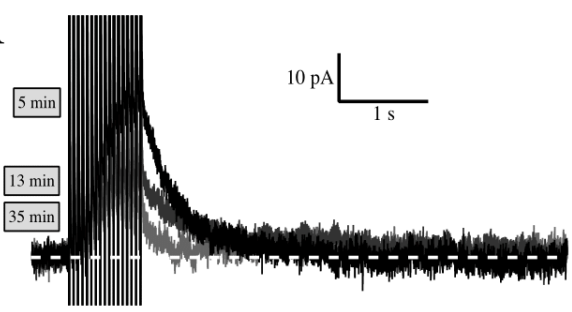

$\mathrm{C}$

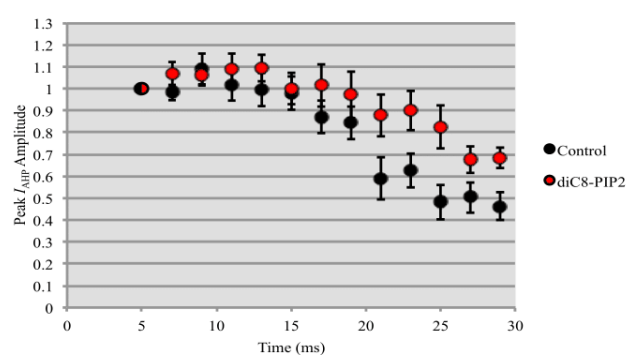

B

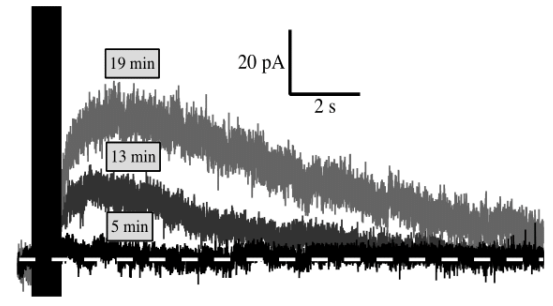

$\mathrm{D}$

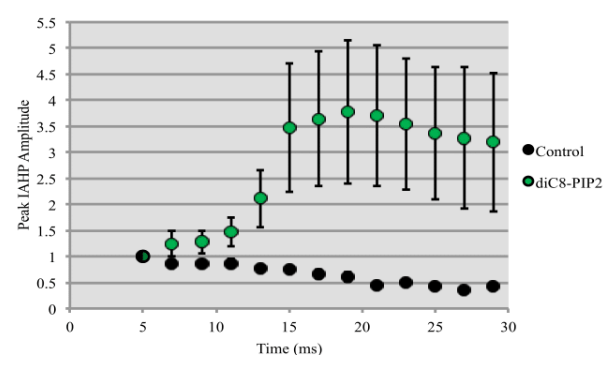

Figure 3-7. Inclusion of water-soluble $\mathrm{PIP}_{2}$ analog diC $\mathrm{di}_{8}-\mathrm{PIP}_{2}(30 \mu \mathrm{M})$ in the recording pipette slows $I_{\mathrm{AHP}}$ rundown in $\mathrm{OT}$

(A) $I_{\mathrm{AHP}}$ recordings in an $\mathrm{MNC}$ under normal conditions demonstrating rundown over a 35 minute time period. Both OT and VP cells display $I_{\mathrm{AHP}}$ rundown over long recording periods. (B) VP neurons dialyzed with $\mathrm{diC}_{8}-\mathrm{PIP}_{2}$ demonstrate steady enhancement of the $I_{\mathrm{sAHP}}$ over a 20 minute period. (C) OT cells dialyzed with diC $_{8}-\mathrm{PIP}_{2}$ display slower rundown and ran down less compared to controls at $30 \mathrm{~min}(\mathrm{n}=9)$. (D) Summary data for the $\mathrm{diC}_{8}$-PIP2 enhancement of the $I_{\mathrm{AHP}}$ amplitude in VP neurons. 
A

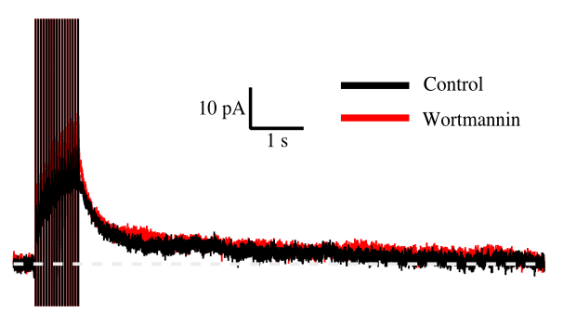

$\mathrm{C}$

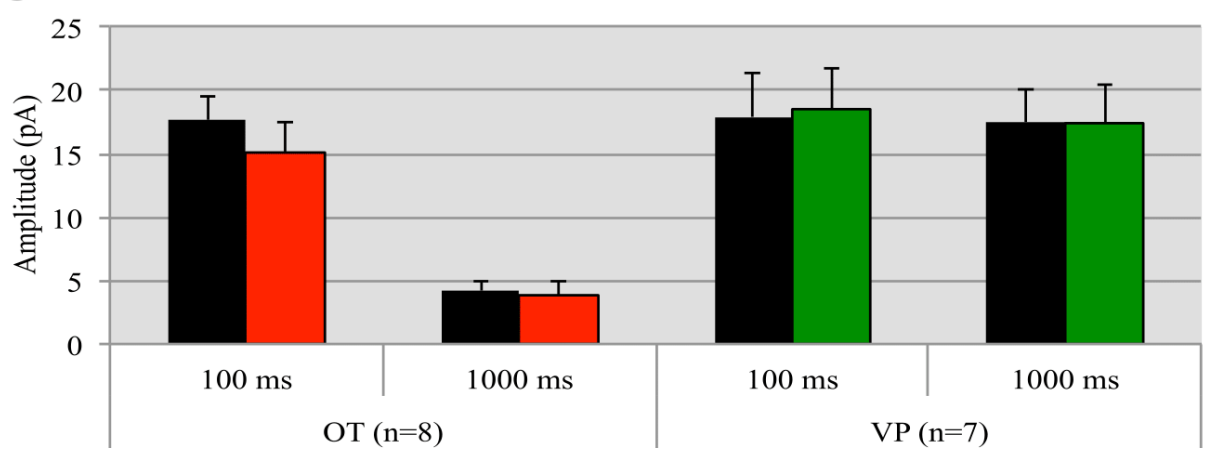

Figure 3-8. Dialyzing OT neurons with $\mathrm{diC}_{8}-\mathrm{PIP}_{2}$ prevents inhibition of the $I_{\mathrm{AHP}}$ by wortmannin.

(A) $I_{\mathrm{AHP}}$ of an OT neuron dialyzed with $\mathrm{diC}_{8}-\mathrm{PIP}_{2}$. $\mathrm{diC}_{8}-\mathrm{PIP}_{2}$ prevents inhibition of the $I_{\mathrm{AHP}}$ by wortmannin. (B) $I_{\mathrm{AHP}}$ of a VP neuron dialyzed with $\mathrm{diC}_{8}-\mathrm{PIP}_{2}$. We waited for the $\mathrm{diC}_{8}-\mathrm{PIP}_{2}$ enhancement to stabilize before applying wortmannin. Wortmannin failed to inhibit the $I_{\mathrm{AHP}}$. (C) Summary data for 8 OT and $7 \mathrm{VP}$ cells tested. Measurements of the $I_{\mathrm{AHP}} 100 \mathrm{~ms}\left(I_{\mathrm{mAHP}}\right)$ and $1000 \mathrm{~ms}\left(I_{\mathrm{sAHP}}\right)$ after the pulse reveal that there are no significant changes in $I_{\text {AHP }}$ peak amplitude after wortmannin application in $\mathrm{diC}_{8}-\mathrm{PIP}_{2}$ dialyzed cells. $(p>0.05)$. 


\section{Supplying the PIP2 Precursor, Myo-Inositol, also Prevents Inhibition by Wortmannin}

Another means of saturating the $\mathrm{PIP}_{2}$ supply is by adding the obligatory precursor myo-inositol in the bath. Myo-inositol is actively transported into the cell and increases $\mathrm{PIP}_{2}$ production (Fisher et al. 1992, 2002; Villalobos et al. 2011). We pre-incubated slices in aCSF in $1 \mathrm{mM}$ myo-inositol for 1 hour. For recording, slices were then transferred to a solution of $300 \mu \mathrm{M}$ myo-inositol in aCSF. Wortmannin $(1 \mu \mathrm{M})$ had no effect on OT AHPs in the presence of myo-inositol (100 ms: $\mathrm{n}=7, p>0.05$; myo-inositol $14.03 \pm 1.6$ pA vs. myo-inositol + wortmannin $14.27 \pm 1.5 \mathrm{pA} ; 1000 \mathrm{~ms}: \mathrm{n}=7 p>0.05$; myo-inositol $4.11 \pm 0.8$ pA vs. myo-inositol + wortmannin $4.49 \pm 0.6$ pA; Fig. 8), similar to the results with $\mathrm{diC}_{8}-\mathrm{PIP}_{2}$ in the pipette (Figure 3-9).

In contrast, wortmannin slightly, but significantly, increased AHPs in VP neurons (100 ms: $\mathrm{n}=6, * * p<0.01$; control $17.97 \pm 2.6 \mathrm{pA}$ vs. wortmannin $23.73 \pm 3.9 \mathrm{pA} ; 1000$ ms: $\mathrm{n}=6 * p<0.05$; control $4.46 \pm 0.9$ pA vs. wortmannin $7.13 \pm 1.2 \mathrm{pA}$ ) (Figure 3-9).

\section{Changes in $I_{\text {mAHP }}$ and $I_{\text {sAHP via PIP }}$ Are Unlikely to Be the Result of Phospholipase C-Dependent Phenomena}

So far, we have demonstrated that a presumed reduction of $\mathrm{PIP}_{2}$ by wortmannin caused a pronounced inhibition of the $I_{\mathrm{mAHP}}$ and $I_{\mathrm{SAHP}}$ in OT neurons, suggesting that $\mathrm{PIP}_{2}$ is required for generation of both AHPs. While these results demonstrate the $I_{\mathrm{mAHP}}$ and $I_{\mathrm{SAHP}}$ require $\mathrm{PIP}_{2}$, they do not provide any evidence for a mechanism by which $\mathrm{PIP}_{2}$ can modulate $I_{\text {AHPs. }}$ For example, PIP $_{2}$ could directly modulate the AHP channels. Alternatively, reduced $\mathrm{PIP}_{2}$ levels could potentially act indirectly through phospholipase $\mathrm{C}$ (PLC)-induced inositol 1,4,5-trisphosphate (IP3) or diacylglycerol (DAG) since $\mathrm{PIP}_{2}$ is a precursor for breakdown by PLC into DAG and $\mathrm{IP}_{3}$ (Suh and Hille 2008). That is, blocking $\mathrm{PIP}_{2}$ production by inhibiting the rate-limiting enzyme of production (PI4K $\alpha$ ) with wortmannin could cause a drop in $\mathrm{PIP}_{2}$, which could in turn would reduce PLCinduced $\mathrm{IP}_{3}$ availability ( $\mathrm{IP}_{3}$ binds to $\mathrm{IP}_{3}$ receptors on the endoplasmic reticulum and induces $\mathrm{Ca}^{2+}$ release into the cytoplasm from internal stores: (Dickson et al. 2013).

To test this, we used the selective PLC inhibitor U73122 $(10 \mu \mathrm{M})$ to directly block the conversion of $\mathrm{PIP}_{2}$ into DAG and $\mathrm{IP}_{3}$ (Bleasdale et al. 1990; Pérez et al. 2010). U73122 has been widely used in the nervous system, including the study of PLCdependent phenomena in SON (Sabatier et al. 1998; Li et al. 1999; Bonfardin et al. 2010). In OT neurons, U73122 had no effect on either the $I_{\mathrm{mAHP}}$ or the $I_{\mathrm{sAHP}}$ amplitude (100 ms: $\mathrm{n}=8, p>0.05$; control $21.48 \pm 2.4$ pA vs. U73122 $20.53 \pm 3.1 \mathrm{pA} ; 1000 \mathrm{~ms}: \mathrm{n}=$ $8 p>0.05$; control $3.45 \pm 0.6$ pA vs. U73122 $3.42 \pm 0.5$ pA; Fig. 10). The decay time constant was also not significantly affected $(\mathrm{n}=8 ; p>0.05$, control $\tau=233.32 \pm 62.9 \mathrm{~ms}$ vs. U73122 $\tau=507.61 \pm 185.5 \mathrm{~ms}$ ) (Figure 3-10).

In contrast, the VP cells treated with U73122 display an enhancement of the $I_{\mathrm{sAHP}}$ 


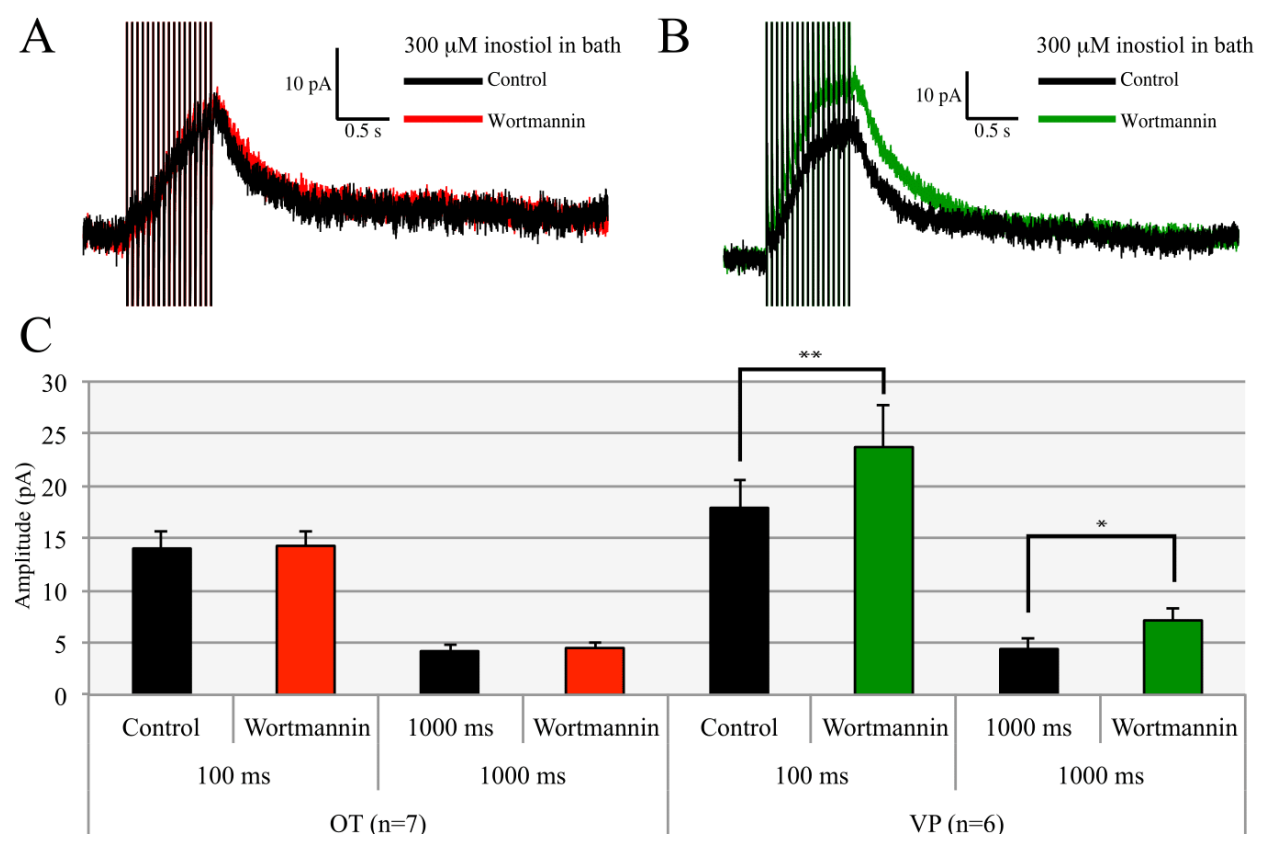

Figure 3-9. Wortmannin fails to inhibit OT neurons in aCSF containing myoinositol.

Slices were preincubated in aCSF containing $1 \mathrm{mM}$ myo-inositol, an important precursor molecule for $\mathrm{PIP}_{2}$ synthesis. When the slice was transported to the stage for patch clamp, the aCSF perfused onto the slice contained $300 \mu \mathrm{M}$ myo-inositol during recording. (A) Voltage clamp trace of an OT neuron before and after application of wortmannin. (B) Voltage clamp trace of a VP neuron before and after application of wortmannin. (C) Summary data of wortmannin on inositol-bathed neurons. OT neurons demonstrated no significant effect of wortmannin in the presence of myo-inositol $(p>0.05)$. VP neurons demonstrated slight enhancements of both the $I_{\mathrm{mAHP}}$ and $I_{\mathrm{sAHP}}\left(I_{\mathrm{mAHP}}{ }^{*} *^{*}<0.01 ; I_{\mathrm{SAHP}}\right.$ : $* p<0.05)$. 
A
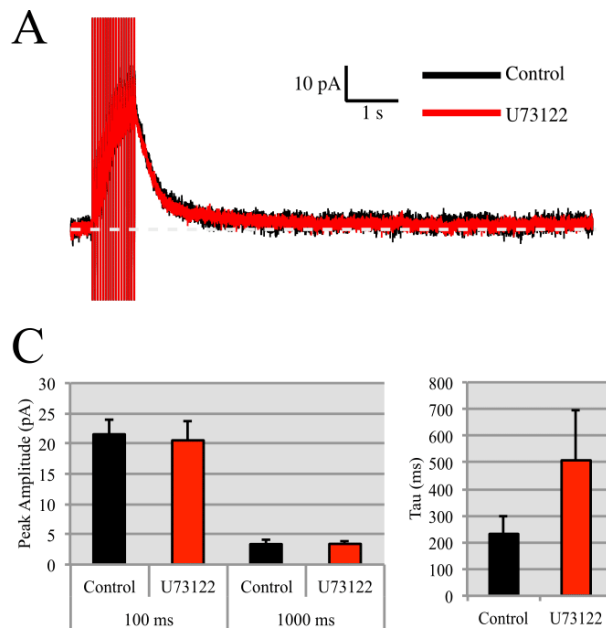

$\mathrm{B}$
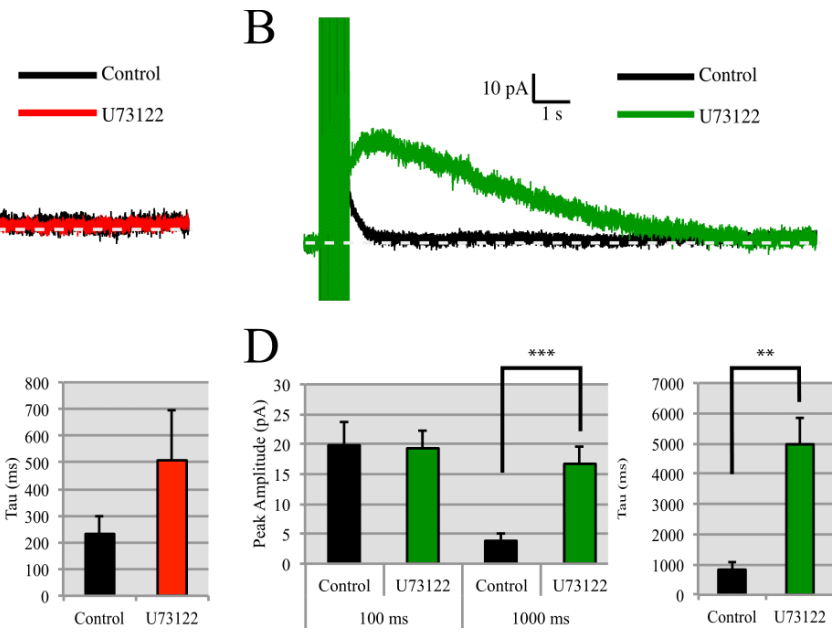

$\mathrm{D}$

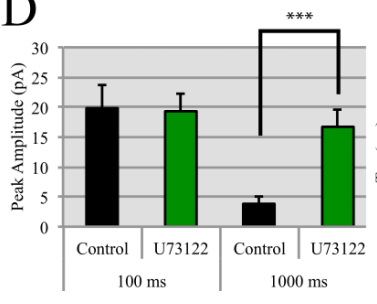

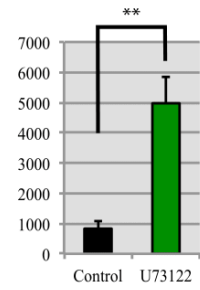

Figure 3-10. The PLC inhibitor U73122 $(10 \mu \mathrm{M})$ failed to inhibit the $I_{\mathrm{mAHP}}$ or $I_{\mathrm{sAHP}}$ in OT neurons.

(A) Voltage clamp trace of an OT neuron before and after application of U73122. (B) Voltage clamp trace of a VP neuron before and after U73122. U73122 causes amplitude enhancement and elongation of the inactivation tau of the sAHP. This enhancement has a similar shape and timecourse to that of diC8-PIP2 dialysis (Figure 3-7). (C) Summary data for OT neurons: current amplitude at $100 \mathrm{~ms}\left(I_{\mathrm{mAHP}}\right), 1000 \mathrm{~ms}\left(I_{\mathrm{sAHP}}\right)$, and $I_{\mathrm{AHP}}$ decay tau $(\mathrm{n}=8, p>0.05)$. (D) Summary data for VP neurons: current amplitude at 100 $\mathrm{ms}\left(I_{\mathrm{mAHP}} ; p>0.05\right), 1000 \mathrm{~ms}\left(I_{\mathrm{sAHP}} ; * * *<0.001\right)$, and $I_{\mathrm{AHP}}$ decay tau $(* * p<0.01)$. 
(Figure 3-10B). U73122 appeared only to significantly enhance the $I_{\mathrm{sAHP}}$ component (100 ms: $\mathrm{n}=9, p>0.05$; control $19.93 \pm 3.8$ pA vs. $\mathrm{U} 7312219.30 \pm 2.8 \mathrm{pA} ; 1000 \mathrm{~ms}: \mathrm{n}=9$ $* * * p<0.001$; control $3.94 \pm 1$ pA vs. U73122 $16.70 \pm 2.96 \mathrm{pA})$. Additionally, the inactivation $\tau$ of the $I_{\mathrm{SAHP}}$ is 4-5 times longer in VP neurons after $\mathrm{U} 73122$ application $(\mathrm{n}=$ 9 ; ${ }^{*} p<0.01$, control $\tau=833.82 \pm 224.1 \mathrm{~ms}$ vs. U73122 $\tau=4973.52 \pm 856 \mathrm{~ms}$ ) (Figure 3-10).

These results show it is unlikely $\mathrm{PIP}_{2}$ modulates the $I_{\mathrm{AHP}}$ by indirectly affecting downstream targets of PLC in OT neurons. This would primarily include $\mathrm{Ca}^{2+}$ release from stores via $\mathrm{IP}_{3}$, or working through $\mathrm{DAG}$ and its product, protein kinase $\mathrm{C}$ (also known to modulate ion channels: Suh and Hille (2008). For VP neurons, we observe an enhancement similar to that of $\mathrm{diC}_{8}-\mathrm{PIP}_{2}$ dialysis. We interpret this as an effective increase in cellular $\mathrm{PIP}_{2}$ resulting from PLC block. Since we are only blocking the breakdown and not the production of $\mathrm{PIP}_{2}$, we effectively increase its concentration.

\section{Differences between OT and VP Neurons in the $I_{\text {mAHP }}$ and $I_{\text {sAHP }}$ May Be Due to Changes in $\mathrm{Ca}^{2+}$ Influx after Wortmannin}

Unlike neocortical pyramidal cells where only the $I_{\mathrm{sAHP}}$ is affected by alterations in $\mathrm{PIP}_{2}$ levels (Villalobos et al. 2011), all of our results in OT neurons occur in parallel for the $I_{\mathrm{mAHP}}$ and $I_{\mathrm{SAHP}}$. A parsimonious explanation for this parallel effect is that $\mathrm{PIP}_{2}$ exerts its effect upstream from the AHP $\mathrm{K}^{+}$channels on $\mathrm{Ca}^{2+}$ entry or $\mathrm{Ca}^{2+}$ availability. We hypothesized that $\mathrm{PIP}_{2}$ may act on regulating $\mathrm{Ca}^{2+}$ entry or otherwise alter $\left[\mathrm{Ca}^{2+}\right]_{\mathrm{i}}$. To test this, we used $\mathrm{Ca}^{2+}$ imaging to determine whether wortmannin's inhibition of the AHPs in OT neurons affected $\left[\mathrm{Ca}^{2+}\right]$ i. We used the high affinity $\mathrm{Ca}^{2+}$ indicator fura-2 (100 nM), as in our previous publications (Roper et al. 2003, 2004; Abel et al. 2004; Teruyama and Armstrong 2005). The relative change in fura-2 fluorescence $(\% \Delta F / F)$ is linearly proportional to bulk $\left[\mathrm{Ca}^{2+}\right]_{\mathrm{i}}$ changes in the cytoplasm when $\% \Delta \mathrm{F} / \mathrm{F}$ is less than $\sim 0.5$ (Abel et al. 2004). Since the peaks of bulk $\left[\mathrm{Ca}^{2+}\right]$ i were less than 0.5 , we used the $\% \Delta \mathrm{F} / \mathrm{F}$ value as an index for changes in $\left[\mathrm{Ca}^{2+}\right]_{\mathrm{i}}$. During the stimulus train, we observed a rapid rise in $\left[\mathrm{Ca}^{2+}\right]_{i}$ that decayed monoexponentially (Figure 3-11). In OT neurons, we found that simultaneous with the reduction in $I_{\mathrm{AHPs}}(100 \mathrm{~ms}: \mathrm{n}=9, p>0.001$; control $30.23 \pm 4.5 \mathrm{pA}$ vs. wortmannin $9.77 \pm 2.5 \mathrm{pA} ; 1000 \mathrm{~ms}: p<0.001$; control $7.64 \pm 0.5 \mathrm{pA}$ vs. wortmannin $4.09 \pm 0.5 \mathrm{pA})$, wortmannin $(1 \mu \mathrm{M})$ also reduced the spike-evoked increase in somatic $\left[\mathrm{Ca}^{2+}\right]_{\mathrm{i}}$ in OT neurons $(\mathrm{n}=9, p<0.001$; control $44.09 \pm 2.3 \% \Delta \mathrm{F} / \mathrm{F}$ vs. wortmannin $30.77 \pm 2.4 \% \Delta \mathrm{F} / \mathrm{F}$ ) (Figure 3-11).

Consistent with our previous experiments showing no inhibition of AHPs, wortmannin had no effect on VP neuron $I_{\mathrm{mAHPs}}$ or $I_{\mathrm{sAHPs}}(100 \mathrm{~ms}$ : $\mathrm{n}=7, p>0.05$; control $23.01 \pm 4.6 \mathrm{pA}$ vs. wortmannin $21.18 \pm 3.98 \mathrm{pA}$; $1000 \mathrm{~ms}: p>0.05$; control $5.34 \pm 1.1$ pA vs. wortmannin $4.41 \pm 0.9 \mathrm{pA})$ or on $\left[\mathrm{Ca}^{2+}\right]_{\mathrm{i}}($ control $47.40 \pm 2.6 \% \Delta \mathrm{F} / \mathrm{F}$ vs. wortmannin $44.03 \pm 2.9 \% \Delta \mathrm{F} / \mathrm{F})$ (Figure 3-11). 

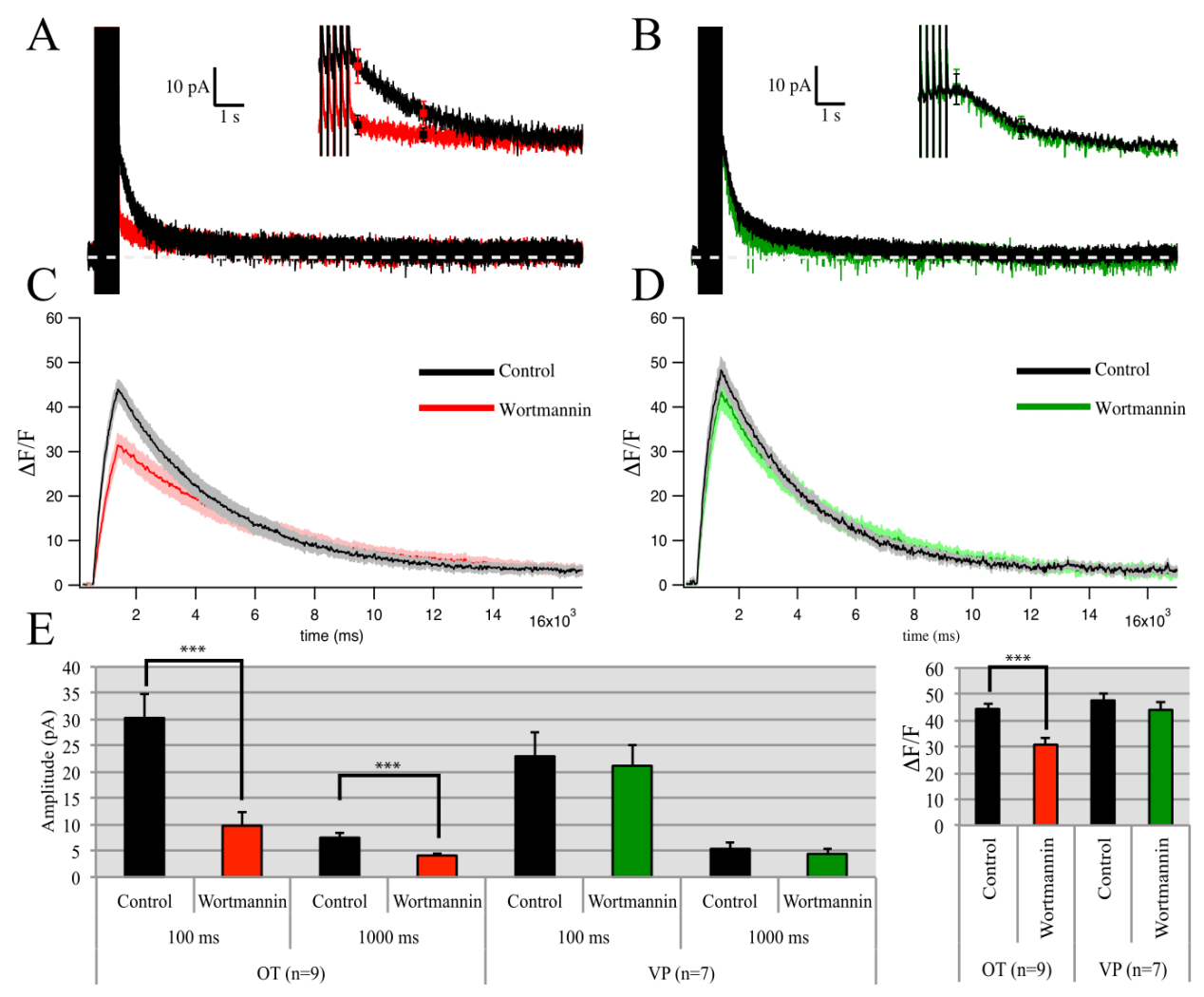

Figure 3-11. Wortmannin $(1 \mu \mathrm{M})$ inhibits the $I_{\mathrm{mAHP}} I_{\mathrm{sAHP}}$ and somatic $\mathrm{Ca}^{2+}$ while having no effect on these measures in VP neurons.

(A, B) Averaged voltage clamp traces of OT (A) and VP (B) cells after wortmannin application; inset is higher temporal resolution of same trace with the mean $\pm \mathrm{SEM}$ values superimposed at $100 \mathrm{~ms}$ and $1000 \mathrm{~ms}$ after the pulse. (C, D) Average intracellular $\mathrm{Ca}^{2+}$ response of OT (C) and VP (D) cells to wortmannin expressed as the change in fluorescence divided by the total fluorescence $(\% \Delta \mathrm{F} / \mathrm{F}$; shaded area of the curve is SEM). (E) Summary data at $100 \mathrm{~ms}\left(I_{\mathrm{mAHP}}\right)$ and $1000 \mathrm{~ms}\left(I_{\mathrm{SAHP}}\right)$ amplitude (OT: $\mathrm{n}=9,100 \mathrm{~ms} \&$ $1000 \mathrm{~ms} * * * p<0.001$; VP: $\mathrm{n}=7,100 \mathrm{~ms}$ and $500 \mathrm{~ms} p>0.05)$ and summary data of $\mathrm{Ca}^{2+}$ transient peak amplitude (OT: $\mathrm{n}=9, * * * p<0.001 ; \mathrm{VP}: \mathrm{n}=7, p>0.05$ ). 


\section{PIP2 Depletion Has No Effect on AHPs Generated by Uncaging $\mathrm{Ca}^{2+}$}

The previous $\mathrm{Ca}^{2+}$ data suggests that $\mathrm{PIP}_{2}$ modulates AHPs by changing $\mathrm{Ca}^{2+}$ entry or $\mathrm{Ca}^{2+}$ availability to the $\mathrm{K}^{+}$channels but does not rule out additional effects on the AHP channel itself. To test whether or not $\mathrm{PIP}_{2}$ modulated AHP channels, we rapidly increased somatic $\left[\mathrm{Ca}^{2+}\right]_{i}$ of the cell via photolytic release of $\mathrm{Ca}^{2+}$ from its caging compound, DM-Nitrophen (2 mM). Neurons were dialyzed with DM-Nitrophen at 40\% $\mathrm{Ca}^{2+}$ occupancy via the recording pipette and stimulated using a UV light flash from a xenon flash bulb. The result of this rapid $\mathrm{Ca}^{2+}$ release is an AHP generated without stimulating a train of action potentials in the cell, and thus an AHP independent of $\mathrm{Ca}^{2+}$ entry through voltage-gated $\mathrm{Ca}^{2+}$ ion channels (Sah and Clements 1999). Using fluo-4 $(50 \mu \mathrm{M})$ as the dye indicator for $\mathrm{Ca}^{2+}$, we elicited AHPs with spiking and uncaging in every cell tested. We opted to use current clamp for these experiments for two reasons: (1) Signal fidelity was much better in current clamp. It was sometimes difficult to see an uncaged AHP in voltage clamp, while it was always clearly present in current clamp. (2) While still present in current clamp, rundown of both the currents and the $\mathrm{Ca}^{2+}$ transient was slower than the rundown we observed in voltage clamp.

For AHPs generated from current injections, we evoked action potentials with suprathreshold current using $20,10 \mathrm{~ms}$ pulses at $20 \mathrm{~Hz}$, from a resting potential of $\sim-55$ $\mathrm{mV}$ (controlled by DC current injection). For AHPs generated from uncaging $\mathrm{Ca}^{2+}$, we administered a UV light flash of $\sim 1 \mathrm{~ms}$ duration at $72.6 \mathrm{~J}$ at the same membrane potential. To control for rundown, we measured AHPs at two time points for each of two groups: one control group and one group that received wortmannin application between the first and second measurements. Consistent with previous results in voltage clamp, both mAHPs and sAHPs generated by spiking were significantly inhibited by wortmannin application $(\mathrm{n}=7 ; 100 \mathrm{~ms}: p<0.001$; control $10.8 \pm 0.6 \mathrm{mV}$ vs. wortmannin $6.7 \pm 1.2 \mathrm{mV}$; $1000 \mathrm{~ms}: p=0.018$; control $(\mathrm{n}=7) 8.3 \pm 1.4 \mathrm{mV}$ vs. wortmannin $4.6 \pm 0.8$ $\mathrm{mV}$ ) (Figure 3-12). The corresponding $\mathrm{Ca}^{2+}$ peak transients using fluo-4 were also inhibited significantly $(\mathrm{n}=7 ; p<0.05$; control $45.2 \pm 6.9 \% \Delta \mathrm{F} / \mathrm{F}$ vs. wortmannin $23.7 \pm$ $4.1 \% \Delta \mathrm{F} / \mathrm{F}$ ) (Figure 3-12). However, when AHPs were generated by uncaging $\mathrm{Ca}^{2+}$ in these same cells, we found no significant differences between groups in either the peak or 1000 ms uncaged AHP amplitude ( $\mathrm{n}=7$; peak: $p>0.05$; control $10.0 \pm 1.2 \mathrm{mV}$ vs. wortmannin $(\mathrm{n}=8) 13.9 \pm 3.0 \mathrm{mV} ; 1000 \mathrm{~ms}: p>0.05$; control $7.9 \pm 3.6 \mathrm{mV}$ vs. wortmannin $10.5 \pm 1.8 \mathrm{mV})$. Additionally, we found no change in the corresponding peak $\mathrm{Ca}^{2+}$ transient $(\mathrm{n}=7 ; p>0.05$; control $128.6 \pm 13.2 \% \Delta \mathrm{F} / \mathrm{F}$ vs. wortmannin $23.7 \pm$ $4.1 \% \Delta \mathrm{F} / \mathrm{F}$ ) (Figure 3-12). This demonstrates that not only does $\mathrm{PIP}_{2}$ likely modulate AHPs via spike-induced $\mathrm{Ca}^{2+}$ entry, but also that $\mathrm{PIP}_{2}$ does not likely gate the AHP channels themselves.

\section{PIP2 Depletion Inhibits Whole Cell $\mathrm{Ca}^{2+}$ Currents in OT Neurons}

The results of our $\mathrm{Ca}^{2+}$ imaging and uncaging data suggest that $\mathrm{PIP}_{2}$ affects the AHP by modulating $\mathrm{Ca}^{2+}$ entry through voltage-gated $\mathrm{Ca}^{2+}$ channels. To further test this, we isolated whole cell $\mathrm{Ca}^{2+}$ currents in slices using $0.0005 \mathrm{mM}$ TTX, $50 \mathrm{mM}$ TEA, and 5 


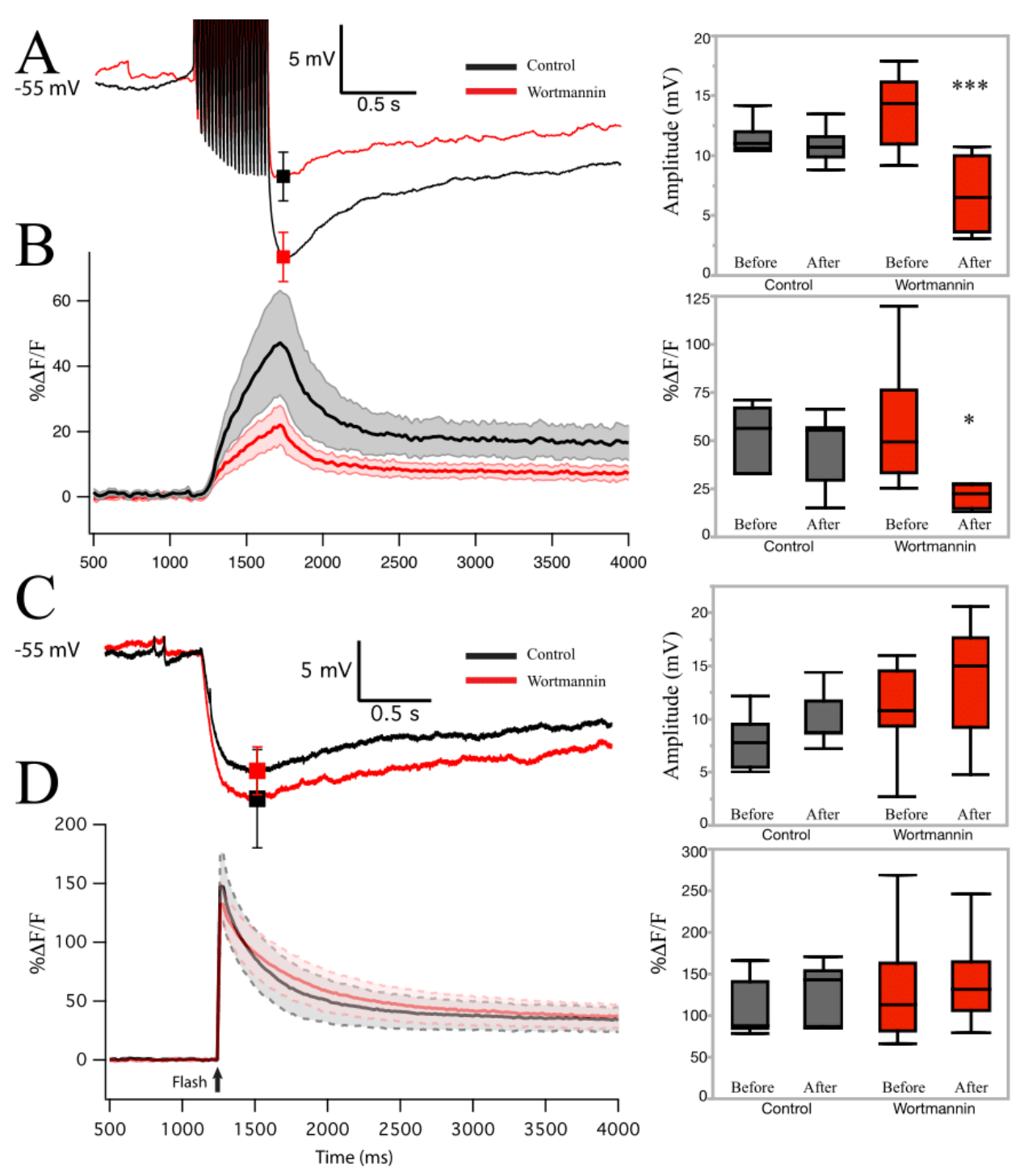

Figure 3-12. Wortmannin has no effect on AHPs or somatic $\mathrm{Ca}^{2+}$ when AHPs are generated via uncaging $\mathrm{Ca}^{2+}$ in OT neurons.

Measurements of AHPs were taken at 2 time points to control for the rundown present in this experiment. In one group, wortmannin was administered between the two measurements. All example traces are group averages of the second measurement from the control and wortmannin groups. (A, left) Averaged current clamp traces of AHPs generated by trains of current injections with a superimposed mean \pm SEM at $100 \mathrm{~ms}$. (A, right) box plot summary data of this effect $(* * p=0.008)$. $(\mathbf{B}$, left $)$ Corresponding $\mathrm{Ca}^{2+}$ signal average for traces shown in (A). Shaded area represents error. (B, right) box plot summary data for $\mathrm{Ca}^{2+}$ transients generated by spike-generated AHPs (left) $(* p<0.05)$. $\left(\mathbf{C}\right.$, left) Averaged current clamp traces of AHPs generated by uncaging $\mathrm{Ca}^{2+}$ inside the cell with a superimposed mean \pm SEM at the peak $(p>0.05)$. (C, right $)$ Box plot summary data for uncaging-generated AHPs. (D, left) Corresponding $\mathrm{Ca}^{2+}$ signal average for traces shown in (C). Shaded area represents error. (D, right) Box plot summary data for $\mathrm{Ca}^{2+}$ transients generated by an uncaging AHP $(p>0.05)$. 
$\mathrm{mM} \mathrm{CsCl}$, measured steady-state current responses to voltage steps, and plotted I-V curves before and after wortmannin application. Space clamp is a prevalent issue when measuring these currents in slice recordings of dendritic neurons, so cells exhibiting marked space clamp errors were excluded from analysis (Criteria included delayed responses to voltage steps and escaping tail currents). Peak current occurred at a step to $10 \mathrm{mV}$, a result consistent with previous studies done on whole cell $\mathrm{Ca}^{2+}$ currents in these neurons (Fisher and Bourque 1995; Foehring and Armstrong 1996; Teruyama and Armstrong 2005). Application of $400 \mu \mathrm{M} \mathrm{Cd}^{2+}$ after each trial resulted in a near complete block of current. When stepping positively, we started to observe inward current at the-40 $\mathrm{mV}$ step. At $-10 \mathrm{mV}$ where steady-state $\mathrm{Ca}^{2+}$ currents are largest, we observed a statistically significant inhibition by wortmannin $(n=7, p=0.018$; control $-459.0 \pm 41.1$ pA vs. wortmannin -260.8 \pm 23.9 pA) in OT neurons (Figure 3-13). By comparison, VP neurons displayed no change in $\mathrm{Ca}^{2+}$ currents after application of wortmannin $(\mathrm{n}=5, p>$ 0.05 ; control $-482.5 \pm 30.9$ pA vs. wortmannin $-493.8 \pm 28.7 \mathrm{pA}$ ) (Figure 3-13). This result demonstrates $\mathrm{PIP}_{2}$ modulates $\mathrm{Ca}^{2+}$ entry through voltage-gated $\mathrm{Ca}^{2+}$ channels.

\section{KCNQ Channels Don't Appear to Contribute the AHP in Either Cell Type}

In an effort to understand the identity of the AHP channel(s), we tested XE-991, a KCNQ channel blocker, on the AHP in OT and VP neurons. Previous studes in CA1 pyramidal neurons demonstrate that KCNQ channels contribute to the sAHP conductance activated upstream by the $\mathrm{Ca}^{2+}$ sensor protein, hippocalcin (Tzingounis et al. 2007, 2010; Tzingounis and Nicoll 2008). We wanted to test this possibility in SON, as KCNQ channels bind $\mathrm{PIP}_{2}$ and have been implicated as partial contributors to the sAHP (Kim et al. 2016b). One issue with this hypothesis is that KCNQ channels are voltage-dependent and not $\mathrm{Ca}^{2+}$ dependent per se. Tzingounis and colleagues, and others have proposed that $\mathrm{PIP}_{2}$ can shift KCNQ channels into the activation range of the sAHP. They've also suggested that PIP2 can act as an intermediary, bypassing the voltage-dependent activation via a $\mathrm{Ca}^{2+}$ sensor protein (Loussouarn et al. 2003; Zaydman and Cui 2014; Kim et al. 2016b). Here in SON, XE-991 failed to block any component of the AHP in both OT and VP neurons ( $p>0.05)$ (Figure 3-14). This suggests that KCNQ channels do not contribute to the sAHP in these cells.

\section{Discussion}

The AHP and its underlying currents are important regulators of intrinsic neuronal excitability. In SON neurons, they control the length and frequency of bursts of action potentials during phasic firing (Kirkpatrick and Bourque 1996; Ghamari-Langroudi and Bourque 2004). Despite the extensive work on the $I_{\mathrm{sAHP}}$, the gating mechanism via $\mathrm{Ca}^{2+}$ is currently unknown. Furthermore, the mechanism appears to vary greatly depending on the neuronal cell type. In neocortical pyramidal cells, the unknown sAHP channels were found to track cytoplasmic $\left[\mathrm{Ca}^{2+}\right]_{i}$ (Abel et al. 2004) and to be sensitive to $\mathrm{PIP}_{2}$ manipulations (Villalobos et al. 2011). $\mathrm{PIP}_{2}$ depletion in these cells by wortmannin reduced the $I_{\mathrm{SAHP}}$, increasing $\mathrm{PIP}_{2}$ levels by adding myo-inositol dramatically slowed 

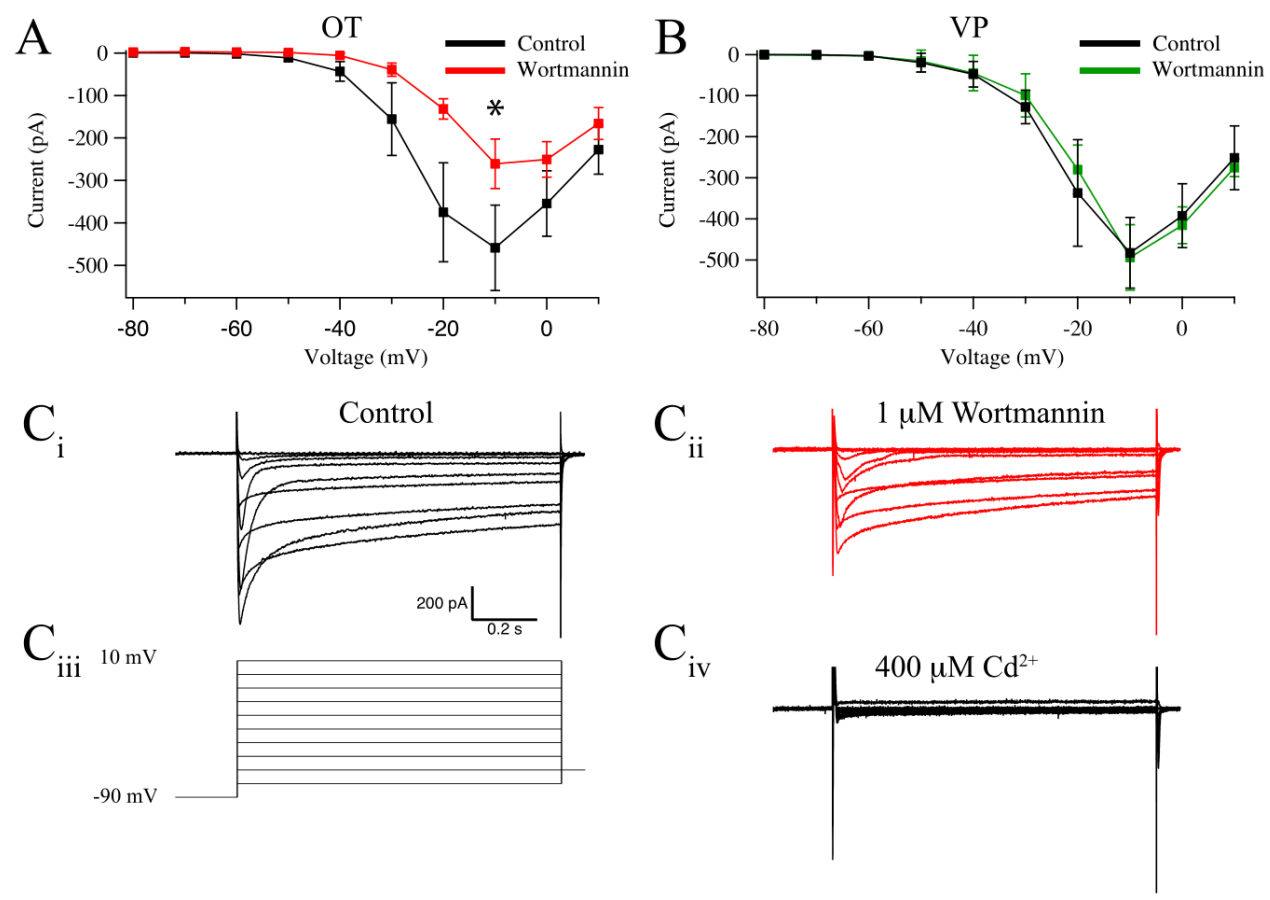

Figure 3-13. Wortmannin inhibits whole cell $\mathrm{Ca}^{2+}$ currents in OT neurons while having no effect in VP neurons.

$\mathrm{Ca}^{2+}$ currents were isolated and subsequently measured before and after wortmannin (1 $\mu \mathrm{M})$. I-V curves were plotted from steady-state measurements of these currents. (A) I-V curve of $\mathrm{Ca}^{2+}$ currents before and after wortmannin in OT neurons. Comparison at the highest amplitude steady-state current $(-10 \mathrm{mV})$ revealed a significant difference $\left({ }^{*} p<\right.$ 0.05). (B) I-V curve of $\mathrm{Ca}^{2+}$ currents before and after wortmannin in OT neurons. (C) Example traces from a single OT neuron of isolated whole cell $\mathrm{Ca}^{2+}$ currents generated by voltage steps from $-90 \mathrm{mV}$ to $+10 \mathrm{mV}$ under control conditions $\left(\mathbf{C}_{\mathbf{i}}\right)$ and after $1 \mu \mathrm{M}$ wortmannin application $\left(\mathbf{C}_{\text {iii). }}\right.$. The voltage protocol $\left(\mathbf{C}_{\text {iii }}\right)$ and $400 \mu \mathrm{M} \mathrm{Cd}^{2+}\left(\mathbf{C}_{\text {iv }}\right)$ are shown for the same cell. 
A

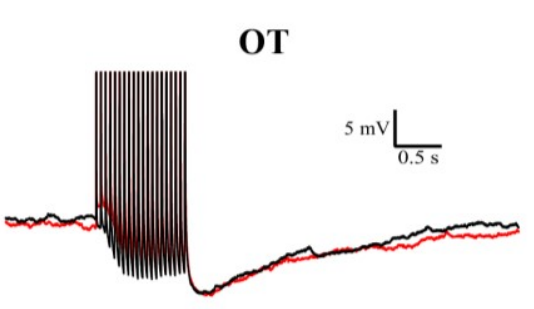

B
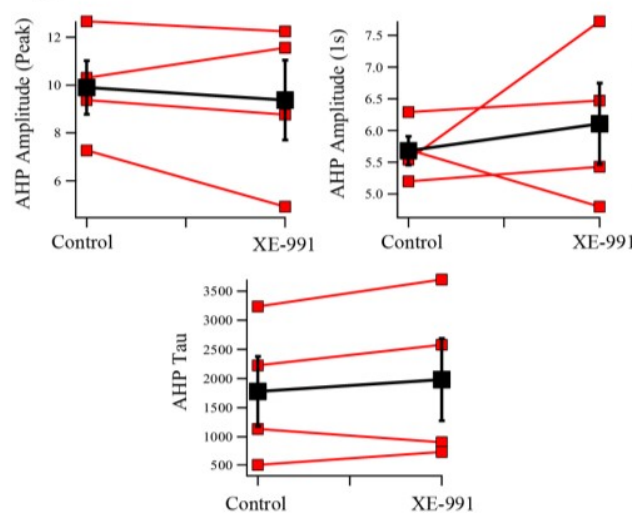

C

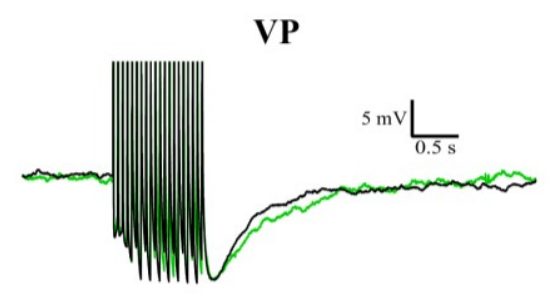

D
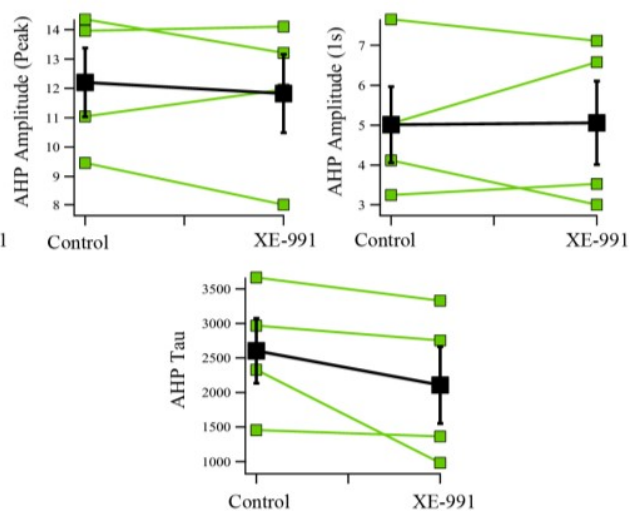

Figure 3-14. XE-991 has no effect on the AHP.

XE-991, a KCNQ channel blocker, has no significant effect on AHPs of either OT or VP neurons. (A) Example traces from an OT neuron before (black trace) and after (red trace) XE-991. (B) Summary data for XE-991's effect on AHPs in OT neurons. red traces are individual neurons; black traces are the average \pm SEM. There is no significant effect on AHP at peak, 1s, or the tau $(p>0.05)$. (C) Example traces from an VP neuron before (black trace) and after (green trace) XE-991. (D) Summary data for XE-991's effect on AHPs in VP neurons. green traces are individual neurons; black traces are the average \pm SEM. There is no significant effect on AHP at peak, $1 \mathrm{~s}$, or the tau $(p>0.05)$. 
$I_{\mathrm{SAHP}}$ rundown, and increasing $\mathrm{PIP}_{2}$ by overexpression of PIP5K facilitated calcium activation of the $I_{\mathrm{SAHP}}$ (Villalobos et al. 2011). Together, these data suggest that in pyramidal neurons, $\mathrm{PIP}_{2}$ may affect $\mathrm{Ca}^{2+}$ sensitivity of the $I_{\mathrm{SAHP}}$ channel. Several $\mathrm{K}^{+}$ channel types are known to require $\mathrm{PIP}_{2}$ for activation, including $\mathrm{KCNQ}\left(\mathrm{K}_{\mathrm{v}} 7\right)$ and $\mathrm{K}_{\mathrm{ATP}}$, among others (Hilgemann and Ball 1996; Delmas and Brown 2005; Suh and Hille 2008; Zaydman et al. 2013; Eckey et al. 2014). In addition, the rundown during recordings of $\mathrm{K}_{\mathrm{V}} 7$ and $\mathrm{K}_{\mathrm{ATP}}$ currents is a result of $\mathrm{PIP}_{2}$ depletion (Hughes et al. 2007; Logothetis et al. 2007). $\mathrm{Ca}^{2+}$ channels also play a critical role in the generation of AHPs, as different channel species are coupled to the AHP depending on the cell type (Andrade et al. 2012). Many of these voltage-gated channels interact with $\mathrm{PIP}_{2}$, and have been shown to have smaller currents when PIP $_{2}$ is depleted from the cells (Suh et al. 2010; Cruz et al. 2016). Because $\mathrm{PIP}_{2}$ availability so greatly affected $I_{\mathrm{SAHP}}$ generation in neocortical pyramidal cells, we tested the extent to which it could regulate the phenotypically similar $I_{\mathrm{AHPs}}$ in SON.

Both OT and VP cells share core AHP features, including robust calcium dependence, voltage independence, modulation by neurotransmitters, and a relationship between amplitude and spike count (Alger and Nicoll 1980; Lorenzon and Foehring 1993; Ghamari-Langroudi and Bourque 2004; Teruyama and Armstrong 2005; Armstrong et al. 2010; Andrade et al. 2012). Suggestions for the potassium channel underlying the sAHP channel across the nervous system include KCNQ, $\mathrm{K}_{\mathrm{ATP}}$, and TREK1 channels (Tzingounis and Nicoll 2008; Tanner et al. 2011; Ford et al. 2013). KCNQ channels have been a focus of study in this regard, considering the exhaustive documentation of their modulation by $\mathrm{PIP}_{2}$ (Suh and Hille 2002; Loussouarn et al. 2003; Li et al. 2005; Winks et al. 2005; Suh and Hille 2007; Liu et al. 2008; Kim et al. 2016b). While KCNQ channels may be promising candidates for at least a component of the sAHP in some cells due to their modulation by $\mathrm{PIP}_{2}$ (Loussouarn et al. 2003; Kim et al. 2016 b), it seems unlikely for SON given our data using XE-991. For example, (Kim et al. $2016 \mathrm{~b}$ ) revealed a complicated dynamic in CA1 pyramidal cells between the $I_{\mathrm{sAHP}}$, the voltage-dependence of KCNQ3 $\left(\mathrm{K}_{\mathrm{v}} 7.3\right)$ channels, and hippocalcin, a $\mathrm{Ca}^{2+}$ sensor protein critical for sAHP generation in CA1 neurons (Tzingounis et al. 2007). However, hippocalcin has not been found in the SON (Paterlini et al. 2000), and although KCNQ channels are expressed in the SON (Zhang et al. 2009b), and muscarinic suppression of sAHPs in SON has been reported, the sAHP does not show any voltage-dependence (Ghamari-Langroudi and Bourque 2004). The latter authors did rule out BK, SK, and IK channels however, based on the insensitivity of the sAHP to toxins targeting these toxins (Ghamari-Langroudi and Bourque 2004).

In SON neurons, we demonstrated an observable mechanistic difference between two similar cell types in the same nucleus. Depletion of $\mathrm{PIP}_{2}$ inhibits both the medium and slow components of the AHP in OT neurons while having no discernable effect on VP neurons. This is a novel and perhaps surprising result. Previous studies described cell type differences in firing patterns and plasticity during the reproductive cycle, but this is the first description of an OT-VP difference in an AHP mechanism (Bourque et al. 1985; Armstrong 1995; Teruyama and Armstrong 2002, 2005). Perhaps the differences are related to the fact that AHP and spike frequency undergo massive plastic changes in $\mathrm{OT}$ 
neurons during pregnancy and lactation, while VP neurons remain mostly unaffected in this regard. Thus $\mathrm{PIP}_{2}$ activity could be a key regulator of AHP changes during the reproductive cycle.

Differences between our results in SON and previous results in neocortical neurons are twofold: First, $\mathrm{PIP}_{2}$ depletion blocked both the $I_{\mathrm{mAHP}}$ and $I_{\mathrm{sAHP}}$ in OT neurons (with no effect in VP neurons), whereas it only affected the $I_{\mathrm{SAHP}}$ in neocortical neurons (Villalobos et al. 2011). This is demonstrated by wortmannin block at $100 \mathrm{~ms}$ (mAHP) and $1000 \mathrm{~ms}$ (sAHP) after the stimulus (Figure 3-2) and inhibition of isolated $I_{\mathrm{SAHP}}$ currents in the presence of apamin (Figure 3-5). Second, $\left[\mathrm{Ca}^{2+}\right]_{i}$ transients are reduced after $\mathrm{PIP}_{2}$ depletion in OT neurons (Figure 3-11) whereas neocortical $\left[\mathrm{Ca}^{2+}\right]_{\mathrm{i}}$ transients were unaffected by $\mathrm{PIP}_{2}$ depletion. These differences reflect a novel distinction between AHP mechanisms of different cell types. The results in cortex likely reflect a change in $\mathrm{Ca}^{2+}$ sensitivity of the AHP while the results in OT neurons appear to reflect a change in $\mathrm{Ca}^{2+}$ entry through voltage-gated $\mathrm{Ca}^{2+}$ channels.

\section{Wortmannin-induced Inhibition of I $_{\text {AHPs }}$ Results from a Restriction of PIP2 Availability}

Wortmannin consistently and effectively blocked the $I_{\mathrm{mAHP}}$ and $I_{\mathrm{sAHP}}$ in OT neurons in a dose-dependent manner. Because wortmannin has multiple targets and drastic effects on OT AHPs, careful dissection of its effects was carried out in this study. One potential confound is non-specific effects of wortmannin, since this drug inhibits more than PI4K $\alpha$. In fact, wortmannin is an inhibitor of PI3K activity as well as the PI3K/Akt signal transduction pathway (Nakanishi et al. 1995; Brunn et al. 1996). PI3K is actually the higher affinity target of wortmannin $\left(\mathrm{IC}_{50}=2-4 \mathrm{nM}\right)$, as opposed to its effect on PI4K $\alpha$ ( $\mathrm{IC}_{50} \approx 50 \mathrm{nM}$ ) (Nakanishi et al. 1995). The previously reported $\mathrm{IC}_{50}$ for wortmannin's effect on PI4K $\alpha$ is consistent with our dose response curve generated by the proportion of peak $I_{\mathrm{AHP}}$ inhibition $\left(\mathrm{IC}_{50}=58 \mathrm{nM}\right)$, which was well fit by a single Langmuir isotherm. Consistent with the $\mathrm{IC}_{50}$ matching $\mathrm{PI} 4 \mathrm{~K} \alpha$ inhibition, the more specific PI3K inhibitor LY294,002 failed to affect the $I_{\mathrm{mAHP}}$ and $I_{\mathrm{sAHP}}$ in OT neurons (Figure 3-3). Elevating $\mathrm{PIP}_{2}$ levels by supplementing the internal solution with $\mathrm{diC}_{8}-\mathrm{PIP}_{2}$ (Figure 3-7), or by exposing the cells to myo-inositol (Figure 3-8), prevented $I_{\mathrm{mAHP}}$ and $I_{\mathrm{sAHP}}$ inhibition by wortmannin. We also demonstrated that wortmanin increases the cytoplasm:membrane ratio of $\mathrm{PIP}_{2}$ in dissociated OT neurons (Figure 3-6). This result has also been reported with oxotremorine-M in MNCs with immunochemistry (Shah et al. 2014), and is consistent with a study in which wortmannin prevented the recovery of $\mathrm{M}$-currents after $\mathrm{PIP}_{2}$ depletion via oxotremorine-M, confirming its inhibitory activity on $\mathrm{PIP}_{2}$ synthesis (Suh and Hille 2002). Together, these results demonstrate that wortmannin blocks the $I_{\mathrm{AHP}}$ by inhibiting $\mathrm{PIP}_{2}$ production and that $\mathrm{PIP}_{2}$ availability is critical for generation of the $I_{\mathrm{mAHP}}$ and $I_{\mathrm{SAHP}}$ in OT neurons. The robust inhibition of both medium and slow components suggests $\mathrm{PIP}_{2}$ affects a common mechanism between the two. The most recognizable connection is the $\mathrm{Ca}^{2+}$ dependence of the $I_{\mathrm{mAHP}}$ and $I_{\mathrm{sAHP}}$. 


\section{$\mathrm{PIP}_{2}$ Depletion Alters $\mathrm{Ca}^{2+}$ Entry through Voltage-gated $\mathrm{Ca}^{2+} \mathrm{Channels}^{2} \mathrm{OT}$ Neurons}

We hypothesized that $\mathrm{PIP}_{2}$ affected either $\mathrm{Ca}^{2+}$ entry or $\mathrm{Ca}^{2+}$ availability to the AHP channels. We first considered that depleting $\mathrm{PIP}_{2}$ was effectively limiting $\mathrm{Ca}^{2+}$ release from $\mathrm{IP}_{3}$-gated $\mathrm{Ca}^{2+}$ stores, shown to be a source of AHP-related $\mathrm{Ca}^{2+}$ in dopamine neurons (Morikawa et al. 2000). To the extent that U73122 is specific to PLC inhibition, this application had no effect on the $I_{\mathrm{mAHP}}$ or $I_{\mathrm{sAHP}}$ of OT neurons (Figure 3-10), consistent with the hypothesis that downstream targets of PLC activity are not involved. In contrast, both $\mathrm{Ca}^{2+}$ transients and whole cell $\mathrm{Ca}^{2+}$ currents were suppressed by wortmannin in OT, but not VP neurons, suggesting that $\mathrm{PIP}_{2}$ is interacting with voltage-gated $\mathrm{Ca}^{2+}$ channels in these cells. This conclusion was further strengthened by a lack of wortmannin effect on uncaging-invoked AHPs (Figure 3-12). Thus, $\mathrm{PIP}_{2}$ depletion simultaneously inhibits AHPs, $\mathrm{Ca}^{2+}$ transients, and $\mathrm{Ca}^{2+}$ currents in OT neurons. Though this result contrasts with observations in cortical neurons, the data do not necessarily rule out a contribution of $\mathrm{Ca}^{2+}$ sensitivity as contributing to the effects of $\mathrm{PIP}_{2}$ on the $I_{\mathrm{SAHP}}$.

Although we observed clear inhibition of HVA currents with wortmannin, several voltage-activated $\mathrm{Ca}^{2+}$ channels are candidates for the $\mathrm{PIP}_{2}$ modulation. It is presently unknown which specific $\mathrm{Ca}^{2+}$ channel types couple to the medium and slow AHP in OT and VP neurons in the SON (see Chapter 4). MNCs express high-voltage-activated (HVA) L-, N-, P/Q-type, and R type channels, as demonstrated with mRNA (Glasgow et al., 1999), immunochemistry (Joux et al., 2001) and pharmacological block of whole cell currents in voltage clamp (Fisher and Bourque 1995; Foehring and Armstrong 1996; Glasgow et al. 1999; Joux et al. 2001), although these studies did not differentiate between OT and VP neurons. Importantly, HVAs have been demonstrated to interact with $\mathrm{PIP}_{2}$ (Suh et al. 2010; Cruz et al. 2016; Kim et al. 2016a). Transient, low-thresholdactivated (LVA) type $\mathrm{Ca}^{2+}$ channels may also contribute to AHPs, and these have been reported in MNCs by some (Erickson et al. 1993; Fisher and Bourque 1995; Israel et al. 2008), although not by all investigators (Foehring and Armstrong 1996; Luther and Tasker 2000; Joux et al. 2001; Luther et al. 2002). Nevertheless, LVAs clearly contribute to sAHPs in thalamic paraventricular neurons (Zhang et al. 2009a). Channel coupling may also be different for the mAHP and sAHP. Previous work in other cell types describes mAHPs being activated by restricted microdomains of membrane $\mathrm{Ca}^{2+}$, while the sAHP has a tighter, cooperative sigmoidal relationship with bulk somatic $\left[\mathrm{Ca}^{2+}\right]_{\mathrm{i}}$ (Wilson and Callaway 2000; Abel et al. 2004). Therefore, the sAHP inhibition caused by $\mathrm{PIP}_{2}$ depletion could be caused by an inhibition of multiple $\mathrm{Ca}^{2+}$ channel species providing diffusible $\mathrm{Ca}^{2+}$. Interestingly, $\mathrm{N}$-type channels contribute to peptide release in OT and VP neurons, while P/Q channels contribute only in VP neurons (Wang and Fisher 2014). This trait might provide a clue about cell-type differences for $\mathrm{PIP}_{2}$ modulation of HVA channels.

It is important to explicitly mention that our results don't assume the same mechanisms for both the $I_{\mathrm{mAHP}}$ and $I_{\mathrm{sAHP}}$, just that $\mathrm{PIP}_{2}$ is a regulator of both, and both are dependent on modulation of $\mathrm{Ca}^{2+}$ entry. For example, previous work demonstrated that 
$\mathrm{PIP}_{2}$ is a necessary cofactor for SK channel activation, binding to the CaM-SK interface on these channels to shift $\mathrm{Ca}^{+}$sensitivity (Zhang et al. 2014). Though this work was done on SK2 channels, the SK3 channel complex also contains CaM, and its modulation in this manner remains a possibility for gating the $I_{\mathrm{mAHP}}$ in SON. 


\section{CHAPTER 4. CALCIUM CHANNELS COUPLED TO THE AHP IN SON}

\section{Introduction}

High voltage-activated (HVA) $\mathrm{Ca}^{2+}$ channels were first categorized by their pharmacology (Tsien 1983) and later by their subunit composition (Birnbaumer et al. 1994). Many neuronal cell types, including magnocellular supraoptic neurons (MNCs), express L-, N-, P/Q-, and R-type HVA Ca ${ }^{2+}$ channels (Fisher and Bourque 1995, 1996; Lorenzon and Foehring 1995a; Foehring and Armstrong 1996; Pineda et al. 1998; Mermelstein et al. 1999; Stewart and Foehring 2000; Castelli and Magistretti 2006; Quinlan et al. 2008; Simms and Zamponi 2014; Wang and Fisher 2014). Like many other neurons (Bean 2007), depolarization due to action potentials triggers the voltagedependent activation of these channels, allowing $\mathrm{Ca}^{2+}$ ions to flow inward. The existence of different HVA channel subtypes reflects a need to meet the complex $\mathrm{Ca}^{2+}$ requirements of neurons and other excitable cells. This is apparent in the coupling of HVA channels to distinct signaling pathways, their anatomical locations, and channel properties such as voltage dependence (Snutch et al. 2013). A classic example in neurons is the specific $\mathrm{Ca}^{2+}$ channel coupling to transmitter release in certain neurons (Wheeler et al. 1994; Cohen-Kutner et al. 2010; Catterall 2011; Snutch et al. 2013; Satake and Imoto 2014). Another example is coupling of L-type channels to excitation-transcription coupling in muscle (Flavell and Greenberg 2008).

HVA $\mathrm{Ca}^{2+}$ channels are also involved in the activation of $\mathrm{Ca}^{2+}$-dependent $\mathrm{K}^{+}$ conductances underlying spike afterhyperpolarizations (AHPs) following spike trains. AHPs shape firing behavior and cause spike frequency adaptation in many cell types (Meech 1978; Storm 1989; Sah 1996; Pineda et al. 1998; Andrade et al. 2012). MNCs demonstrate three distinct AHPs after spiking. The fast AHP (fAHP) follows a single spike and is involved in repolarization of the cell after an action potential. We do not address the fAHP here. In MNCs, the medium AHP (mAHP) is a $\mathrm{Ca}^{2+}$-dependent conductance activated after 1-3 spikes, has an inactivation time constant $(\tau)$ of 200-400 $\mathrm{ms}$, and is blocked by the SK channel toxin apamin (Bourque and Brown 1987; Armstrong et al. 1994; Kirkpatrick and Bourque 1996; Teruyama and Armstrong 2005). The mAHP contributes strongly to spike frequency adaptation in MNCs but also contributes to burst length in vasopressin (VP) neurons (Kirkpatrick and Bourque 1996). The slow AHP (sAHP) is also $\mathrm{Ca}^{2+}$-dependent, but requires longer spike trains, lasts for seconds, is insensitive to apamin, and is markedly attenuated by muscarinic receptor activation (Ghamari-Langroudi and Bourque 2004); the underlying channel is unknown. The sAHP contributes to phasic patterning in VP neurons (Ghamari-Langroudi and Bourque 2004).

Which $\mathrm{Ca}^{2+}$ channels couple to AHPs differs among neuronal cell types, and are often different for the mAHP and sAHP within the same neuron. In mature neocortical pyramidal neurons P-type currents are coupled to the mAHP while N-, P-, and Q-type currents are coupled to the sAHP (Pineda et al. 1998). In myenteric neurons and vagal motoneurons, N-type currents are coupled to both mAHPs and sAHPs (Sah 1995; 
Vogalis et al. 2001). N-type currents contribute the $\mathrm{Ca}^{2+}$ that activates the mAHP in midbrain dopamine neurons (de Vrind et al. 2016) and striatal cholinergic interneurons (Goldberg and Wilson 2005). In non-neuronal cell types such as pancreatic $\beta$-cells, Ltype channels are coupled to SK channel activation (Wang et al. 2014). L-type channels contribute to the sAHP in CA1, CA3, and sympathetic neurons (Moyer et al. 1992;

Tanabe et al. 1998; Martínez-Pinna et al. 2000). An extensive review of the $\mathrm{HVA} \mathrm{Ca}^{2+}$ channels coupling to sAHPs can be found in Andrade et al. (2012).

Although both oxytocin (OT) and VP MNCs exhibit prominent mAHPs and sAHPs (Teruyama and Armstrong 2005), the associated $\mathrm{Ca}^{2+}$ channels contributing to their activation are unknown. Previous work in our lab has demonstrated a stark mechanistic difference in that both the mAHP and sAHP are dependent on $\mathrm{PIP}_{2}$ in OT, but not VP neurons (Kirchner et al. 2017). It is possible that some of the observed differences could be explained by a difference in coupling of AHPs to $\mathrm{Ca}^{2+}$ channels between the cell types. Here we present a direct comparison of the $\mathrm{Ca}^{2+}$ channels involved in the generation of AHPs between OT and VP neurons.

\section{Results}

To determine which specific $\mathrm{Ca}^{2+}$ channel subtypes contributed $\mathrm{Ca}^{2+}$ that elicited the mAHP and sAHP in SON neurons, we measured AHPs in current clamp before and after the application of pharmacological channel blockers. We used a train of 5 or 20 spikes stimulated at $20 \mathrm{~Hz}$ from a resting potential of $-55 \mathrm{mV}$ to control for effects on spike frequency adaptation and ensure all neurons received the same stimulus. We simultaneously monitored changes in bulk somatic $\mathrm{Ca}^{2+}\left(\left[\mathrm{Ca}^{2+}\right]_{\mathrm{i}}\right)$ during stimulation. This measurement reflects $\mathrm{Ca}^{2+}$ entry plus extrusion and buffering. Measuring this allowed us to confirm the efficacy of toxin block on $\mathrm{Ca}^{2+}$ entry through its respective $\mathrm{Ca}^{2+}$ channel.

\section{$\mathrm{Cd}^{2+}$ Block of HVA Ca ${ }^{2+}$ Channels Inhibits Most of the AHP}

We first tested whether the AHP in both MNC cell types required $\mathrm{Ca}^{2+}$ entry with the inorganic HVA and LVA Ca ${ }^{2+}$ channel blocker, $\mathrm{Cd}^{2+}$ (Figure 4-1). $400 \mu \mathrm{M} \mathrm{Cd}^{2+}$ blocked $80 \pm 18 \%$ of the mAHP and $81 \pm 7 \%$ of the sAHP in OT neurons $(n=6)$. In VP neurons, it blocked $79 \pm 17 \%$ of the mAHP and $89 \pm 2 \%$ of the sAHP $(n=6)$. These data are consistent with previous reports that inorganic blockers such as $\mathrm{Cd}^{2+}, \mathrm{Mn}^{2+}$, and $\mathrm{Co}^{2+}$ block most of the AHP in MNCs (Bourque et al. 1985; Kirkpatrick and Bourque 1996; Ghamari-Langroudi and Bourque 2004). Even stronger block can be achieved by chelating intracellular $\mathrm{Ca}^{2+}$, highlighting that activation of AHPs is dependent on elevated intracellular $\mathrm{Ca}^{2+}$ (Andrew and Dudek 1984). Though, chelators may bind other compounds besides $\mathrm{Ca}^{2+}$ (Schwindt et al. 1992). 

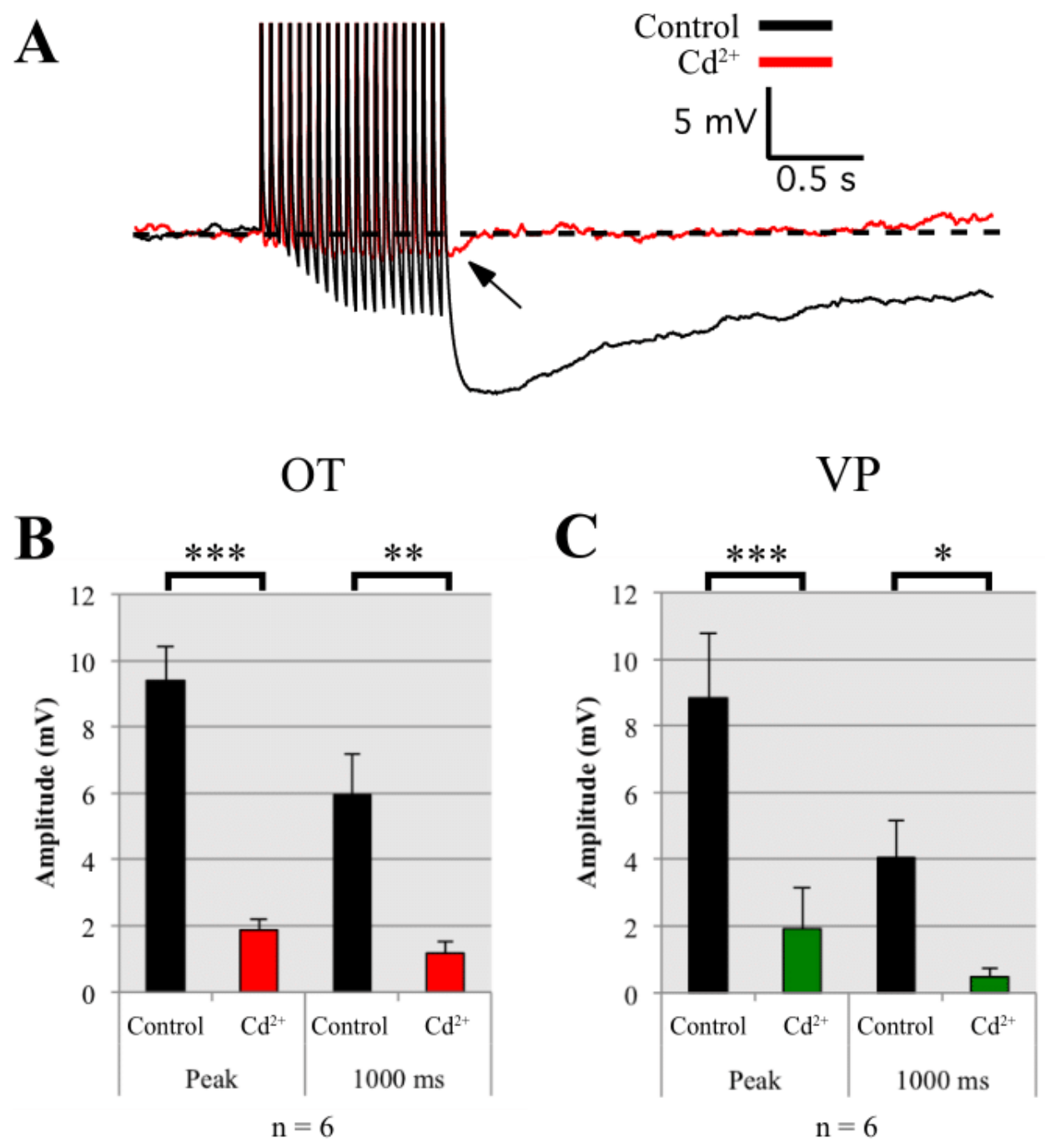

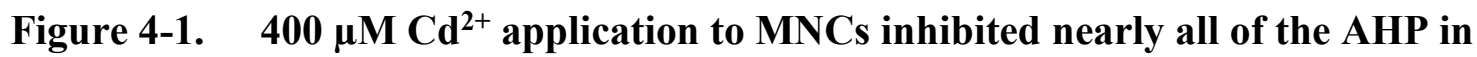
current clamp. AHPs were evoked using a pulse train of 20 spikes and measured at peak (mAHP + sAHP) and 1s (sAHP) following the pulse.

(A) Example of an OT neuron before and after $\mathrm{Cd}^{2+}$ application of an AHP in current clamp. The only remaining portion of the AHP is small and decays rapidly. (B, C) Summary data for $\mathrm{Cd}^{2+}$ inhibition at the peak current and $1 \mathrm{sec}$ following the pulse train in both OT (B) and VP (C) neurons. 


\section{L-Type Channels}

Application of the dihydropyridine L-type channel blocker Nif $(5 \mu \mathrm{M})$ did not alter either the mAHP nor sAHP in OT $(\mathrm{n}=6 p>0.05)$ and VP $(\mathrm{n}=6 p>0.05)$ neurons (Figure 4-2). However, Nif reduced the peak $\left[\mathrm{Ca}^{2+}\right]_{i}$, suggesting reduced $\mathrm{Ca}^{2+}$ entry. In OT neurons, we observed a $40 \pm 1 \%$ reduction in peak $\mathrm{Ca}^{2+}$ signal after 20 spikes $(\mathrm{n}=5 p$ $<0.01)$ and a $34 \pm 4 \%$ reduction after 5 spikes $(n=5 p<0.01)$. In VP neurons, we observed a $36 \pm 2 \%$ reduction in peak $\mathrm{Ca}^{2+}$ signal after 20 spikes $(\mathrm{n}=5 p<0.01)$ and a 43 $\pm 1 \%$ reduction after 5 spikes $(\mathrm{n}=5 p<0.01)$. The reduction in $\mathrm{Ca}^{2+}$ signal is consistent with previous observations in which $5-10 \mu \mathrm{M}$ Nif blocked a similar proportion of whole cell $\mathrm{Ca}^{2+}$ currents in acutely dissociated supraoptic neurons (Fisher and Bourque 1995; Foehring and Armstrong 1996).

\section{N-Type Channels}

We next tested for effects of the N-type channel blocker GVIA $(1 \mu \mathrm{M})$ (Figure 4-3). In OT neurons, GVIA strongly reduced measurements at peak and $1 \mathrm{sec}$ in both 20and 5-spike protocols of AHP generation $(n=8)$. GVIA inhibited the 20 -spike peak AHP by $39 \pm 7 \%(p<0.0001)$, at $1000 \mathrm{~ms}$ after the pulse by $38 \pm 7 \%(p<0.01)$, and the $5-$ spike peak AHP by $61 \pm 11 \%(p<0.0001)$. GVIA inhibited the corresponding peak $\mathrm{Ca}^{2+}$ signals by $61 \pm 4 \%$ for 20 spikes $(p<0.0001)$ and $69 \pm 5 \%$ for 5 spikes $(p<0.0001)$.

In VP neurons, GVIA inhibited the 20-spike peak AHP by $25 \pm 9 \%(p<0.01)$, at $1000 \mathrm{~ms}$ after the pulse by $29 \pm 5 \%(p>0.05)$, and the 5 -spike peak AHP by $25 \pm 12 \%(p$ $<0.01)$. These effects on peak AHPs in VP neurons were significantly smaller when compared to OT neurons $(20$-spike and 5-spike AHP peak; $p<0.05)$. Nevertheless, GVIA strongly inhibited the corresponding peak $\mathrm{Ca}^{2+}$ signals by $60 \pm 4 \%$ for 20 spikes ( $p$ $<0.0001)$ and $67 \pm 6 \%$ for 5 spikes $(p<0.008)$ in VP neurons. Furthermore, there was no difference in control $\left[\mathrm{Ca}^{2+}\right]_{\mathrm{i}}$ peaks or percentage inhibition of $\left[\mathrm{Ca}^{2+}\right]_{\mathrm{i}}$ by GVIA between OT and VP neurons $(p>0.05)$. Thus, while N-type channels were found to be a major contributor of $\mathrm{Ca}^{2+}$ to the mAHP in both cell types, this relationship was stronger for OT neurons, and N-channels contributed significantly to production of the sAHP in OT neurons only.

\section{P/Q-Type Channels}

To evaluate P/Q-type channel contribution, we used AgTx IVA $(0.5 \mu \mathrm{M})$ (Figure 4-4). P- and Q-type variants are often distinguished by their sensitivity to AgTx IVA (Mintz et al. 1992); lower concentrations of AgTx IVA (10-100 nM) have been shown to block only P-type variants, while $0.5 \mu \mathrm{M}$ blocks both P- and Q-type (Zhang et al. 1993; Foehring and Armstrong 1996). Both P- and Q-type currents are generated by the CACNA1A gene, and splice variants may explain the phenotypic differences (Bourinet et al. 1999; Nimmrich and Gross 2012). In OT $(n=6)$ and VP $(n=5)$ neurons, application of $0.5 \mu \mathrm{M}$ AgTx IVA had no significant effect on either the mAHP or sAHP $(p>0.05)$, suggesting neither P- nor Q-type currents couple to the AHPs. Simultaneous $\mathrm{Ca}^{2+}$ 
Figure 4-2. Effect of L-type blocker $5 \mu \mathrm{M}$ Nif on AHPs and corresponding $\mathrm{Ca}^{2+}$ transients in OT (A-D) and VP (E-H) neurons.

(A) Example of an AHP after a $20 \mathrm{~Hz}, 20$-spike train from an OT neuron treated with Nif and the corresponding somatic $\mathrm{Ca}^{2+}$ signal. (B) Example of an AHP after a $20 \mathrm{~Hz}, 5-$

spike train from an OT neuron treated with Nif and its corresponding somatic $\mathrm{Ca}^{2+}$ signal. (C) Summary data for OT neuron AHP measurements at the 20-spike peak amplitude (mAHP + sAHP), at $1 \mathrm{sec}$ after the train (sAHP), and 5-spike AHPs at the peak amplitude (mAHP). Red points are individual cells and black points are group averages (paired ttest; $p>0.05$ for all 3 measurements). (D) Summary data for OT neuron $\mathrm{Ca}^{2+}$ transients. Nif significantly reduced peak $\% \Delta \mathrm{F} / \mathrm{F}$ in 20 -spike AHPs (paired t-test; ** $p<0.01$ ) and 5spike AHPs $(* * p<0.01)$. (E) AHP after a $20 \mathrm{~Hz}, 20$-spike train from a VP neuron treated with Nif and its corresponding somatic $\mathrm{Ca}^{2+}$ signal. (F) AHP after a $20 \mathrm{~Hz}, 5$-spike train from a VP neuron treated with Nif and its corresponding somatic $\mathrm{Ca}^{2+}$ signal. (G) Summary data for VP neuron AHP measurements at the 20-spike peak amplitude (mAHP + sAHP), at $1 \mathrm{sec}$ after the train (sAHP), and 5-spike AHPs at the peak amplitude (mAHP). Green points are individual cells and black points are group averages (paired ttest; $p>0.05$ for all 3 measurements). (H) Nif significantly reduced peak $\% \Delta \mathrm{F} / \mathrm{F}$ from 20 -spike trains (paired t-test; ${ }^{*} p<0.01$ ) and 5-spike trains (paired t-test; $* * p<0.01$ ). 


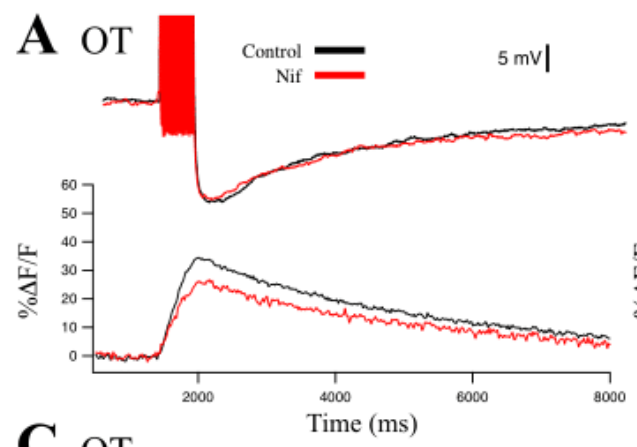

C oт
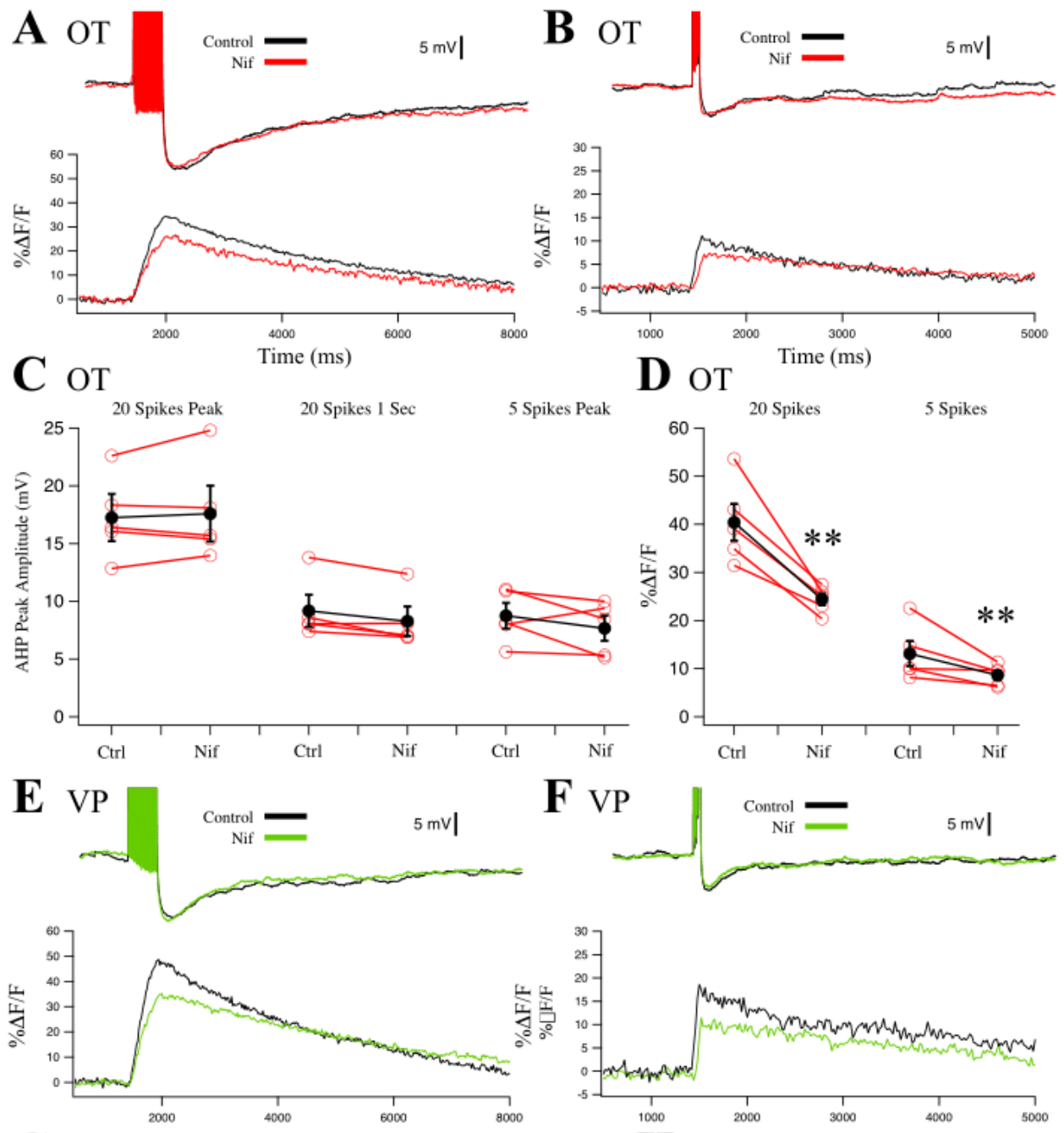

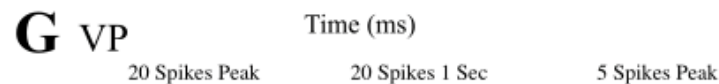
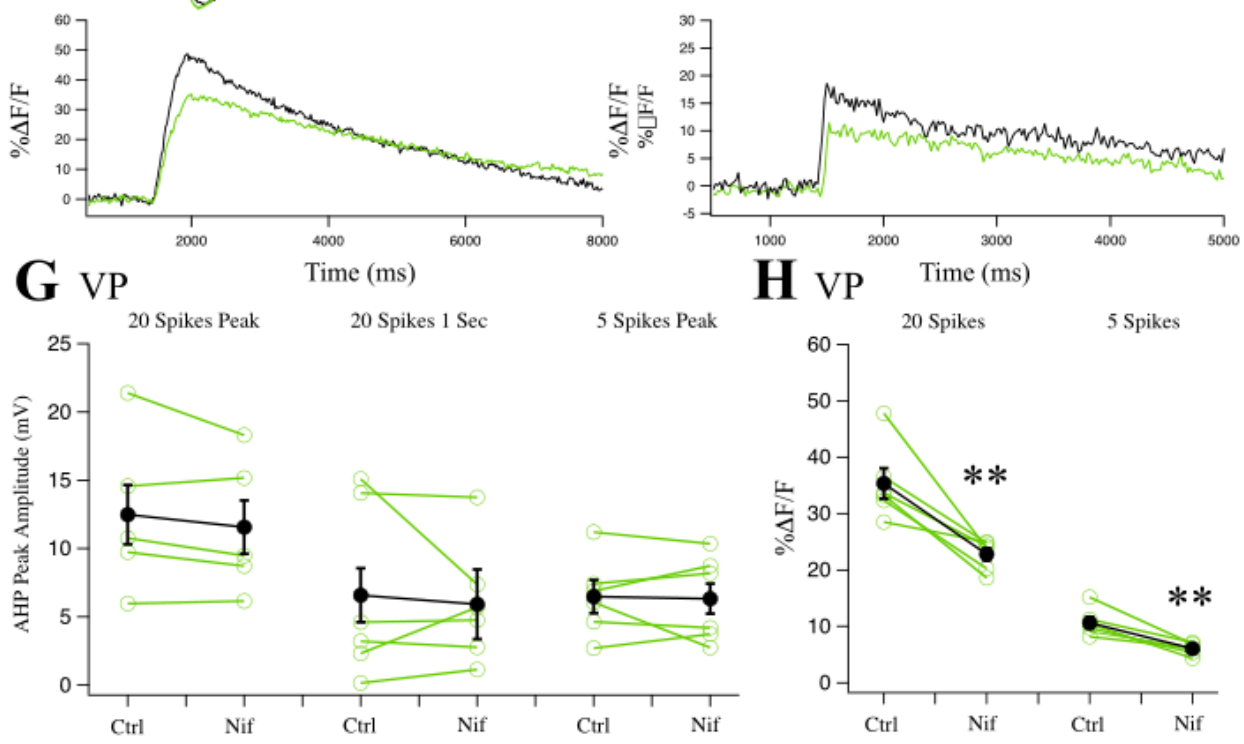

HVP ${ }_{20 \text { Spikes }}$ Time (ms)

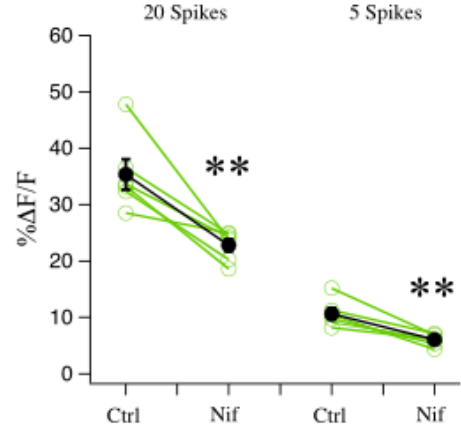


Figure 4-3. $\quad$ Effect of N-type blocker $1 \mu M$ CnTx GVIA on AHPs and corresponding $\mathrm{Ca}^{2+}$ transients in OT (A-D) and VP (E-H) neurons.

(A) Example of an AHP after a $20 \mathrm{~Hz}, 20$-spike train from an OT neuron treated with CnTx GVIA and its corresponding somatic $\mathrm{Ca}^{2+}$ signal. (B) Example of an AHP after a $20 \mathrm{~Hz}, 5$-spike train from an OT neuron treated with CnTx GVIA and its corresponding somatic $\mathrm{Ca}^{2+}$ signal. (C) Summary data for OT neuron AHP measurements at the 20spike peak (mAHP + sAHP; $* * * * p<0.0001)$, at $1 \mathrm{sec}$ after the train (sAHP; $* * p<0.01$ ), and 5-spike AHPs at the peak amplitude (mAHP; ****p $<0.0001)$. Red points are individual cells and black points are group averages. (D) Summary data for OT neuron $\mathrm{Ca}^{2+}$ transients during AHP stimulation. CnTx GVIA significantly reduced peak $\% \Delta \mathrm{F} / \mathrm{F}$ in 20 -spike AHPs $(* * * * p<0.0001)$ and reduced $\% \Delta \mathrm{F} / \mathrm{F}$ in 5 -spike AHPs $(* * * * p<$ 0.0001). (E) Example of an AHP after a $20 \mathrm{~Hz}, 20$-spike train from a VP neuron treated with CnTx GVIA and its corresponding somatic $\mathrm{Ca}^{2+}$ signal. (F) Example of an AHP after a $20 \mathrm{~Hz}$, 5-spike train from a VP neuron treated with CnTx GVIA and its corresponding somatic $\mathrm{Ca}^{2+}$ signal. (G) Summary data for VP neuron AHP measurements at the 20-spike peak amplitude (mAHP + sAHP; $* * p<0.01$ ), at $1 \mathrm{sec}$ after the train (sAHP; $p>0.05$ ), and 5-spike AHPs at the peak amplitude (mAHP; **p<0.01). Green points are individual cells and black points are group averages. (H) CnTx GVIA significantly reduced peak $\% \Delta \mathrm{F} / \mathrm{F}$ in 20 -spike AHPs (paired t-test; $* * * * p<0.0001$ ) and 5 -spike AHPs $(* * p<0.008)$. 

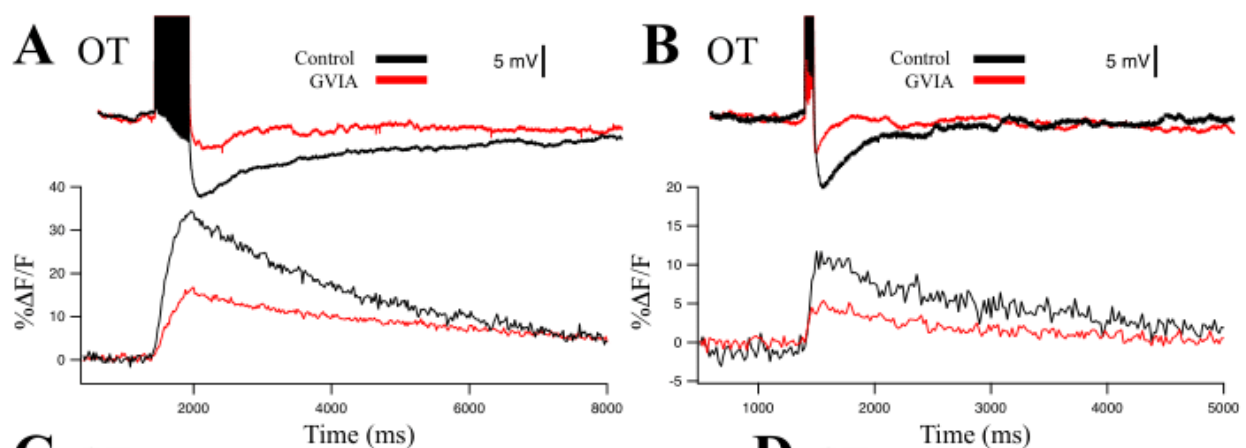

C от

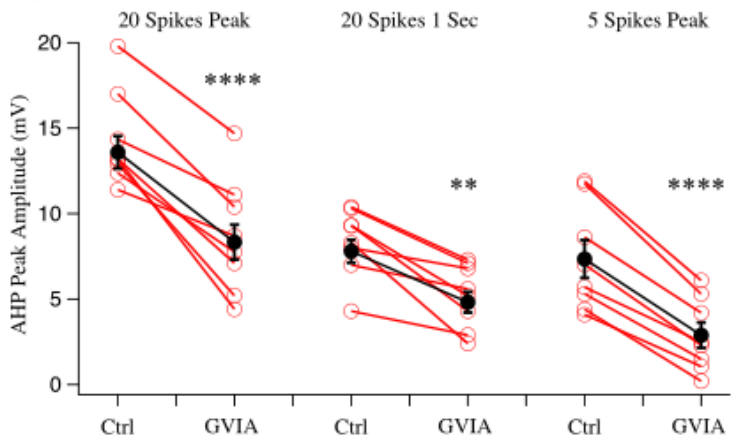

D от
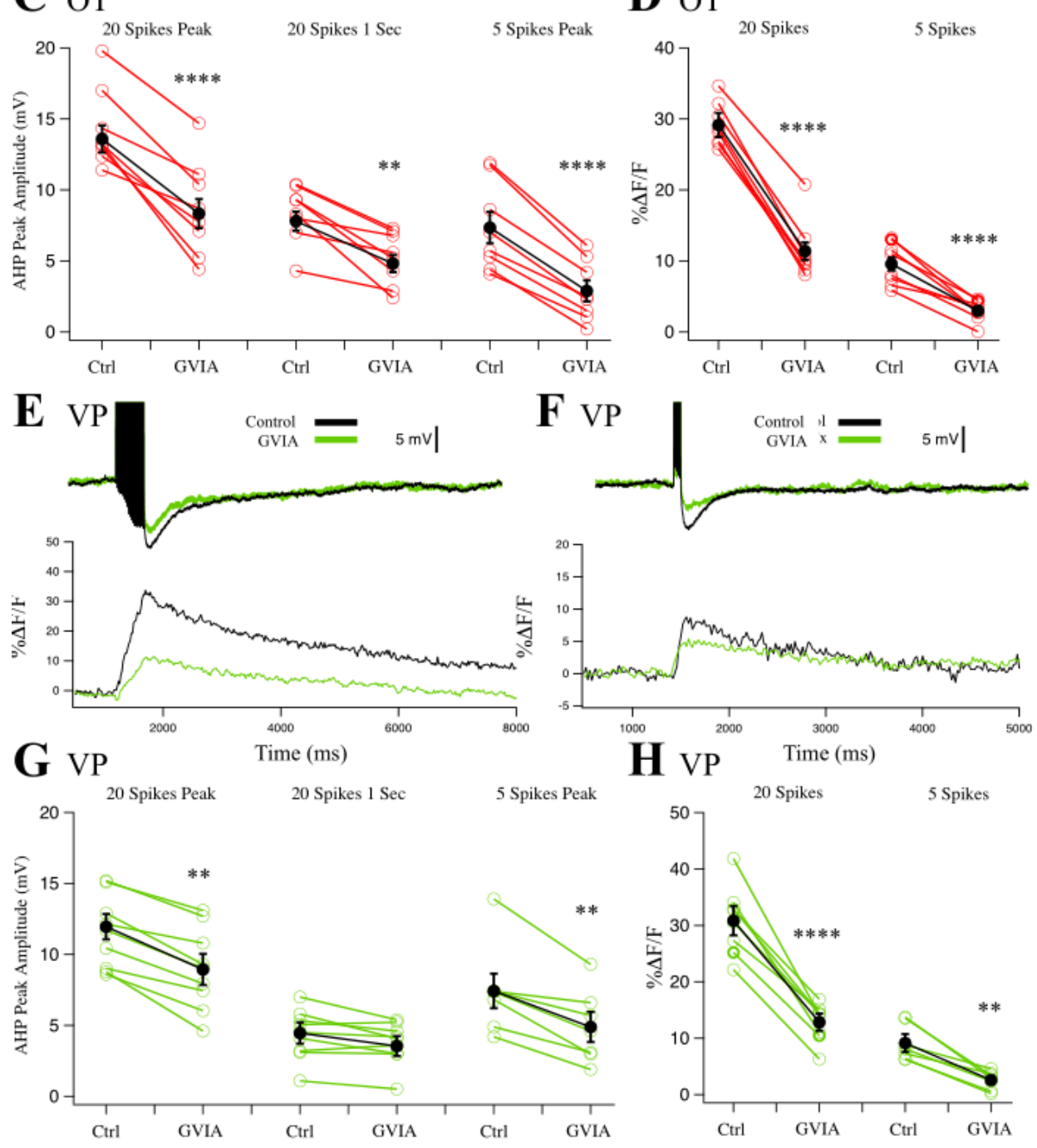
Figure 4-4. Effect of P/Q-type blocker $0.5 \mu \mathrm{M}$ AgTx IVA on AHPs and corresponding $\mathrm{Ca}^{2+}$ transients in OT (A-D) and VP (E-H) neurons.

(A) Example of an AHP after a $20 \mathrm{~Hz}, 20$-spike train from an OT neuron treated with AgTx IVA and its corresponding somatic $\mathrm{Ca}^{2+}$ signal. (B) Example of an AHP after a 20 $\mathrm{Hz}, 5$-spike train from an OT neuron treated with AgTx IVA and its corresponding somatic $\mathrm{Ca}^{2+}$ signal. (C) Summary data for OT neuron AHP measurements at the 20spike peak amplitude (mAHP + sAHP), at $1 \mathrm{sec}$ after the train (sAHP), and 5-spike AHPs at the peak amplitude (mAHP). Red points are individual cells and black points are group averages (paired t-test; $p>0.05$ for all 3 measurements). (D) Summary data for OT neuron $\mathrm{Ca}^{2+}$ transients. AgTx IVA significantly reduced peak $\% \Delta \mathrm{F} / \mathrm{F}$ after 20 -spike AHPs (paired t-test; $\left.{ }^{* *} p<0.01\right)$ and 5-spike AHPs $(p<0.01)$. (E) Example of an AHP after a $20 \mathrm{~Hz}, 20$-spike train from a VP neuron treated with AgTx IVA and its corresponding somatic $\mathrm{Ca}^{2+}$ signal. (F) Example of an AHP after a $20 \mathrm{~Hz}, 5$-spike train from a VP neuron treated with AgTx IVA and its corresponding somatic $\mathrm{Ca}^{2+}$ signal. (G) Summary data for VP neuron AHP measurements at the 20-spike peak amplitude (mAHP + sAHP), at $1 \mathrm{sec}$ after the train (sAHP), and 5-spike AHPs at the peak amplitude $(\mathrm{mAHP})$. Green points are individual cells and black points are group averages (paired ttest; $p>0.05$ for all 3 measurements). (H) AgTx IVA significantly reduced peak $\% \Delta \mathrm{F} / \mathrm{F}$ in 20-spike AHPs $(* p<0.05)$ and 5-spike AHPs $(p>0.05)$. 

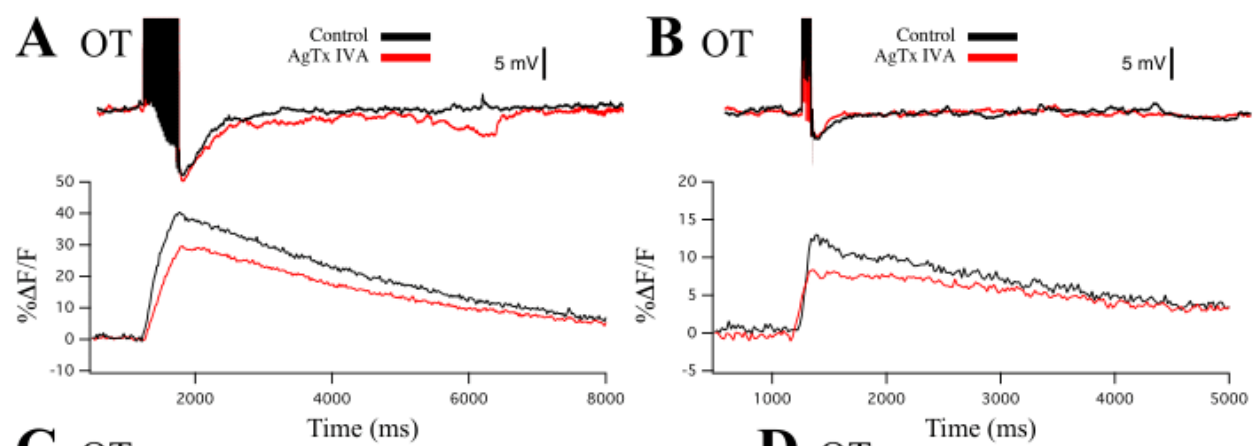

$\mathbf{C}$ от
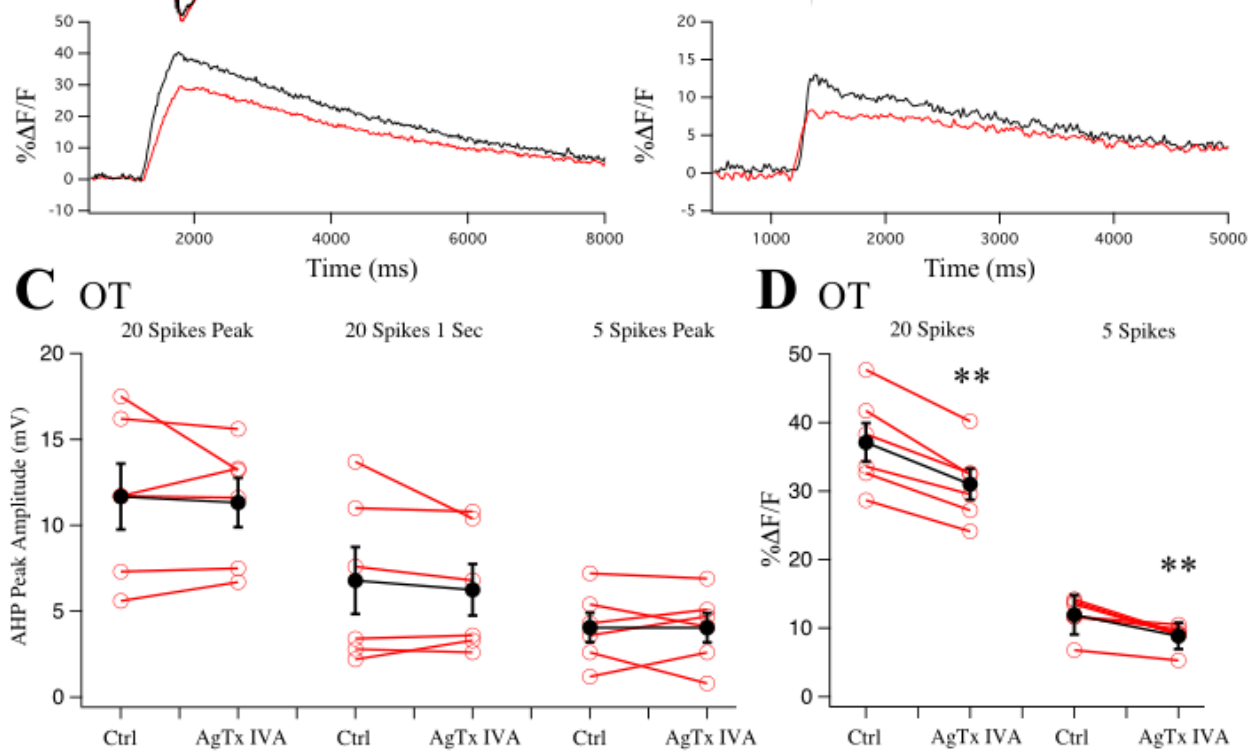

D от
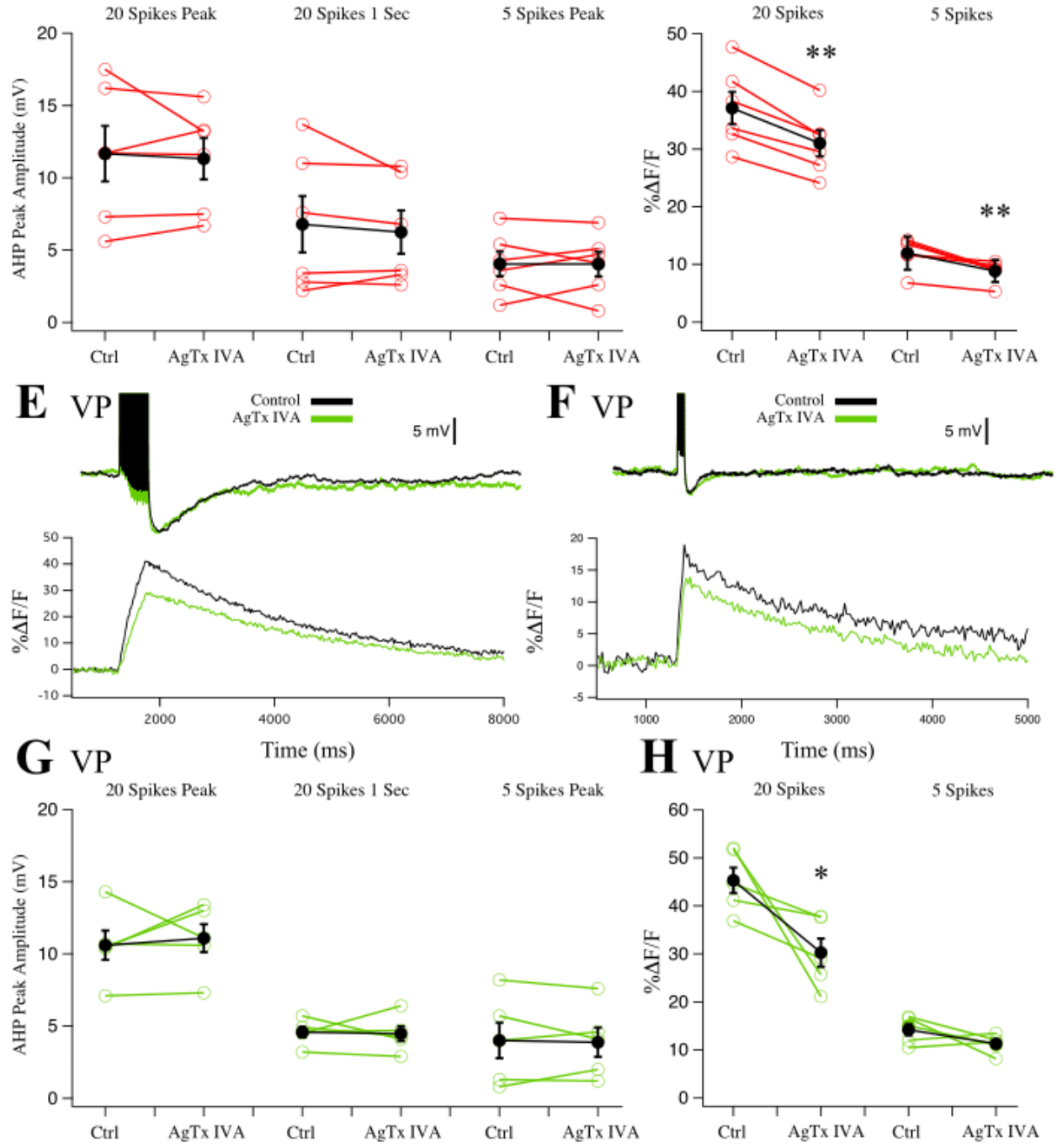

H VP Time (ms)

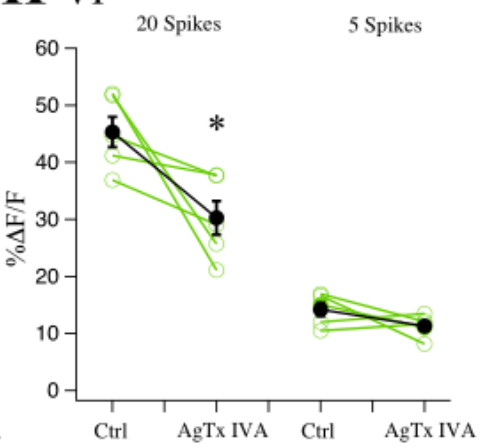


imaging revealed a decrease in peak somatic $\mathrm{Ca}^{2+}$. In OT neurons, AgTx IVA significantly inhibited the 20 -spike $\mathrm{Ca}^{2+}$ peak by $16 \pm 6 \%(p<0.01)$ and the 5 -spike $\mathrm{Ca}^{2+}$ peak by $25 \pm 6 \%(p<0.01)$. In VP neurons, AgTx IVA significantly inhibited the 20spike $\mathrm{Ca}^{2+}$ peak by $33 \pm 5 \%(p<0.04)$. The 5 -spike $\mathrm{Ca}^{2+}$ peak decreased by $20 \pm 5 \%$, but not significantly $(p>0.05)$. Given the lack of effect at $0.5 \mu \mathrm{M}$, we did not test lower concentrations of AgTx IVA to sort P from Q channel contributions.

\section{R-Type Channels}

We also tested the R-type blocker SNX-482 $(0.3 \mu \mathrm{M})$. While a potent blocker of R-type channels, SNX-482 also blocks $I_{\mathrm{A}}$ with high affinity (1-10 nM) (Liu and Bean 2014). Block of $I_{\mathrm{A}}$ increases action potential width in MNCs, increasing $\mathrm{Ca}^{2+}$ influx during spike trains, and consequently altering the AHP amplitude and time course (Bourque 1988; Hlubek and Cobbett 2000). We therefore characterized SNX-482's potentially confounding effects on $I_{\mathrm{A}}$ (Figure 4-5). We initially observed that SNX-482 greatly broadened single spikes (Figure 4-5 $\mathbf{A}_{\mathbf{i}}$ ). This effect mimicked that of 4-AP (4 $\mathrm{mM}$ ), which blocks $I_{\mathrm{A}}$, as well as other Kv channels. SNX-482 only widened APs slightly after prior 4-AP $(4 \mathrm{mM})$ application (Figure 4-5 $\left.\mathbf{A}_{\mathbf{i}}\right)$. Second, we observed a decrease in the transient outward rectifier (Figure 4-5B), similar to the $I_{\mathrm{A}}$ block by 4-AP application reported previously in MNCs (Bourque 1988; Stern and Armstrong 1997; Fisher and Bourque 1998). With these considerations, we quantified the spike broadening of spikes by measuring the half width of the first action potential (AP) of each 20 -spike train (OT $\mathrm{n}=5$; $\mathrm{VP} \mathrm{n}=5$; Figure 4-5C). Neurons dosed with 4-AP $(4 \mathrm{mM})$ showed significantly larger AP half widths in OT $(p<0.05)$ and VP $(p<0.01)$ neurons. Subsequent SNX-482 did not further increase spike width (OT $p>0.05$; VP $p>0.05$ ). These data demonstrate that 4-AP blocks almost all of $I_{\mathrm{A}}$, and that SNX-482 effects on AHPs can't be attributed to changes in spike width. Additionally, 4-AP application increased spike widths more in VP neurons, consistent with previous reports of VP neurons having a larger $I_{\mathrm{A}}$ (Stern and Armstrong 1997; Fisher and Bourque 1998).

Finally, we evaluated spike broadening from the first to the 20th spike during the train. Repetitive activity produces spike frequency dependent broadening (Andrew and Dudek 1985; Bourque and Renaud 1985; Hlubek and Cobbett 2000) which has been shown to increase $\mathrm{Ca}^{2+}$ influx further complicating SNX-482 effects (Jackson et al. 1991). We measured the ratio of the 20th and 1st spike in each train as an index of frequency-dependent broadening (Figure 4-5D). In both OT and VP neurons, spike broadening we observed during the train was significantly inhibited by 4-AP (OT and VP: $p<0.05)$. In 4-AP, the spike broadening index was $1.0 \pm 0.1$ for OT and $0.96 \pm 0.1$ for VP indicating there was almost no change in AP half width during trains in 4-AP. This suggests a majority of the spike broadening in MNCs is the result of $I_{\mathrm{A}}$ inactivation. Further application of SNX-482 to block R-type channels did not significantly alter the spike broadening index $(p>0.05)$. Since changes in AHP amplitude could reflect both changes in spike broadening and consequent $\mathrm{Ca}^{2+}$ entry as well as reduction of $\mathrm{Ca}^{2+}$ channels, we tested the R-type channel effects of SNX-482 on the AHP after pre-applied 4-AP. 

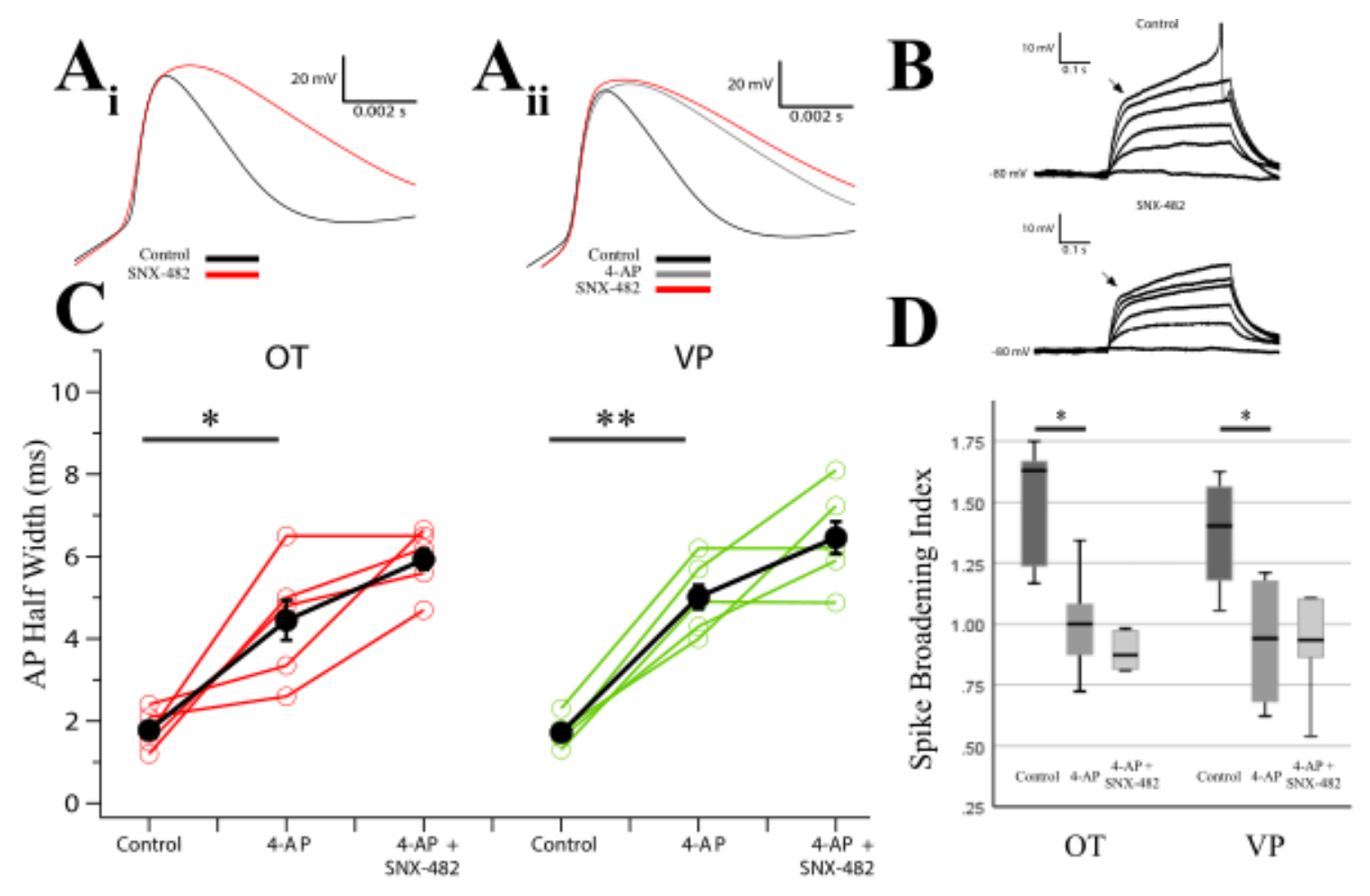

Figure 4-5. SNX-482 blocks transient outward rectification and broadens spikes. $\left(\mathbf{A}_{\mathbf{i}}\right)$ Example of a single action potential from an OT neuron treated with SNX-482 (0.3 $\mu \mathrm{M}$ ) showing obvious broadening of the action potential. ( $\mathbf{A}_{\text {ii) }}$ Example of a single action potential from a different OT neuron than $\left(\mathrm{A}_{\mathrm{i}}\right)$, treated first with $4 \mathrm{mM} 4-\mathrm{AP}$, followed by subsequent application of SNX-482. (B) Step injections of depolarizing current reveal a fast transient outward rectifier that is reduced by SNX-482 in the same cell as $\mathbf{A}_{\mathbf{i}}$. Positive steps (25 pA) were generated from cells at $-80 \mathrm{mV}$. (C) In 20-spike trains, we measured AP half width of the first spike. In OT and VP neurons, 4-AP results in significant spike broadening (OT: ${ }^{*} p<0.05$; VP: $\left.{ }^{* *} p<0.01\right)$. Subsequent application of SNX-482 produced no further broadening $(p>0.05)$. (D) Changes in spike broadening between the first and 20th spike in a train represented as the ratio of AP half width between the two spikes. Values greater than 1 indicate spike-dependent broadening while values lower than 1 indicate narrowing. Application of 4-AP significantly reduced spike-dependent broadening within the 20 -spike train in both cell types $(* p<0.05)$. Subsequent application of SNX-482 does not significantly reduce the spike broadening index compared to 4-AP alone. 
We evaluated R-type channel contribution to AHPs in MNCs (Figure 4-6). In AHP measurements from both OT and VP neurons, 4-AP enhanced 20-spike AHP amplitude, spike width, and the corresponding $\mathrm{Ca}^{2+}$ transients, suggesting that the broader spikes increased $\mathrm{Ca}^{2+}$ entry. In OT neurons the AHP enhancement was significant for 20 spikes at peak $(20 \pm 10 \%$ increase $)$ and $1 \mathrm{sec}(71 \pm 11 \%$ increase $)(p<0.05$ for both $)$. In VP neurons, the measurement at $1 \mathrm{sec}$ after 20 spikes was significant ( $60 \pm 12 \%$ increase; $p<0.05)$ while the peak measurement was not significant $(16 \pm 26 \%$ increase; $p>0.05)$. The 5-spike AHP was unaffected by 4-AP in either cell type $(p>0.05)$.

The corresponding OT $\mathrm{Ca}^{2+}$ transients were significantly increased by 4-AP application in 20-spike AHPs by $15 \pm 5 \%$ (Control vs. 4-AP $p<0.05$ ) and 5-spike AHPs by $31+8 \%$ (Control vs. 4-AP $p<0.05$ ). Likewise, VP $\mathrm{Ca}^{2+}$ transients in 20 - and 5-spike peaks significantly increased after 4 -AP by $21 \pm 6 \%$ and $38 \pm 2 \%$, respectively $(20$ spikes: Control vs. 4-AP $p<0.05 ; 5$ spikes: Control vs. 4-AP $p<0.05$ ). These data were also consistent with the notion that broader spikes after 4-AP increased $\mathrm{Ca}^{2+}$ entry.

While OT neurons demonstrated no significant inhibition of the AHP after subsequent application of SNX-482, the response of VP neurons was different. Here SNX-482 significantly reduced 20-spike AHPs at peak by $15 \pm 8 \%$ and $1 \mathrm{sec}$ by $26 \pm$ $11 \%$ after 4-AP application (20-spike peak: 4-AP vs. 4-AP + SNX $p<0.05 ; 20$-spike 1 sec: 4-AP vs. 4-AP + SNX $p<0.05)$. This was despite the further increase in AP width in SNX-482 after 4-AP (see above). SNX-482 did not significantly affect 5-spike peaks ( $p$ $>0.05)$.

These differential responses may be due to different $\mathrm{Ca}^{2+}$ channel contribution to $\mathrm{Ca}^{2+}$ entry. Application of SNX-482 in OT neurons inhibited the 20 -spike $\mathrm{Ca}^{2+}$ peak by only $15 \pm 5 \%(4-\mathrm{AP}$ vs. 4 -AP $+\mathrm{SNX} p<0.05)$ and the 5 -spike $\mathrm{Ca}^{2+}$ peak by only $22 \pm$ $10 \%$ (4-AP vs. 4-AP + SNX $p<0.05)$. However, SNX-482 inhibited the 20 -spike Ca ${ }^{2+}$ peak by $45 \pm 6 \%$ (4-AP vs. 4 -AP + SNX $p<0.05$ ) and the 5 -spike $\mathrm{Ca}^{2+}$ peak by $45 \pm 5 \%$ (4-AP vs. 4-AP + SNX $p<0.05)$ in VP neurons. The simplest interpretation of the significant reduction of the sAHP and the stronger inhibition of peak $\mathrm{Ca}^{2+}$ in VP neurons is that R-type contribution to the sAHP is larger in VP neurons. Because SNX-482 block of R-type channels does not result in spike narrowing during the trains (Figure 4-5), this inhibition is unlikely due to a decreased level of depolarization during the train, that might allow less $\mathrm{Ca}^{2+}$ influx.

\section{N-Type Block with Subsequent P/Q Block}

While OT neurons show considerable mAHP and sAHP inhibition by GVIA, VP neurons demonstrated significantly less inhibition by comparison. N-type block does significantly reduce the mAHP in VP neurons, but our evidence suggests no single HVA channel is strictly coupled to the AHP in VP neurons. It's possible that VP neurons would then have enough $\mathrm{Ca}^{2+}$ entry to generate a robust sAHP, even in the presence of any single $\mathrm{Ca}^{2+}$ channel blocker. To test this idea, we bath-applied $1 \mu \mathrm{M}$ GVIA followed by a subsequent application of $1 \mu \mathrm{M}$ MVIIC, which blocks N- and P/Q-type channels (Figure 4-7). All reported percentages reflect a percent change between the two groups stated. 
Figure 4-6. Effect of R-type blocker SNX-482 (0.3 $\mu \mathrm{M})$ on AHPs and their corresponding $\mathrm{Ca}^{2+}$ transients in OT (A-D) and VP (E-H) neurons.

4-AP was pre-applied to block Kv4 channels and isolate SNX-482's effect on R-type $\mathrm{Ca}^{2+}$ channels. (A) Example of an AHP after a $20 \mathrm{~Hz}, 20$-spike train from an OT neuron and its corresponding somatic $\mathrm{Ca}^{2+}$ signal. (B) Example of an AHP after a $20 \mathrm{~Hz}, 5$-spike train from an OT neuron and its corresponding somatic $\mathrm{Ca}^{2+}$ signal. (C) Summary data for OT neuron AHP measurements at the 20-spike peak amplitude (mAHP + sAHP), at 1 sec after the (sAHP), and 5-spike AHPs at the peak amplitude (mAHP). Red points are individual cells and black points are group averages. After 20 spikes, 4-AP significantly increased the AHP at peak and $1 \mathrm{sec}$ in 20 spike AHPs $\left({ }^{*} p<0.05\right)$. Subsequent application of SNX-482 did not significantly reduce the AHP compared to 4-AP. 5-spike AHPs were unaffected. (D) Summary data for OT neuron peak $\mathrm{Ca}^{2+}$ transients during AHP stimulation in 20-spike AHPs and in 5-spike AHPs. 4-AP increased $\mathrm{Ca}^{2+}$ transients significantly in 20 -spike trains $(* p<0.05)$, and successive SNX-482 significantly inhibited the $\mathrm{Ca}^{2+}$ signal compared to 4 -AP after both 20 - and 5 -spikes $\left({ }^{*} p<0.05\right)$. (E) Example of an AHP after a 20 -spike train from a VP neuron and its corresponding somatic $\mathrm{Ca}^{2+}$ signal. (F) Example of an AHP after a 5-spike train from a VP neuron and its corresponding somatic $\mathrm{Ca}^{2+}$ signal. (G) Summary data for VP neuron AHP measurements at the 20-spike peak amplitude (mAHP + sAHP), at one sec after the train (sAHP), and 5-spike AHPs at the peak amplitude (mAHP). Green points are individual cells and black points are group averages. 4-AP significantly increased the 20-spike AHP at $1 \sec (* * p<0.01)$. Subsequent SNX-482 significantly reduced the 20 -spike peak and 1 sec AHP when compared to 4-AP alone $(* p<0.05)$. 5-spike AHPs were unaffected. (H) Summary data for VP neuron peak $\mathrm{Ca}^{2+}$ transients in 20-spike AHPs and 5-spike AHPs. 4-AP and significantly increased $\mathrm{Ca} 2+$ in the 20 -spike $\left({ }^{*} p<0.05\right)$ and 5 -spike $(* * p<$ 0.01 ) protocol. Subsequent SNX-482 significantly decreased $\mathrm{Ca}^{2+}$ transients in both 20 and 5-spike AHPs $(* * p<0.01)$. 

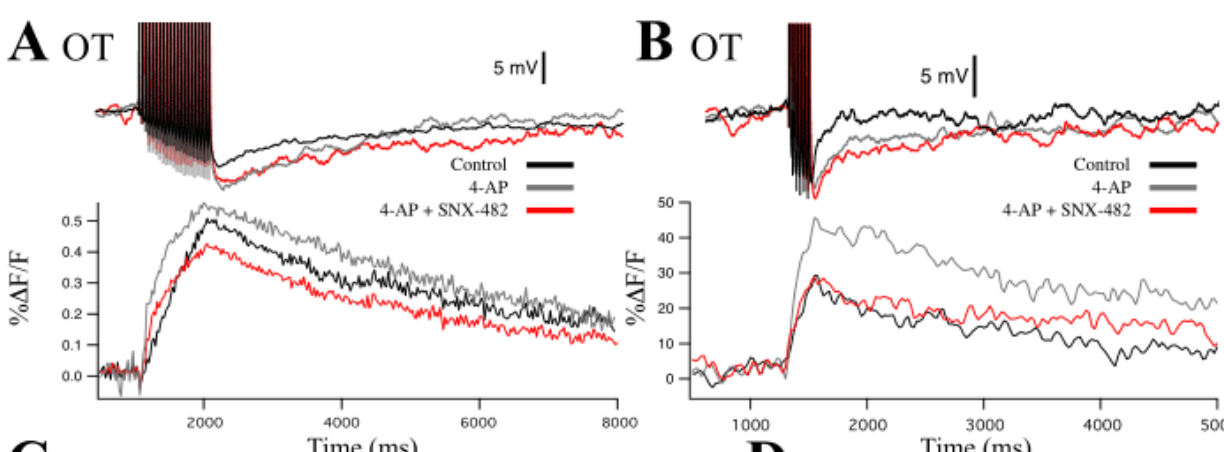

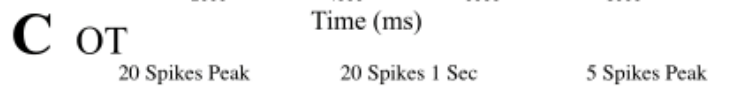
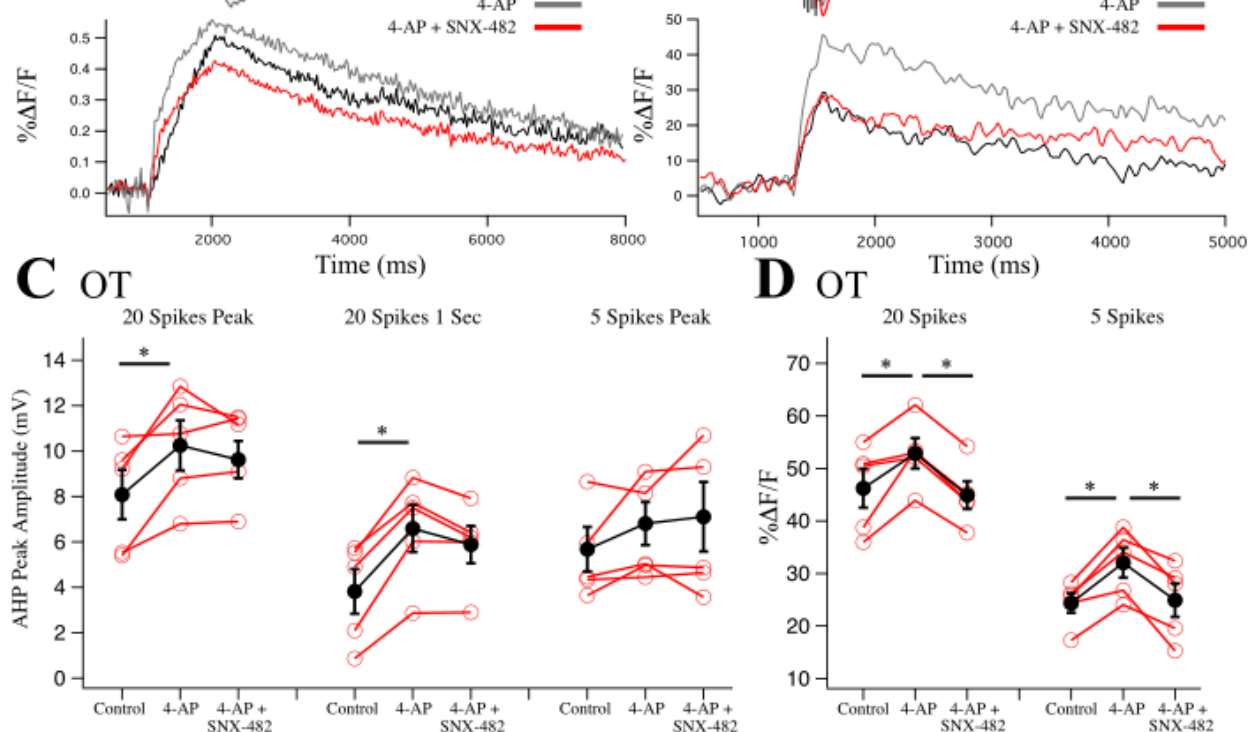

D OT ${ }_{20 \text { Spikes }}$ Time (ms)

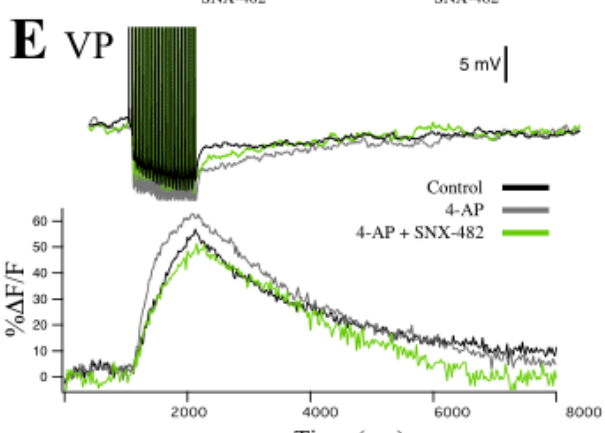

G VP
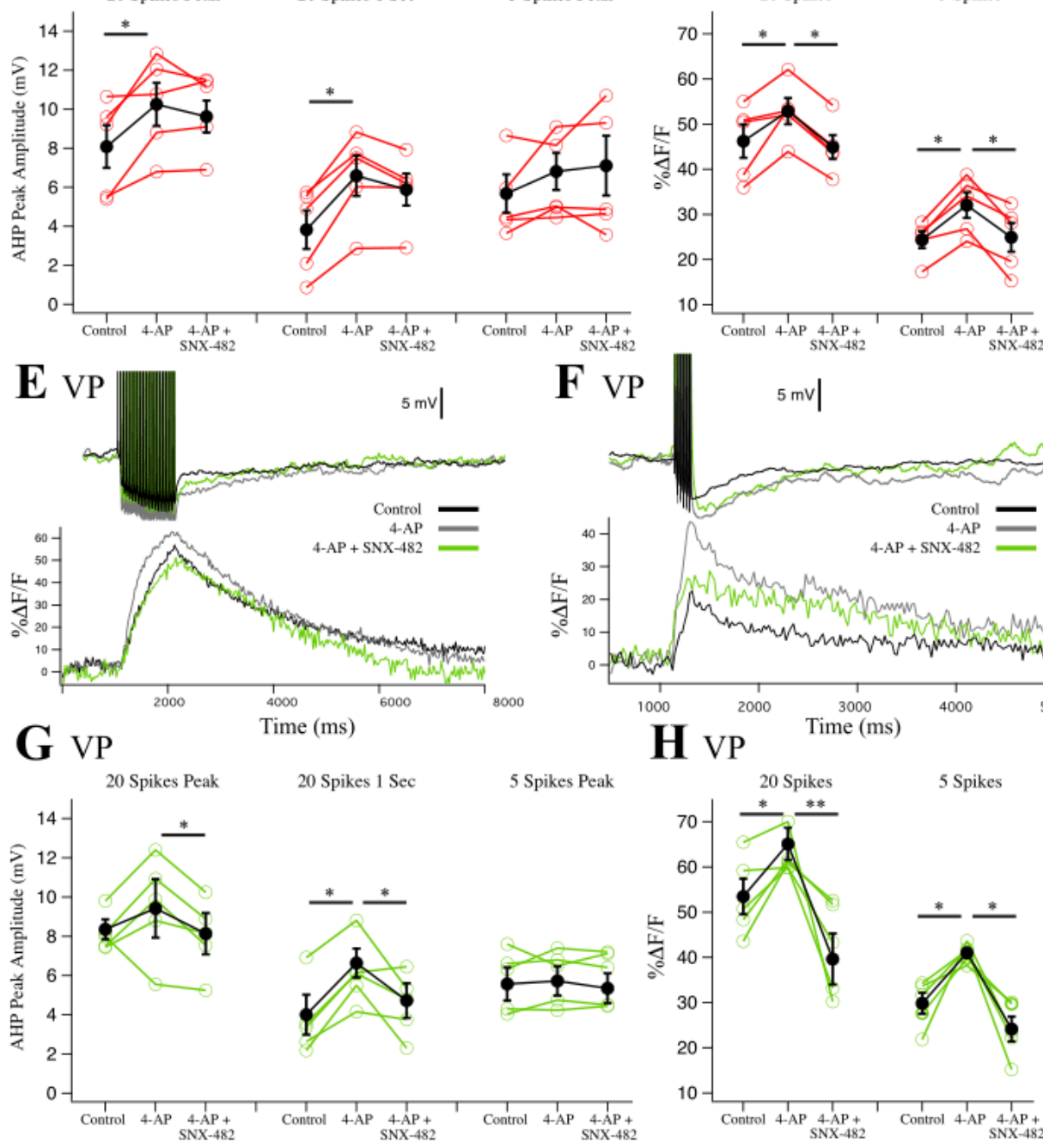

H VP

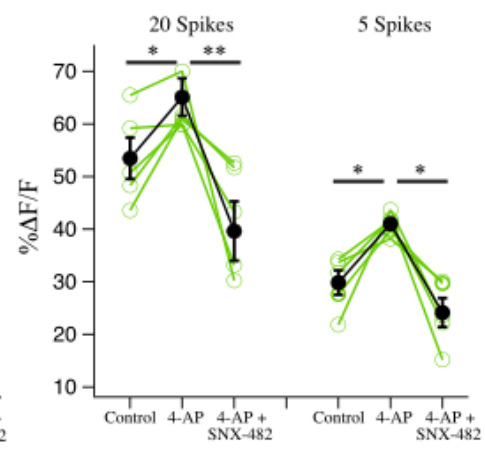


Figure 4-7. $\quad$ N-type blocker $1 \mu \mathrm{M}$ CnTx GVIA and subsequent block with $1 \mu \mathrm{M}$ CnTx MVIIC on AHPs and corresponding $\mathrm{Ca}^{2+}$ transients in OT (A-D) and VP (EH) neurons.

(A) Example of an AHP after a $20 \mathrm{~Hz}, 20$-spike train from an OT neuron and its corresponding somatic $\mathrm{Ca}^{2+}$ signal. (B) Example of an AHP after a $20 \mathrm{~Hz}, 5$-spike train from an OT neuron and its corresponding somatic $\mathrm{Ca}^{2+}$ signal. (C) Summary data for OT neuron AHP measurements at the 20-spike peak amplitude (mAHP + sAHP), at $1 \mathrm{sec}$ after the (sAHP), and 5-spike AHPs at the peak amplitude (mAHP). Red points are individual cells and black points are group averages. At all measurements, GVIA significantly reduced the AHP (20-spike peak ** $p<0.01 ; 1$ sec \& 5-spike peak * $p<$ 0.05). Subsequent application of MVIIC reduced the AHP further at the 20-spike peak compared to control $(* * p<0.01)$. (D) Summary data for OT neuron peak $\mathrm{Ca}^{2+}$ transients during AHP stimulation in 20-spike AHPs and in 5-spike AHPs. GVIA significantly reduced 20 -spike $(* p<0.0001)$ and 5-spike $(* p<0.01) \mathrm{Ca}^{2+}$. Subsequent MVIIC significantly inhibited 20 -spike $\left({ }^{*} p<0.05\right)$ and 5 -spike $\left({ }^{*} p<0.05\right) \mathrm{Ca}^{2+}$ further. (E) Example of an AHP after a $20 \mathrm{~Hz}, 20$-spike train from a VP neuron and its corresponding somatic $\mathrm{Ca}^{2+}$ signal. (F) Example of an AHP after a $20 \mathrm{~Hz}, 5$-spike train from a VP neuron and its corresponding somatic $\mathrm{Ca}^{2+}$ signal. (G) Summary data for VP neuron AHP measurements at the 20-spike peak amplitude (mAHP + sAHP), at $1 \mathrm{sec}$ after the train (sAHP), and 5-spike AHPs at the peak amplitude (mAHP). Green points are individual cells and black points are group averages. CnTx GVIA consistently reduced the AHP, but to a lesser degree compared to OT neurons $(p>0.05)$. Subsequent CnTx MVIIC significantly reduced the 20-spike peak AHP when compared to GVIA alone $\left({ }^{*} p<0.05\right)$ and in $1 \mathrm{sec}$ after the pulse when compared to Controls $\left({ }^{*} p<0.05\right)$. (H) Summary data for VP neuron peak $\mathrm{Ca}^{2+}$ transients in 20-spike AHPs and 5-spike AHPs. CnTx GVIA significantly reduced $\mathrm{Ca} 2+$ transients in both protocols $(* p<0.05)$. Subsequent MVIIC significantly reduced $\mathrm{Ca}^{2+}$ transients in both $20-\left({ }^{*} p<0.05\right)$ and 5-spike $(* * p<0.01)$ AHPs. 
A oт

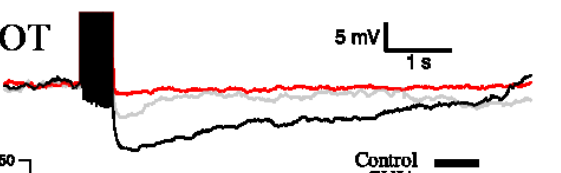

B ot
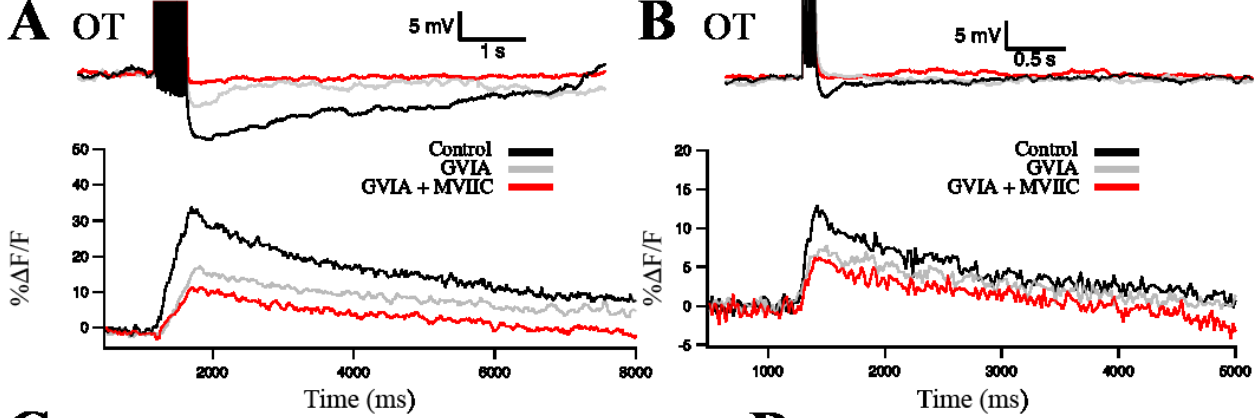

C от
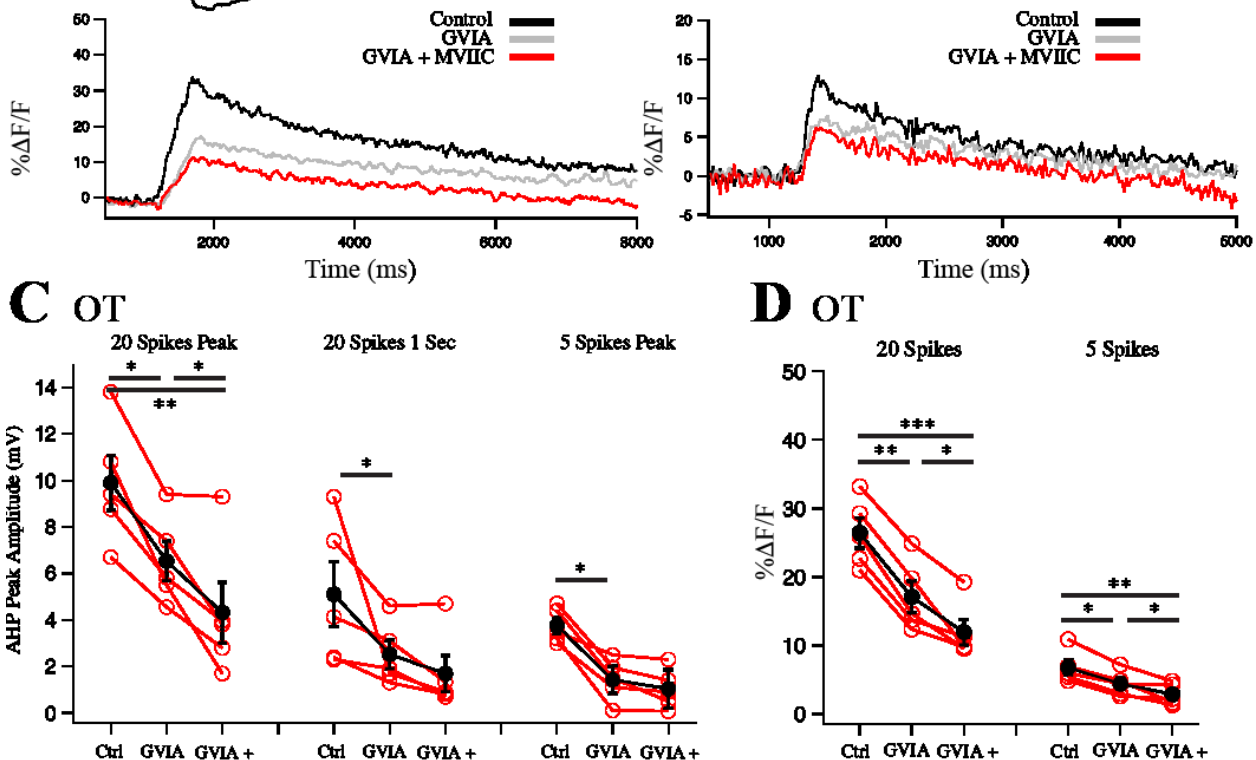

Curl GVIA GVIA MVIC $^{+}$Cirl GVIA GVIA ${ }^{+}$Curl GVIA GVIA ${ }^{+}$

D oт
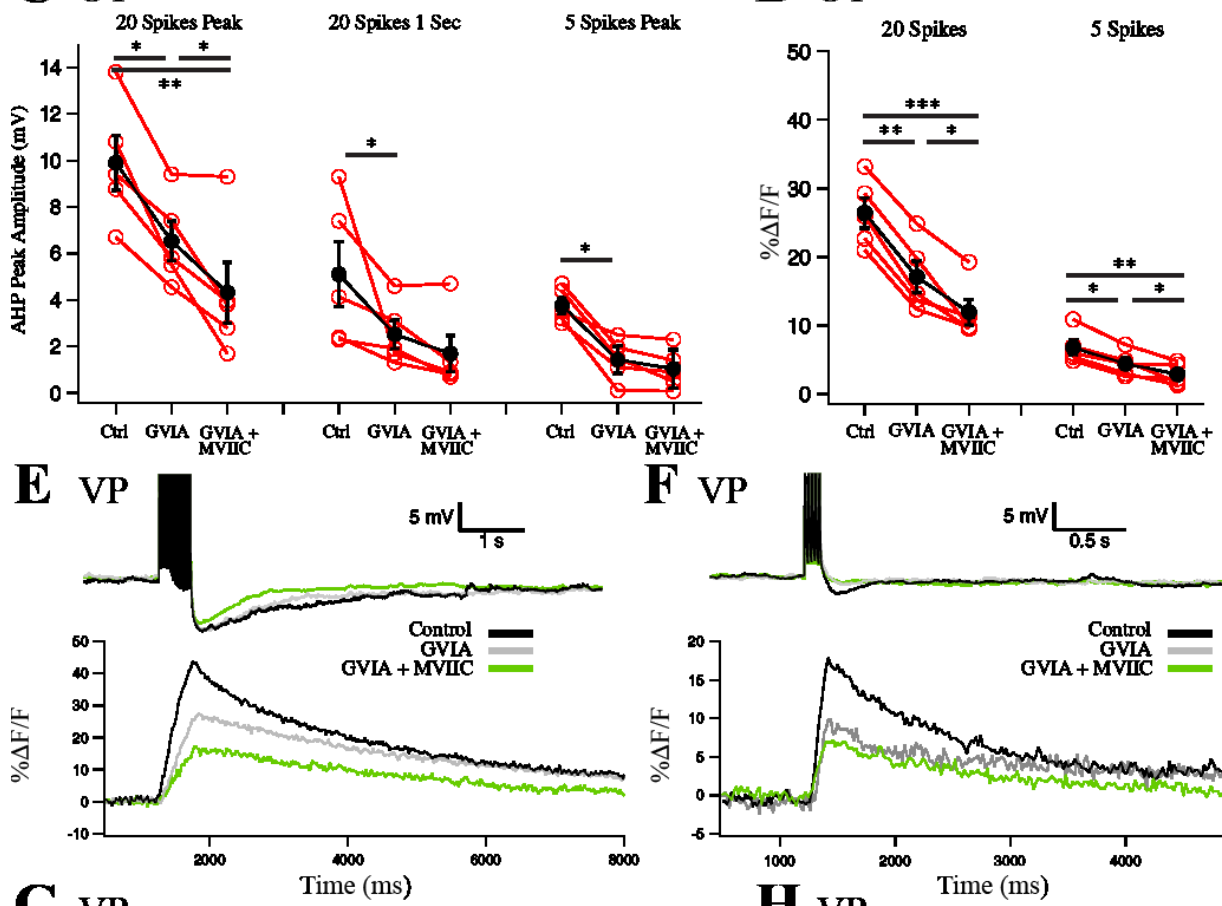

G VP
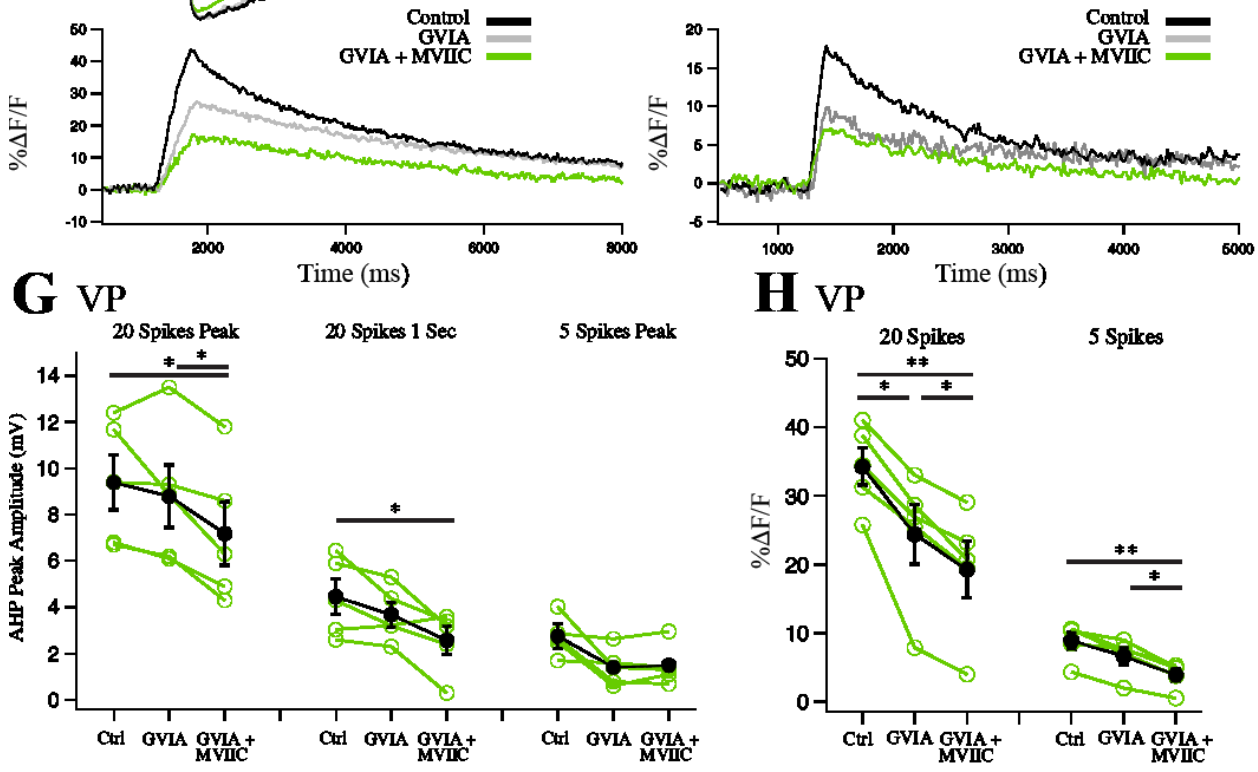
OT neurons responded to GVIA as previously, displaying significantly reduced 20 -spike AHPs at peak $(33 \pm 12 \%$ inhibition; $p<0.05), 1 \mathrm{sec}(49 \pm 15 \%$ inhibition; $p<0.05)$, and 5 spike AHP peak $(55 \pm 8 \%$ inhibition; $p<0.05)$. Successive addition of MVIIC further reduced the 20-spike peak AHP (GVIA vs. GVIA+MVIIC: $34 \pm 13 \%$ inhibition, $p<$ 0.05; Control vs. GVIA+MVIIC: $56 \pm 13 \%$ inhibition, $p<0.01)$. It had no further effect on 5 spike AHPs $(p>0.05)$. The corresponding 20 spike peak $\mathrm{Ca}^{2+}$ transients were significantly inhibited in cells treated with GVIA by $35 \pm 4 \%(p<0.01)$ and subsequent GVIA + MVIIC by $30 \pm 6 \%(p<0.05) .5$-spike peak $\mathrm{Ca}^{2+}$ transients were significantly reduced after GVIA by $35 \pm 3 \%(p<0.05)$, and after MVIIC by $35 \pm 6 \%(p<0.05)$. Ntype block accounted for much of the sAHP in OT neurons, while subsequent $\mathrm{P} / \mathrm{Q}$ channel block had little effect. Additionally, we observed a reduction in $\mathrm{Ca}^{2+}$ transients in both GVIA and GVIA + MVIIC signifying block of the channels.

As before, VP neurons showed a modest reduction in AHP amplitude following GVIA. In these experiments, the mAHP block was not significant (5-spike Control vs. GVIA: $p>0.05$ ), as was the sAHP (20-spike peak Control vs. GVIA: $p>0.05 ; 20$-spike $1 \mathrm{sec}$ Control vs. MVIIC: $p>0.05)$. Subsequent addition of MVIIC significantly reduced the AHP measured at the 20-spike peak (GVIA vs. GVIA+MVIIC: $18 \pm 15 \%$ inhibition, $p<0.05)$. At $1 \mathrm{sec}$ after the pulse, the difference between controls and the combined toxins was significant (Control vs. GVIA + MVIIC: $43 \pm 13 \%$ inhibition, $p<0.05$ ). mAHP measurements showed no further reduction by MVIIC (GVIA vs. MVIIC: $p>$ 0.05 , Control vs. GVIA+MVIIC: $p>0.05)$. Corresponding $\mathrm{Ca}^{2+}$ peak transients were reduced in all cases for both 20-spike (Control vs. GVIA: $28 \pm 5 \%$ inhibition, $p<0.05$, GVIA vs. GVIA+MVIIC: $20 \pm 7 \%$ inhibition, $p<0.05$ ) and 5-spike AHPs (Control vs. GVIA: $24 \pm 12 \%$ inhibition, $p>0.05$; GVIA vs. GVIA+MVIIC: $22 \pm 4 \%$ inhibition, $p<$ 0.05). Thus, while P/Q-type block alone was insufficient to reduce VP sAHPs, it significantly reduced sAHPs when combined with N-type block.

\section{Discussion}

We tested which HVA $\mathrm{Ca}^{2+}$ channels elicit the medium and slow phases of AHPs in OT- and VP-releasing neurons of the SON. Our lab has previously observed distinct mechanistic differences in AHP generation between OT and VP neurons (Kirchner et al. 2017), spurring interest in the possibility of cell-type differences in coupling of $\mathrm{Ca}^{2+}$ channel types to AHPs. The present study demonstrates that $\mathrm{Ca}^{2+}$ channel contributions differ between OT and VP cells.

\section{The Major Contribution of N-type Channels to the AHP}

In both cell types studied, N-type channels appear to be the most influential of the HVA types for $\mathrm{Ca}^{2+}$-dependent AHP generation. OT neurons show especially strong reduction in the mAHP and SAHP after GVIA application. The coupling to the mAHP was the strongest, but there is also a major contribution to the sAHP. Thus, N-type channels provide the primary source of $\mathrm{Ca}^{2+}$ for both the mAHP and sAHP in OT neurons. It is important to note that some sAHP remains in OT neurons after N-type 
channel block, suggesting that other sources of $\mathrm{Ca}^{2+}$ exist for OT sAHPs as well. Block of the other individual HVA $\mathrm{Ca}^{2+}$ channels had no effect on the AHP in these cells. Block of $\mathrm{P} / \mathrm{Q}$ channels produces a significant reduction in sAHP if N-type channels are already blocked, suggesting that $\mathrm{P} / \mathrm{Q}$ channels can compensate in the absence of $\mathrm{N}$-type channels.

N-type channels also couple to mAHPs in VP neurons; GVIA significantly reduces the mAHP. However the percent inhibition by GVIA is significantly less in VP neurons compared to OT despite similar inhibition of $\mathrm{Ca}^{2+}$ transients between the cell types. Perhaps this is related to our group's finding that depletion of $\mathrm{PIP}_{2}$ simultaneously inhibits AHPs in OT while leaving VP cells unaffected (Kirchner et al. 2017). Like OT neurons, GVIA is the only HVA channel toxin that we tested that affected VP mAHPs. Like OT neurons, if $\mathrm{N}$-type channels are unavailable $\mathrm{P} / \mathrm{Q}$ channels can provide $\mathrm{Ca}^{2+}$ to the sAHP.

\section{Corresponding $\left[\mathrm{Ca}^{2+}\right]_{\mathrm{i}}$ Signals in MNCs}

Regardless of whether or not an HVA $\mathrm{Ca}^{2+}$ channel blocker was able to affect the AHP, we consistently observed a significant reduction in cytoplasmic $\left[\mathrm{Ca}^{2+}\right]_{i}$ after each application, indicating the toxins were effectively blocking $\mathrm{Ca}^{2+}$ channels. We acknowledge that summation of toxin effects on $\left[\mathrm{Ca}^{2+}\right]_{i}$ from all experiments exceeds $100 \%$. There are a few reasons for this. First, we compared populations of cells where there was individual variation in expression levels of HVA channels types between cells. Second, since preapplication of 4-AP increases $\left[\mathrm{Ca}^{2+}\right]$ i, percent reduction by SNX-482 will be skewed because $\mathrm{Ca}^{2+}$ inhibition is not being compared to the cell at the control peak $\left[\mathrm{Ca}^{2+}\right]_{\mathrm{i}}$ value. Finally, while $\mathrm{Ca}^{2+}$ channel toxins are highly selective (Pringos et al. 2011), there is some overlap in targets (Gandía et al. 1995; Lorenzon and Foehring 1995b; Foehring and Armstrong 1996).

The $\left[\mathrm{Ca}^{2+}\right]_{\text {i }}$ reduction after $\mathrm{N}$-type block is the greatest of all the blockers in both cell types. This indicates MNCs contain a large population of N-type channels, as reported previously (Fisher and Bourque 1996; Foehring and Armstrong 1996; Lemos et al. 2012).

As discussed earlier, SNX-482 blocks $I_{\mathrm{A}}$ in addition to R-type channels, resulting in larger AP half widths. This broadening was coincident with an increased in $\left[\mathrm{Ca}^{2+}\right]_{\mathrm{i}}$, and posed a potential confound for our evaluation of SNX-482 alone on the $\mathrm{Ca}^{2+}$ dependent AHP. After 4-AP block of A-current, we observed a significant reduction in $\left[\mathrm{Ca}^{2+}\right]_{i}$ after SNX-482 despite no change in the spike broadening index (Figure 4-5), demonstrating its ability to block R-type channels independent of changes in spike width.

\section{Strict Coupling of mAHPs to $\mathrm{Ca}^{2+}$ Microdomains}

mAHPs in other cell types are often exclusively coupled to a specific $\mathrm{HVA} \mathrm{Ca}^{2+}$ channel (Sah 1995; Vogalis et al. 2001). This strict coupling is consistent with SK channel activation by microdomains of $\mathrm{Ca}^{2+}$, suggesting that $\mathrm{Ca}^{2+}$ channels must be in 
close proximity to the SK channels and that bulk $\mathrm{Ca}^{2+}$ would be a poor indicator of $\left[\mathrm{Ca}^{2+}\right]_{\mathrm{i}}$ at the membrane (Neher 1998; Hallworth et al. 2003; Fakler and Adelman 2008). In neocortical pyramidal neurons, the relationship between the mAHP and bulk $\mathrm{Ca}^{2+}$ is poor (Abel et al. 2004), consistent with its activation from microdomains concentrated near the membrane. Our results are also consistent with this idea, as GVIA is the only toxin to inhibit mAHPs in OT and VP neurons, despite the other toxins' ability to reduce $\left[\mathrm{Ca}^{2+}\right]_{\mathrm{i}}$.

\section{Coupling of $\mathrm{Ca}^{2+}$ to the sAHP in VP Neurons}

$\mathrm{Cd}^{2+}$ effectively blocks both mAHPs and sAHPs in both cell types, indicating dependence on $\mathrm{Ca}^{2+}$ entry. However, only block of $\mathrm{N}$-type channels resulted in a decisive reduction in OT mAHPs or sAHPs. N-type channels are coupled to mAHPs in VP neurons as well, but only after R-type block (Figure 4-6) was the sAHP was inhibited in VP neurons. While N-type (OT) or R-type (VP) channels may be the preferred $\mathrm{Ca}^{2+}$ source, it is possible that block of the preferred $\mathrm{Ca}^{2+}$ channels could reveal other $\mathrm{Ca}^{2+}$ channels with looser coupling to the sAHP, as is suggested by the cells treated with MVIIC after GVIA. This could be facilitated by the slow kinetics of the sAHP. In other cell types there is lower specificity in the coupling of $\mathrm{Ca}^{2+}$ channels to the sAHP compared to the mAHP (Lorenzon and Foehring 1992; Ghamari-Langroudi and Bourque 2004). This may also explain why $\mathrm{Cd}^{2+}$ is such a potent blocker of the AHP compared to GVIA or SNX-482.

It has been proposed that there is an intermediate step between $\mathrm{Ca}^{2+}$ entry and activation of the sAHP (reviewed in Andrade et al. 2012). In this model cytoplasmic $\mathrm{Ca}^{2+}$ binding proteins act as the calcium sensor for the sAHP. Evidence consistent with a cytoplasmic $\mathrm{Ca}^{2+}$ sensor for the sAHP includes experiments where ablation of cytoplasmic calcium binding proteins (e.g., hippocalcin, visinin-like calcium binding, and calcineurin) resulted in substantial sAHP inhibition of myenteric and hippocampal neurons (Vogalis et al. 2004; Tzingounis et al. 2007; Villalobos and Andrade 2010). Another possible source for $\mathrm{Ca}^{2+}$ is from intracellular stores, which contribute to sAHPs in hippocampal neurons (Torres et al. 1996; van de Vrede et al. 2007) and immature neocortical pyramidal neurons (Pineda et al. 1998). It is possible that the sAHP in VP neurons is activated by $\mathrm{Ca}^{2+}$-induced $\mathrm{Ca}^{2+}$ release from internal stores, resulting in AHP resistance to block by specific $\mathrm{Ca}^{2+}$ channel blockers. One final source could be from transient, low voltage activated (LVA) T-type $\mathrm{Ca}^{2+}$ channels. While the presence of Tchannels in MNCs has been reported (Erickson et al. 1993; Fisher and Bourque 1995),

others report little low threshold $\mathrm{Ca}^{2+}$ current (Foehring and Armstrong 1996; Luther and Tasker 2000; Luther et al. 2002). An LVA type current sensitive to $\mathrm{Ni}^{2+}$ was shown to contribute to the depolarizing afterpotential in guinea pig SONs (Erickson et al. 1993).

\section{Conclusions}

These studies revealed the HVA channel sources of $\mathrm{Ca}^{2+}$ to the AHP in MNCs. Briefly, in OT and VP neurons of the SON, it appears that mAHP generation reflects 
activation of only N-type channels, though to a significantly less degree in VP compared to OT neurons. We observed cell type specific preferential coupling of the sAHP with specific $\mathrm{Ca}^{2+}$ channels: N-type for OT neurons and R-type for VP neurons. This reinforces mechanistic differences of AHP generation between cell types, some of which might underlie PIP2's differential modulation of AHPs by affecting HVA currents (Kirchner et al. 2017). 


\section{CHAPTER 5. PIP2 MODULATION OF CALCIUM CHANNEL CURRENTS IN SON}

\section{Introduction}

Voltage-gated $\mathrm{Ca}^{2+}(\mathrm{Cav})$ channels regulate transmembrane $\mathrm{Ca}^{2+}$ influx in neurons throughout the brain by opening in response to membrane depolarization. Elevated $\mathrm{Ca}^{2+}$ as a result of this influx activates neurotransmission, second messenger pathways, ion channels, and gene expression (Catterall 2011). There are five members of the $\mathrm{Ca}_{\mathrm{V}}$ family named L-, N-, P/Q-, R-, and T-type divided into two general groups based on their voltage dependence, the high-voltage (HVA) and low-voltage activated (LVA) channels. T-type channels are the only members of the LVA group while the other four occupy the HVA group. In addition to activation by shifts in membrane voltage, these channels are modulated by an array of mechanisms including auxiliary $\beta$-subunits, calmodulin, G-proteins, and second messenger $\mathrm{Ca}^{2+}$.

Plasma membrane-bound phospholipid phosphatidylinositol 4,5 bisphosphate $\left(\mathrm{PIP}_{2}\right.$ ) regulates Cav channels (Suh et al. 2010; Hille et al. 2015). $\mathrm{PIP}_{2}$ is a long chain phospholipid found on the inner leaflet of cell membranes and it is critically involved in the maintenance of the $\mathrm{IP}_{3} / \mathrm{DAG}$ second messenger pathway. $\mathrm{PIP}_{2}$ levels are constitutive. In other words, molecules of $\mathrm{PIP}_{2}$ are constantly generated and broken down, this production is cyclical and tonic, and a basal population of $\mathrm{PIP}_{2}$ molecules is constantly maintained regardless of a cell's current $\mathrm{PIP}_{2}$ demand (Xu et al. 2003). In addition to the $\mathrm{IP}_{3} / \mathrm{DAG}$ pathway, $\mathrm{PIP}_{2}$ controls a varied range of cellular functions including organization of filamentous actin, cellular differentiation, exocytosis, and ion channel maintenance (Eberhard et al. 1990; Sun et al. 1999; Hilgemann et al. 2001). PIP_'s modulation of ion channels is well known. KCNQ $\left(\mathrm{K}_{\mathrm{V}} 7\right)$ channels are certainly the best documented example ( $\mathrm{Li}$ et al. 2005; Suh et al. 2006; Kim et al. 2017), but evidence exists for modulation of Cav channels by PIP $_{2}$. TsA201 cell lines transfected with different $\mathrm{Cav}$ channels show drastically reduced L- and N-type currents after $\mathrm{PIP}_{2}$ depletion, including an acceleration of inactivation (Suh et al. 2010). Retarding of P/Qtype rundown occurs when PIP2 is supplemented to the cells (Wu et al. 2002). This study analyzes how the absence of $\mathrm{PIP}_{2}$ affects HVA channel currents in magnocellular neurohypophysial cells (MNCs) of supraoptic nucleus (SON).

MNCs are large ( $\sim 25 \mu \mathrm{M})$ neurons that secrete oxytocin (OT) and vasopressin (VP) via action potential-triggered exocytosis that express L-, N-, P/Q-, R, and T-type voltage-dependent $\mathrm{Ca}^{2+}$ channels (Poulain and Wakerley 1982; Fisher and Bourque 1996; Foehring and Armstrong 1996). The interest in $\mathrm{PIP}_{2}$ modulation of $\mathrm{Cav}$ channels is spurred by previous work of our group on $\mathrm{PIP}_{2}$ 's modulation of $\mathrm{Ca}^{2+}$-dependent afterhyperpolarizations (AHPs) in these neurons. We determined that $\mathrm{PIP}_{2}$ was required for AHP generation in OT, but not VP neurons (Kirchner et al. 2017). Our previous study suggested that $\mathrm{PIP}_{2}$ regulates AHP generation by gating $\mathrm{Ca}_{\mathrm{v}}$ channels in OT neurons. Furthermore, AHPs are coupled tightly to N-type channel currents in OT neurons, while in VP neurons the mAHP is coupled to N-type channels and the sAHP is coupled to the 
sAHP (Chapter 4). $\mathrm{Ca}^{2+}$ through P/Q-type channels can also activate the sAHP if N-type channels are unavailable (see Chapter 4). Given the striking similarity between $\mathrm{PIP}_{2} / \mathrm{N}-$ type interactions in previous work (Delmas and Brown 2005; Michailidis et al. 2007), and the dependence of MNC AHPs on $\mathrm{PIP}_{2}$ and N-currents, we tested for the modulation of whole-cell and N-type $\mathrm{Ca}^{2+}$ currents by $\mathrm{PIP}_{2}$ in acutely dissociated MNCs from transgenic Wistar-Kyoto rats.

\section{Results}

In the study of $\mathrm{Ca}^{2+}$ channel currents, we used dissociated neurons to study modulation of $\mathrm{Ca}^{2+}$ currents because it avoids the issues of space clamp that a slice preparation has wherein the dendrites are present. replaced $\mathrm{Ca}^{2+}$ with $\mathrm{Ba}^{2+}$ as the charge carrier because $\mathrm{Ba}^{2+}$ produces larger currents through the channels, it prevents the activation of $\mathrm{Ca}^{2+}$-activated mechanisms, and it assists in the block of $\mathrm{K}^{+}$channels. We contained the cells in a background flow of HBSS and isolated $\mathrm{Ca}^{2+}$ currents with barrel delivery of a solution that isolates $\mathrm{Ca}^{2+}$ channel currents by omitting $\mathrm{Na}^{+}$and $\mathrm{K}^{+}$ions and by blocking $\mathrm{Na}^{+}$and $\mathrm{K}^{+}$channels pharmacologically.

Two different protocols were employed to study $\mathrm{Ca}^{2+}$ channel in these neurons, a step protocol and ramp protocol (Figure 5-1). The step protocol is positive square pulses in $10 \mathrm{mV}$ increments from $-60 \mathrm{mV}$. The ramp protocol is a $0.33 \mathrm{mV} / \mathrm{ms}$ ramp from -60 $\mathrm{mV}$ to $+50 \mathrm{mV}$. We first determined if I-V curves plotted from steps versus ramps were different from one another. We ran both protocols on the same cell populations. The traces from both protocols were averaged and then normalized to the maximal current. We did two comparisons: Control steps versus control ramps and wortmannin steps versus wortmannin ramps (Figure 5-1C). We determined that the ramp protocol provides an I-V curve that accurately reflects one plotted from peak currents generated in the step protocol. In this study, we evaluated changes in current amplitude and voltage dependence using the ramp protocol and changes in channel gating using the step protocol.

\section{PIP2 Inhibits Isolated $\mathrm{Ca}^{2+}$ Currents in OT Neurons}

Though we've previously demonstrated that $\mathrm{PIP}_{2}$ depletion via wortmannin inhibits whole-cell $\mathrm{Ca}^{2+}$ currents in slices from wild-type Sprague-Dawley rats (OT neurons) (Kirchner et al. 2017), we wanted to test the wortmannin's effect under conditions where voltage was better controlled and solutions could be rapidly changed. We tested wortmannin's effect in transgenic dissociated neurons from transgenic WistarKyoto rats.

In OT neurons, wortmannin $(0.5 \mu \mathrm{M})$ significantly inhibited whole-cell $\mathrm{Ca}^{2+}$ currents but had no effect in VP neurons (Figure 5-2). Wortmannin inhibited ramp- 

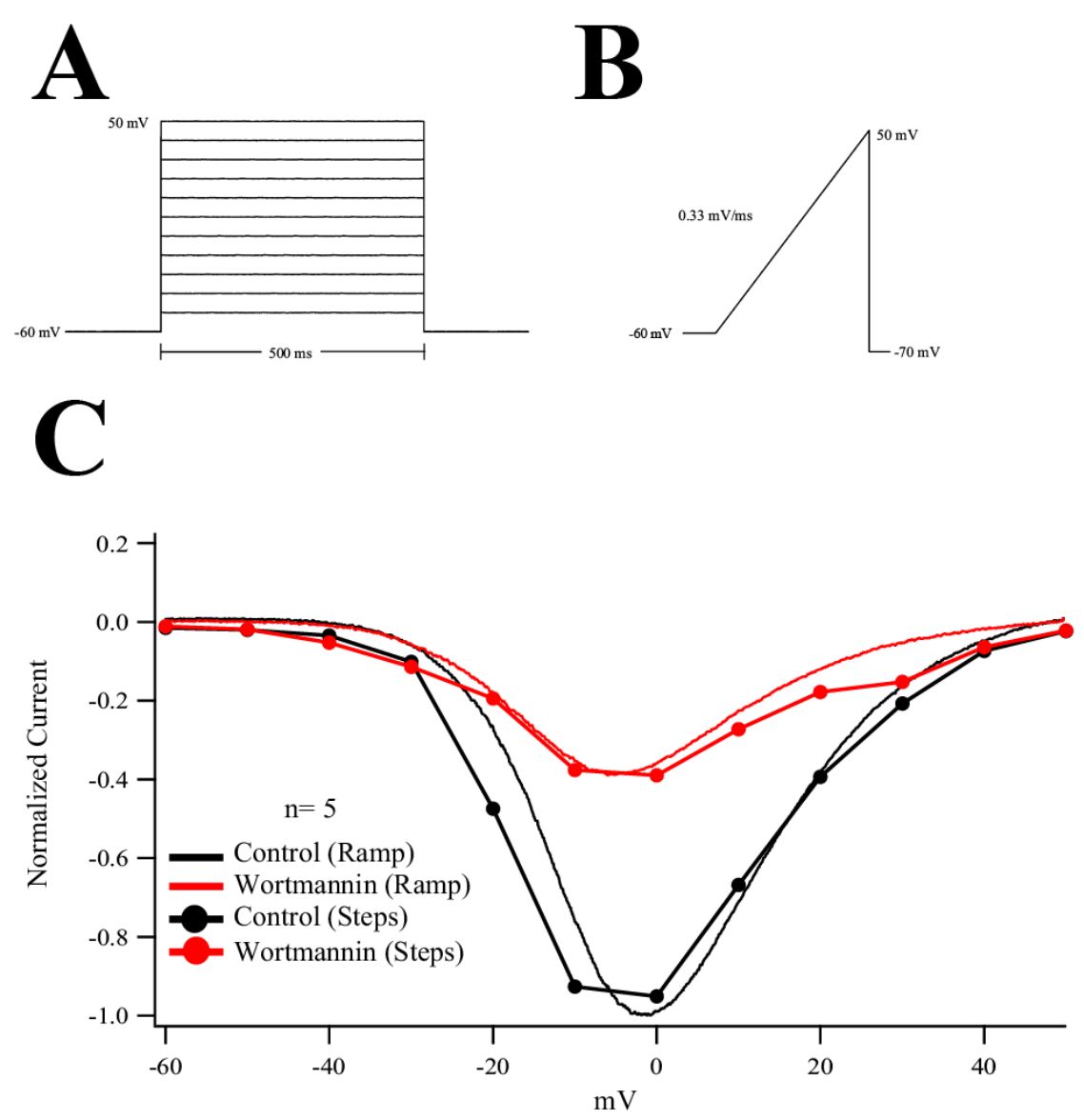

Figure 5-1. Comparison of $\mathrm{Ca}^{2+}$ current $\mathrm{I}-\mathrm{V}$ relationship in ramps versus steps. To confirm that the I-V relationship of whole cell $\mathrm{Ca}^{2+}$ currents generated from ramps reflected the currents seen with steps to specific voltages, we plotted I-V curves from OT neurons $(n=5)$ from ramps and steps. $\mathrm{Ba}^{2+}$ currents through $\mathrm{Ca}^{2+}$ channels were isolated with $150 \mathrm{mM}$ TEA, $.0005 \mathrm{mM}$ TTX, and removal of $\mathrm{Na}^{+} / \mathrm{K}^{+}$from the bath solution. $\mathrm{Ba}^{2+}$ replaced $\mathrm{Ca}^{2+}$ as the charge carrier for $\mathrm{Ca}^{2+}$ channel currents. (A) Step protocol used to generate whole-cell $\mathrm{Ca}^{2+}$ currents. We stimulated from $-60 \mathrm{mV}$ to $50 \mathrm{mV}$ in $10 \mathrm{mV}$ increments for $500 \mathrm{~ms}$ before returning to baseline. (B) Ramp protocol used to generate whole-cell $\mathrm{Ca}^{2+}$ currents. We stimulated from $-60 \mathrm{mV}$ and ramped voltage to $+50 \mathrm{mV}$ at a rate of $0.33 \mathrm{mV} / \mathrm{ms}$. (C) Summary plot of normalized ramps and steps I-V relationship in OT neurons before and after wortmannin. Each curve is an average of all five OT neurons tested. We included wortmannin inhibition as a second measure to confirm consistency in pharmacologicaly inhibited currents. All traces are normalized to the control trace. Note the similarity in I-V relationship between the two protocols under control and wortmannin conditions. 
Figure 5-2. Wortmannin inhibits whole cell $\mathrm{Ca}^{2+}$ currents in OT neurons but not VP neurons.

(A) (left) Whole cell $\mathrm{Ca}^{2+}$ currents generated via ramp protocol from an mRFP-labeled OT neuron before and after wortmannin $(0.5 \mu \mathrm{M})$. (right) Summary graph of wortmannin's effect on OT neurons. Wortmannin inhibited whole cell $\mathrm{Ca}^{2+}$ currents 52.2 $\pm 8 \%(\mathrm{n}=6, * * * p<0.001)$. (B) (left) Whole cell $\mathrm{Ca}^{2+}$ currents generated via ramp protocol from a GFP-labeled VP neuron before and after wortmannin $(0.5 \mu \mathrm{M})$. (right) Summary graph of wortmannin's effect on VP neurons. Wortmannin had no significant effect on whole cell VP Ca ${ }^{2+}$ currents $(n=5, p>0.05)$. (C) Same experiment as (A) but with $\mathrm{diC}_{8}-\mathrm{PIP}_{2}$ supplemented in the internal solution. (left) Whole cell $\mathrm{Ca}^{2+}$ currents generated via ramp protocol from an mRFP-labeled OT neuron before and after wortmannin. (right) Summary graph of wortmannin's effect on OT neurons. Wortmannin had no significant effect on whole cell OT Ca ${ }^{2+}$ currents when $\mathrm{diC}_{8}-\mathrm{PIP}_{2}$ was dialyzed through the pipette $(n=6, p>0.05)$. (D) Activation plots of OT (left; $n=6)$ and VP (right; $\mathrm{n}=6$ ) neurons. These plots represent averages of all neurons derived from ramp protocols. While neither cell type demonstrates changes in slope, OT neurons demonstrate a significant hyperpolarizing shift of $-4.6 \mathrm{mV}$ after wortmannin measured at $\mathrm{V}_{1 / 2}(* p<0.05)$. (E) Dose dependent wortmannin inhibition of whole cell $\mathrm{Ca}^{2+}$ currents in a single mRFP-labeled OT neuron. 


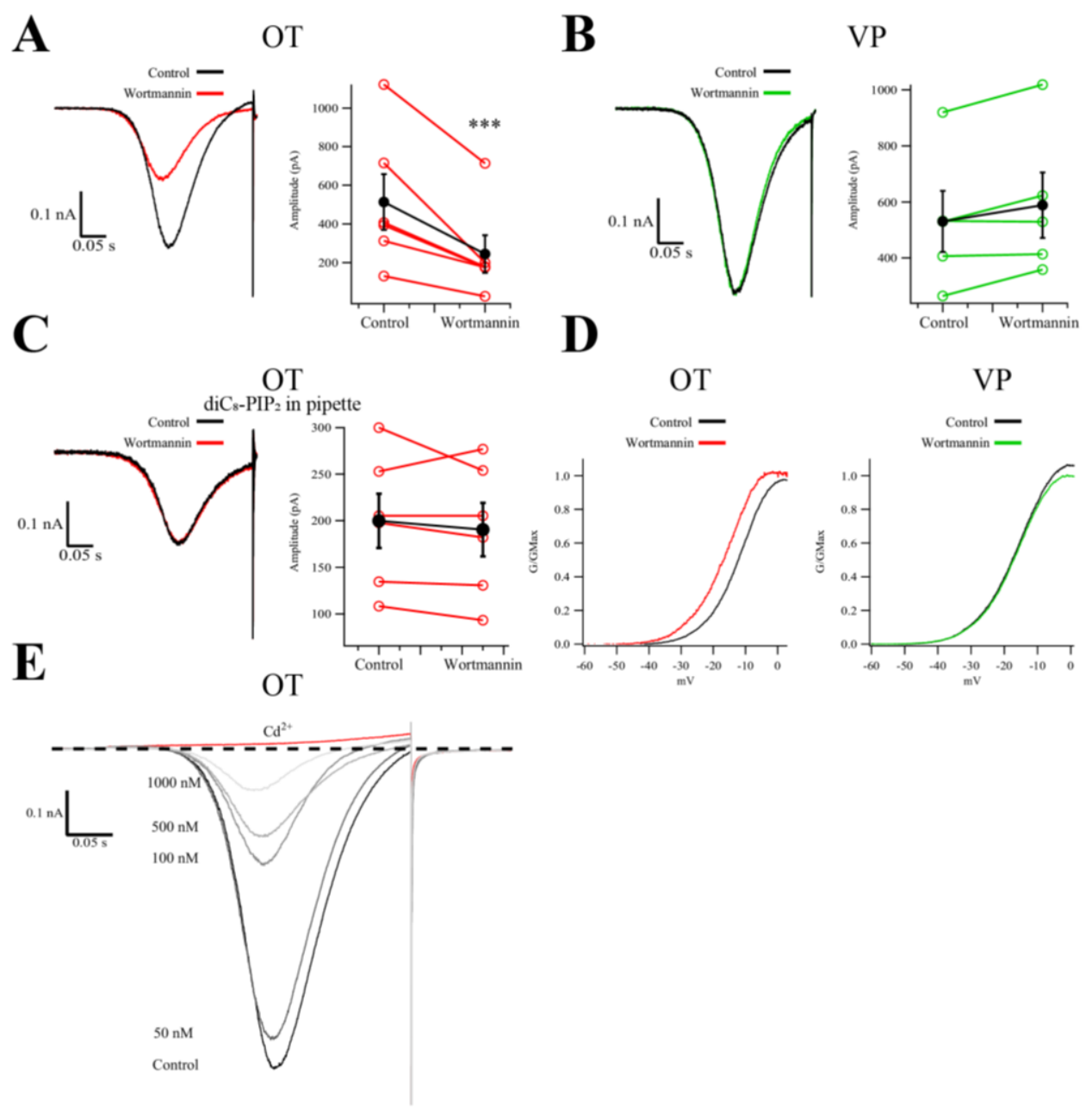


generated $\mathrm{Ca}^{2+}$ channel current amplitudes by $52.2 \pm 8 \%$ in OT neurons $(\mathrm{n}=5 ; p<$ $0.001)$. This effect was prevented when the water soluble, synthetic $\mathrm{PIP}_{2}$, dic $_{8}-\mathrm{PIP}_{2}(30$ $\mu \mathrm{M})$ was supplied to the cells via the patch pipette $(\mathrm{n}=5 ; p>0.05)$. We observed a dose dependence of the wortmannin effect on $\mathrm{Ca}^{2+}$ channel currents (Figure 5-3C), similar to our previous observations in slices. Wortmannin failed to inhibit ramp-generated $\mathrm{Ca}^{2+}$ currents in VP neurons $(\mathrm{n}=5 ; p>0.05)$.

In addition to an effect of $\mathrm{PIP}_{2}$ depletion on current amplitude, we observed a significant shift in the voltage dependent activation for OT neurons. To determine this, we generated a plot from ramps wherein current was converted to conductance $(\mathrm{G})$, normalized as G/GMax, plotted versus voltage, and fit to a standard Boltzmann equation. We measured both half-activation $\left(\mathrm{V}_{1 / 2}\right)$ and slope of the Boltzmann. Wortmannin application negatively shifts the voltage-dependent activation of whole-cell $\mathrm{Ca}^{2+}$ currents by $-4.6 \mathrm{mV}$ measured at $\mathrm{V}_{0.5}(\mathrm{n}=5 ; p<0.05)$. There was no change in slope of the curve (control $6.14 \pm 0.01$ vs. wortmannin $5.94 \pm 0.01$ ). VP neurons demonstrated no changes in $\mathrm{V}_{1 / 2}$ (control -15.8 vs. wortmannin -16.1) or slope (control $6.34 \pm 0.01$ vs. wortmannin $6.10 \pm 0.01)$.

\section{PIP2 $_{2}$ Effects on $\mathrm{Ca}^{2+}$ Channel Gating}

We generated $\mathrm{Ca}^{2+}$ currents using a step protocol and measured the kinetics of current activation, deactivation, and inactivation as a function of membrane voltage. We determined these kinetics by measuring percent inactivation (\%Inactivation). We operationally defined \% inactivation as the percent change in current between peak and steady-state values. We chose to use this measure instead of time constants because these cells $\mathrm{Ca}^{2+}$ channel currents don't demonstrate full inactivation. We observed that even during steps lasting upwards of 5 seconds, the currents were not fully inactivating, especially in OT neurons. To avoid fatiguing the cells and current rundown, we opted to use a $500 \mathrm{~ms}$ step and measure the \% Inactivation within this step.

At all membrane potentials measured, wortmannin had no significant effect on either activation $\tau$ in OT or VP neurons $(n=5)$ (Figure 5-3). For deactivation $\tau$ where we measured the tail current stepping down to $-70 \mathrm{mV}$, wortmannin had no significant effect $(p>0.05)$. However, we did find a significant difference between OT and VP neuron deactivation $\tau\left({ }^{*} p<0.05\right)$.

For measures of $\%$ inactivation, we observed large differences in the presence of wortmannin (Figure 5-4). When comparing \% inactivation of OT and VP neurons under control conditions, we observed significantly faster inactivation in VP neurons $(p<0.05$;

Figure 5-4A). This suggests differences in $\mathrm{Ca}^{2+}$ channel density and/or a proportion of different channel types between the two neurons. Furthermore, there are differences in how wortmannin affects \% inactivation in OT and VP neurons. In OT neurons, wortmannin accelerates inactivation of $\mathrm{Ca}^{2+}$ currents significantly at potentials measured $(p<* 0.05, * * 0.01$; Figure 5-4B). Inactivation becomes rapid and some steady-state current remains after wortmannin (Figure 5-4D). While VP neurons demonstrate faster 


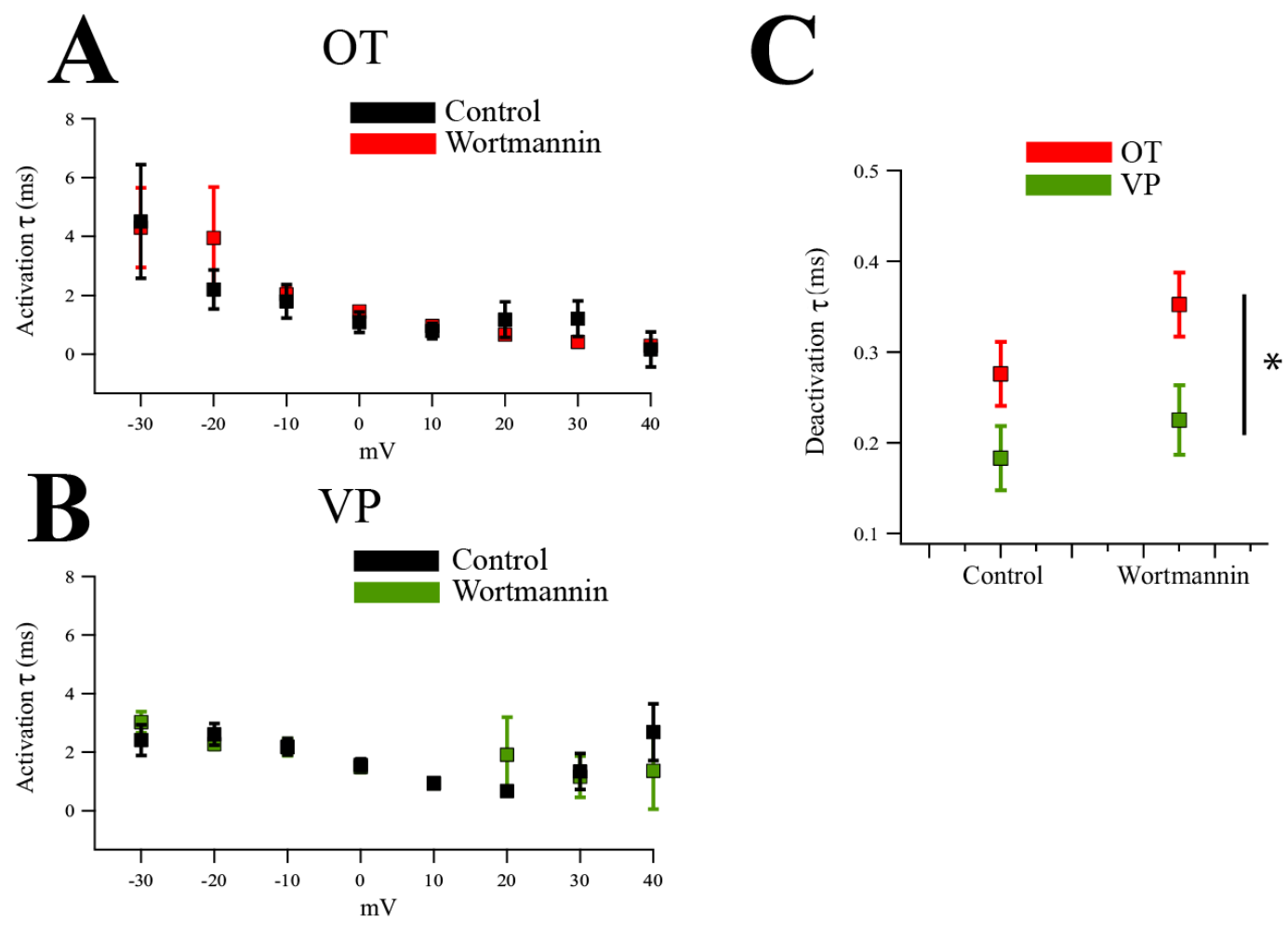

Figure 5-3. Wortmannin does not significantly affect activation and deactivation time constants in both OT and VP neurons.

Measurements of activation and deactivation time constants $(\tau)(\mathbf{A}, \mathbf{C})$ were extracted from $\mathrm{Ca}^{2+}$ currents generated via a step protocol in OT $(\mathbf{A}, \mathbf{B})$ and VP $(\mathbf{C}, \mathbf{D})$ neurons. Activation of the current was fit to a single exponential function. We fit tail currents to a double exponential function, interpreting the first, faster $\tau$ value as the deactivation $\tau$. Activation $\tau$ was not significantly altered in either cell type after wortmannin application $(p>0.05)$. Deactivation $\tau$ was unaffected by wortmannin $(p>0.05)$, but there was a significant difference between OT and VP neurons $\left({ }^{*} p<0.05\right)$ (Two-way repeated measures ANOVA). 
Figure 5-4. Inactivation properties of OT and VP neurons before and after wortmannin.

$\%$ Inactivation was measured as a \% change between peak and steady-state current. We compared wortmannin's $(0.5 \mu \mathrm{M})$ effect on \% Inactivation in OT (B-D) and VP (E-G) neurons. (A) Control solution whole-cell \% inactivation values for OT and VP neurons. At potentials where current is largest $(-10 \& 0 \mathrm{mV})$, VP neurons demonstrate significantly faster $\mathrm{Ca}^{2+}$ current inactivation. (B) Summary data of wortmannin's effect on $\mathrm{Ca}^{2+}$ currents generated from steps in OT neurons. Wortmannin significantly inhibits $\%$ inactivation. Below is an example of OT $\mathrm{Ca}^{2+}$ currents before (C) and after (D) wortmannin. Note the different scale of the currents in (D) versus (C). Because the greatly decreased current amplitude would make it hard to see the change in $\%$ inactivation at the original scale, we chose to zoom the scale. (E) Summary data of wortmannin's effect on $\mathrm{Ca}^{2+}$ currents generated from steps in VP neurons. Wortmannin had no significant effect on $\mathrm{Ca}^{2+}$ currents. Below this summary is an example trace from a VP neuron before (F) and after (G) wortmannin. Note the increased \% inactivation compared to their OT counterparts, but also the lack of wortmannin effect this measure. Significance values are marked with asterisks as follows: ${ }^{*} p<0.05,{ }^{*} p<0.01$. 

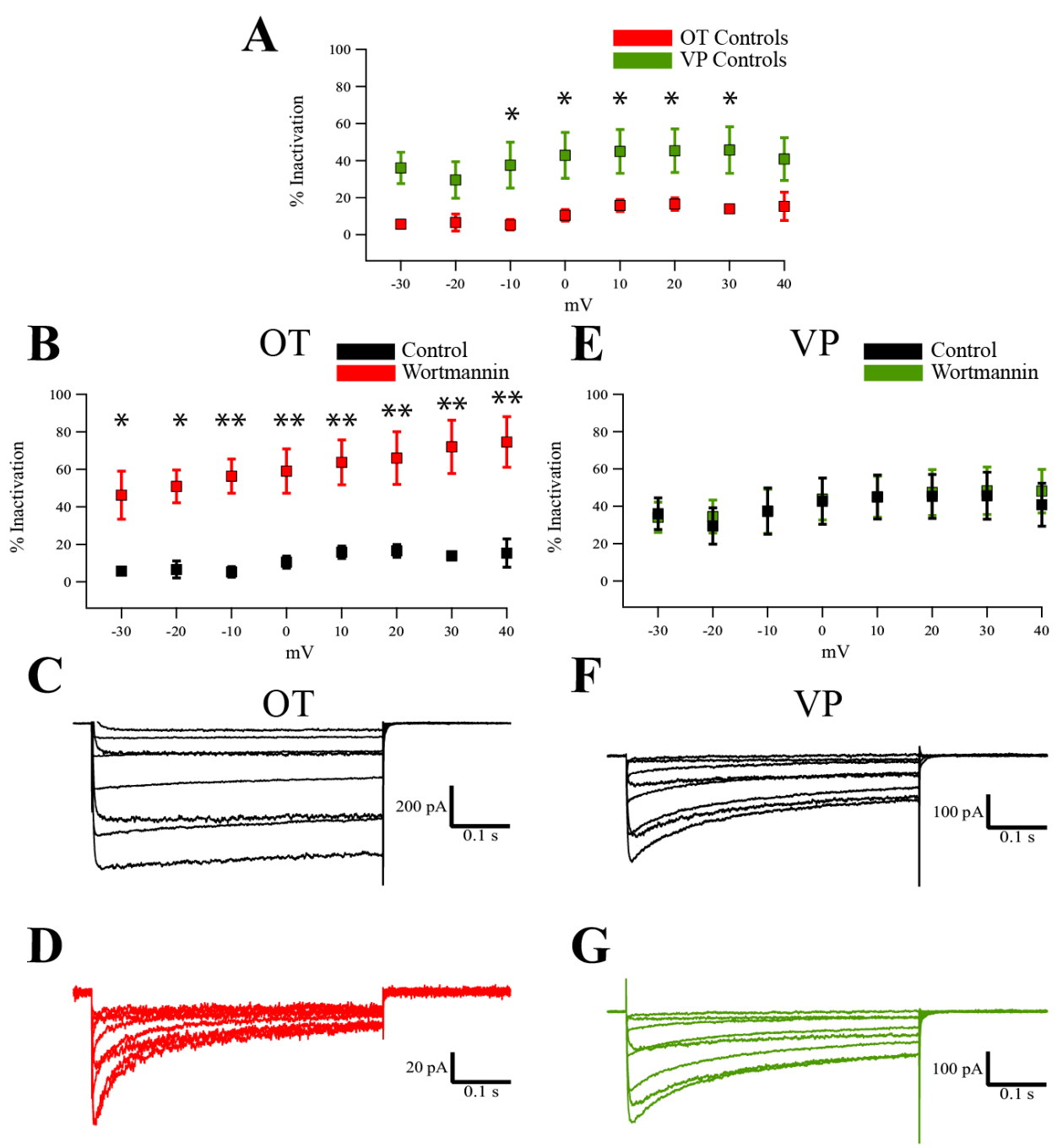
inactivation compared to their OT counterparts, they are unaffected by wortmannin application in this regard at any potential (Figure 5-4E).

\section{Modulation of N-type Current in OT Neurons}

As noted earlier, there is a strong precedence for modulation and even necessity of $\mathrm{PIP}_{2}$ for N-type channel activation (Michailidis et al. 2007; Suh et al. 2010). We have observed specific $\mathrm{Ca}^{2+}$ channels couple to each AHP component, and specifically, that Ntype channels couple to AHPs in OT neurons. We therefore tested how $\mathrm{PIP}_{2}$ depletion effects $\mathrm{N}$-type current. To study this, we isolated N-type currents by blocking all other HVA channels in the neurons with a cocktail of HVA channel blockers including nifedipine (Nif; $5 \mu \mathrm{M}$ ), agatoxin IVA (AgTx IVA; $0.5 \mu \mathrm{M})$, and SNX-482 (0.3 $\mu \mathrm{M})$. After stable isolation of N-type currents, we applied wortmannin $(0.5 \mu \mathrm{M})$ to the cell (Figure 5-5). In $\mathrm{Ca}^{2+}$ channel currents generated from ramps, isolation of $\mathrm{N}$-type resulted in a $69.6 \pm 6 \%$ reduction of the whole-cell peak current. Wortmannin inhibited the isolated N-type currents compared to just the isolation by $44 \pm 6 \%(n=5 ; p<0.05)$.

We also tested wortmannin on remaining $\mathrm{Ca}^{2+}$ channel currents after N-type channel block with CnTx GVIA. We used conotoxin GVIA (CnTx GVIA; $1 \mu \mathrm{M}$ ) to block N-type currents. Block of N-type current resulted in $46 \pm 6 \%$ reduction of wholecell current. Wortmannin inhibited the current further by $12 \pm 1 \%$, but this was not statistically significant $(\mathrm{n}=5 ; p>0.05)$.

Because wortmannin accelerates inactivation of whole cell $\mathrm{Ca}^{2+}$ currents, we wanted to evaluate how much of this inactivation could be attributed to effects at N-type channels versus all other HVA currents (Figure 5-6). We found that N-type isolation resulted in a significant reduction of $\%$ inactivation at $-30,-20$, and $-10 \mathrm{mV}(\mathrm{n}=7 ; p<$ $0.05)$. Application of wortmannin on N-type currents resulted in significant inhibition of $\%$ inactivation at almost all measured potentials $(n=7 ; p<0.05)$. This is most apparent when the isolated N-type current and the wortmannin-treated current are scaled to the control amplitude, where rapid inactivation is apparent (Figure 5-6C $\mathbf{i i )}$.

In contrast the isolated $\mathrm{N}$-type currents, we observed no changes for $\%$ inactivation measured at any potential from the whole-cell currents with $\mathrm{N}$-type channels blocked ( $n=5 ; p>0.05$; Figure 5-6B). Again, this is apparent when the traces with CnTx GVIA and wortmannin are scaled to the control amplitude (Figure 5-6Dii).

\section{Discussion}

Herein we provide evidence for two different but related aims: (1) to understand the precise mechanism by which $\mathrm{PIP}_{2}$ modulates $\mathrm{Ca}^{2+}$ channels in MNCs and (2) to determine if $\mathrm{PIP}_{2}$ can specifically modulate the N-type channel, which has been shown to be a critical source of $\mathrm{Ca}^{2+}$ for generation of AHPs in OT neurons of SON. 

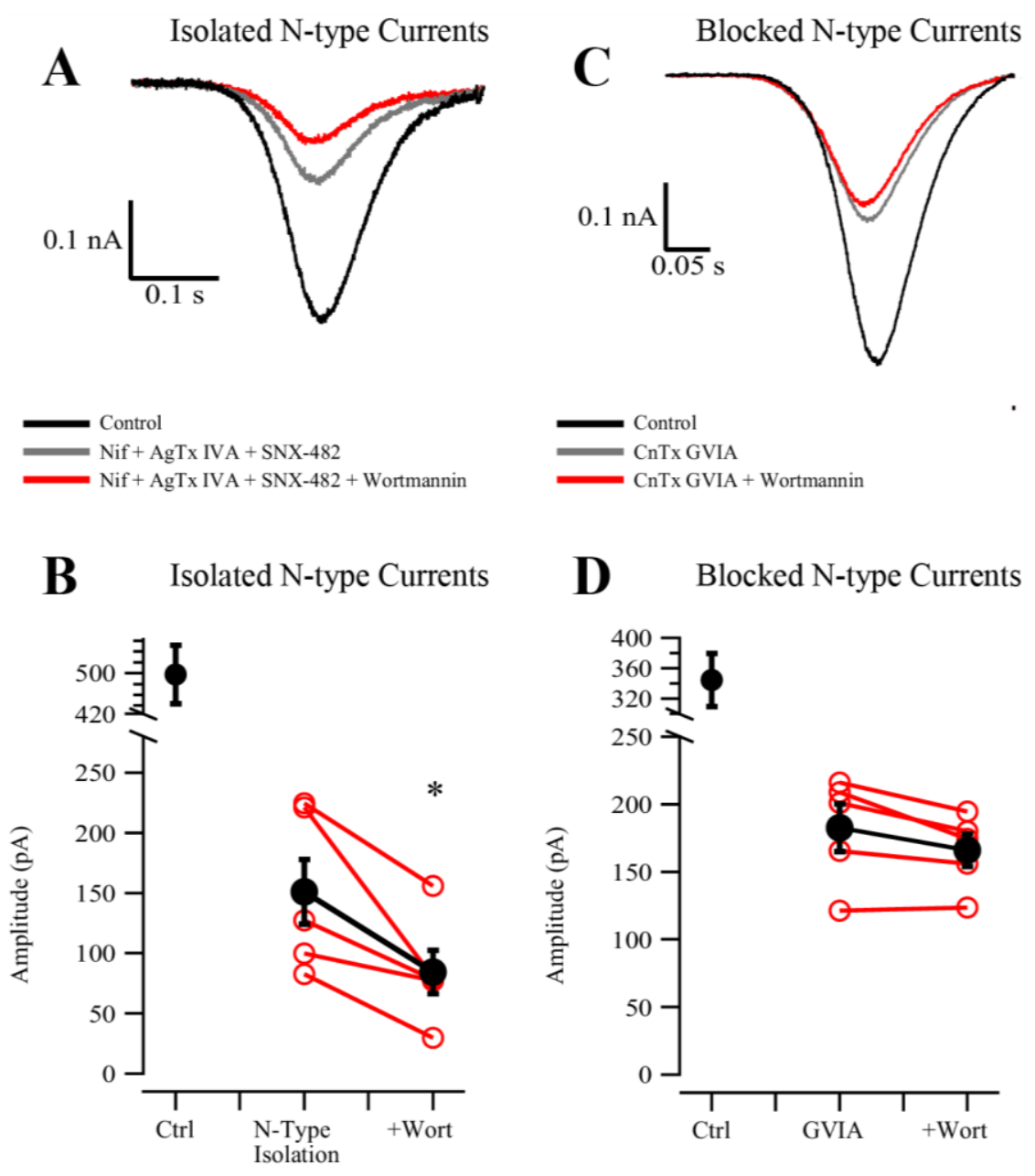

Figure 5-5. PIP2 significantly reduces pharmacologically isolated $\mathrm{N}$-type $\mathrm{Ca}^{2+}$
currents in OT neurons.

$\mathrm{PIP}_{2}$ depletion via wortmannin $(0.5 \mu \mathrm{M})$ appears to inhibit N-type currents $(\mathbf{A}, \mathbf{B})$ while unaffecting $\mathrm{Ca}^{2+}$ channel currents when N-type channels are blocked with CnTx GVIA (1 $\mu \mathrm{M})(\mathbf{C}, \mathbf{D})$. (A) $\mathrm{Ca}^{2+}$ channel current from a neuron (black trace) where N-type channels are isolated by blocking all other $\mathrm{HVA} \mathrm{Ca}^{2+}$ channels (gray trace) with L-type blocker nifedipine (Nif, $5 \mu \mathrm{M}$ ), P/Q-type blocker agatoxin IVA (AgTx-IVA, $0.5 \mu \mathrm{M}$ ), and R-type blocker SNX-482 $(0.3 \mu \mathrm{M})$. The neurons were subsequently treated with wortmannin (red trace). (B) Summary data of peak $\mathrm{Ca}^{2+}$ channel currents from ramps. Isolation of Ntype currents resulted in a $69.6 \pm 6 \%$ reduction of whole-cell current. Wortmannin significantly inhibits the isolated N-type current by $44 \pm 6 \%(* p<0.05)$. Red traces represent individual neurons while the black trace is the average. (C) $\mathrm{Ca}^{2+}$ channel current from a neuron (black trace) where N-type channels are blocked with conotoxin GVIA (CnTx GVIA, $1 \mu \mathrm{M}$ ) (gray trace). The neurons were subsequently treated with wortmannin (red trace) to evaluate $\mathrm{PIP}_{2}$ depletion effects on the reciprocal $\mathrm{HVA} \mathrm{Ca}^{2+}$ channel currents. (D) Summary data of peak $\mathrm{Ca}^{2+}$ channel currents from ramps. Block of $\mathrm{N}$-type currents resulted in a $45.6 \pm 6 \%$ reduction of whole-cell current. Wortmannin inhibited the current further by $12 \pm 1 \%$, but this was not statistically significant $(p>$ $0.05)$. Red traces represent individual neurons while the black trace is the average. 


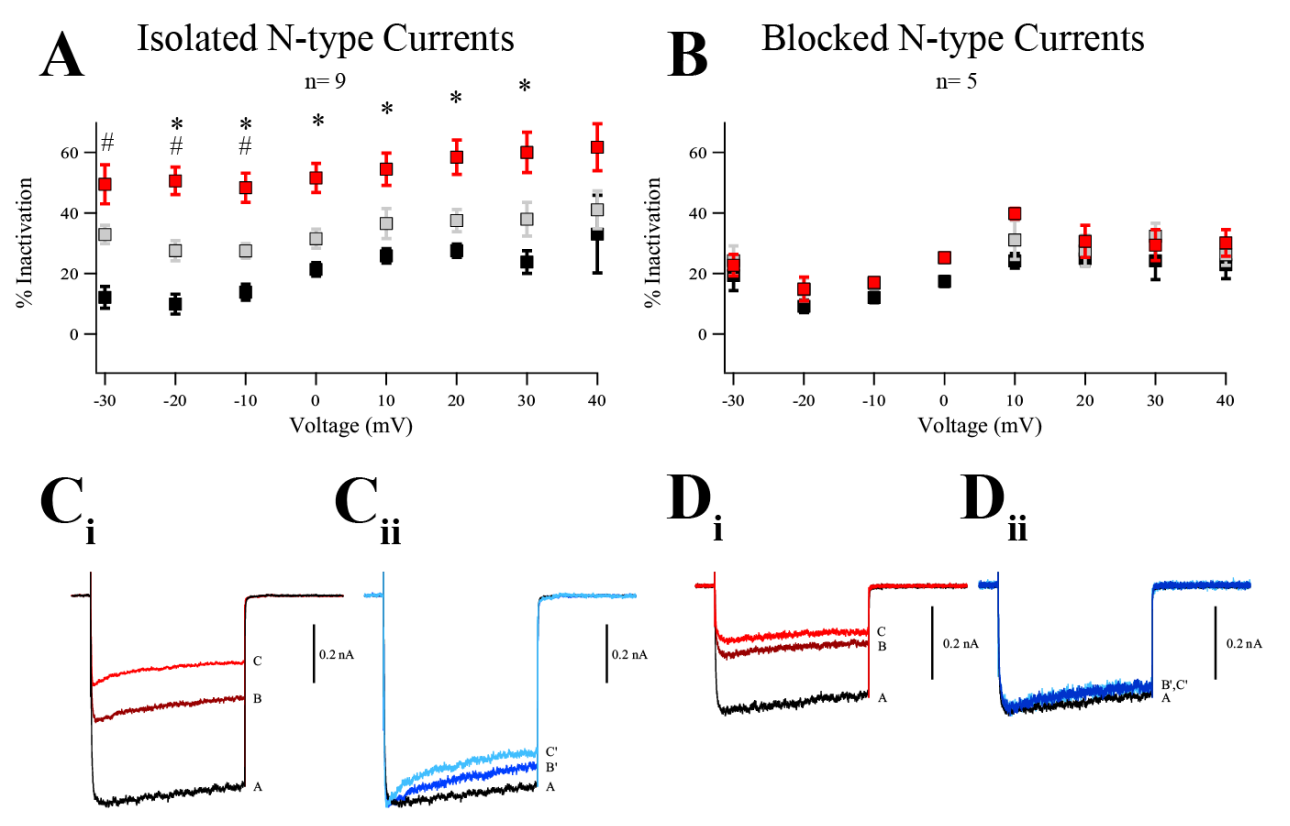

Figure 5-6. Wortmannin significantly accelerates inactivation of N-Type currents in OT neurons.

$\mathrm{PIP}_{2}$ depletion via wortmannin $(0.5 \mu \mathrm{M})$ inhibits isolated $\mathrm{N}$-current $\%$ inactivation $(\mathbf{A}, \mathbf{C})$ while having no effect on this parameter for $\mathrm{Ca}^{2+}$ currents in which $\mathrm{N}$-type channels are blocked (B, D) in OT neurons. (A) Summary data of \% inactivation under control conditions (black points), N-type channel isolation (gray points), and N-type isolation + wortmannin (red points). Significant differences between control and N-type isolation is marked with a pound symbol (\#) while a significant difference between N-type currents before and after wortmannin is marked with an asterisk $(*)$. (B) Summary data of \% inactivation under control conditions (black points), N-type channel block (gray points), and N-type block + wortmannin (red points). No significant differences occurred between any groups at the measured potentials $(p>0.05)$. $\left(\mathbf{C}_{\mathbf{i}}\right)$ Representative example of $\mathrm{Ca}^{2+}$ channel currents generated by a step protocol at $-10 \mathrm{mV}$, the step with the largest current tested. Within the graphic, trace A is a baseline $\mathrm{Ca}^{2+}$ channel current. Trace $\mathrm{B}$ is the pharmacologically isolated $\mathrm{N}$-type current. Trace $\mathrm{C}$ is this isolated current after wortmannin. $\left(\mathbf{C}_{\text {ii) }}\right)$ Traces B' and C' are the same respective traces scaled to the peak of the control. This highlights the effect of $\mathrm{PIP}_{2}$ depletion on $\%$ inactivation of the current. ( $\left.\mathbf{D}_{\mathbf{i}}\right)$ Representative example of $\mathrm{Ca}^{2+}$ channel currents generated by a step protocol at -10 $\mathrm{mV}$. Within the graphic, trace $\mathrm{A}$ is a baseline $\mathrm{Ca}^{2+}$ channel current. trace $\mathrm{B}$ is the wholecell $\mathrm{Ca}^{2+}$ channel current with blocked $\mathrm{N}$-type current. trace $\mathrm{C}$ is this whole-cell current after wortmannin. ( $\left.\mathbf{D}_{\mathrm{ii}}\right)$ Traces B' and C' are the same respective traces scaled to the peak of the control. In contrast to (C), wortmannin doesn't significantly change the $\%$ inactivation of these currents. 
We observe inhibition of $\mathrm{Ca}^{2+}$ channel current amplitudes after wortmannin in acutely dissociated OT (but not VP) neurons of Wistar-Kyoto rats. Wortmannin fails to inhibit the neurons when the patch pipette contains $\mathrm{diC}_{8}-\mathrm{PIP}_{2}$, suggesting that wortmannin's effect on $\mathrm{Ca}^{2+}$ channel currents is indeed the result of $\mathrm{PIP}_{2}$ depletion. In contrast to OT neurons, wortmannin has no effect on VP neuron currents. These results are consistent with our previous observations in slices of wild-type Sprague-Dawley rats (Kirchner et al. 2017). Interestingly, we also observed a hyperpolarizing shift in the voltage-dependent activation of whole-cell $\mathrm{Ca}^{2+}$ currents. This result is consistent with previous reports in which $\mathrm{PIP}_{2}$ depletion results in a left-ward shift of voltage-dependent activation of N-type channels. While the shift was not statistically significant, they observed a 2-3 mV leftward shift, slightly less than our observed -4.6 mV shift (Suh et al. 2010). This finding is puzzling because if $\mathrm{PIP}_{2}$ gated the current simply by shifting voltage dependence, then depleting $\mathrm{PIP}_{2}$ should depolarize the activation curve, resulting in a higher threshold of activation. Indeed, this has been demonstrated for $\mathrm{K}_{\mathrm{V}} 7$ and $\mathrm{P} / \mathrm{Q}-$ type $\mathrm{Ca}^{2+}$ channels in which augmented $\mathrm{PIP}_{2}$ production hyperpolarizes voltagedependent activation (Wu et al. 2002; Kim et al. 2016b). It's clear the presence $\mathrm{PIP}_{2}$ has modest effects on voltage-dependent activation of $\mathrm{Ca}^{2+}$ currents, but that it doesn't explain how $\mathrm{PIP}_{2}$ specifically affects the channel.

While VP neurons are unaffected in any way by wortmannin, they demonstrated significantly faster inactivation at high-conductance potentials compared to their OT counterparts. This suggests differences in $\mathrm{Ca}^{2+}$ channel density, family, and/or subunit populations between the two cell types. This hypothesis is backed by previous observations in which the percent of current blocked by $\mathrm{HVA} \mathrm{Ca}^{2+}$ channel toxins was highly variable, and thus it was hypothesized that the $\mathrm{Ca}^{2+}$ channel populations were different between the cell types (Foehring and Armstrong 1996). Additionally, reports show that N-type channels in VP neurons contain a $\beta_{2}$ subunit absent in OT neurons (Ortiz-Miranda et al. 2010). This subunit is known to drastically alter the biophysical properties of the channel (Campiglio and Flucher 2015).

During exploration of how $\mathrm{PIP}_{2}$ 's presence affects $\mathrm{Ca}^{2+}$ channel activity, we observed a significant effect of wortmannin on the $\%$ inactivation of OT $\mathrm{Ca}^{2+}$ currents, but not VP. Wortmannin application produced $\mathrm{Ca}^{2+}$ currents that rapidly inactivated, compared to their slowly-inactivating, or sometimes non-inactivating $\mathrm{Ca}^{2+}$ currents. These currents still display a fair amount of steady-state current after wortmannin. We found no effect of wortmannin on activation or deactivation $\tau$, but did find a difference in the deactivation $\tau$ between OT and VP neurons under control conditions.

It's clear that the presence of $\mathrm{PIP}_{2}$ allows for more robust $\mathrm{Ca}^{2+}$ channel currents (Kirchner et al. 2017). However, it was previously unknown which $\mathrm{HVA} \mathrm{Ca}^{2+}$ channels $\mathrm{PIP}_{2}$ affects in MNCs. Because of our interest in N-type channels as the $\mathrm{Ca}^{2+}$ source for OT AHPs, and the wealth of evidence for $\mathrm{PIP}_{2}$ modulation of these channels, we focused our efforts on the specific modulation of N-type channels in OT neurons. We observed an inhibition of isolated $\mathrm{N}$-type currents in which wortmannin reduced them by approximately half and no significant inhibition of current after block of N-type chanels. Furthermore, we observed significant increases in \% inactivation of isolated N-type 
currents after wortmannin, while $\%$ inactivation in GVIA-blocked $\mathrm{Ca}^{2+}$ currents was unaffected. This demonstrates the vast majority of $\mathrm{PIP}_{2}-\mathrm{Ca}^{2+}$ channel activity, including the inactivation of the currents, occurs at N-type channels in OT neurons.

The $\%$ inactivation changes following $\mathrm{PIP}_{2}$ depletion are small compared to inhibition of the current amplitude. It seems unlikely that they could account for the entirety of inhibition $\mathrm{Ca}^{2+}$ currents. This observation is consistent with those in ts A-201 cells in which they were large depressions of currents but relatively small changes in gating (Suh et al. 2010). They suggested that with reduced $\mathrm{PIP}_{2}$, fewer channels were available to open. It seems likely then that $\mathrm{PIP}_{2}$ increases open probability of the channel, something that has been previously demonstrated in KCNQ channels (Li et al. 2005). Another possibility is that $\mathrm{PIP}_{2}$ regulates single channel conductance. These possibilities remain to be tested.

Unlike KCNQ channels, the depletion of $\mathrm{PIP}_{2}$ doesn't result in failure of $\mathrm{Ca}^{2+}$ channel activity in this study (Hille et al. 2015). Even in isolated N-type channels, the channels which the majority of $\mathrm{PIP}_{2}$ modulation appears to occur among HVA channels of OT neurons, doesn't result in complete abolishment of the current. This suggests that $\mathrm{PIP}_{2}$ is a co-factor, and not a requirement for $\mathrm{Ca}^{2+}$ channel activation, as has been previously reported (Suh et al. 2010). 


\section{CHAPTER 6. DENDRITIC ARCHITECTURE AND AHPS}

\section{Introduction}

In addition to questions regarding mechanisms, there is also a question of cellular localization of the AHP. A small, but diligent body of literature exists exploring where within the cell the mAHP and sAHP are generated. With regards to the mAHP, the channel is known to be SK1-3, and thus it can be concluded that the mAHP is localized to wherever SK channels are found in the cell. For supraoptic neurons, SK3 staining was colocalized with both OT- and VP-neurophysins, and was found at the membrane of soma and dendritic processes (Armstrong et al. 2005). The staining was stronger at the soma with weak staining in the dendritic process, with apparent denser reactivity at the proximal dendrites.

With regards to the sAHP, study of localization is more challenging. The channel(s) are unknown, so the approach must be different. In CA1 neurons, it's been reported that the sAHP is primarily somatic (Lima and Marrion 2007). This was demonstrated by puffing BAPTA at the soma, which disrupted the trajectory of the AHP. The same BAPTA puff at an apical dendrite produced no such disruption. This contrasts with other experiments that proposed dendritic localization of the sAHP channels in CA1 pyramidal neurons. These experiments used a different approach wherein they took advantage of electrotonic properties of the cell (Sah and Bekkers 1996). AHPs would be generated and during the sAHP conductance, a brief hyperpolarizing pulse would be administered. Measuring the time constant to relaxation of the new current would serve as an index for how far from the somatic patch the AHP was conducted. They established that this pulse interruption during a GABA IPSC had a longer time constant to relaxation for IPSCs in dendrites compared to soma. When this same protocol was employed in the measurement of AHPs, the time constant of relaxation was significantly longer compared to the IPSCs in soma but not dendrite. They later demonstrated that severing of the apical dendrite produced about a 30\% reduction in sAHP amplitude; cutting the axon had no effect (Bekkers 2000). This suggests that sAHP channels are distributed in soma and dendrites apart from axons.

A later study in basolateral amygdala measured dendritic localization with the same electrotonic protocols to estimate the distance from the soma of a current (Power et al. 2011). Comparing the time constant of relaxation of an interrupting current, they argue that the AHP is produced primarily in dendrites. Furthermore, they demonstrated that when calcium influx is restricted to the soma, no AHP is produced. The sAHP also reduces EPSP summation and reduces the dendritic AP-evoked calcium response. They conclude that the sAHP may play a role in synaptic plasticity and dendritic action potentials as well as spike frequency adaptation. These studies establish a precedent for sAHP currents in dendrites and thus I investigated this investigation in SON, where localization of sAHPs is unknown and dendrites play a major role in neuronal physiology and plasticity (Morris and Ludwig 2004). 
A few obeservations in MNCs suggest that AHP conductances occur in the dendrites. First and foremost, wortmannin in the bath solution rapidly inhibits AHPs. By contrast, diC 8 -PIP 2 dialyzed through the patch pipette takes a minimum of 15 minutes before any indication of sAHP enhancement is observed in VP neurons. It often takes at least 20 minutes to see a maximum enhancement. This may reflect the time it takes for $\mathrm{diC}_{8}-\mathrm{PIP}_{2}$ to distribute to the ends of the dendrites. Furthermore, all types of $\mathrm{HVA} \mathrm{Ca}^{2+}$ channels are found in soma and dendrites of both OT and VP neurons, meaning that $\mathrm{Ca}^{2+}$ channels that couple to the AHP are available in the dendrites (Tobin et al. 2011). It should be noted that dissociated MNCs have AHPs, demonstrating that at least some of the AHP channel localization is in the soma (Oliet and Bourque 1992).

To investigate possible dendritic contribution to AHPs of MNCs, we traced biocytin-filled neurons and correlated AHP and $\left[\mathrm{Ca}^{2+}\right]_{i}$ measurements to dendritic length, area, and volume. We did this initial pass to see if direct test of dendritic localization is warranted. Neurons were recorded with a biocytin-loaded patch pipette. The tissue was fixed and post-hoc ABC-DAB staining with osmium was performed on the slices to reveal the recorded neuron (Figure 6-1). We measured 9 OT, 12 VP, and 2 unidentified neurons using Neurolucida 10.0. The 2 unidentified neurons were pooled into our regression plots in which we combined OT and VP neurons.

\section{Results and Discussion}

\section{OT Neurons}

Regression analysis of OT neurons revealed some trends between AHP amplitude, $\left[\mathrm{Ca}^{2+}\right]_{\mathrm{i}}$, and dendritic architecture in 20 -spike protocols. $\mathrm{R}^{2}=0.14$ for comparisons of AHP amplitude with $\left[\mathrm{Ca}^{2+}\right]_{i}$. While demonstrating a positive trend, this value doesn't represent a strong relationship between AHP and $\left[\mathrm{Ca}^{2+}\right]_{\mathrm{i}}$. Regression analysis of AHP to Dendritic length revealed a relationship $\left(\mathrm{R}^{2}=0.29\right)($ Figure 6-2). This trend broke down when comparing the AHP to dendritic area $\left(\mathrm{R}^{2}=0.15\right)$, but interestingly increased with volume $\left(\mathrm{R}^{2}=0.29\right)$. Together, OT neurons demonstrate evidence that dendrite length weakly correlates with sAHP amplitude and $\left[\mathrm{Ca}^{2+}\right]$. This suggests that larger dendrites may allow for the expression of more AHP channels, and that sAHP conductances (20 spikes), in part, could be happening in dendrites.

\section{VP Neurons}

Regression analysis of VP neurons in 20-spike protocols reveals a small linear relationship between peak $\left[\mathrm{Ca}^{2+}\right]_{i}$ and AHP amplitude $\left(\mathrm{R}^{2}=0.33\right)$. Additionally, a moderate relationship was observed between AHP amplitude and dendritic length $\left(\mathrm{R}^{2}=\right.$ 0.30) (Figure 6-2). This relationship breaks down completely when AHP amplitudes are compared to dendritic area $\left(\mathrm{R}^{2}=0.08\right)$ and volume $\left(\mathrm{R}^{2}=0.08\right)$. This observation is interesting because this trend is much stronger in VP neurons compared to OT neurons. Like OT neurons, VP neurons display a moderate relationship between AHP amplitude 

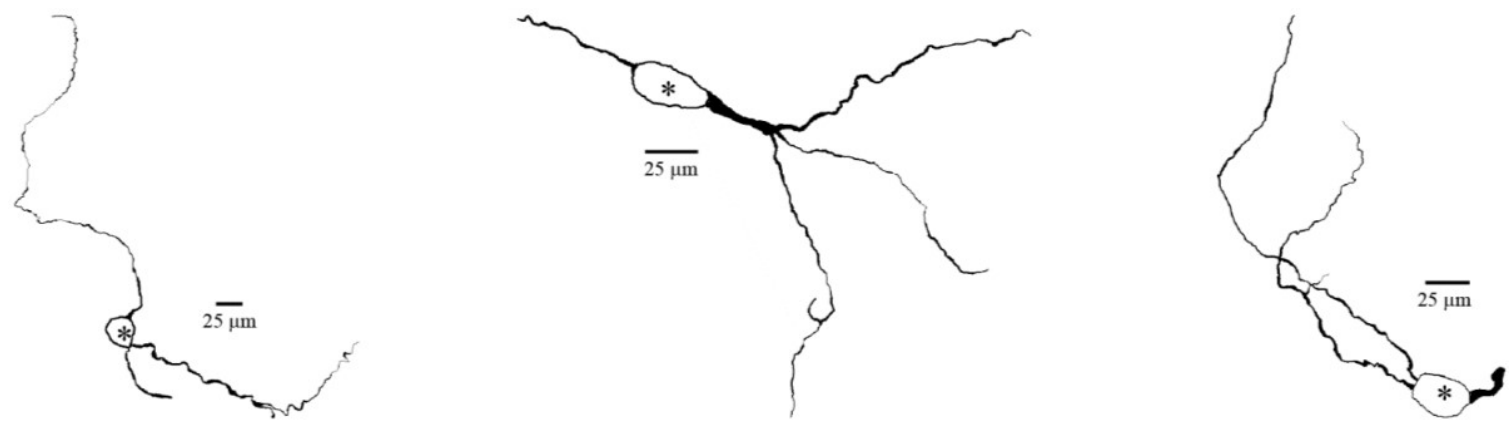

Figure 6-1. Drawings of MNCs in which dendritic size was measured.

Examples of MNCs traced from ABC-DAB treated tissue. The left and middle neuron are OT neurons and the right cell is a VP neuron. They display classic morphology of MNCs including lengthy dendrites with few second and third order branches. Somas are marked with an asterisk.
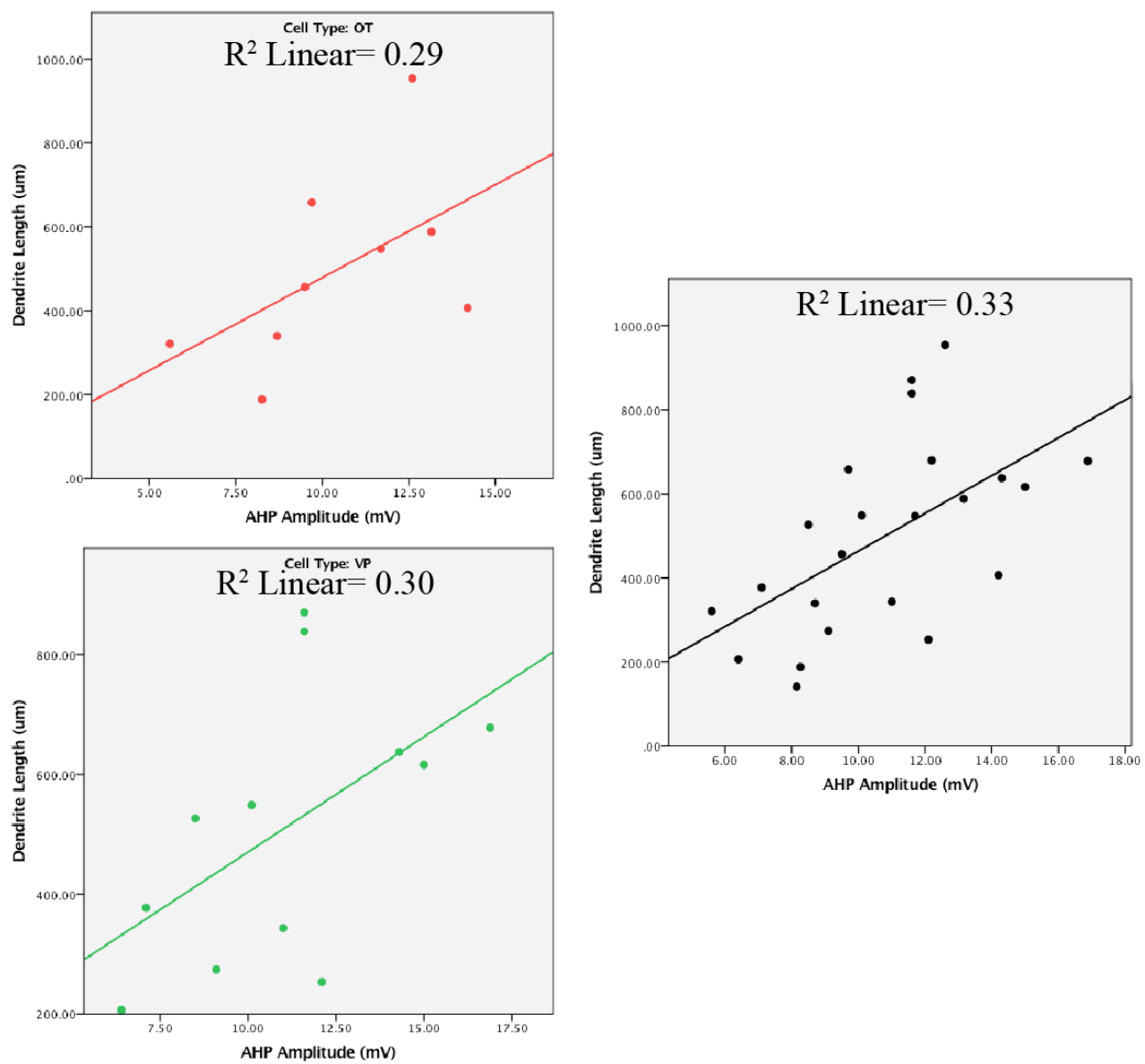

Figure 6-2. Regression plots for OT (top) VP (bottom) and OT+VP (right) for AHP amplitude vs. dendritic length. 
and dendritic length, suggesting that a portion of the AHP conductance occurs in dendrites.

\section{Combined OT and VP Neurons}

We performed the same comparisons on the combined pools of OT and VP data and an additional 2 unidentified cells (Figure 6-2). This was done to understand the general trend of magnocellular neurons, and perform the regression analysis on a robust sample size of data points $(n=23)$. For the 20 -spike protocol, there was notable relationships between AHP amplitude and $\left[\mathrm{Ca}^{2+}\right]_{i}\left(\mathrm{R}^{2}=0.29\right)$, and dendritic length $\left(\mathrm{R}^{2}=\right.$ 0.32). $\left[\mathrm{Ca}^{2+}\right]_{\mathrm{i}}$ trends with dendritic length as well $\left(\mathrm{R}^{2}=0.23\right)$. When examining combined trends for 5-spike protocols, there are no notable relationships between these parameters. 


\section{CHAPTER 7. ELUSIVE PIP 2 ENHANCEMENT OF VP NEURONS, AND CONCLUSIONS}

\section{PIP2 Enhancement of VP Neuron sAHPs}

As demonstrated in (Figures 3-7 and 3-8), dialysis of the $\mathrm{PIP}_{2}$ analgoue $\mathrm{diC}_{8}-\mathrm{PIP}_{2}$ into VP neurons causes drastic enhancement of the sAHP duration and amplitude. This contrasts with OT neurons where the $\mathrm{PIP}_{2}$ analog does not enhance the sAHP. This phenomenon appears to be the consequence of excessive $\mathrm{PIP}_{2}$, as PLC inhibition results in the same enhancement (Figure 3-9). PLC is responsible for breaking down $\mathrm{PIP}_{2}$ into DAG and $\mathrm{IP}_{3}$, and we interpret the PIP $\mathrm{P}_{2}$ enhancement caused by the block of PLC a consequence of continued production but terminated breakdown. When I initially attempted to measure the $\left[\mathrm{Ca}^{2+}\right]_{i}$ of the neurons during this phenomenon, I could not replicate the enhancement. It turned out that replacing EGTA with fura-2 in the pipette was the issue, and that switching back to EGTA rescued the $\mathrm{PIP}_{2}$ enhancement. This posed a challenge for visualizing the $\mathrm{Ca}^{2+}$ time course during the sAHP enhancement of VP neurons.

Fluorescent $\mathrm{Ca}^{2+}$ dyes, including fura-2, are derivatives of BAPTA. BAPTA and EGTA are $\mathrm{Ca}^{2+}$ buffers inserted into the pipette (Cobbold and Rink 1987). During $\mathrm{Ca}^{2+}$ imaging experiments the dye $\mathrm{Ca}^{2+}$ indicator acts as the $\mathrm{Ca}^{2+}$ buffer, replacing EGTA. Binding affinities between EGTA and BAPTA are similar (K $\mathrm{K}_{\mathrm{D}}$ : EGTA $150 \mathrm{nM}$; BAPTA $160 \mathrm{nM}$ ), however the kinetics of these two chelators are drastically different. BAPTA binds $\mathrm{Ca}^{2+}$ approximately 150 times faster (Forward Rate Constants, $\mathrm{K}_{\mathrm{ON}}$ : EGTA 0.025 $\mathrm{x} 10^{8} \mathrm{M}^{-1} \mathrm{~s}^{-1}$; BAPTA $4 \times 10^{8} \mathrm{M}^{-1} \mathrm{~s}^{-1}$ ) (Naraghi and Neher 1997). The consequence is that BAPTA reaches equilibrium with cytoplasmic $\mathrm{Ca}^{2+}$ rapidly compared to EGTA. Thus, it appears that when $\mathrm{Ca}^{2+}$ is buffered too quickly, $\mathrm{PIP}_{2}$ cannot exert its amplifying effect on the sAHP.

We explored the possibility that buffering speed of available $\mathrm{Ca}^{2+}$ was critical for $\mathrm{PIP}_{2}$ enhancement of VP AHPs. We tested many different $\mathrm{Ca}^{2+}$ buffer mixtures in the pipette, but observed the most consistent enhancements with $25 \mu \mathrm{M}$ fluo- $4+175 \mu \mathrm{M}$ EGTA. Fluo-4 is a BAPTA-derived $\mathrm{Ca}^{2+}$ indicator dye with a binding affinity on the same order of magnitude as fura-2 (fura-2 $145 \mathrm{nM}$; fluo-4 $345 \mathrm{nM}$ ). We attempted to curb the rapid chealation of the dyes by minimizing their concentration of fluo- 4 in the pipette and substituting with EGTA to maintain the same total concertation of buffer $(200 \mu \mathrm{M})$. When $\mathrm{diC}_{8}-\mathrm{PIP}_{2}$ was dialyzed through the pipette using this protocol, AHP amplitude and duration increased over a 20-minute recording period (Figure 7-1). The enhancement is more pronounced after a 40-spike trace (Figure 7-1C and D). The corresponding $\mathrm{Ca}^{2+}$ signals demonstrated inhibited and delayed peaks as well as prolonged transients. The peaks are occurring after the end of the spike train, and the transients are slower to return to baseline. This may suggest that PIP $P_{2}$ is recruiting the release of $\mathrm{Ca}^{2+}$ from internal stores. Another possibility is that $\mathrm{PIP}_{2}$ is interfering with a cytoplasmic mechanism that 

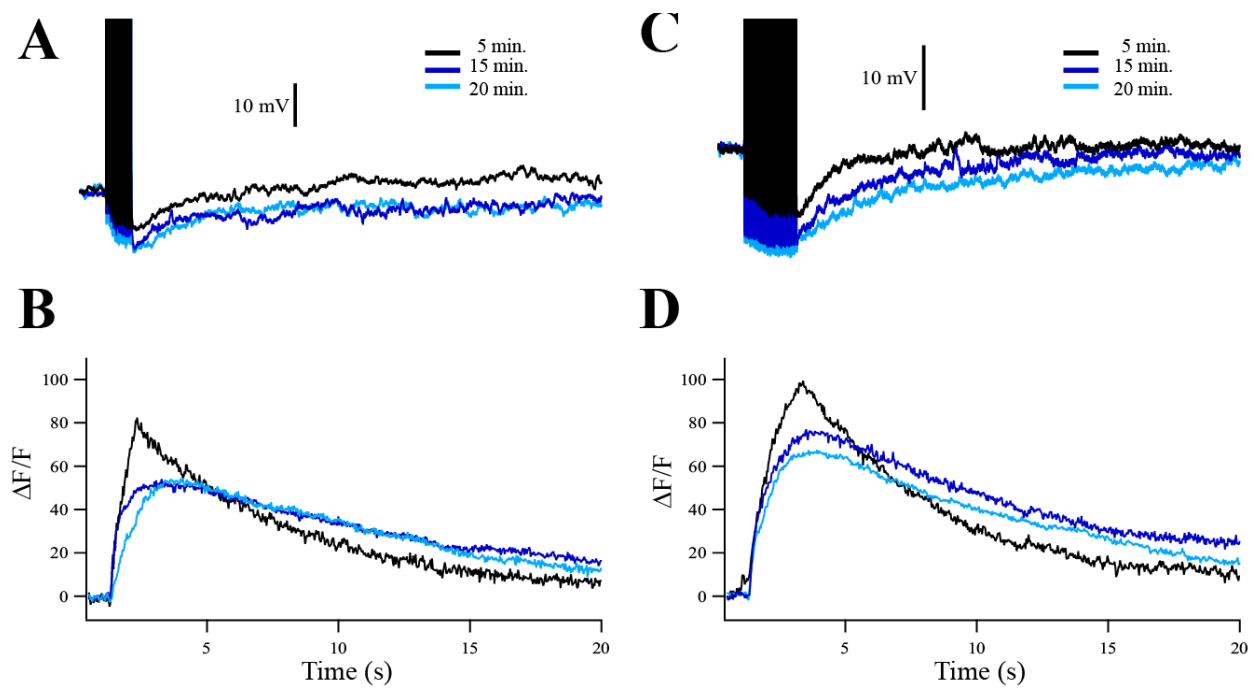

D

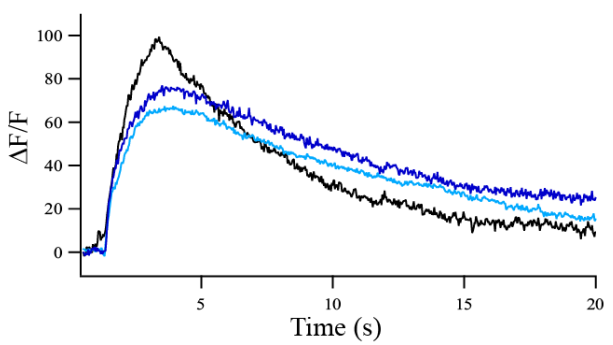

Figure 7-1. diC8-PIP $_{2}$ dialyzed through the pipette enhances $\mathrm{Ca}_{2}+$ in the presence of fluo-4 and EGTA.

$\mathrm{diC}_{8}$-PIP 2 successfully enhances VP sAHPs during $\mathrm{Ca}^{2+}$-imaging when the pipette contains $25 \mu \mathrm{M}$ fluo-4 and $175 \mu \mathrm{M}$ EGTA. (A) 20-spike protocol reveals enhanced AHP amplitude and duration over a 20 minute recording period. (B) Corresponding $\mathrm{Ca}^{2+}$ traces for the traces in (A). Note the delayed time to peak and the prolonged transient after peak. (C) 40-spike protocol AHP from the same cell as (A, B). The AHP enhancement is even more pronounced under these conditions. (D) Corresponding $\mathrm{Ca}^{2+}$ signals for traces in $(\mathrm{C}$ (C). Note again the delayed time to peak and slower transients during $\mathrm{diC}_{8}-\mathrm{PIP}_{2}$ dialysis. 
buffers $\mathrm{Ca}^{2+}$. The traces provided are preliminary, as we had limited success with our buffer ratio $(25 \mu \mathrm{M}$ fluo-4; $175 \mu \mathrm{M}$ EGTA). Fluo-4, even at low concentrations, often resulted in spontaneous, high frequency spiking during the stimulus. This made it challenging to acquire data over an adequate length of time. VP neurons without $\mathrm{diC}_{8}-$ $\mathrm{PIP}_{2}$ and OT neurons with $\mathrm{diC}_{8}-\mathrm{PIP}_{2}$ showed no signs of enhancement under these conditions (not shown).

\section{Conclusions}

The original undertaking was to better elucidate AHP mechanisms in AHPs of MNCs residing in the SON, testing the possibility of $\mathrm{PIP}_{2}$ 's role in such a mechanism. $\mathrm{PIP}_{2}$ undoubtedly contributes to the generation of an AHP in both cell types, but interestingly the mechanisms for the AHPs differ between the cell types. It plays an essential role in OT neurons where it is required for AHP activation while it plays a subtler role in modulation of the SAHP in VP neurons.

In Chapter 3, I characterized PIP,'s role in AHP activation of OT and VP neurons. Much of this work characterizes the effects of wortmannin, a toxin that inhibits PIP $_{2}$ production, but has higher affinity for $\mathrm{PIP}_{3}$ inhibition. We determined that wortmannin doesn't significantly affect cell viability, nor are its effects on AHPs attributable to PIP $_{3}$ inhibition. Both mAHP and sAHP are affected by wortmannin in OT neurons. I isolated the sAHP using apamin to block the mAHP and found that wortmannin inhibited the sAHP in OT but not VP neurons. Furthermore, wortmannin inhibits OT AHPs in a dose dependent manner. This demonstrates that in both medium and slow AHPs of OT neurons, $\mathrm{PIP}_{2}$ is required to activate. Increasing PIP 2 levels had no effect on OT neurons besides slowing rundown and preventing the effects of wortmannin, consistent to observations in Villalobos et al. 2011. By contrast, increasing PIP $_{2}$ enhances the sAHP in VP neurons drastically. PLC inhibition has a similar effect as $\mathrm{diC}_{8}-\mathrm{PIP}_{2}$.

Because $\mathrm{PIP}_{2}$ depletion appears to inhibit both the mAHP and sAHP in OT neurons, an effect on $\mathrm{Ca}^{2+}$ entry or buffering within the cells seemed like a parsimonious explanation for PIP 2 's effects. Failure of PLC inhibition to affect OT neurons indicates that downstream release of $\mathrm{Ca}^{2+}$ from $\mathrm{Ca}^{2+}$ stores via $\mathrm{IP}_{3}$ activation was unlikely.

Remaining possibilities included $\mathrm{Ca}^{2+}$ entry or $\mathrm{Ca}^{2+}$ sensitivity as modulation targets of $\mathrm{PIP}_{2}$. I determined that $\mathrm{PIP}_{2}$ modulated $\mathrm{Ca}^{2+}$ entry through voltage-gated ion channels by demonstrating AHPs generated from uncaging $\mathrm{Ca}^{2+}$ were unaffected by wortmannin. This result was reinforced by demonstration (in slice and dissociated neurons (Ch. 5)) that $\mathrm{Ca}^{2+}$ currents were reduced after wortmannin in OT but not VP neurons.

Chapter 4 explored another aspect of AHP mechanisms in MNCs: The $\mathrm{HVA} \mathrm{Ca}^{2+}$ channels that contribute $\mathrm{Ca}^{2+}$ that activates the AHPs. I demonstrated that in OT neurons, $\mathrm{Ca}^{2+}$ from N-type channels couples to both the mAHP and sAHP. N-type channel block doesn't completely abolish the AHP in these neurons, suggesting that these AHPs aren't only coupled to $\mathrm{N}$-type channels, but rather coupling is strongest for $\mathrm{N}$-type channels. 
The mAHP in VP neurons couples to N-type channels like OT, but the percent inhibition by CnTx GVIA was significantly lower compared to its effects in OT neurons. The R-type channel blocker SNX-482 produced a significant reduction in sAHP amplitude in VP neurons. Unlike N-type block in OT neurons, much of the AHP remains even after SNX-482. This suggests that VP neurons may receive $\mathrm{Ca}^{2+}$ from other sources such as LVA T-type channels or internal $\mathrm{Ca}^{2+}$ stores.

In Chapter 5, I investigated the manner in which $\mathrm{PIP}_{2}$ modulates $\mathrm{Ca}^{2+}$ channels in OT neurons. Our previous data indicated that $\mathrm{Ca}^{2+}$ entry was the primary locus where $\mathrm{PIP}_{2}$ effects AHP production (Chapter 3 ). In this chapter, we characterized $\mathrm{Ca}^{2+}$ channel currents in acutely dissociated MNCs from fluorescent protein-labeled neurons to avoid space clamp artifacts such as delayed activation or escaping tail currents. As observed in slices, wortmannin inhibits $\mathrm{Ca}^{2+}$ channel currents in OT but not VP neurons.

Additionally, wortmannin shifts the activation curve leftward by $4.6 \mathrm{mV}$ without changing the shape of the curve. There were no notable effects on activation time constants. Accelerated inactivation results from wortmannin application in OT neurons.

Since N-type channels appear to be the primary source of $\mathrm{Ca}^{2+}$ for AHPs in OT neurons, we tested the effects of wortmannin on pharmacologically-isolated N-type channels as well as the reciprocal whole-cell currents in which N-type channels were blocked. We found a significant reduction of N-type current after wortmannin and no significant change in current where $\mathrm{N}$-type channels were blocked. These data show that the primary effect of $\mathrm{PIP}_{2}$ manipulation in OT neurons is exerted on $\mathrm{N}$-type $\mathrm{Ca}^{2+}$ channels. Additionally, the isolated N-type currents display accelerated inactivation after wortmannin. This change in inactivation is unlikely to fully account for the drastic reduction in $\mathrm{Ca}^{2+}$ current amplitude.

Chapter 6 provides a cursory screening of possible relationships between AHPs and dendritic size. I find that there is a considerable relationship between AHP amplitude and dendritic length in OT $\left(\mathrm{R}^{2}=0.29\right)$ and VP $\left(\mathrm{R}^{2}=0.30\right)$ neurons. This relationship diminishes when the AHP is compared to dendritic area and dendritic volume. The poor relationship with volume may reflect the difficulty of deriving a three-dimensional architecture from a two-dimensional drawing of a dendrite.

Chapter 7 provides some preliminary findings that indicate that $\mathrm{PIP}_{2}$ affects $\mathrm{Ca}^{2+}$ buffering in VP neurons. This could possibly occur in the manipulation of $\mathrm{Ca}^{2+}$ from internal $\mathrm{Ca}^{2+}$ stores. 


\section{LIST OF REFERENCES}

Abel HJ, Lee JCF, Callaway JC, Foehring RC. Relationships Between Intracellular Calcium and Afterhyperpolarizations in Neocortical Pyramidal Neurons. J Neurophysiol 91: 324-335, 2004.

Adelman JP, Maylie J, Sah P. Small-Conductance $\mathrm{Ca}^{2+}$-Activated $\mathrm{K}^{+}$Channels: Form and Function. Annu Rev Physiol 74: 245-269, 2012.

Alger BE, Nicoll RA. Epileptiform Burst Afterhyperpolarization: Calcium-Dependent Potassium Potential in Hippocampal CA1 Pyramidal Cells. Science 210: 1122-1124, 1980.

Andrade R, Aghajanian GK. Locus coeruleus activity in vitro: intrinsic regulation by a calcium-dependent potassium conductance but not alpha 2-adrenoceptors. J Neurosci Off J Soc Neurosci 4: 161-170, 1984.

Andrade R, Foehring RC, Tzingounis AV. The calcium-activated slow AHP: cutting through the Gordian knot. Front Cell Neurosci 6, 2012.

Andrew R, Dudek F. Spike broadening in magnocellular neuroendocrine cells of rat hypothalamic slices. Brain Res 334: 176-179, 1985.

Andrew RD, Dudek FE. Burst discharge in mammalian neuroendocrine cells involves an intrinsic regenerative mechanism. Science 221: 1050-1052, 1983.

Andrew RD, Dudek FE. Intrinsic inhibition in magnocellular neuroendocrine cells of rat hypothalamus. J Physiol 353: 171-185, 1984.

Armstrong W. The Rat Nervous System - 4th Edition, Chapter 14 [Online]. 2015a. https://www.elsevier.com/books/the-rat-nervous-system/paxinos/978-0-12-374245-2 [30 Apr. 2018].

Armstrong WE. Morphological and electrophysiological classification of hypothalamic supraoptic neurons. Prog Neurobiol 47: 291-339, 1995.

Armstrong WE. Chapter 14 - Hypothalamic Supraoptic and Paraventricular Nuclei. In: The Rat Nervous System (Fourth Edition), edited by Paxinos G. Academic Press, p. 295314.

Armstrong WE, Rubrum A, Teruyama R, Bond CT, Adelman JP. Immunocytochemical localization of small-conductance, calcium-dependent potassium channels in astrocytes of the rat supraoptic nucleus. J Comp Neurol 491: 175-185, 2005.

Armstrong WE, Smith BN. Tuberal supraoptic neurons-II. Electrotonic properties. Neuroscience 38: 485-494, 1990. 
Armstrong WE, Smith BN, Tian M. Electrophysiological characteristics of immunochemically identified rat oxytocin and vasopressin neurones in vitro. $J$ Physiol 475: 115-128, 1994.

Armstrong WE, Wang L., Li C, Teruyama R. Performance, Properties and Plasticity of Identified Oxytocin and Vasopressin Neurones In Vitro. J Neuroendocrinol 22: 330 $342,2010$.

Armstrong WE, Warach S, Hatton GI, Mcneill TH. Subnuclei in the rat hypothalamic paraventricular nucleus: A cytoarchitectural, horseradish peroxidase and immunocytochemical analysis. Neuroscience 5: 1931-1958, 1980.

Baldissera F, Gustafsson B. Regulation of repetitive firing in motoneurones by the afterhyperpolarization conductance. Brain Res 30: 431-434, 1971.

Baldissera F, Gustafsson B. Afterhyperpolarization conductance time course in lumbar motoneurones of the cat. Acta Physiol Scand 91: 512-527, 1974a.

Baldissera F, Gustafsson B. Firing behaviour of a neurone model based on the afterhyperpolarization conductance time course and algebraical summation. Adaptation and steady state firing. Acta Physiol Scand 92: 27-47, 1974b.

Bean BP. The action potential in mammalian central neurons. Nat Rev Neurosci 8: 451465, 2007.

Behrens MI, Vergara C, Latorre R. Calcium-activated potassium channels of large unitary conductance. Braz J Med Biol Res Rev Bras Pesqui Medicas E Biol 21: 1101$1117,1988$.

Bekkers JM. Distribution of Slow AHP Channels on Hippocampal CA1 Pyramidal Neurons. J Neurophysiol 83: 1756-1759, 2000.

Belin, Moos. Paired recordings from supraoptic and paraventricular oxytocin cells in suckled rats: recruitment and synchronization. J Physiol 377: 369-390, 1986.

Belin V, Moos F, Richard P. Synchronization of oxytocin cells in the hypothalamic paraventricular and supraoptic nuclei in suckled rats: direct proof with paired extracellular recordings. Exp Brain Res 57: 201-203, 1984.

Bicknell RJ. Optimizing release from peptide hormone secretory nerve terminals. $J$ Exp Biol 139: 51-65, 1988.

Bicknell RJ, Leng G. Relative efficiency of neural firing patterns for vasopressin release in vitro. Neuroendocrinology 33: 295-299, 1981.

Birnbaumer L, Campbell KP, Catterall WA, Harpold MM, Hofmann F, Horne WA, Mori Y, Schwartz A, Snutch TP, Tanabe T, Tsien RW. The naming of voltage-gated calcium channels. Neuron 13: 505-506, 1994. 
Blatz AL, Magleby KL. Single apamin-blocked Ca-activated K+ channels of small conductance in cultured rat skeletal muscle. Nature 323: 718-720, 1986.

Bleasdale JE, Thakur NR, Gremban RS, Bundy GL, Fitzpatrick FA, Smith RJ, Bunting S. Selective inhibition of receptor-coupled phospholipase C-dependent processes in human platelets and polymorphonuclear neutrophils. J Pharmacol Exp Ther 255: 756-768, 1990.

Bonfardin VDJ, Fossat P, Theodosis DT, Oliet SHR. Glia-dependent switch of kainate receptor presynaptic action. J Neurosci Off J Soc Neurosci 30: 985-995, 2010.

Borschel WF, Wang S, Lee S, Nichols CG. Control of Kir channel gating by cytoplasmic domain interface interactions. J Gen Physiol 149: 561-576, 2017.

Bourinet E, Soong TW, Sutton K, Slaymaker S, Mathews E, Monteil A, Zamponi GW, Nargeot J, Snutch TP. Splicing of alpha 1A subunit gene generates phenotypic variants of P- and Q-type calcium channels. Nat Neurosci 2: 407-415, 1999.

Bourque CW. Calcium-dependent spike after-current induces burst firing in magnocellular neurosecretory cells. Neurosci Lett 70: 204-209, 1986.

Bourque CW. Transient calcium-dependent potassium current in magnocellular neurosecretory cells of the rat supraoptic nucleus. $J$ Physiol 397: 331-347, 1988.

Bourque CW, Brown DA. Apamin and d-tubocurarine block the after-hyperpolarization of rat supraoptic neurosecretory neurons. Neurosci Lett 82: 185-190, 1987.

Bourque CW, Kirkpatrick K, Jarvis CR. Extrinsic modulation of spike afterpotentials in rat hypothalamoneurohypophysial neurons. Cell Mol Neurobiol 18: 3-12, 1998.

Bourque CW, Randle JC, Renaud LP. Calcium-dependent potassium conductance in rat supraoptic nucleus neurosecretory neurons. J Neurophysiol 54: 1375-1382, 1985.

Bourque CW, Renaud LP. Activity patterns and osmosensitivity of rat supraoptic neurones in perfused hypothalamic explants. J Physiol 349: 631-642, 1984.

Bourque CW, Renaud LP. Calcium-dependent action potentials in rat supraoptic neurosecretory neurones recorded in vitro. J Physiol 363: 419-428, 1985.

Brimble MJ, Dyball REJ. Characterization of the responses of oxytocin- and vasopressin-secreting neurones in the supraoptic nucleus to osmotic stimulation. $J$ Physiol 271: 253-271, 1977.

Brown CH, Bull PM, Bourque CW. Phasic bursts in rat magnocellular neurosecretory cells are not intrinsically regenerative in vivo. Eur J Neurosci 19: 2977-2983, 2004.

Brown DA, Griffith WH. Calcium-activated outward current in voltage-clamped hippocampal neurones of the guinea-pig. J Physiol 337: 287-301, 1983. 
Brunn GJ, Williams J, Sabers C, Wiederrecht G, Lawrence JC, Abraham RT.

Direct inhibition of the signaling functions of the mammalian target of rapamycin by the phosphoinositide 3-kinase inhibitors, wortmannin and LY294002. EMBO J 15: 52565267, 1996.

Burgess GM, Claret M, Jenkinson DH. Effects of quinine and apamin on the calciumdependent potassium permeability of mammalian hepatocytes and red cells. J Physiol 317: 67-90, 1981.

Cabanos C, Wang M, Han X, Hansen SB. A Soluble Fluorescent Binding Assay Reveals PIP2 Antagonism of TREK-1 Channels. Cell Rep 20: 1287-1294, 2017.

Campiglio M, Flucher BE. The Role of Auxiliary Subunits for the Functional Diversity of Voltage-Gated Calcium Channels. J Cell Physiol 230: 2019-2031, 2015.

Cassels J. The Posterior Pituitary Pathway | GLOWM [Online].

2012. http://www.glowm.com/section_view/item/283/recordset/18975/value/283 [23 Jul. $2018]$.

Castelli L, Magistretti J. High-voltage-activated Ca2+ currents show similar patterns of expression in stellate and pyramidal cells from rat entorhinal cortex layer II. Brain Res 1090: 76-88, 2006.

Catterall WA. Voltage-Gated Calcium Channels. Cold Spring Harb Perspect Biol 3, 2011.

Cazalis M, Dayanithi G, Nordmann JJ. The role of patterned burst and interburst interval on the excitation-coupling mechanism in the isolated rat neural lobe. J Physiol 369: 45-60, 1985.

Clark BA, Monsivais P, Branco T, London M, Häusser M. The site of action potential initiation in cerebellar Purkinje neurons. Nat Neurosci 8: 137-139, 2005.

Cobbold PH, Rink TJ. Fluorescence and bioluminescence measurement of cytoplasmic free calcium. Biochem J 248: 313-328, 1987.

Cobo E, Bernal MMD, Gaitan E, Quintero CA. Neurohypophyseal hormone release in the human: II. Experimental study during lactation. Am J Obstet Gynecol 97: 519-529, 1967.

Cohen-Kutner M, Nachmanni D, Atlas D. CaV2.1 (P/Q channel) interaction with synaptic proteins is essential for depolarization-evoked release. Channels Austin Tex 4: 266-277, 2010.

Cruz L de la, Puente EI, Reyes-Vaca A, Arenas I, Garduño J, Bravo-Martínez J, Garcia DE. PIP2 in pancreatic $\beta$-cells regulates voltage-gated calcium channels by a voltage-independent pathway. Am J Physiol - Cell Physiol 311: C630-C640, 2016. 
Dayanithi G, Sabatier N, Widmer H. Intracellular calcium signalling in magnocellular neurones of the rat supraoptic nucleus: understanding the autoregulatory mechanisms. Exp Physiol 85 Spec No: 75S-84S, 2000.

De Crescenzo V, ZhuGe R, Velázquez-Marrero C, Lifshitz LM, Custer E, Carmichael J, Lai FA, Tuft RA, Fogarty KE, Lemos JR, Walsh JV. Ca2+ syntillas, miniature $\mathrm{Ca} 2+$ release events in terminals of hypothalamic neurons, are increased in frequency by depolarization in the absence of Ca2+ influx. J Neurosci Off J Soc Neurosci 24: 1226-1235, 2004.

DeHaan RL, Gottlieb SH. The Electrical Activity of Embryonic Chick Heart Cells Isolated in Tissue Culture Singly or in Interconnected Cell Sheets. J Gen Physiol 52: 643-665, 1968.

Dekin MS, Getting PA. Firing pattern of neurons in the nucleus tractus solitarius: modulation by membrane hyperpolarization. Brain Res 324: 180-184, 1984.

Delmas P, Brown DA. Pathways modulating neural KCNQ/M (Kv7) potassium channels. Nat Rev Neurosci 6: 850-862, 2005.

Dickson EJ, Falkenburger BH, Hille B. Quantitative properties and receptor reserve of the IP3 and calcium branch of Gq-coupled receptor signaling. J Gen Physiol 141: 521$535,2013$.

Dopico AM, Bukiya AN, Martin GE. Ethanol modulation of mammalian BK channels in excitable tissues: molecular targets and their possible contribution to alcohol-induced altered behavior. Front Physiol 5, 2014.

Dopico AM, Widmer H, Wang G, Lemos JR, Treistman SN. Rat supraoptic magnocellular neurones show distinct large conductance, $\mathrm{Ca} 2+$-activated $\mathrm{K}+$ channel subtypes in cell bodies versus nerve endings. J Physiol 519: 101-114, 1999.

Drummond GB. Reporting ethical matters in The Journal of Physiology: standards and advice. $J$ Physiol 587: 713-719, 2009.

Dutton A, Dyball REJ. Phasic firing enhances vasopressin release from the rat neurohypophysis. $J$ Physiol 290: 433-440, 1979.

Eberhard DA, Cooper CL, Low MG, Holz RW. Evidence that the inositol phospholipids are necessary for exocytosis. Loss of inositol phospholipids and inhibition of secretion in permeabilized cells caused by a bacterial phospholipase $\mathrm{C}$ and removal of ATP. Biochem J 268: 15-25, 1990.

Eckey K, Wrobel E, Strutz-Seebohm N, Pott L, Schmitt N, Seebohm G. Novel Kv7.1-phosphatidylinositol 4,5-bisphosphate interaction sites uncovered by charge neutralization scanning. J Biol Chem 289: 22749-22758, 2014. 
Erickson KR, Ronnekleiv OK, Kelly MJ. Role of a T-type calcium current in supporting a depolarizing potential, damped oscillations, and phasic firing in vasopressinergic guinea pig supraoptic neurons. Neuroendocrinology 57: 789-800, 1993.

Fakler B, Adelman JP. Control of KCa Channels by Calcium Nano/Microdomains. Neuron 59: 873-881, 2008.

Fisher SK, Heacock AM, Agranoff BW. Inositol lipids and signal transduction in the nervous system: an update. J Neurochem 58: 18-38, 1992.

Fisher SK, Novak JE, Agranoff BW. Inositol and higher inositol phosphates in neural tissues: homeostasis, metabolism and functional significance. J Neurochem 82: 736-754, 2002.

Fisher TE, Bourque CW. Voltage-gated calcium currents in the magnocellular neurosecretory cells of the rat supraoptic nucleus. J Physiol 486: 571-580, 1995.

Fisher TE, Bourque CW. Calcium-channel subtypes in the somata and axon terminals of magnocellular neurosecretory cells. Trends Neurosci 19: 440-444, 1996.

Fisher TE, Bourque CW. Properties of the transient $\mathrm{K}+$ current in acutely isolated supraoptic neurons from adult rat. Adv Exp Med Biol 449: 97-106, 1998.

Flavell SW, Greenberg ME. Signaling mechanisms linking neuronal activity to gene expression and plasticity of the nervous system. Annu Rev Neurosci 31: 563-590, 2008.

Foehring RC, Armstrong WE. Pharmacological dissection of high-voltage-activated $\mathrm{Ca} 2+$ current types in acutely dissociated rat supraoptic magnocellular neurons. $J$ Neurophysiol 76: 977-983, 1996.

Foehring RC, Lorenzon NM, Herron P, Wilson CJ. Correlation of physiologically and morphologically identified neuronal types in human association cortex in vitro. $J$ Neurophysiol 66: 1825-1837, 1991.

Foehring RC, Schwindt PC, Crill WE. Norepinephrine selectively reduces slow Ca2+and $\mathrm{Na}+-m e d i a t e d \mathrm{~K}+$ currents in cat neocortical neurons. J Neurophysiol 61: 245-256, 1989.

Ford KJ, Arroyo DA, Kay JN, Lloyd EE, Bryan RM, Sanes JR, Feller MB. A role for TREK1 in generating the slow afterhyperpolarization in developing starburst amacrine cells. J Neurophysiol 109: 2250-2259, 2013.

Freund-Mercier M J, Richard P. Electrophysiological evidence for facilitatory control of oxytocin neurones by oxytocin during suckling in the rat. $J$ Physiol 352: 447-466, 1984.

Freund-Mercier MJ, Richard P. Excitatory effects of intraventricular injections of oxytocin on the milk ejection reflex in the rat. Neurosci Lett 23: 193-198, 1981. 
Freund-Mercier MJ, Stoeckel ME. Somatodendritic autoreceptors on oxytocin neurones. Adv Exp Med Biol 395: 185-194, 1995.

Freund-Mercier MJ, Stoeckel ME, Klein MJ. Oxytocin receptors on oxytocin neurones: histoautoradiographic detection in the lactating rat. J Physiol 480 ( Pt 1): 155$161,1994$.

Gandía L, Borges R, Albillos A, García AG. Multiple calcium channel subtypes in isolated rat chromaffin cells. Pflugers Arch 430: 55-63, 1995.

Ghamari-Langroudi M, Bourque C. Muscarinic Receptor Modulation of Slow Afterhyperpolarization and Phasic Firing in Rat Supraoptic Nucleus Neurons. J Neurosci 24: 7718-7726, 2004.

Ghamari-Langroudi M, Bourque CW. Caesium blocks depolarizing after-potentials and phasic firing in rat supraoptic neurones. J Physiol 510: 165-175, 1998.

Ghamari-Langroudi M, Bourque CW. Flufenamic acid blocks depolarizing afterpotentials and phasic firing in rat supraoptic neurones. $J$ Physiol 545: 537-542, 2002.

Ghorbel MT, Sharman G, Hindmarch C, Becker KG, Barrett T, Murphy D. Microarray screening of suppression subtractive hybridization-PCR cDNA libraries identifies novel RNAs regulated by dehydration in the rat supraoptic nucleus. Physiol Genomics 24: 163-172, 2006.

Glasgow E, Kusano K, Chin H, Mezey E, Young WS, Gainer H. Single cell reverse transcription-polymerase chain reaction analysis of rat supraoptic magnocellular neurons: neuropeptide phenotypes and high voltage-gated calcium channel subtypes.

Endocrinology 140: 5391-5401, 1999.

Goldberg JA, Wilson CJ. Control of Spontaneous Firing Patterns by the Selective Coupling of Calcium Currents to Calcium Activated Potassium Currents in Striatal Cholinergic Interneurons. J Neurosci Off J Soc Neurosci 25: 10230-10238, 2005.

Greenwood MP, Mecawi AS, Hoe SZ, Mustafa MR, Johnson KR, Al-Mahmoud GA, Elias LLK, Paton JFR, Antunes-Rodrigues J, Gainer H, Murphy D, Hindmarch CCT. A comparison of physiological and transcriptome responses to water deprivation and salt loading in the rat supraoptic nucleus. Am J Physiol Regul Integr Comp Physiol 308: R559-568, 2015.

Greffrath W, Magerl W, Disque-Kaiser U, Martin E, Reuss S, Boehmer G. Contribution of $\mathrm{Ca} 2+-$-Activated $\mathrm{K}+$ Channels to Hyperpolarizing After-Potentials and Discharge Pattern in Rat Supraoptic Neurones. J Neuroendocrinol 16: 577-588, 2004.

Greffrath W, Martin E, Reuss S, Boehmer G. Components of after-hyperpolarization in magnocellular neurones of the rat supraoptic nucleus in vitro. J Physiol 513: 493-506, 1998. 
Grunnet M, Jensen BS, Olesen SP, Klaerke DA. Apamin interacts with all subtypes of cloned small-conductance Ca2+-activated K+ channels. Pflugers Arch 441: 544-550, 2001.

Guan D, Higgs MH, Horton LR, Spain WJ, Foehring RC. Contributions of Kv7mediated potassium current to sub- and suprathreshold responses of rat layer II/III neocortical pyramidal neurons. J Neurophysiol 106: 1722-1733, 2011.

Guerini D. The $\mathrm{Ca} 2+$ pumps and the $\mathrm{Na}+/ \mathrm{Ca} 2+$ exchangers. Biometals Int J Role Met Ions Biol Biochem Med 11: 319-330, 1998.

Gulledge AT, Dasari S, Onoue K, Stephens EK, Hasse JM, Avesar D. A SodiumPump-Mediated Afterhyperpolarization in Pyramidal Neurons. J Neurosci 33: 1302513041, 2013.

Haas HL, Konnerth A. Histamine and noradrenaline decrease calcium-activated potassium conductance in hippocampal pyramidal cells. Nature 302: 432-434, 1983.

Hallworth NE, Wilson CJ, Bevan MD. Apamin-sensitive small conductance calciumactivated potassium channels, through their selective coupling to voltage-gated calcium channels, are critical determinants of the precision, pace, and pattern of action potential generation in rat subthalamic nucleus neurons in vitro. J Neurosci Off J Soc Neurosci 23: 7525-7542, 2003.

Harris MC, Dreifuss JJ, Legros JJ. Excitation of phasically firing supraoptic neurones during vasopressin release. Nature 258: 80-82, 1975.

Hatton GI. Phasic bursting activity of rat paraventricular neurones in the absence of synaptic transmission. J Physiol 327: 273-284.2, 1982.

Hatton GI. Pituicytes, glia and control of terminal secretion. J Exp Biol 139: 67-79, 1988.

Hernandez CC, Falkenburger B, Shapiro MS. Affinity for phosphatidylinositol 4,5bisphosphate determines muscarinic agonist sensitivity of Kv7 K+ channels. J Gen Physiol 134: 437-448, 2009.

Higuchi T, Uchide K, Honda K, Negoro H. Oxytocin release during parturition in the pelvic-neurectomized rat. J Endocrinol 109: 149-154, 1986.

Hilgemann DW, Ball R. Regulation of cardiac $\mathrm{Na}+, \mathrm{Ca} 2+$ exchange and KATP potassium channels by PIP2. Science 273: 956-959, 1996.

Hilgemann DW, Feng S, Nasuhoglu C. The Complex and Intriguing Lives of PIP2 with Ion Channels and Transporters. Sci Signal 2001: re19-re19, 2001.

Hille B. Modulation of ion-channel function by G-protein-coupled receptors. Trends Neurosci 17: 531-536, 1994. 
Hille B, Dickson EJ, Kruse M, Vivas O, Suh B-C. Phosphoinositides regulate ion channels. Biochim Biophys Acta 1851: 844-856, 2015.

Hlubek MD, Cobbett P. Outward potassium currents of supraoptic magnocellular neurosecretory cells isolated from the adult guinea-pig. .

Hlubek MD, Cobbett P. Differential effects of $\mathrm{K}(+)$ channel blockers on frequencydependent action potential broadening in supraoptic neurons. Brain Res Bull 53: 203$209,2000$.

Hotson JR, Prince DA. A calcium-activated hyperpolarization follows repetitive firing in hippocampal neurons. J Neurophysiol 43: 409-419, 1980.

Hughes S, Marsh SJ, Tinker A, Brown DA. PIP(2)-dependent inhibition of M-type (Kv7.2/7.3) potassium channels: direct on-line assessment of PIP(2) depletion by Gqcoupled receptors in single living neurons. Pflüg Arch Eur J Physiol 455: 115-124, 2007.

Israel J-M, Poulain DA, Oliet SHR. Oxytocin-Induced Postinhibitory Rebound Firing Facilitates Bursting Activity in Oxytocin Neurons. J Neurosci 28: 385-394, 2008.

Jackson MB, Konnerth A, Augustine GJ. Action potential broadening and frequencydependent facilitation of calcium signals in pituitary nerve terminals. Proc Natl Acad Sci US A 88: 380-384, 1991.

Jensen BS, Strøbaek D, Olesen SP, Christophersen P. The Ca2+-activated K+ channel of intermediate conductance: a molecular target for novel treatments? Curr Drug Targets 2: 401-422, 2001.

Joux N, Chevaleyre V, Alonso G, Boissin-Agasse L, Moos FC, Desarménien MG, Hussy N. High voltage-activated $\mathrm{Ca} 2+$ currents in rat supraoptic neurones: biophysical properties and expression of the various channel alpha1 subunits. J Neuroendocrinol 13: 638-649, 2001.

Ju G, Liu S, Tao J. Projections from the hypothalamus and its adjacent areas to the posterior pituitary in the rat. Neuroscience 19: 803-828, 1986.

Katoh A, Fujihara H, Ohbuchi T, Onaka T, Hashimoto T, Kawata M, Suzuki H, Ueta Y. Highly visible expression of an oxytocin-monomeric red fluorescent protein 1 fusion gene in the hypothalamus and posterior pituitary of transgenic rats. Endocrinology 152: 2768-2774, 2011.

Kim D-I, Kweon H-J, Park Y, Jang D-J, Suh B-C. Ca2+ controls gating of voltagegated calcium channels by releasing the $\beta 2$ e subunit from the plasma membrane. Sci Signal 9: ra67-ra67, 2016a.

Kim KS, Duignan KM, Hawryluk JM, Soh H, Tzingounis AV. The Voltage Activation of Cortical KCNQ Channels Depends on Global PIP2 Levels. Biophys J 110: 1089-1098, 2016b. 
Kim RY, Pless SA, Kurata HT. PIP2 mediates functional coupling and pharmacology of neuronal KCNQ channels. Proc Natl Acad Sci U S A 114: E9702-E9711, 2017.

King B, Rizwan AP, Asmara H, Heath NC, Engbers JDT, Dykstra S, Bartoletti TM, Hameed S, Zamponi GW, Turner RW. IKCa Channels Are a Critical Determinant of the Slow AHP in CA1 Pyramidal Neurons. Cell Rep 11: 175-182, 2015.

Kirchner MK, Foehring RC, Wang L, Chandaka GK, Callaway JC, Armstrong WE. Phosphatidylinositol 4,5-bisphosphate (PIP2 ) modulates afterhyperpolarizations in oxytocin neurons of the supraoptic nucleus. J Physiol 595: 4927-4946, 2017.

Kirkpatrick K, Bourque CW. Activity dependence and functional role of the apaminsensitive K+ current in rat supraoptic neurones in vitro. J Physiol 494: 389-398, 1996.

Köhler M, Hirschberg B, Bond CT, Kinzie JM, Marrion NV, Maylie J, Adelman JP. Small-conductance, calcium-activated potassium channels from mammalian brain. Science 273: 1709-1714, 1996.

Krause M, Offermanns S, Stocker M, Pedarzani P. Functional Specificity of Gaq and $\mathrm{G} \alpha 11$ in the Cholinergic and Glutamatergic Modulation of Potassium Currents and Excitability in Hippocampal Neurons. J Neurosci 22: 666-673, 2002.

Kruse M, Hille B. The phosphoinositide sensitivity of the KV channel family. Channels 7: 530-536, 2013.

Lancaster B, Hu H, Gibb B, Storm JF. Kinetics of ion channel modulation by cAMP in rat hippocampal neurones. J Physiol 576: 403-417, 2006.

Lancaster B, Nicoll RA. Properties of two calcium-activated hyperpolarizations in rat hippocampal neurones. J Physiol 389: 187, 1987.

Lasser-Ross N, Miyakawa H, Lev-Ram V, Young SR, Ross WN. High time resolution fluorescence imaging with a CCD camera. J Neurosci Methods 36: 253-261, 1991.

Lee J, Jung K, Kim YS, Park D. Diosgenin inhibits melanogenesis through the activation of phosphatidylinositol-3-kinase pathway (PI3K) signaling. Life Sci 81: 249$254,2007$.

Lemos JR, Ortiz-Miranda SI, Cuadra AE, Velázquez-Marrero C, Custer EE, Dad T, Dayanithi G. Modulation/physiology of calcium channel sub-types in neurosecretory terminals. Cell Calcium 51: 284-292, 2012.

Leng G, Caquineau C, Sabatier N. Regulation of oxytocin secretion. Vitam Horm 71: 27-58, 2005.

Li C, Tripathi PK, Armstrong WE. Differences in spike train variability in rat vasopressin and oxytocin neurons and their relationship to synaptic activity. $J$ Physiol 581: 221-240, 2007. 
Li Y, Gamper N, Hilgemann DW, Shapiro MS. Regulation of Kv7 (KCNQ) K+ Channel Open Probability by Phosphatidylinositol 4,5-Bisphosphate. J Neurosci 25: 9825-9835, 2005.

Li Z, Decavel C, Hatton GI. Calbindin-D28k: role in determining intrinsically generated firing patterns in rat supraoptic neurones. J Physiol 488 ( Pt 3): 601-608, 1995.

Li Z, Hatton GI. Reduced outward K+ conductances generate depolarizing afterpotentials in rat supraoptic nucleus neurones. J Physiol 505 ( Pt 1): 95-106, 1997.

Li Z, Miyata S, Hatton GI. Inositol 1,4,5-trisphosphate-sensitive Ca2+ stores in rat supraoptic neurons: involvement in histamine-induced enhancement of depolarizing afterpotentials. Neuroscience 93: 667-674, 1999.

Lima PA, Marrion NV. Mechanisms underlying activation of the slow AHP in rat hippocampal neurons. Brain Res 1150: 74-82, 2007.

Lincoln DW, Paisley AC. Neuroendocrine control of milk ejection. $J$ Reprod Fertil 65: 571-586, 1982.

Lincoln, Wakerley. Electrophysiological evidence for the activation of supraoptic neurones during the release of oxytocin. J Physiol 242: 533-554, 1974.

Liu B, Liang H, Liu L, Zhang H. Phosphatidylinositol 4,5-bisphosphate hydrolysis mediates histamine-induced KCNQ/M current inhibition. Am J Physiol - Cell Physiol 295: C81-C91, 2008.

Liu PW, Bean BP. Kv2 Channel Regulation of Action Potential Repolarization and Firing Patterns in Superior Cervical Ganglion Neurons and Hippocampal CA1 Pyramidal Neurons. J Neurosci 34: 4991-5002, 2014.

Logothetis DE, Jin T, Lupyan D, Rosenhouse-Dantsker A. Phosphoinositide-mediated gating of inwardly rectifying K+. Pflüg Arch - Eur J Physiol 455: 83-95, 2007.

Lorenzon NM, Foehring RC. Relationship between repetitive firing and afterhyperpolarizations in human neocortical neurons. J Neurophysiol 67: 350-363, 1992.

Lorenzon NM, Foehring RC. The ontogeny of repetitive firing and its modulation by norepinephrine in rat neocortical neurons. Brain Res Dev Brain Res 73: 213-223, 1993.

Lorenzon NM, Foehring RC. Characterization of pharmacologically identified voltagegated calcium channel currents in acutely isolated rat neocortical neurons. II. Postnatal development. J Neurophysiol 73: 1443-1451, 1995a.

Lorenzon NM, Foehring RC. Characterization of pharmacologically identified voltagegated calcium channel currents in acutely isolated rat neocortical neurons. I. Adult neurons. J Neurophysiol 73: 1430-1442, 1995b. 


\section{Loussouarn G, Park K-H, Bellocq C, Baró I, Charpentier F, Escande D.}

Phosphatidylinositol-4,5-bisphosphate, PIP2, controls KCNQ1/KCNE1 voltage-gated potassium channels: a functional homology between voltage-gated and inward rectifier $\mathrm{K}+$ channels. EMBO J 22: 5412-5421, 2003.

Ludwig M. Dendritic release of vasopressin and oxytocin. J Neuroendocrinol 10: 881$895,1998$.

Ludwig M, Leng G. Dendritic peptide release and peptide-dependent behaviours. Nat Rev Neurosci 7: 126-136, 2006.

Luther JA, Daftary SS, Boudaba C, Gould GC, Halmos KC, Tasker JG.

Neurosecretory and non-neurosecretory parvocellular neurones of the hypothalamic paraventricular nucleus express distinct electrophysiological properties. $J$ Neuroendocrinol 14: 929-932, 2002.

Luther JA, Tasker JG. Voltage-gated currents distinguish parvocellular from magnocellular neurones in the rat hypothalamic paraventricular nucleus. J Physiol $523 \mathrm{Pt}$ 1: 193-209, 2000.

Madison DV, Nicoll RA. Noradrenaline blocks accommodation of pyramidal cell discharge in the hippocampus. Nature 299: 636-638, 1982.

Maícas Royo J, Brown CH, Leng G, MacGregor DJ. Oxytocin Neurones: Intrinsic Mechanisms Governing the Regularity of Spiking Activity. J Neuroendocrinol 28: n/a, 2016.

Martínez-Pinna J, Davies PJ, McLachlan EM. Diversity of channels involved in $\mathrm{Ca}(2+)$ activation of $\mathrm{K}(+)$ channels during the prolonged AHP in guinea-pig sympathetic neurons. J Neurophysiol 84: 1346-1354, 2000.

Marty A, Neher E. Potassium channels in cultured bovine adrenal chromaffin cells. $J$ Physiol 367: 117-141, 1985.

Meech RW. Calcium-dependent potassium activation in nervous tissues. Annu Rev Biophys Bioeng 7: 1-18, 1978.

Meech RW, Standen NB. Potassium activation in Helix aspersa neurones under voltage clamp: a component mediated by calcium influx. J Physiol 249: 211-239, 1975.

Mermelstein PG, Foehring RC, Tkatch T, Song W-J, Baranauskas G, Surmeier DJ. Properties of Q-Type Calcium Channels in Neostriatal and Cortical Neurons are Correlated with $\beta$ Subunit Expression. J Neurosci 19: 7268-7277, 1999.

Meyers R, Cantley LC. Cloning and characterization of a wortmannin-sensitive human phosphatidylinositol 4-kinase. J Biol Chem 272: 4384-4390, 1997. 
Mezey E, Kiss JZ. Coexpression of Vasopressin and Oxytocin in Hypothalamic Supraoptic Neurons of Lactating Rats. Endocrinology 129: 1814-1820, 1991.

Michailidis IE, Zhang Y, Yang J. The lipid connection-regulation of voltage-gated $\mathrm{Ca}<$ Superscript $>2+</$ Superscript $>$ channels by phosphoinositides. Pflüg Arch - Eur $J$ Physiol 455: 147, 2007.

Mintz IM, Venema VJ, Swiderek KM, Lee TD, Bean BP, Adams ME. P-type calcium channels blocked by the spider toxin omega-Aga-IVA. Nature 355: 827-829, 1992.

Morikawa H, Imani F, Khodakhah K, Williams JT. Inositol 1,4,5-triphosphateevoked responses in midbrain dopamine neurons. J Neurosci Off J Soc Neurosci 20: RC103, 2000.

Morita K, North RA, Tokimasa T. The calcium-activated potassium conductance in guinea-pig myenteric neurones. J Physiol 329: 341-354, 1982.

Morris JF. Distribution of neurosecretory granules among the anatomical compartments of the neurosecretory processes of the pituitary gland: a quantitative ultrastructural approach to hormone storage in the neural lobe. J Endocrinol 68: 225-234, 1976a.

Morris JF. Hormone storage in individual neurosecretory granules of the pituitary gland: A quantitative ultrastructural approach to hormone storage in the neural lobe. $J$ Endocrinol 68: 209-224, 1976b.

Morris JF, Christian H, Ma D, Wang H. Dendritic secretion of peptides from hypothalamic magnocellular neurosecretory neurones: a local dynamic control system and its functions. Exp Physiol 85 Spec No: 131S-138S, 2000.

Morris JF, Ludwig M. Magnocellular dendrites: prototypic receiver/transmitters. $J$ Neuroendocrinol 16: 403-408, 2004.

Mourre C, Hugues M, Lazdunski M. Quantitative autoradiographic mapping in rat brain of the receptor of apamin, a polypeptide toxin specific for one class of $\mathrm{Ca} 2+-$ dependent K+ channels. Brain Res 382: 239-249, 1986.

Moyer JR, Thompson LT, Black JP, Disterhoft JF. Nimodipine increases excitability of rabbit CA1 pyramidal neurons in an age- and concentration-dependent manner. $J$ Neurophysiol 68: 2100-2109, 1992.

Nakanishi S, Catt KJ, Balla T. A wortmannin-sensitive phosphatidylinositol 4-kinase that regulates hormone-sensitive pools of inositolphospholipids. Proc Natl Acad Sci US A 92: 5317-5321, 1995.

Naraghi M, Neher E. Linearized Buffered Ca2+ Diffusion in Microdomains and Its Implications for Calculation of $[\mathrm{Ca} 2+]$ at the Mouth of a Calcium Channel. J Neurosci 17: 6961-6973, 1997. 
Neher E. Vesicle pools and $\mathrm{Ca} 2+$ microdomains: new tools for understanding their roles in neurotransmitter release. Neuron 20: 389-399, 1998.

Neylon CB, Nurgali K, Hunne B, Robbins HL, Moore S, Chen MX, Furness JB. Intermediate-conductance calcium-activated potassium channels in enteric neurones of the mouse: pharmacological, molecular and immunochemical evidence for their role in mediating the slow afterhyperpolarization. J Neurochem 90: 1414-1422, 2004.

Nimmrich V, Gross G. P/Q-type calcium channel modulators. Br J Pharmacol 167: 741-759, 2012.

Nissen R, Hu B, Renaud LP. Regulation of spontaneous phasic firing of rat supraoptic vasopressin neurones in vivo by glutamate receptors. J Physiol 484: 415-424, 1995.

Oliet SH, Bourque CW. Properties of supraoptic magnocellular neurones isolated from the adult rat. J Physiol 455: 291-306, 1992.

Ortiz-Miranda SI, Dayanithi G, Velázquez-Marrero C, Custer EE, Treistman SN, Lémos JR. Differential Modulation of N-Type Calcium Channels by $\mu$-Opioid Receptors in Oxytocinergic Versus Vasopressinergic Neurohypophysial Terminals. J Cell Physiol 225: 276-288, 2010.

Ott I, Scott JC. The Action of Glandular Extracts Upon the Contractions of the Uterus. $J$ Exp Med 11: 326-330, 1909.

Paterlini M, Revilla V, Grant AL, Wisden W. Expression of the neuronal calcium sensor protein family in the rat brain. Neuroscience 99: 205-216, 2000.

Pathak D, Guan D, Foehring RC. Roles of specific Kv channel types in repolarization of the action potential in genetically identified subclasses of pyramidal neurons in mouse neocortex. J Neurophysiol 115: 2317-2329, 2016.

Pedarzani P, Storm JF. PKA mediates the effects of monoamine transmitters on the K+ current underlying the slow spike frequency adaptation in hippocampal neurons. Neuron 11: 1023-1035, 1993.

Pedarzani P, Storm JF. Dopamine modulates the slow $\mathrm{Ca}(2+)$-activated $\mathrm{K}+$ current IAHP via cyclic AMP-dependent protein kinase in hippocampal neurons. $J$ Neurophysiol 74: 2749-2753, 1995.

Pennefather P, Lancaster B, Adams PR, Nicoll RA. Two distinct Ca-dependent K currents in bullfrog sympathetic ganglion cells. Proc Natl Acad Sci U S A 82: 3040-3044, 1985.

Pérez C, Vega R, Soto E. Phospholipase C-mediated inhibition of the M-potassium current by muscarinic-receptor activation in the vestibular primary-afferent neurons of the rat. Neurosci Lett 468: 238-242, 2010. 
Perlmutter LS, Tweedle CD, Hatton GI. Neuronal/glial plasticity in the supraoptic dendritic zone: dendritic bundling and double synapse formation at parturition. Neuroscience 13: 769-779, 1984.

Pineda JC, Galarraga E, Bargas J, Cristancho M, Aceves J. Charybdotoxin and apamin sensitivity of the calcium-dependent repolarization and the afterhyperpolarization in neostriatal neurons. J Neurophysiol 68: 287-294, 1992.

Pineda JC, Waters RS, Foehring RC. Specificity in the Interaction of HVA Ca2+ Channel Types With Ca2+-Dependent AHPs and Firing Behavior in Neocortical Pyramidal Neurons. J Neurophysiol 79: 2522-2534, 1998.

Poulain DA, Wakerley JB. Electrophysiology of hypothalamic magnocellular neurones secreting oxytocin and vasopressin. Neuroscience 7: 773-808, 1982.

Pow DV, Morris JF. Dendrites of hypothalamic magnocellular neurons release neurohypophysial peptides by exocytosis. Neuroscience 32: 435-439, 1989.

Power JM, Bocklisch C, Curby P, Sah P. Location and Function of the Slow Afterhyperpolarization Channels in the Basolateral Amygdala. J Neurosci 31: 526-537, 2011.

Preston RJ, Bishop GA, Kitai ST. Medium spiny neuron projection from the rat striatum: An intracellular horseradish peroxidase study. Brain Res 183: 253-263, 1980.

Pringos E, Vignes M, Martinez J, Rolland V. Peptide Neurotoxins that Affect VoltageGated Calcium Channels: A Close-Up on $\omega$-Agatoxins. Toxins 3: 17-42, 2011.

Quinlan ME, Alberto CO, Hirasawa M. Short-term potentiation of mEPSCs requires $\mathrm{N}-, \mathrm{P} / \mathrm{Q}-$ and L-type Ca2+ channels and mitochondria in the supraoptic nucleus. J Physiol 586: 3147-3161, 2008.

Randle JCR, Bourque CW, Renaud LP. Serial reconstruction of lucifer yellow-labeled supraoptic nucleus neurons in perfused rat hypothalamic explants. Neuroscience 17: 453467, 1986.

Romey G, Lazdunski M. The coexistence in rat muscle cells of two distinct classes of $\mathrm{Ca} 2+$-dependent $\mathrm{K}+$ channels with different pharmacological properties and different physiological functions. Biochem Biophys Res Commun 118: 669-674, 1984.

Roper P, Callaway J, Armstrong W. Burst Initiation and Termination in Phasic Vasopressin Cells of the Rat Supraoptic Nucleus: A Combined Mathematical, Electrical, and Calcium Fluorescence Study. J Neurosci 24: 4818-4831, 2004.

Roper P, Callaway J, Shevchenko T, Teruyama R, Armstrong W. AHP's, HAP's and DAP's: how potassium currents regulate the excitability of rat supraoptic neurones. $J$ Comput Neurosci 15: 367-389, 2003. 
Sabatier N, Brown CH, Ludwig M, Leng G. Phasic spike patterning in rat supraoptic neurones in vivo and in vitro. J Physiol 558: 161-180, 2004.

Sabatier N, Leng G. Bistability with Hysteresis in the Activity of Vasopressin Cells. $J$ Neuroendocrinol 19: 95-101, 2007.

Sabatier N, Richard P, Dayanithi G. Activation of multiple intracellular transduction signals by vasopressin in vasopressin-sensitive neurones of the rat supraoptic nucleus. $J$ Physiol 513 ( Pt 3): 699-710, 1998.

Sah P. Different calcium channels are coupled to potassium channels with distinct physiological roles in vagal neurons. Proc R Soc Lond B 260: 105-111, 1995.

Sah P. Ca(2+)-activated K+ currents in neurones: types, physiological roles and modulation. Trends Neurosci 19: 150-154, 1996.

Sah P, Bekkers JM. Apical Dendritic Location of Slow Afterhyperpolarization Current in Hippocampal Pyramidal Neurons: Implications for the Integration of Long-Term Potentiation. J Neurosci 16: 4537-4542, 1996.

Sah P, Clements JD. Photolytic Manipulation of [Ca2+]iReveals Slow Kinetics of Potassium Channels Underlying the Afterhyperpolarization in Hipppocampal Pyramidal Neurons. J Neurosci 19: 3657-3664, 1999.

Salzmann M, Seidel KN, Bernard R, Prüss H, Veh RW, Derst C. BK $\beta 1$ Subunits Contribute to BK Channel Diversity in Rat Hypothalamic Neurons. Cell Mol Neurobiol 30: 967-976, 2010.

Satake S, Imoto K. Cav2.1 channels control multivesicular release by relying on their distance from exocytotic $\mathrm{Ca} 2+$ sensors at rat cerebellar granule cells. $J$ Neurosci Off $J$ Soc Neurosci 34: 1462-1474, 2014.

Schwindt PC, Spain WJ, Crill WE. Effects of intracellular calcium chelation on voltage-dependent and calcium-dependent currents in cat neocortical neurons. Neuroscience 47: 571-578, 1992.

Schwindt PC, Spain WJ, Foehring RC, Chubb MC, Crill WE. Slow conductances in neurons from cat sensorimotor cortex in vitro and their role in slow excitability changes. J Neurophysiol 59: 450-467, 1988a.

Schwindt PC, Spain WJ, Foehring RC, Stafstrom CE, Chubb MC, Crill WE. Multiple potassium conductances and their functions in neurons from cat sensorimotor cortex in vitro. J Neurophysiol 59: 424-449, 1988 b.

Scroggs RS, Cardenas CG, Whittaker JA, Kitai ST. Muscarine reduces calciumdependent electrical activity in substantia nigra dopaminergic neurons. J Neurophysiol 86: 2966-2972, 2001. 
Shah L, Bansal V, Rye PL, Mumtaz N, Taherian A, Fisher TE. Osmotic activation of phospholipase $\mathrm{C}$ triggers structural adaptation in osmosensitive rat supraoptic neurons. $J$. Physiol. ( July 11, 2014). doi: 10.1113/jphysiol.2014.273813.

Shah M, Haylett DG. The pharmacology of hSK1 Ca2+-activated K+ channels expressed in mammalian cell lines. Br J Pharmacol 129: 627-630, 2000.

Simms BA, Zamponi GW. Neuronal Voltage-Gated Calcium Channels: Structure, Function, and Dysfunction. Neuron 82: 24-45, 2014.

Smith BN, Armstrong WE. Tuberal supraoptic neurons-I. Morphological and electrophysiological characteristics observed with intracellular recording and biocytin filling in vitro. Neuroscience 38: 469-483, 1990.

Smith BN, Armstrong WE. Histamine enhances the depolarizing afterpotential of immunohistochemically identified vasopressin neurons in the rat supraoptic nucleus via H1-receptor activation. Neuroscience 53: 855-864, 1993.

Snutch TP, Peloquin J, Mathews E, McRory JE. Molecular Properties of VoltageGated Calcium Channels [Online]. Landes Bioscience. https://www.ncbi.nlm.nih.gov/books/NBK6181/ [16 Oct. 2017].

Sofroniew MV. Vasopressin- and neurophysin-immunoreactive neurons in the septal region, medial amygdala and locus coeruleus in colchicine-treated rats. Neuroscience 15: 347-358, 1985.

Sofroniew MV, Glasmann W. Golgi-like immunoperoxidase staining of hypothalamic magnocellular neurons that contain vasopressin, oxytocin or neurophysin in the rat. Neuroscience 6: 619-643, 1981.

Somponpun SJ, Sladek CD. Osmotic Regulation of Estrogen Receptor- $\beta$ in Rat Vasopressin and Oxytocin Neurons. J Neurosci 23: 4261-4269, 2003.

Stern JE, Armstrong WE. Changes in the Electrical Properties of Supraoptic Nucleus Oxytocin and Vasopressin Neurons during Lactation. J Neurosci 16: 4861-4871, 1996.

Stern JE, Armstrong WE. Sustained outward rectification of oxytocinergic neurones in the rat supraoptic nucleus: ionic dependence and pharmacology. J Physiol 500: 497-508, 1997.

Stewart A, Foehring RC. Calcium Currents in Retrogradely Labeled Pyramidal Cells From Rat Sensorimotor Cortex. J Neurophysiol 83: 2349-2354, 2000.

Stocker M, Pedarzani P. Differential Distribution of Three Ca2+-Activated K+ Channel Subunits, SK1, SK2, and SK3, in the Adult Rat Central Nervous System. Mol Cell Neurosci 15: 476-493, 2000. 
Storm JF. Intracellular injection of a $\mathrm{Ca} 2+$ chelator inhibits spike repolarization in hippocampal neurons. Brain Res 435: 387-392, 1987.

Storm JF. An after-hyperpolarization of medium duration in rat hippocampal pyramidal cells. J Physiol 409: 171-190, 1989.

Storm JF. Potassium currents in hippocampal pyramidal cells. Prog Brain Res 83: 161187, 1990.

Stricker EM, Hosutt JA, Verbalis JG. Neurohypophyseal secretion in hypovolemic rats: inverse relation to sodium appetite. Am J Physiol 252: R889-896, 1987.

Suh B-C, Hille B. Recovery from Muscarinic Modulation of M Current Channels Requires Phosphatidylinositol 4,5-Bisphosphate Synthesis. Neuron 35: 507-520, 2002.

Suh B-C, Hille B. Electrostatic Interaction of Internal Mg2+ with Membrane PIP2 Seen with KCNQ K+ Channels. J Gen Physiol 130: 241-256, 2007.

Suh B-C, Hille B. PIP2 is a necessary cofactor for ion channel function: how and why? Annu Rev Biophys 37: 175-195, 2008.

Suh B-C, Inoue T, Meyer T, Hille B. Rapid chemically induced changes of PtdIns(4,5)P2 gate KCNQ ion channels. Science 314: 1454-1457, 2006.

Suh B-C, Leal K, Hille B. Modulation of High-Voltage Activated Ca2+ Channels by Membrane Phosphatidylinositol 4,5-Bisphosphate. Neuron 67: 224-238, 2010.

Sun HQ, Yamamoto M, Mejillano M, Yin HL. Gelsolin, a multifunctional actin regulatory protein. J Biol Chem 274: 33179-33182, 1999.

Swanson LW, Kuypers HG. The paraventricular nucleus of the hypothalamus: cytoarchitectonic subdivisions and organization of projections to the pituitary, dorsal vagal complex, and spinal cord as demonstrated by retrograde fluorescence doublelabeling methods. J Comp Neurol 194: 555-570, 1980.

Swanson LW, Sawchenko PE, Lind RW. Regulation of multiple peptides in CRF parvocellular neurosecretory neurons: implications for the stress response. Prog Brain Res 68: 169-190, 1986.

Tacconi S, Carletti R, Bunnemann B, Plumpton C, Merlo Pich E, Terstappen GC. Distribution of the messenger RNA for the small conductance calcium-activated potassium channel SK3 in the adult rat brain and correlation with immunoreactivity. Neuroscience 102: 209-215, 2001.

Tanabe M, Gähwiler BH, Gerber U. L-Type Ca2+ Channels Mediate the Slow Ca2+Dependent Afterhyperpolarization Current in Rat CA3 Pyramidal Cells In Vitro. $J$ Neurophysiol 80: 2268-2273, 1998. 
Tanner GR, Lutas A, Martínez-François JR, Yellen G. Single K ATP channel opening in response to action potential firing in mouse dentate granule neurons. $J$ Neurosci Off J Soc Neurosci 31: 8689-8696, 2011.

Tasker JG, Dudek FE. Local inhibitory synaptic inputs to neurones of the paraventricular nucleus in slices of rat hypothalamus. J Physiol 469: 179-192, 1993.

Teruyama R, Armstrong WE. Changes in the Active Membrane Properties of Rat Supraoptic Neurones During Pregnancy and Lactation. J Neuroendocrinol 14: 933-944, 2002.

Teruyama R, Armstrong WE. Enhancement of calcium-dependent afterpotentials in oxytocin neurons of the rat supraoptic nucleus during lactation. $J$ Physiol 566: 505-518, 2005.

Teruyama R, Armstrong WE. Calcium-Dependent Fast Depolarizing Afterpotentials in Vasopressin Neurons in the Rat Supraoptic Nucleus. J Neurophysiol 98: 2612-2621, 2007.

Teruyama R, Lipschitz DL, Wang L, Ramoz GR, Crowley WR, Bealer SL, Armstrong WE. Central blockade of oxytocin receptors during mid-late gestation reduces amplitude of slow afterhyperpolarization in supraoptic oxytocin neurons. $A J P$ Endocrinol Metab 295: E1167-E1171, 2008.

Tobin VA, Douglas AJ, Leng G, Ludwig M. The Involvement of Voltage-Operated Calcium Channels in Somato-Dendritic Oxytocin Release. PLoS ONE 6, 2011.

Torres GE, Arfken CL, Andrade R. 5-Hydroxytryptamine4 receptors reduce afterhyperpolarization in hippocampus by inhibiting calcium-induced calcium release. Mol Pharmacol 50: 1316-1322, 1996.

Trudel E, Bourque CW. Central clock excites vasopressin neurons by waking osmosensory afferents during late sleep. Nat Neurosci 13: 467-474, 2010.

Tsien RW. Calcium channels in excitable cell membranes. Annu Rev Physiol 45: 341$358,1983$.

Tweedle CD, Hatton GI. Ultrastructural comparisons of neurons of supraoptic and circularis nuclei in normal and dehydrated rats. Brain Res Bull 1: 103-121, 1976.

Tzingounis AV, Heidenreich M, Kharkovets T, Spitzmaul G, Jensen HS, Nicoll RA, Jentsch TJ. The KCNQ5 potassium channel mediates a component of the afterhyperpolarization current in mouse hippocampus. Proc Natl Acad Sci U S A 107: 10232-10237, 2010.

Tzingounis AV, Kobayashi M, Takamatsu K, Nicoll RA. The Diffusible Calcium Sensor, Hippocalcin, Gates the Calcium Activation of the Slow Afterhyperpolarization in Hippocampal Pyramidal Neurons. Neuron 53: 487-493, 2007. 
Tzingounis AV, Nicoll RA. Contribution of KCNQ2 and KCNQ3 to the medium and slow afterhyperpolarization currents. Proc Natl Acad Sci U S A 105: 19974-19979, 2008.

Ueta Y, Fujihara H, Serino R, Dayanithi G, Ozawa H, Matsuda K, Kawata M, Yamada J, Ueno S, Fukuda A, Murphy D. Transgenic expression of enhanced green fluorescent protein enables direct visualization for physiological studies of vasopressin neurons and isolated nerve terminals of the rat. Endocrinology 146: 406-413, 2005.

Vanhaesebroeck, B, Leevers SJ, Ahmadi K, Timms J, Katso R, Driscoll PC, Woscholski R, Parker PJ, Waterfield MD. Synthesis and Function of 3-Phosphorylated Inositol Lipids. Annu Rev Biochem 70: 535-602, 2001.

Villalobos C, Andrade R. Visinin-Like Neuronal Calcium Sensor Proteins Regulate the Slow Calcium-Activated Afterhyperpolarizing Current in the Rat Cerebral Cortex. $J$ Neurosci 30: 14361-14365, 2010.

Villalobos C, Foehring RC, Lee JC, Andrade R. Essential Role for Phosphatidylinositol 4,5-Bisphosphate in the Expression, Regulation, and Gating of the Slow Afterhyperpolarization Current in the Cerebral Cortex. J Neurosci 31: 18303$18312,2011$.

Vlahos CJ, Matter WF, Hui KY, Brown RF. A specific inhibitor of phosphatidylinositol 3-kinase, 2-(4-morpholinyl)-8-phenyl-4H-1-benzopyran-4-one (LY294002). J Biol Chem 269: 5241-5248, 1994.

Vogalis F, Furness JB, Kunze WAA. Afterhyperpolarization Current in Myenteric Neurons of the Guinea Pig Duodenum. J Neurophysiol 85: 1941-1951, 2001.

Vogalis F, Harvey JR, Furness JB. PKA-mediated inhibition of a novel K+ channel underlies the slow after-hyperpolarization in enteric AH neurons. J Physiol 548: 801$814,2003 a$.

Vogalis F, Harvey JR, Furness JB. Suppression of a slow post-spike afterhyperpolarization by calcineurin inhibitors. Eur J Neurosci 19: 2650-2658, 2004.

Vogalis F, Storm JF, Lancaster B. SK channels and the varieties of slow afterhyperpolarizations in neurons. Eur J Neurosci 18: 3155-3166, 2003 b.

van de Vrede Y, Fossier P, Baux G, Joels M, Chameau P. Control of IsAHP in mouse hippocampus CA1 pyramidal neurons by RyR3-mediated calcium-induced calcium release. Pflugers Arch 455: 297-308, 2007.

de Vrind V, Scuvée-Moreau J, Drion G, Hmaied C, Philippart F, Engel D, Seutin V. Interactions between calcium channels and SK channels in midbrain dopamine neurons and their impact on pacemaker regularity: Contrasting roles of N- and L-type channels. Eur J Pharmacol 788: 274-279, 2016. 
Wakerley JB, Lincoln DW. Intermittent Release of Oxytocin during Suckling in the Rat. Nature New Biol 233: 180-181, 1971.

Wakerley JB, Poulain DA, Brown D. Comparison of firing patterns in oxytocin- and vasopressin-releasing neurones during progressive dehydration. Brain Res 148: 425-440, 1978.

Wakerly JB, Lincoln DW. Milk ejection in the rat: recordings of intramammary pressure during suckling. J Endocrinol 51: 13-14, 1971.

Wang D, Fisher TE. Expression of CaV 2.2 and splice variants of $\mathrm{CaV} 2.1$ in oxytocinand vasopressin-releasing supraoptic neurones. J Neuroendocrinol 26: 100-110, 2014.

Wang K, Mateos-Aparicio P, Hönigsperger C, Raghuram V, Wu WW, Ridder MC, Sah P, Maylie J, Storm JF, Adelman JP. IK1 channels do not contribute to the slow afterhyperpolarization in pyramidal neurons. eLife 5, $2016 \mathrm{a}$.

Wang L, Chandaka GK, Foehring RC, Callaway JC, Armstrong WE. Changes in Potassium Channel Modulation May Underlie Afterhyperpolarization Plasticity in Oxytocin Neurons During Late Pregnancy. J. Neurophysiol. ( March 14, 2018). doi: 10.1152/jn.00608.2017.

Wang Q, Xia X, Deng X, Li N, Wu D, Zhang L, Yang C, Tao F, Zhou J. Lambdacyhalothrin disrupts the up-regulation effect of $17 \beta$-estradiol on post-synaptic density 95 protein expression via estrogen receptor $\alpha$-dependent Akt pathway. J Environ Sci China 41: 252-260, 2016b.

Wang Y, Jarrard RE, Pratt EPS, Guerra ML, Salyer AE, Lange AM, Soderling IM, Hockerman GH. Uncoupling of Cav1.2 from $\mathrm{Ca}(2+)$-induced $\mathrm{Ca}(2+)$ release and $\mathrm{SK}$ channel regulation in pancreatic $\beta$-cells. Mol Endocrinol Baltim Md 28: 458-476, 2014.

Watson C, Paxinos. Paxinos and Watson's The Rat Brain in Stereotaxic Coordinates Seventh Edition [Online]. https://espace.curtin.edu.au/handle/20.500.11937/10457 [4 May 2018].

Wheeler DB, Randall A, Tsien RW. Roles of N-type and Q-type Ca2+ channels in supporting hippocampal synaptic transmission. Science 264: 107-111, 1994.

Widmer H, Lemos JR, Treistman SN. Ethanol reduces the duration of single evoked spikes by a selective inhibition of voltage-gated calcium currents in acutely dissociated supraoptic neurons of the rat. J Neuroendocrinol 10: 399-406, 1998.

Williams JT, North RA, Shefner SA, Nishi S, Egan TM. Membrane properties of rat locus coeruleus neurones. Neuroscience 13: 137-156, 1984.

Wilson CJ, Callaway JC. Coupled oscillator model of the dopaminergic neuron of the substantia nigra. J Neurophysiol 83: 3084-3100, 2000. 
Winks JS, Hughes S, Filippov AK, Tatulian L, Abogadie FC, Brown DA, Marsh SJ. Relationship between Membrane Phosphatidylinositol-4,5-Bisphosphate and ReceptorMediated Inhibition of Native Neuronal M Channels. J Neurosci 25: 3400-3413, 2005.

Wu L, Bauer CS, Zhen X, Xie C, Yang J. Dual regulation of voltage-gated calcium channels by PtdIns(4,5)P2. Nature 419: 947-952, 2002.

Xie L, Liang T, Kang Y, Lin X, Sobbi R, Xie H, Chao C, Backx P, Feng Z-P, Shyng S-L, Gaisano HY. Phosphatidylinositol 4,5-biphosphate (PIP2) modulates syntaxin-1A binding to sulfonylurea receptor $2 \mathrm{~A}$ to regulate cardiac ATP-sensitive potassium (KATP) channels. J Mol Cell Cardiol 75: 100-110, 2014.

Xu C, Watras J, Loew LM. Kinetic analysis of receptor-activated phosphoinositide turnover. J Cell Biol 161: 779-791, 2003.

Yang H, Zhang G, Cui J. BK channels: multiple sensors, one activation gate. Front Physiol 6: 29, 2015.

Yang J, Zhao Z, Gu M, Feng X, Xu H. Release and uptake mechanisms of vesicular $\mathrm{Ca}<$ Superscript $>2+</$ Superscript $>$ stores. Protein Cell ( March 16, 2018). doi: $10.1007 / \mathrm{s} 13238-018-0523-\mathrm{x}$.

Zaydman MA, Cui J. PIP2 regulation of KCNQ channels: biophysical and molecular mechanisms for lipid modulation of voltage-dependent gating. Front Physiol 5, 2014.

Zaydman MA, Silva JR, Delaloye K, Li Y, Liang H, Larsson HP, Shi J, Cui J. Kv7.1 ion channels require a lipid to couple voltage sensing to pore opening. Proc Natl Acad Sci US A 110: 13180-13185, 2013.

Zhang JF, Randall AD, Ellinor PT, Horne WA, Sather WA, Tanabe T, Schwarz TL, Tsien RW. Distinctive pharmacology and kinetics of cloned neuronal $\mathrm{Ca} 2+$ channels and their possible counterparts in mammalian CNS neurons. Neuropharmacology 32: 10751088, 1993.

Zhang L, Renaud LP, Kolaj M. Properties of a T-Type Ca2+Channel-Activated Slow Afterhyperpolarization in Thalamic Paraventricular Nucleus and Other Thalamic Midline Neurons. J Neurophysiol 101: 2741-2750, 2009a.

Zhang M, Meng X-Y, Cui M, Pascal JM, Logothetis DE, Zhang J-F. Selective phosphorylation modulates the PIP2 sensitivity of the CaM-SK channel complex. Nat Chem Biol 10: 753-759, 2014.

Zhang W, Wang D, Liu X-H, Kosala W r. a., Rajapaksha J s., Fisher TE. An osmosensitive voltage-gated $\mathrm{K}+$ current in rat supraoptic neurons. Eur J Neurosci 29: 2335-2346, 2009b. 
Zhou P, Yu H, Gu M, Nan F, Gao Z, Li M. Phosphatidylinositol 4,5-bisphosphate alters pharmacological selectivity for epilepsy-causing KCNQ potassium channels. Proc Natl Acad Sci U S A 110: 8726-8731, 2013. 


\section{VITA}

Matthew Karl Kirchner was born in Nashville, Tennessee, USA in the year 1990. He attended the College of Wooster in Wooster, Ohio, USA where he earned his Bachelor Arts in Neuroscience and Philosophy in 2013. He was accepted to the $\mathrm{PhD}$ program in Neuroscience within the school of Integrated Biomedical Sciences at the University of Tennessee Health Science Center in Memphis, Tennessee, USA. He was awarded his PhD in August of 2018. 